\title{
5. CLEMENS' VERHÄLTNIS ZU SEINEN KARDINÄLEN: KARDINALSLEGATIONEN
}

\subsection{Die päpstliche Diplomatie in den Auseinandersetzungen zwischen England und Frankreich}

\subsubsection{Päpstliche Legaten und Nuntien im 14. Jahrhundert}

Die päpstlichen Gesandten trugen als Teil des päpstlichen Leibes, berufen in partem sollicitudinis, dazu bei, die natürliche Beschränktheit des Pontifex aufzuheben und damit eine unmittelbare päpstliche Präsenz am jeweiligen Ort zu gewährleisten. Insbesondere im 13. Jahrhundert wurde der Grundstein zur institutionellen Vervollkommnung dieses Konzeptes gelegt, das eng mit der Vorstellung einer raumübergreifenden, an allen Orten und $z u$ allen Zeiten gültigen päpstlichen Vollgewalt, der plenitudo potestatis, verbunden war. Legationsgewalt wurde somit zur »Aktualisierung der päpstlichen plenitudo potestatis « 1 . Angelegenheiten, die ex officio dem Papst oblagen, konnten nun von seinen confratres cardinales ausgeführt werden, deren herausragende Stellung durch die Entsendung a latere, »aus der Seite des Papstes« heraus, zusätzlich unterstrichen wurde ${ }^{2}$. In besonderer Weise waren sie für die Kommu-

1 Vgl. Paul Hinschius, Das Kirchenrecht der Katholiken und Protestanten in Deutschland, Bd.1 (System des katholischen Kirchenrechts mit besonderer Rücksicht auf Deutschland), Berlin 1869, S.511-522; Hans-Joachim ScHMIDT, Kirche, Staat, Nation. Raumgliederung der Kirche im mittelalterlichen Europa, Weimar 1999, S. 250-285, hier S. 258. Als Gesamtdarstellung der Geschichte päpstlicher Diplomatie ist nach wie vor unverzichtbar Pierre BLET, Histoire de la Représentation diplomatique du Saint Siège des origines à l'aube du XIX ${ }^{\mathrm{e}}$ siècle, Vatican 21990 ; Knut WALF, Die Entwicklung des päpstlichen Gesandtschaftswesens in dem Zeitabschnitt zwischen Dekretalenrecht und Wiener Kongreß (1159-1815), München 1966. Einen groben Überblick liefert Michael FELDKAMP, La diplomazia pontificia, Mailand 1998; vgl. auch Donald E. QuelLER, The office of ambassador in the Middle Ages, Princeton 1967. Kein Sendschreiben kommt ohne den Verweis auf die skizzierte Problematik aus, vgl. beispielsweise die Ernennung von Kardinal Gui de Boulogne zum Legaten für die Lombardei, für Ungarn und die Kirchenprovinz Salzburg im November 1348, in: Lenzenweger, Acta Pataviensia Austriaca I, n. 290, S.559: Nos [...] qui ubique locorum presentialiter esse non possumus, quamquam potestatis plenitudo, in quam assumpti sumus, protendatur ubique ad exequendum utiliter partes sollicitudinis incumbentis, quam soli procul dubio implere nequimus, fratres nostros [...] cardinales [...] assumamus.

2 Der Titel eines legatus a latere war ausschließlich den Kardinälen vorbehalten. Für Guillelmus Duranti besteht darin die größte Prärogative der Kardinäle. In seinem zwischen 1271 und 1276 entstandenen Speculum iuris drückt er dies wie folgt aus: Romane usus Ecclesie solos cardinales legatos de latere revocat [...]. Laterales sunt quia a latere domini pape emanent [...]. Legati tanquam dominus papa sunt honorandi [...]. Non est credendum, quod ipsi aliter iudicent, quam ipse dominus papa iudicaturus esset, ed. Frankfurt 1612, 
nikation zwischen der Kurie und dem Rest der Christenheit verantwortlich, wurden sie zu "Transmissionsriemen, mit denen der Papst seine Autorität innerhalb der Kirche zur Geltung brachte «3.

Wie keiner seiner Vorgänger in Avignon vor ihm machte Clemens VI. die Diplomatie zu einem zentralen Instrument seiner Politik ${ }^{4}$. Dabei spielten die Kardinäle eine besondere Rolle. Nur wenige Wochen nach seiner Krönung wurde mit der Entsendung zweier Kardinäle zwecks Vermittlung im englischfranzösischen Konflikt die Reihe der kardinalizischen Legationen und Nuntiaturen - von denen in der Folge als Gesandtschaften gesprochen wird - eröffnet. Bis zu seinem Tod 1352 waren es zehn kardinalizische Gesandtschaften,

S. 30; in den canones des Konzils von Posen wird ausdrücklich darauf verwiesen, daß debitum Apostolicae servitutis explere nititur modo per episcopos, imo per archiepiscopos nonnunquam, et per legatos a latere suo missos, quos quia ejus privilegia gaudent, cujus legatione funguntur, a cunctis Christi fidelibus tanquam Apostolicam Sedem, imo Christum, qui in eis se recipi praedicat et audiri, honorari convenit et foveri, in: Caesarius BARONIUS (Hg.), Annales ecclesiastici, Bd. 25 (1334-1335), Rom 1872, S. 407f.

3 Stefan WEISS, Die Urkunden der päpstlichen Legaten von Leo IX. bis Coelestin III. (1049-1198), Köln, Weimar, Wien 1995, S. 362.

4 Darstellungen zum Legationsinstitut im Spätmittelalter sind rar, am profundesten MoLLAT, Contribution, S. 566-594; vgl. auch Karl GugGENBERGER, Die Legation des Kardinals Pileus in Deutschland 1378-1382, München 1907; Clifford Ian KEYER, Legatus and nuntius as used to denote papal envoys: 1245-1378, in: Mediaeval Studies 40 (1978) S.473-477; Hans Jörg BRANDT, Kardinal Philippe d'Alençon (1338/39-1397). Zur Biographie eines päpstlichen Legaten römischer Obödienz für Deutschland während des Großen abendländischen Schismas, in: Ecclesia peregrinans. Josef Lenzenweger zum 70. Geburtstag, Wien 1986, S. 119-132; Marianne ScHMITZ, Lebens- und Arbeitsweise zweier südfranzösischer Kollektoren in der ersten Hälfte des 14. Jahrhunderts in England, Frankfurt a.M. u.a. 1993 (Europäische Hochschulschriften, Reihe III: Geschichte und ihre Hilfswissenschaften, 550); Christiane SchuChaRd, Päpstliche Legaten und Kollektoren nördlich der Alpen, in: Kommunikation und Mobilität im Mittelalter, hg.v. Siegfried de RACHEwILTZ und Josef RiedmanN, Sigmaringen 1995, S. 261-275; Dies., Die päpstlichen Kollektoren im späten Mittelalter, Tübingen 2000 (Bibliothek des Deutschen Historischen Instituts Rom, 91); Birgit STUDT, Legationen als Instrument päpstlicher Reform- und Kreuzzugspropaganda im 15. Jahrhundert, in: Formen und Funktionen öffentlicher Kommunikation im Mittelalter, hg.v. Gerd AlTHOFF, Stuttgart 2001, S. 421-453; Werner MALECZEK, Die päpstlichen Legaten im 14. und 15. Jahrhundert, in: Gesandtschafts- und Botenwesen im spätmittelalterlichen Europa, hg.v. Rainer C. SCHwingeS, Klaus WRIEDT, Ostfildern 2003 (Vorträge und Forschungen, 60), S.33-87. An älteren Arbeiten, die sich zumeist der Ausbildung und Konsolidierung des Legationsinstituts im Hochmittelalter widmen, sind zu nennen Ina FrIEDLÄNDER, Die päpstlichen Legaten in Deutschland und Italien am Ende des XII. Jahrhunderts (1181-1198), Berlin 1928; Gino FrANCESCHINI, Il cardinale Anglico Grimoard e la sua opera di legato, in: Bollettino della deputazione di Storia Patria per l'Umbria 51 (1954) S. 45-72; Wilhelm JANSSEN, Die päpstlichen Legaten in Frankreich vom Schisma Anaklets II. bis zum Tode Coelestins III. (1130-1198), Köln, Graz 1961; Robert Charles FigueIRA, Legatus apostolice sedis. The Pope's alter ego according to thirteenthcentury canon law, in: Studi medievali 27 (1986) S. 527-574; DERS., Decretalists, medieval papal legation, and the Roman law of offices and jurisdiction, in: Res publica litterarum 9 (1986) S.119-137; vor allem aber Karl RuEss, Die rechtliche Stellung der päpstlichen Legaten bis Bonifaz VIII., Paderborn 1912. 
die Avignon mit unterschiedlichen Zielen verließen ${ }^{5}$. Eine regionale Schwerpunktbildung tritt dabei unverkennbar zu Tage. Vier politische Brennpunkte ließen gleich mehrmals eine diplomatische Intervention nötig werden: Aragon/Mallorca, England/Frankreich, Ober- und Mittelitalien und schließlich das Königreich Neapel. Päpstliche Gesandte im Kardinalsrang trugen um die Mitte des 14. Jahrhunderts die offizielle Bezeichnung eines Nuntius oder eines Legaten. Was beide Kategorien voneinander unterschied, ist im Falle der von Clemens VI. initiierten Gesandtschaften nicht immer schlüssig zu beantworten $^{6}$. Das in diesem Zusammenhang stets bemühte Kriterium der jurisdiktionellen Vollmachten greift nur bedingt, zeigt doch ein Blick auf die konzedierten Fakultäten, daß sowohl Nuntien als auch Legaten über einen soliden Grundbestand an entsprechenden Kompetenzen verfügten, der in beiden Fällen fast deckungsgleich war, mithin auf keine untergeordnete Stellung des Nuntius gegenüber dem Legaten schließen läßt. Fehlende iurisdictio ordinaria auf seiten des Nuntius wurde durch Formen der iurisdictio mandata und iurisdictio delegata, d.h. durch Übertragung päpstlicher vices und ad causam zugeschnittener Spezialmandate, mehr als wettgemacht. Eine Bevorzugung der einen oder der anderen Kategorie läßt sich unter Clemens VI. nicht feststellen: Fünf Gesandtschaften wurden von Nuntien, weitere fünf von Legaten ausgeführt.

Die beiden Kardinalbischöfe Annibaldo Ceccano und Pierre Desprez nahmen ihre Vermittlungstätigkeit im Krieg zwischen England und Frankreich 1342-1343 als Nuntien wahr, was insofern erstaunt, als sowohl ihre Stellung an der Kurie als auch die Bedeutung ihrer diplomatischen Mission eine Entsendung als legati a latere nahegelegt hätten ${ }^{7}$. Auch der am 30. Dezember 1342

${ }^{5}$ Die folgende, chronologisch geordnete Auflistung umfaßt die Namen der entsandten Kardinäle, ihren Rang (Nuntius/Legat), das Entsendungsdatum und das Zielgebiet: 1. Pierre Desprez/Annibaldo Ceccano, Nuntien, 31.05.1342, England/Frankreich; 2. Guillaume Court, Legat, 19.07.1342, Oberitalien; 3. Aimeric de Châtelus, Legat, 14.10.1342, Mittelitalien (erweitert 13.10.1343 um das Königreich Neapel); 4. Andreas Ghini Malpigli, Nuntius, 30.12.1342, Aragon/Mallorca; 5. Bernard d'Albi, Nuntius, 09.06.1343, Aragon/ Mallorca; 6. Bertrand de Deux, Nuntius, 12.05.1344, Aragon/Mallorca; 7. Bertrand de Deux, Legat, 31.07.1346, Königreich Neapel/Rom; 8. Annibaldo Ceccano/Étienne Aubert, Nuntien, 07.09.1346, England/Frankreich; 9. Gui de Boulogne, Legat, 22.06.1348, Lombardei/Ungarn; 10. Annibaldo Ceccano, Legat, 30.11.1348, Mittelitalien.

${ }^{6}$ Unsicherheiten in der Terminologie manifestieren sich allenthalben. So lobt beispielsweise das Kapitel von Saint-Lambert zu Lüttich den von Clemens VI. 1343 ausgesandten Nuntius Jean de Forly cum igitur idem nuntius seu legatus apostolicam missionem sic sagaciter, sic solerter [...] studuerit adimplere [...], vgl. SCHOOLMEESTERS, Recueil, S. 24.

7 Drei Gruppen von päpstlichen Gesandten werden in der kanonistischen Literatur seit dem 13. Jh. unterschieden: 1. Legati nati, besonders Ortsbischöfe, denen dieser Titel als besondere Ehre verliehen wird; 2 . Nuntii, Gesandte mit beschränktem Auftrag; 3. Legati a latere, Gesandte, die über exzeptionelle Vollmachten verfügen; vgl. dazu Hans Erich FEINE, Kirchliche Rechtsgeschichte. Die katholische Kirche, Köln, Wien 51964, S. 327-328; Hans ZimmermanN, Die päpstlichen Legaten in der ersten Hälfte des 13. Jahrhunderts, 
zur Beilegung des Konfliktes zwischen den Königen von Aragon und Mallorca in den Süden entsandte Kardinal Andreas Ghini Malpigli trug lediglich den Titel eines Nuntius ${ }^{8}$. Kardinal Guillaume Court wirkte hingegen zeitgleich als Legat in der Lombardei, später im Königreich Neapel ${ }^{9}$. Daß Clemens VI. jedoch nicht nach Gutdünken entschied, sondern sehr genau um den Rangunterschied zwischen Nuntien und Legaten wußte, belegt ein Passus seiner Begrüßungsansprache für Guillaume Court. Darin wird von dem hohen Vorrang (magna preeminentia) der Legaten, zumal der legati a latere, vor den Nuntien gesprochen, ohne daß jedoch begründet würde, worin er besteht ${ }^{10}$. Der Streit um termini technici ist in diesen Fällen ein rein akademischer: Der Wirkungsgrad einer diplomatischen, vom Papst ausgehenden Initiative hing nicht vom Titel, sondern von der Fülle und Qualität der den Gesandten zur Verfügung stehenden Fakultäten $a b^{11}$.

Petrarca bezeichnet Legaten als »feierliche Nuntien « und verweist damit auf ein Mehr an zeremonieller Bedeutung, dem nicht notwendigerweise größere Vollmachten entsprechen mußten ${ }^{12}$. Der Rang eines Nuntius hatte zumindest einen entscheidenden finanziellen Vorteil. Im Gegensatz zu den Legaten, die in der Zeit ihrer Abwesenheit von der Kurie kein Anrecht mehr auf die dem Kardinalskolleg zustehenden Zahlungen hatten - besonders lukrativ war der Anteil an den servitia communia und den Censuszahlungen, die zwischen Papst und Kardinalskolleg geteilt wurden -, behielten die Nuntien

Paderborn 1913, S. 247-249; John W. PERrin, Legatus, the lawyers and the terminology of power in Roman law, in: Studia Gratiana 11 (1967) S. 461-489; DeRS., Legatus in medieval roman law, in: Traditio 29 (1973) S. 357-378; Richard A. SCHMUTZ, Medieval papal representatives: legates, nuncios, and judge-delegate, in: Studia Gratiana 15 (1972) S. 441-463; Clifford Ian KYER, Legatus and nuntius as used to denote papal envoys: 1244-1378, in: Mediaeval Studies 40 (1978) S.473-477; Robert Charles FigueIRA, The canon law of medieval papal legation, $\mathrm{PhD}$, Cornell University 1980.

8 Vgl. Lettres Clément VI, n. 168.

9 Die Entsendungsbulle ist auf den 19. Juli 1342 datiert, vgl. Lettres Clément VI autres que la France, n. 4.

${ }_{10}$ MS 240, fol.250vb: Et ideo iste tantam habuit celsitudinem ut legatus, qui habet magnam preeminentiam supra nuncium et non quicumque legatus, sed legatus a latere.

11 Vgl. Gerhard SCHORMaN, Beiträge zur Ehepolitik der Päpste von Benedikt XII. bis Gregor XI., Bonn 1969, S.98f.

12 Vgl. Petrarca, Variae, in: Opera, Bd. 2, Basel 1554 (ND 1965), S. 1117: Regum quoque gentiumque nuncios solennes Legatos dici solitos scimus, horum plena est omnis historia [...]. In seinem Bestreben, das Legatenwesen der Kurie im antiken Rom zu verorten, wird er noch expliziter: Romanam ecclesiam sibi proprium vendicasse, ne dicam usurpasse. Itaque iam Legatos exercituum suis quoque nominibus vocat at quibus mandata regum aut urbium committuntur, nuncios dicunt, sive aliter, aut vulgo, alius atque alius sermo est. Soli igitur sunt Legati, quos ut aiunt Romanus Pontifex ad aliquas provincias destinavit, e quibus quidam legati tantum, quidam vero de latere legati nuncupantur, quos videlicet missos, collegio quid sacrum vocant Romulei cardinis fulgor illustrat. Tatsächlich standen die von Clemens VI. entsandten Nuntien nicht an der Spitze von Heeren - bei Abfassung der Variae dürfte Petrarca die Gestalt von Kardinal Albornoz vor Augen gestanden haben -, sondern fungierten als Überbringer päpstlicher Botschaften. 
ihren Anteil an diesen Einkünften ${ }^{13}$. Der Legationsbezirk wurde bei allen unter Clemens VI. ausgehenden Gesandtschaften genau definiert, in einigen Fällen im nachhinein erweitert ${ }^{14}$. Mit der stereotyp wiederkehrenden, an Ier 1,10 angelehnten Beauftragungsforme ${ }^{15}$ wurde auf die idealtypische Zielsetzung jeder Legation verwiesen: Reform. Daß damit nicht allein die Reform der Kirche, sondern auch diejenige ganzer Nationen und Königreiche gemeint war, wird mit Blick auf die einzelnen Legationen deutlich. Kardinalizische Gesandte fungierten als pacis angeli, waren mit Hilfe der ihnen übertragenen Fakultäten in der Lage, den Zustand des Friedens, oder das, was man an der Kurie darunter verstand, mit drastischen Mitteln durchzusetzen. Gleichwohl vermied man es, über Gebühr kirchliche Zensuren zu verhängen, zog es vielmehr vor zu verhandeln. Die Kurie war darauf bedacht, mit dem Verhandlungsgeschick, der Klugheit und natürlichen Autorität ihrer Gesandten Elemente in den Vordergrund zu rücken, die zwar vom Machtanspruch des Papstes kündeten, gleichwohl jedoch dazu angetan waren, diesen Anspruch den aktuellen Gegebenheiten anzupassen. Das Entsendungsschreiben legte im Verbund mit zahlreichen Empfehlungsschreiben und noch umfangreicheren Fakultäten den Grundstein für eine erfolgreiche Gesandtentätigkeit und steckte den Rahmen jedweder Vermittlungstätigkeit ab.

Der Schriftverkehr der Gesandten, mit dessen Erledigung die Mitglieder einer eigenen Kanzlei betraut waren, wurde in eigenen Registerbänden er$\mathrm{faßt}$, von denen einige die Zeitläufte überdauert haben ${ }^{16}$. Für den hier behandelten Untersuchungszeitraum liegt ein Registerband des im Königreich Neapel tätigen Legaten Aimeric de Châtelus vor, der jedoch nur Aufschluß über das Wirken des Legaten insbesondere in minder wichtigen Verwaltungsange-

13 Vgl. Dykmans, Cérémonial II, S. 500: Sciendum est autem quod cardinalis legatus, postquam recesserit de curia, quousque redierit de legatione sua ad curiam, nichil recipit de censibus ecclesie, nec de servitiis prelatorum, per dominum papam medio tempore factorum, nec de aliis camere domini pape medio tempore debitis, in quibus cardinales presentes partem dimidiam habere et percipere consueverunt. Exceptis anulis cardinalium medio tempore decedentium, in quibus anulis cardinales legati absentes a curia tantum recipiunt ac si essent presentes. Nuntius vero missus tantum recipit in absentia de predictis quantum reciperet si in curia esset presens.

14 Vgl. zur Bedeutung der Legationsgebiete SchmidT, Kirche, S. 265-272.

15 Ier 1,10: Ecce constitui te hodie super gentes et super regna, ut evellas et destruas et dissipes et disperdas et edifices et plantes.

16 Guido LEvI, Registri dei cardinali Ugolino d'Ostia e Ottaviano degli Ubaldini, Rom 1890; Jean GléNISSON, Guillaume Mollat (Hg.), Correspondance des légats et vicaires généraux, I, Gil Albornoz et Androin de la Roche (1353-1367), Paris 1964; Diplomatario del Cardenal Gil de Albornoz. Cancilleria pontificia (1351-1356), 2 Bde., Barcelona 1976-1981. Noch unveröffentlicht ist die Arbeit von Pierre JugIE, Chancelleries et cardinalat pendant la papauté d'Avignon, Rom 1992 (Mémoire de l'École française de Rome); vgl. einstweilen DERS., Cardinaux et chancelleries pendant la papauté d'Avignon: une voie royale vers les honneurs?, in: Offices et papauté (XIVe-XVII e siècle). Charges, hommes, destins, hg.v. Armand JAMME, Olivier PONCET, Rom 2005, S. 651-739. 
legenheiten erlaubt ${ }^{17}$. Welche Schwierigkeiten hinsichtlich der Informationsübermittlung die räumliche Distanz zwischen Kurie und Legaten mit sich brachte, wird weiter unten gezeigt.

Die Bedeutung, die die Kurie der Ernennung und Entsendung von Nuntien und Legaten beimaß, wird aus den Zeremonienbüchern ersichtlich. Dabei kommt dem zwischen 1300 und 1340 verfaßten Zeremoniale des Jacopo Stefaneschi besondere Bedeutung $\mathrm{zu}^{18}$. Ein eigener Abschnitt ist in ihm der Kreation von Kardinälen und deren Entsendung als Nuntien und Legaten gewidmet $^{19}$. Der Papst war gehalten, die Gesamtheit des Kardinalskollegiums nach ihrer Meinung zu befragen und seine eigenen Beweggründe für eine Entsendung darzulegen. Daran schloß sich die Konsultation - fiunt auricularia consilia - eines jeden einzelnen Kardinals an. Bereits am folgenden Tag wurde die Entscheidung, die stets de consilio ipsorum fratrum nostrorum erging, bekanntgegeben. Teil des Zeremoniells war die Erklärung des Legaten, unwürdig für dieses Amt zu sein. Die von ihm vorgebrachten Gründe wurden nicht weiter erörtert, vielmehr schloß der erste Teil des Ernennungszeremoniells mit dem osculum pedis et oris pape durch den Designierten. Gelegenheit zur Erörterung der anstehenden Aufgaben bot sich bei einem abendlichen Festmahl mit dem Papst, zu dem lediglich der oder die neuernannten Legaten eingeladen wurden. Vor dem Antritt der Reise - ein Monat Vorbereitungszeit wurde gemeinhin konzediert ${ }^{20}$ - waren Besuche bei den einzelnen Mitgliedern des Kollegiums vorgesehen. Am Tag der Abreise wurde der Legat - nach einer Messe in der Kathedrale - von allen Kardinälen vor den Toren der Stadt verabschiedet ${ }^{21}$.

17 Der Band - aufbewahrt im Vatikanischen Archiv im Bestand der Collectoriae 279 - umfaßt 203 Seiten und deckt - chronologisch ungeordnet - die Zeit der gesamten Legation mit einem klaren Schwerpunkt auf den beiden letzten Monaten des Jahres 1344 ab. Unter der Rubrik »Schreibgebühren« überliefern die Rechnungsbücher einen auf den 24. Dezember 1345 datierten Eintrag pro scriptura 4 sexternorum cum 8 foliis per ipsum scriptorem in edulis continentium omnes scripturas autenticas factas per rev. p. d. Aymericum tit. S.Martini in Montibus presbiteri cardinalis in regno Sicilie tempore sue legationis, vgl. SCHÄFER, Ausgaben Klemens VI., S. 316.

$18 \mathrm{Vgl}$. Kap. 2.

19 Dykmans, Cérémonial II, S. 245-247; 475-502, bes. S. 495-498; vgl. auch MoLlat, Contribution, S. 580-586.

20 Dykmans, Cérémonial II, S. 501: Notandum etiam quod cardinalibus qui debent ire legati vel nuntii, consuetum est, ad parandum se et iter arripiendum, unius mensis terminum communiter assignare. Besondere Erwähnung findet in diesem Zusammenhang der Fall des Kardinallegaten Bernard d'Albi, der um den 9. Juni 1343 zu seiner Legation nach Mallorca und Aragon, mithin nur rund 12 Tage nach seiner Ernennung, aufbrach, vgl. ibid., S. 501: Licet propter periculum grande quod imminebat et timebatur imminere fortius, in regno Maioricarum, quod rex Aragonum cum armis intraverat, et civitate Maioricam iam receperat, dominus B(ernardus), cardinalis Ruthenesis, ad ipsa regna ordinatus legatus, die XII post diem sue publicationis, legationis iter suum arripuit versus illa; vgl. BALUZE/MOLLAT, Vitae II, S.325.

${ }^{21}$ Für den Empfang eines Legaten vor Ort wurde innerhalb der sermones ad status ein eigener Predigttypus konzipiert, vgl. Humbertus de RoMANs, De modo cudendi sermones, 
Bei seiner Rückkehr geschah ähnliches: Man erwartete ihn vor den Toren der Stadt, begrüßte und geleitete ihn ehrenvoll bis zum Papstpalast, wo die offizielle Begrüßung erfolgte. Auf die Abhaltung eines Konsistoriums wurde bei diesen Gelegenheiten verzichtet ${ }^{22}$. Im Mittelpunkt des Begrüßungszeremoniells stand die Ansprache des Papstes, die ausdrücklich lobenden Charakters sein sollte und deren Thema von ihm frei gewählt wurde ${ }^{23}$. Im Anschluß an die Collatio fand ein Festmahl statt, zu dem alle Kardinäle geladen waren. Ebenfalls in Form einer Collatio hatte im Rahmen des folgenden Konsistoriums der Rechenschaftsbericht des Legaten zu erfolgen. Auch in bezug auf die Privilegien des Legaten verlautet einiges. Nach Verlassen des Kuriensitzes war er befugt, seinen neuen Rang durch einen Wechsel der Gewandung zu kennzeichnen. Er durfte jetzt einen scharlachroten Mantel - cappa rubea und ein scharlachrotes Birrett - birretum rubeum - tragen. Ebenso stand es ihm frei, seine Hand zum segnenden Gestus zu erheben. Galten alle Verfügungen bisher gleichermaßen für Nuntien wie für Legaten, blieben letztere Privilegien, die tatsächlich Petrarcas Diktum, Legaten agierten als "feierliche Nuntien«, stützten, ausdrücklich den Legaten vorbehalten.

Im Gegensatz zu den Nuntien hatten sie in der Zeit ihrer Abwesenheit von der Kurie keinen Anteil an den Zahlungen, die von der Camera gemeinhin den Kardinälen geleistet wurden. Als Legaten waren sie zudem gehalten, ihren Mitbrüdern bei der Rückkehr Geschenke - iocalia - zu überreichen. Vor diesem Hintergrund wird die Sorge der Kardinäle um eine angemessene Aufwandsentschädigung in legationibus verständlich. Dafür vorgesehen waren die Prokurationen ${ }^{24}$, deren Höhe in einer eigenen facultas angegeben wurde. Als

Hagenau 1516; Rogerius de Platea, Sermones, hg.v. Cataldo Roccaro, Bd. 1, Palermo 1992, S. 63. Rogerius de Platea verweist darin ausdrücklich auf die eigentliche Legitimation des Legaten durch päpstliche litterae: Unde, si quis esset legatus a summo pontefice in Ytaliam destinatus, non plura posset nisi quantum sue delegationis litterae se extenderet ad agenda et in locis illis, in quibus explicite vel implicite fieret mentio in eisdem.

22 Dykmans, Cérémonial II, S. $422 \mathrm{f}$.

23 Ibid., S. 499: Quibus residentibus, papa recipit aliquod thema et facit quandam collationem ad commendationem et laudem ipsorum legatorum vel nuntiorum, prout videtur pape. In qua collatione ipsi legati vel nuntii sedent in locis suis capitibus omnino discopertis etiam absque birretis. Et est ratio quia laus et commendatio illius collationis ipsis diriguntur per papam. In einer späteren Hinzufügung wird auf die Entstehungsgeschichte dieser BegrüBungsform eingegangen, vgl. ibid., S.499: Dicta namque collatio que fit per papam in adventu nuntiorum vel legatorum, fuit introducta per dominum Benedictum papam XII, et observata per dominum Clementem VI. Tamen, temporibus domini Clementis V et domini Iohannis XII non observabatur. Jean d'Annonay, der Sekretär von Kardinal Pierre Bertrand, vermerkt in seinem Liber de coronatione Karoli IV imperatoris, hg. v. Richard SALOMON, Hannover 1913, S. 118: Romanus pontifex in reditu cujuscumque cardinalis legati vel nuncii solet sermonem publicum facere ad laudem redeuntis et gaudium aliorum. Unter Clemens VI. eingeführt, scheint diese Collationsform bereits unter Innozenz VI, wieder in Vergessenheit geraten zu sein, vgl. ibid., S.118: Dominus noster papa Innocentius VI hoc facere non curavit.

24 Vgl. MolLat, Contribution, S. 571-574. 
eine Art Entschädigungszahlung an den jeweiligen Legaten mußte die Höhe der Prokurationen so bemessen sein, daß zum einen die durch seine Abwesenheit von der Kurie entstandenen Einbußen, zum anderen die durch die Reise bedingten Mehraufwendungen ausgeglichen wurden. 1317 wurden Gaucèlme de Jean 30 Florin pro Tag zugestanden ${ }^{25}$, Bernard d'Albi verfügte 1343 über 50 Florin $^{26}$, Bertrand de Deux 1346 ebenso wie Gui de Boulogne 1348 über 40 Florin täglich ${ }^{27}$. Im Falle der Legationen von Annibaldo Ceccano, Guillaume Court und Aimeric de Châtelus begnügte man sich innerhalb der entsprechenden facultas mit dem Verweis auf procurationes consuete ${ }^{28}$, den $\gg$ üblicherweise « einem Legaten zustehenden finanziellen Leistungen. Zur Zahlung verpflichtet war - von wenigen, immer wieder aufs neue strittigen Ausnahmen abgesehen - der gesamte Klerus des entsprechenden Legationsgebietes ${ }^{29}$. Im Falle der procurationes consuete lag es im Ermessen des Legaten, die Höhe der finanziellen Zuwendung zu bestimmen, die im Falle beharrlicher Zahlungsunwilligkeit zwangsweise eingefordert werden konnte ${ }^{30}$. Dazu bedurfte es freilich wie im Falle des Gui de Boulogne, der dem Papst zu verstehen gab, $\mathrm{da}$ die ihm konzedierten Prokurationen - immerhin 40 Florin täglich - die realen Kosten nicht decken konnten, einer besonderen Genehmigung ${ }^{31}$. Als weitere, sehr viel unbedeutendere Einkommensquellen in legationibus sind die evectiones zu nennen, durch die die Verpflegung des Trosses sichergestellt wurde. Daneben erhob die Kanzlei des Legaten beträchtliche Gebühren für Dispense und andere Verwaltungsakte ${ }^{32}$.

25 Lettres Jean XXII, n. 5148.

26 Lettres Clément VI autres que la France, n.219.

27 Ibid., n. 1083; Lenzenweger, Acta Pataviensia Austriaca I, n. 290, S. 562.

28 Lettres Clément VI, nn. 116, 153, 945; Lettres Clément VI autres que la France, n. 48.

29 Im Falle von Gui de Boulogne erfolgte eine detaillierte Auflistung der Kontributoren, in die ausdrücklich auch die Vertreter der exemten Orden mit aufgenommen wurden vgl. LeNZENWEger, Acta Pataviensia Austriaca I, S.562f.: [...] volumus, quod non solum patriarche, archiepiscopi, episcopi, electi, abbates, priores, decani, prepositi, archidiaconi, archipresbiteri, plebani et alii ecclesiarum prelati eorumque vicegerentes ac persone ecclesiastice, religiose et seculares, ecclesiarum et monasteriorum capitula et conventus, exempti et non exempti, Cisterciensium, Cluniacensium, Cartusiensium, Premonstratensium, sanctorum Benedicti et Augustini, Camaldulensium, Humiliatorum et aliorum ordinum nec non magistri et preceptores hospitalium Sancti Johannis Jerosolomitani, Sancte Marie Theotonicorum et aliorum hospitalium et locorum ecclesiasticorum rectores, ubi dictus legatus fuerit, vel adiacentium partium, per quas transierit, seu etiam remotarum, dum ipse legatus in eis manserit, contribuere in subventionibus huiusmodi teneantur.

30 Vgl. ibid., n.292, S. 578.

${ }^{31}$ Lettres Clément VI autres que la France, n. 1991; vgl. LANG, Acta Salzburgo-Aquilejensia I, n. 406: Cum [...] procurationum legatis Sedis Apostolice de latere debitarum taxatio de consuetudine vel alias, sicut accepimus, minime habeatur, discretioni tue [...] procurationes rationabiliter taxandi ac illas, postquam a te taxate fuerint, recipiendi, hujusmodi tua durante, tam in absentia quam in presentia [...] concedimus facultatem; vgl. auch MoLlar, Contribution, S. 572.

32 Ibid., S. 574. 
Der finanzielle Aspekt war jedoch nicht der dominierende einer Legation. Eine Entsendung als Legat bzw. Nuntius eröffnete die Möglichkeit, auf die eigenen Fähigkeiten aufmerksam zu machen und sich für höhere und verantwortungsvollere Ämter zu empfehlen, war andererseits aber mit vielerlei Unwägbarkeiten und Unannehmlichkeiten verbunden, die das Gegenteil des erwünschten Effektes erzielen konnten: nämlich die eigene Diskreditierung. Die Übernahme einer Legation wollte wohlüberlegt sein und verschaffte am Ende den Gesandten nur selten volle Befriedigung.

\subsubsection{Moult felonneuse et très horrible: Die Auseinandersetzung zwischen England und Frankreich während des Pontifikates Clemens' VI.}

Der Konflikt zwischen England und Frankreich, den beiden in ihrer Entwicklung weit fortgeschrittenen Nationalstaaten, gehört zu den großen Auseinandersetzungen des 14 . und 15 . Jahrhunderts, die nicht nur militärisch und diplomatisch, sondern auch publizistisch mit äußerster Schärfe geführt wur$\mathrm{den}^{33}$. Vordergründig handelte es sich um einen dynastisch motivierten Konflikt, der, was England betraf, die schwer zu legitimierende Präsenz auf französischem Boden sichern sollte. Für die französische Monarchie war das Jahr 1328 von entscheidender Bedeutung. Nach dem Tode Karls IV., des letzten Kapetingers, sah sich Frankreich zwischen die Scylla einer Machtübernahme durch Edward III. von England und die Charybdis einer Thronbesteigung durch Philipp von Valois gestellt. In ersterem Falle hätte der englische König vom Recht der Sukzession;auch in weiblicher Linie profitiert ${ }^{34}$, war doch sei-

33 Die derzeit gültige Gesamtdarstellung des Konflikts, der als »Hundertjähriger Krieg“ in die Geschichte eingegangen ist, liefert Jonathan SuMPTION, Trial by battle. The Hundred Years War I, London 1990 (fortan: Sumption, I) und DERS., Trial by fire. The Hundred Years War II, London 1999 (fortan: Sumption, II); vgl. auch Malcolm G. VALE, The origins of the Hundred Years War. The Angevin Legacy 1250-1340, Oxford 1996; Jürgen SARNowSKY, England im Mittelalter, Darmstadt 2002, S. 151-173. Über die Kriegstaktik insbesondere Edwards III. informiert Clifford J. RoGERs, War cruel and sharp. English strategy under Edward III (1327-1360), Woodbridge 2001; vgl. auch Clifford J. RogERs (Hg.), The wars of Edward III. Sources and interpretations, Bury St. Edmunds 1999; vgl. allgemein zur Bedeutung von Kriegen im Mittelalter: Horst BrunNeR (Hg.), Der Krieg im Mittelalter und in der Frühen Neuzeit. Gründe, Begründungen, Bilder, Bräuche, Recht, Wiesbaden 1999 (Imagines Medii Aevi, 3); Werner RöSENER (Hg.), Staat und Krieg. Vom Mittelalter bis zur Moderne, Göttingen 2000; die "Konflikte vor dem Konflikt « behandelt Klaus van EICKELS, Vom inszenierten Konsens zum systematisierten Konflikt. Die englisch-französischen Beziehungen und ihre Wahrnehmung an der Wende vom Hoch- zum Spätmittelalter, Stuttgart 2002 (Mittelalterforschungen, 10).

34 Zusammenfassend Philippe ConTAmine, Le royaume de France ne peut tomber en fille. Fondement, formulation et implication d'une théorie politique à la fin du Moyen Âge, in: Perspectives médiévales 13 (1987) S. 67-81 (wieder abgedruckt als: Le royaume de France ne peut tomber en fille. Une théorie politique à la fin du Moyen Âge, in: Institutionen und Geschichte. Theoretische Aspekte und mittelalterliche Befunde, hg.v. Gert MELVILLE, Köln, Weimar, Wien 1992, S. 187-207); vgl. auch Helmut SchEIDGEN, Die französi- 
ne Mutter Isabella eine Schwester Karls IV., in letzterem wäre dem Prinzip einer rein männlichen Sukzession zum Durchbruch verholfen worden, handelte es sich bei Philipp von Valois doch um einen Cousin Karls IV. Den Ausschlag für die Thronübernahme Philipps und damit für die Etablierung einer Seitenlinie der Kapetinger als neuer Dynastie gab das, was Joseph Calmette als »instinct national «35 apostrophiert hat: die Überzeugung der französischen Barone, daß die Interessen Frankreichs eher von einem auf französischem Boden Geborenen als von einem Ausländer wahrgenommen werden könnten. Philipp von Valois, dem also eher zufällig die Königskrone zugefallen war, erwies sich zwar als ernstzunehmender Machtpolitiker, ließ aber den Pragmatismus seines Onkels, Philipps des Schönen, vermissen. Fehlende politische Weitsicht und mangelndes diplomatisches Gespür ließen ihn bereits in den ersten Monaten seiner Regentschaft Fehler machen, die sich später als desaströs erweisen sollten. Im August 1328 stand Philipp mit seinem Heer in Flandern und machte sich durch das Massaker von Cassel die flämische bourgeoisie zum Feind. Im selben Jahr führte das Vorgehen gegen seinen Schwager Robert d'Artois, dessen Verurteilung aufgrund gefälschter Dokumente, die seinen Anspruch auf das Artois begründen sollten, zwar als rechtens erscheinen konnte, aber dennoch übermäßig scharf war, zu einem Stimmungsumschwung bei einem Teil des französischen Adels.

In England stellte Edward III. nach den Wirren um die Person seines Vaters Edward II. die politische Ordnung wieder her, indem er seine Mutter entmachtete und deren Günstling Roger Mortimer of Wigmore ermorden ließ. Auf dem Festland hatte er vitale Interessen Englands in Gestalt der Guyenne zu verteidigen, eines Herzogtums, für das er dem französischen König lehenspflichtig war, dessen Besitz er jedoch durch französische Machtpolitik gefährdet sah. Geschickte Diplomatie sicherte ihm die Unterstützung der flandrischen Städte; Gespür für die Erfordernisse von Realpolitik zeitigte beeindruckende militärische Rüstungserfolge. Anders als im vorangegangenen Jahrhundert, wo der Streit zwischen England und Frankreich um die Guyenne von Ludwig IX. 1259 im Vertrag von Paris geregelt werden konnte, machte Edward die Legitimation Philipps zum Ausgangspunkt der Auseinandersetzungen.

Der Konflikt spitzte sich zu und erreichte am 7. Oktober 1337 einen ersten Höhepunkt, als Edward III. den dem französischen König geleisteten Treueschwur ${ }^{36}$ für nichtig erklärte und Anspruch auf den Thron Philipps von Valois

sche Thronfolge 987-1500. Der Ausschluß der Frauen und das salische Gesetz, Phil. Diss. Bonn 1976, bes. S.123-170; Claude BEAUNE, Histoire et politique. La recherche de la loi salique de 1350 à 1450 , in: Actes du 104 e congrès national des Sociétés savantes (Bordeaux 1979), Paris 1981, S.25-35.

35 Vgl. Joseph CALMETTE, L'élaboration du monde moderne, Paris 1934, S. 4.

36 Auf Betreiben seiner Mutter Isabella, die zu diesem Zeitpunkt die Regentschaft innehatte, leistete der minderjährige Edward III. dem neuen französischen König und neuen Suzerain der Guyenne am 6. Juni 1329 in Amiens den Lehnseid; vgl. zur Person Edwards vor allem William M. ORMROD, The reign of Edward III. Crown and political society in 
erhob. Edward, der seine militärische Stärke überschätzte, profitierte von der vermeintlichen Langmut des französischen Königs, der in dieser Herausforderung nichts weiter als jugendlichen Übermut und Unbesonnenheit erkennen konnte, mithin die Sache auf sich beruhen ließ. Der entscheidende Kriegsauslöser ist einmal mehr in Flandern zu suchen, wo Jacob von Artevelde als Führer der flämischen Bourgeoisie für Edward warb. Tatsächlich landete dieser in Flandern, ließ sich jedoch von den päpstlichen Legaten zu einem Waffenstillstand bewegen. Die Flamen gaben der Angelegenheit eine andere Wendung, als sie ihn zum einzig legitimen Nachfolger Karls IV. ausriefen. Derart gestärkt, nahm er am 8. Februar 1340 den Titel eines Königs von Frankreich an und erklärte Philipp den Krieg.

Das Kriegsglück schien zunächst auf seiten der Engländer zu liegen. In der Seeschlacht von Sluys vernichteten sie am 24. Juni 1340 die französische Flotte. Nach einer Zeit immer wieder aufflammender Kämpfe insbesondere in der Guyenne landete Edward am 12. Juli 1346 auf dem Festland und zog gegen Paris, dem er sich bis auf wenige Kilometer nähern konnte. Der Eroberung durch die Engländer entging die Stadt nur deshalb, weil Edward in der Absicht, die Flamen zu unterstützen, weiter nach Osten zog. Bei Crécy trafen Engländer und Franzosen am 26. August aufeinander. Die resignativ-lakonische Bemerkung Froissarts, die Schlacht sei moult felonneuse et très horrible ${ }^{37}$ gewesen, charakterisiert ein Aufeinandertreffen, bei dem sich die englische Infanterie der französischen Schlachtenordnung als deutlich überlegen erwiesen hatte. Philipp indes zog aus seiner Niederlage keine weiterreichenden Schlüsse. Noch immer hing er einer Kriegskonzeption an, die dem Adel eine Schlüsselstellung im Kampfgeschehen zuwies und den Kampf selbst ritterlichen Vorstellungen von Recht und Ordnung unterwarf. Erst später wurde ihm klar, daß er in der Konfrontation mit England gut daran tat, Vorstellungen von Ritterlichkeit nurmehr gering zu veranschlagen ${ }^{38}$. Das englische Heer eroberte Calais. Trotz dieses Erfolges machte sich auf englischer Seite Kriegsmüdigkeit breit, die sich die vom Papst entsandten Nuntien bei der Vermittlung eines Waffenstillstands zunutze machten. In dem am 28. September 1347 in Calais unterzeichneten Waffenstillstand, dessen Bestimmungen zugunsten der Engländer ausfielen, wurde eine zeitlich eng befristete Kampfpause ver-

England 1327-1377, London 22000; des weiteren Scott L. WAUGH, England in the reign of Edward III., Cambridge 1991.

37 Froissart, CEuvres, ed. de LeTtenhove, V, S.64.

38 Am 27. September 1347 hielt Philipp die Stellung bei Sangatte, in Sichtweite des Lagers der Engländer, die Calais belagerten. Ein Angriff auf das strategisch hervorragend positionierte englische Lager schien Philipp nicht möglich, weshalb er Edward darum bitten ließ, einen anderen Kampfplatz zu akzeptieren, wo sich beide Heere mit gleichen Chancen miteinander messen konnten. Keine Szene verdeutlicht anschaulicher, wie realitätsfern der französische König auf längst obsolet gewordene Anschauungen von Ritterlichkeit pochte und damit in einer Zeit scheitern muBte, in der das Wohl und Wehe von Heeren nicht mehr vom Schlachtenglück einzelner Adliger abhing. 
einbart, die immer wieder verlängert und bis zum 6. April 1354 eingehalten wurde. Inzwischen war Philipp am 22. August 1350 gestorben. Sein Nachfolger, von Jean le Bel als lent à informer et dur à ôter d'une opinion beschrieben, wurde Johann der Gute, dessen Fähigkeiten zur Kriegsführung vielleicht noch rudimentärer als die seines Vaters entwickelt waren. Immerhin war er es, der aufgrund seiner Gefangennahme durch die Engländer in der Schlacht von Poitiers am 19. September 1356 zumindest traurige Berühmtheit erlangte.

\subsubsection{Preciosissimum donum pacis: Die Legation der Kardinäle Annibaldo Ceccano und Pierre Desprez im Konflikt zwischen England und Frankreich} (1342-1343)

Eine der ersten Amtshandlungen Clemens' VI. bestand in der Entsendung zweier Nuntien in Kardinalsrang, denen es oblag, im Krieg zwischen England und Frankreich zu vermitteln, durfte Friedensvermittlung zwischen christlichen Nationen doch als eine der Grundkonstituenten im Selbstverständnis nicht nur des neuen Papstes gelten ${ }^{39}$. Unmittelbar nach seiner Inthronisierung waren bereits - der Tradition entsprechend - Wahlanzeigen an kirchliche und weltliche Würdenträger, an Erzbischöfe und Herrscher Europas ergangen ${ }^{40}$. Am 21. Mai 1342 hatten fast hundert Schreiben die Kurie verlassen, die einzig dazu dienten, in nahezu identischem Wortlaut von Wahl und Krönung des neuen Pontifex zu künden ${ }^{41}$. Lediglich ein Brief fiel dabei aus dem Rahmen der hochgradig formalisierten Adressen: derjenige an Philipp VI. von Valois. Clemens VI. unterstrich darin die besondere Zuneigung, die ihn bereits vor seiner Wahl mit Frankreich verbunden habe, und gab seiner Hoffnung Aus-

39 Maurice R. Powicke, War as a means to peace: some late medieval themes, in: Documenting the past. Essays in medieval history presented to George Peddy Cuttino, Bury St. Edmunds 1989, S. 217-223; Bernard Guillemain, Les tentatives pontificales de médiation dans le litige franco-anglais de Guyenne au XIV siècle, in: Bulletin philologique et historique du Comité des travaux historiques et scientifiques, année 1957, Paris 1958, S. 423-432; Jean GAUDEMET, Le rôle de la papauté dans le règlement des conflits entre états aux XIII e et XIV ${ }^{e}$ siècles, in: Recueils de la Société Jean Bodin 15 (1961) S.79-106.

$40 \mathrm{Vgl}$. Felix Gutmann, Die Wahlanzeigen der Päpste bis zum Ende der avignonesischen Zeit, Marburg 1931.

41 Vgl. Lettres Clément VI, nn. 4-93. Das Formular der Briefe präsentiert sich grob wie folgt: 1. Arenga; 2. Wahlmitteilung (Tod des Vorgängers, Begräbnis, Zusammenkunft der Wähler, nähere Umstände der Wahl, Betonung der unanimitas, aber auch der eigenen Unzulänglichkeit); 3. große Besorgnis und Bestürzung des Ausstellers (Höhe des Amtes versus eigene Niedrigkeit); 4. anfängliche Ablehnung der Wahl; 5. Annahme aus unterschiedlichen Beweggründen; 6. Bitte an Empfänger um Gebete für Papst und Kirche; 7. Zusicherung der päpstlichen Gunst für Empfänger. Auch nach den von Hermann Hold zuletzt vorgelegten Arbeiten bleibt eine stringente Analyse der Arengen Rhetorik der avignonesischen Päpste dringendes Forschungsdesiderat, vgl. Hermann HoLD, Autoritative Rhetorik. Eine Untersuchung an Arengen in Schreiben des Avignoneser Papsttums, in: AHP 40 (2002) S. 175-197; Ders., Unglaublich glaubhaft. Die Arengen-Rhetorik des Avignoneser Papsttums, Frankfurt a.M. 2004. 
druck, Philipp möge sich als ein Friedensherrscher erweisen, dessen Sinnen und Trachten sowohl auf die gerechte und gute Lenkung des eigenen Königreichs als auch auf die Unterstützung der Kirche gerichtet sei ${ }^{42}$. Nachdrücklich betonte Clemens das Prinzip der unanimitas, das bei seiner Wahl ausschlaggebend gewesen sei. Quasi per inspirationem sei er von einem Kollegium gewählt worden, dessen Stimmen sich einträchtig auf seine Person vereint hätten ${ }^{43}$. Damit verwies er auf eines der drei in Canon 24 des IV. Lateranum festgelegten Wahlverfahren, nämlich die electio per inspirationem divinam $^{44}$. Unanimitas als Zeichen und Garant von Rechtgläubigkeit ermöglichte im Idealfall ein Zusammenwirken von Papst und Kardinälen, das sich frei von Dissens zeigte, somit also zur eigentlichen Voraussetzung für eine fruchtbare Arbeit im Interesse der gesamten Christenheit werden konnte ${ }^{45}$. Ut unum sint: diese Aufforderung, die Christus beim Abschied an seine Jünger richtete ${ }^{46}$, lag allen päpstlichen Vermittlungsbemühungen zugrunde, war es doch nicht zuletzt die immer wieder beschworene Einheit der christlichen Nationen, die als Grundvoraussetzung für den erfolgreichen Kampf gegen die Heiden galt. In wenigen Zeilen wurde so der Boden für ein Unternehmen bereitet, das während der folgenden sechs Jahre den diplomatischen Apparat der Kurie in Atem halten sollte: die Vermittlungstätigkeit des Papstes in den kriegerischen Auseinandersetzungen zwischen England und Frankreich ${ }^{47}$.

42 Lettres Clément VI, n. 4, Sp. 4: Et quia, fili carissime, sicut nosti, inter alios reges et principes, dum nos minor status haberet, ad personam et regnum tua semper gessimus precipue dilectionis affectum, et erga te velut spirituale ipsius ecclesie brachium paterne dilectionis plenitudinem non solum continuare intendimus, sed augere, tibique et tuis subditis pacis et prosperitatis commoda indefesse sollicitudinis studio procurare, serenitatem regiam rogamus in Domino et hortamur, quatenus Deum timens [...] studeas custodire mandata, justitiam colere, ac diligere in omnibus equitatem.

${ }^{43}$ Ibid., n. 4, Sp. 3: Venerabiles fratres nostri episcopi, presbyteri et diaconi sancte Romane Ecclesie cardinales, de quorum numero tunc eramus, pro futuri substitutione Romani pontificis convenientes in unum, sancti spiritus, ut moris est, gratia invocata, quasi per inspiraionem ipsius in nos, sicut divine clementie placuit, vota sua concorditer direxerunt.

$44 \mathrm{Vgl}$. Giuseppe Alberigo (Hg.), Conciliorum Oecumenicorum Decreta, Rom 1962, S. 222. Die neue, 1996 durch Papst Johannes Paul II. angeregte Wahlrechtsreform sieht neben der Wahl per compromissum auch die Wahl per acclamationem seu inspirationem nicht mehr vor, vgl. Apostolische Konstitution Universi dominici gregis vom 22. Februar 1996, in: Acta Apostolicae Sedis 88 (1996) S. 305-343.

45 Vgl. Werner MALECZEK, Abstimmungsarten. Wie kommt man zu einem vernünftigen Wahlergebnis?, in: Wahlen und Wählen im Mittelalter, hg.v. Reinhard SCHNEIDER, Harald ZIMMERMANN, Sigmaringen 1990, S. 79-134; Jean GAUDEMET, Unanimité et majorité. Observations sur quelques études récentes, in: Études historiques à la mémoire de N. Didier, Paris 1960, S. 149-162.

46 Io 17,11; ähnlich Act 4,32.

$47 \mathrm{Vgl}$. Alain Demurger, Le pape Clément VI et l'Orient: ligue ou croisade?, in: Guerre, pouvoir et noblesse au Moyen Âge. Mélanges en l'honneur de Philippe Contamine, hg.v. Jacques Pavior, Jacques Verger, Paris 2000, S. 207-214, bes. S. 207, wo es zur Charakterisierung des Pontifikatsbeginns heißt: "Les problèmes préoccupants sont nombreux, mais aucun ne l'est plus que le conflit franco-anglais $\ll$. 
Wird von den Vermittlungsbemühungen Clemens' VI. gesprochen, sollte dabei nicht vergessen werden, daß auch die Kardinäle imstande waren, eigenverantwortlich die Aussöhnung zwischen England und Frankreich voranzutreiben. In der Vakanz nach dem Tod Benedikts XII. am 25. April 1342 und dem Beginn des Konklaves am 3. Mai, das fünf Tage später mit der Wahl Pierre Rogers zum neuen Papst enden sollte, hatten sie bereits die Initiative ergriffen ${ }^{48}$. Das zu diesem Zeitpunkt aus 19 Kardinälen bestehende Kollegium mit Kardinal de Farges als Dekan entschloß sich am 2. Mai zur Entsendung zweier Nuntien, Guillaume Ami, Bischof von Apt, und William of Norwich, Dekan der Kirche von Lincoln, der an der Kurie als päpstlicher Kaplan und Auditor des Apostolischen Palastes tätig war. Als Zeugen des 1340 geschlossenen Waffenstillstands von Esplechin waren beide mit den Positionen sowohl der kriegführenden Parteien als auch der Kurie bestens vertraut ${ }^{49}$. Der Auftrag der Nuntien bestand in der Überbringung von Briefen der Kardinäle, die an Edward III. und Philipp VI. gerichtet waren. Darin wurden die beiden Könige aufgefordert, von einem Krieg Abstand zu nehmen, den Ermahnungen der Kurie zu folgen, die Feindseligkeiten einzustellen und einem neuen Waffenstillstand zuzustimmen beziehungsweise den bereits bestehenden zu verlängern ${ }^{50}$. Briefe, die diese diplomatische Mission befördern sollten, waren ebenso an die Königinnen Englands und Frankreichs ${ }^{51}$, an die Verhandlungsführer der jeweiligen Nationen ${ }^{52}$ sowie den Grafen und die Gräfin von Hennegau ${ }^{53}$ gerichtet. Mit den Amtsträgern der Stadt Ypern wurden auch potentielle Verbündete Englands miteinbezogen ${ }^{54}$.

Clemens VI. konnte somit nach seiner Wahl - und noch vor seiner Krönung - nicht nur auf die eindrucksvolle Vermittlungsbilanz seines unmittelbaren Vorgängers Benedikt XII., sondern mit der von den Kardinälen - und damit auch von ihm selbst - initiierten diplomatischen Mission auf ein work in pro-

48 Vgl. Eugène DÉPREZ, La guerre de Cent Ans à la mort de Benoît XII. Lintervention des cardinaux avant le conclave et du pape Clément VI avant son couronnement, in: Revue historique 83 (1903) S. 58-76; Marc DyKMANS, Les pouvoirs des cardinaux pendant la vacance du Saint Siège d'après un nouveau manuscrit de Jacques Stefaneschi, in: Archivio della Società Romana di Storia Patria 104 (1981) S. 119-145.

$49 \mathrm{Vgl}$. DEPREZ, Préliminaires, pièces justificatives, nn. XI-XIII.

$50 \mathrm{Vgl}$. DÉPreZ, La guerre de Cent ans, pièces justificatives, n. 1, S. 66f. Als Grundlage der Edition dient eine Handschrift des späten 14. Jahrhunderts aus dem Bestand der BnF. Da die Register, in denen von den päpstlichen Skriptoren in Avignon die Korrespondenz der Kardinäle in Zeiten der Vakanz verwaltet wurde, ebensowenig erhalten sind wie diejenigen, die die Korrespondenz Clemens' VI. in der Zeit zwischen seiner Wahl und seiner Krönung (8.-19. Mai 1342) enthielten - ganz zu schweigen von den Sekretbriefen des ersten Pontifikatsjahres, die als Totalverlust gelten müssen -, füllen die im MS lat. 4122 der Pariser BnF überlieferten Briefe also eine Leerstelle innerhalb der kurialen Briefüberlieferung.

51 DÉPREZ, Guerre, pièces justificatives, n. 2, S.67f.

52 Ibid., n. 3, S. 68f.

53 Ibid., nn. 4, 5, S. 69-71.

54 Ibid., n. 6, S. 71f. 
gress zurückgreifen. So bestätigte Clemens VI. denn auch mit einem Schreiben vom 10. Mai die Mission ${ }^{55}$ und ließ den Nuntien neue Briefe übermitteln, die diese noch vor ihrer Ankunft in Paris erreichten. Zusammen mit den vom Kardinalskolleg verfaßten Schreiben sollten sie den jeweiligen Souveränen überreicht werden ${ }^{56}$. Das Einvernehmen mit dem Kardinalskollegium wurde von ihm noch im August 1346 besonders hervorgehoben ${ }^{57}$. Die Grundlagen waren damit gelegt: Der Papst konnte auf Bestehendes zurückgreifen, sich als Bewahrer einer Traditionslinie erweisen und damit der Gefahr entgehen, als eifernder Neuerer von Frankreichs Gnaden zu gelten. Mit Blick auf einige Äußerungen, die von ihm während seines Kardinalats formuliert worden waren, mußte er in der Tat großes Interesse daran haben, von seiner damaligen klaren Parteinahme für die Sache Frankreichs abzulenken und seine aktuelle Position als unparteiischer Vermittler zu unterstreichen. Als Papst versagte sich Pierre Roger jeden Hinweis auf die "gerechte Sache" Frankreichs im Kampf gegen England ${ }^{58}$. Zu Beginn seiner Bemühungen griff er auf zwei Persönlichkeiten zurück, die zu den politisch erfahrensten Mitgliedern des zu diesem Zeitpunkt 18 Purpurträger umfassenden Kardinalskollegs zählten: Pierre Desprez, Kardinalbischof von Palestrina und Vizekanzler des Heiligen Stuhls, und Annibaldo Ceccano, Kardinalbischof von Tusculum. Der für den Pontifikat Clemens' VI. singuläre Fall einer gemeinsamen Entsendung zweier Kardinalbischöfe läßt die Bedeutung, die der Papst dieser Friedensmission beimaß, erkennen.

Das auf den 31. Mai 1342 datierte Entsendungsschreiben weist trotz aller stereotypen Formulierungen einige Besonderheiten auf ${ }^{59}$. Der Eingangsteil besticht durch eine präzise Erläuterung, was unter dem Begriff des preciosissimum donum pacis zu verstehen sei. Clemens fächert die Begrifflichkeit dreifach auf - ein Verfahren, das aus den Predigten des Papstes wohlvertraut ist.

55 Ibid., n. 9, S. 74 .

56 Ibid., n. 8, S. 72-74.

57 Lettres Clément VI, n. 2726: [...] opus pacis super sedanda infesta regum ipsorum dis. cordia, cum fratribus nostris S.E.R. cardinalibus, ad id pari voto ferventibus, inchoantes etiam, antequam coronationis nostre suscepissemus insignia, matura deliberatione prehabita, de ipsorum consilio, per nuncios et litteras eisdem regibus per nos missos, eos ad pacem et concordiam reformandas invicem monuimus [...].

58 Aufschlußreich für die politische Haltung von Kardinal Pierre Roger 1338 ist seine Collatio Accingimini et estote filii potentes, vgl. Bibliothèque Sainte-Geneviève, MS 240, fol. 308vb-314rb. Darin werden Urteile folgender Art gefällt: Modo de iusticia istius guerre possumus vos merito reddere certiores. Certum est enim, quod Bavarus et rex Anglie nullo modo possunt habere causam iustam regnum Francie invadendi, regnum, inquam, benedictum in quo regnat iusticia, in quo pax viget, securitas floret, fides et devotio ceteraque omnia bona pollent [...], vgl. MS 240, fol.311va. Unterstrichen wird die Verletzung der lehnsrechtlichen Abhängigkeit Edwards vom französischen König, vgl. MS 240, fol.313vb: [...] quia contra dictum regem, cui Rex Anglie tenetur ad amorem, honorem et reverentiam, fidelitatem, obedientiam non solum ex consanguinitatis et affinitatis vinculo, sed etiam ex homagio, ligio et ex multiplici beneficio liberaliter impenso.

59 Lettres Clément VI, n. 94, Sp. 8-12; Lettres Clément VI autres que la France, n.3. 
Durch das Geschenk des Friedens werde nicht nur eine unverbrüchliche Verbindung zwischen Gott und den Menschen hergestellt, werde Leid in Freude verkehrt, nein, dieses Geschenk sei Grundlage für den Fortbestand jedweder menschlichen Gesellschaft ${ }^{60}$. Das von Gott durch Jesus Christus den Menschen gemachte Geschenk finde seinen vornehmsten Verteidiger in der Person des Papstes, der als vicarius suus in militanti ecclesia die ihm anvertraute Herde more pastoris schützen und sich um deren Seelenheil besorgt zeigen solle ${ }^{61}$. Verursacher des Krieges inter carissimos in Christo filios nostros Philippum Francie et Eduardum Anglie reges illustres sei der Teufel.

Nach diesen Betrachtungen geht der Papst auf den aktuellen AnlaB seiner Interventionsbemühungen ein. Verhindert werden soll ein erneutes kriegerisches Zusammentreffen. In Formulierungen, die in nichts die dem Papst immer wieder unterstellte Parteilichkeit zugunsten Frankreichs erkennen las$\operatorname{sen}^{62}$, zeigt er sich um das Wohlergehen beider Nationen besorgt, entwirft ein düsteres Gemälde des Kriegszustandes mit seinen immensen Verlusten an Mensch und Besitz und geht erst dann dazu über, seine konkreten Gegenmaßnahmen zu benennen. Als Vermittler entsandt werden zwei Persönlichkeiten, die durch Tugend, Wissen, Weisheit, Gerechtigkeitssinn ausgezeichnet seien, auf deren tägliche Mitarbeit die Kurie zwar nur schwer verzichten könne, die sie aber dennoch entsende, damit sie durch Mahnungen und Gespräche die beiden verfeindeten Parteien auf den Weg des Friedens zurückführten ${ }^{63}$.

Gedacht war an eine körperliche Präsenz der Kardinäle in den jeweiligen Königreichen ${ }^{64}$ - wohl deshalb erfolgte die Entsendung zweier Purpurträger. Pierre Desprez und Annibaldo Ceccano schien jedoch an einem konzertierten Vorgehen gelegen gewesen zu sein: Die Gesandtschaft wurde gemeinsam ausgeführt, eine räumliche Trennung der beiden über einen längeren Zeitraum ist nicht nachweisbar ${ }^{65}$. Als Friedensboten oblag ihnen wenn nicht die Vermittlung eines dauerhaften Friedens, so doch die eines zeitlich befristeten Waffenstillstandes. Damit waren die Aufgaben der Nuntien jedoch noch nicht voll-

60 Lettres Clément VI, n. 94, Sp. 9: Hoc est igitur felicissimum donum per quod Deo, cujus in pace factus est locus, ejus indissolubilis amoris unione conjungimur, hoc est donum gloriosissimum cujus consilia ineuntes ingentia gaudia subsecuntur; hoc est donum utilissimum conservativum societatis humane, beatificans regnantium solia et conservans in opulentia regnorum statum et etiam populorum $[. .$.$] .$

61 Ibid.

62 Insbesondere Diana Wood hat die in ihren Augen nur scheinbare Unparteilichkeit Clemens' VI. einer kritischen Wertung unterzogen, vgl. Diana Wood, Omnino partialitate cessante. Clement VI and the Hundred Years War, in: Studies in Church History 20 (1983) S. 179-189; vgl. Kap. 3.1.

63 Die Auflistung der den Legaten eigenen Qualitäten ist topisch. Der Auftrag ergeht stets ad viros laudande virtutis scientia, et innata prudentia preditos, cultores justicie, sedulos pacis amicos, et concordie zelatores; so z. B. Lettres Clément VI, n. 94, Sp. 11.

64 Ibid., n. 94, Sp. 12: [...] vos ad regna et terras predicta personaliter conferentes [...].

65 Der Papst gestand jedem der Kardinäle ausdrücklich das Recht zu, im Falle einer Verhinderung des jeweils anderen allein und eigenverantwortlich zu handeln, vgl. ibid., n.95. 
ständig umrissen. Sie sollten dafür Sorge tragen, daß die durch den Krieg beschnittenen kirchlichen Freiheiten wiederhergestellt und im Falle Englands die Ansprüche Edwards III. auf die Pfründen der Kardinäle zurückgewiesen würden ${ }^{66}$. In letzterem Falle handelten die Kardinäle in eigenem Interesse. Eine Fülle von Fakultäten sollte ihnen ein effizientes und zielgerichtetes Vorgehen ermöglichen ${ }^{67}$. Insbesondere die Dispens- und Ablaßfakultäten waren umfangreich $^{68}$ und versetzten die Kardinäle in die Lage, das Füllhorn päpstlicher Gnadenerweise über einer Vielzahl von Personen auszuschütten. Auch die Möglichkeiten zur Verleihung von Benefizien, deren Provision sich ansonsten der Papst selbst vorbehielt, waren Teil jener Fakultäten, von denen man sich eine positive Wirkung versprach ${ }^{69}$. In Verbindung mit den Zensurfakultä$\operatorname{ten}^{70}$ verfügten die päpstlichen Diplomaten somit über ein Instrumentarium, mit dessen Hilfe einer effizienten Vermittlungstätigkeit nichts mehr im Weg stehen sollte. Selbstverständlich fand auch die Frage der den Kardinälen in der Zeit ihrer Abwesenheit von der Kurie zu zahlenden Prokurationen Beachtung ${ }^{71}$.

Annibaldo Ceccano war bereits am 8. Mai damit beauftragt worden, die Wahl des neuen Papstes dem englischen König mitzuteilen. Der Kardinal kam diesem Auftrag zusammen mit Raymond de Farges nach. Die Wahlanzeige zeugt von dem Bemühen, den englischen König des besonderen Wohlwollens Clemens' VI. zu versichern, sei er doch de vestro ducatu natus, habe er ihm doch als Erzbischof von Rouen den Treueid geleistet und damit die Basis für ein besonderes, noch andauerndes Vertrauensverhältnis gelegt ${ }^{72}$. Der König könne sicher sein, im neuen Papst einen Hirten zu finden, dem parteiisches

66 Ibid., nn. 97-99.

67 Ibid., nn. 96-153 (31.Mai 1342); nachgeschoben wird lediglich eine weitere Fakultät: n. 166 (8. Dezember 1342; Ausweitung aller bereits gewährten Fakultäten auf das Gebiet der Grafschaft Hennegau).

68 Vgl. Ibid., nn. 105, 118, 119, 129-131, 133-139, 141.

69 Vgl. Ibid., nn. 143, 145, 148-150 (die Verleihung der wirklich lukrativen Pfründen, deren Wert 15 Pfund Tur. überstieg, blieb dem Papst vorbehalten), 152. Annibaldo Ceccano übertrat in mindestens drei Fällen seine Befugnisse und verlieh Benefizien an zwei Italiener, Pietro de Miredollo und Francesco Odonis, und einen Benediktiner aus dem Anjou. Da die in der entsprechenden Fakultät genannte Höchstsumme von 15 Pfund Tur. in allen Fällen überschritten wurde, erklärte der Papst die Provisionen für ungültig, vgl. ibid., nn. 195, 313, 542.

70 Vgl. Ibid., nn. 100-104, $113 \mathrm{f}$.

71 Vgl. Ibid., n. 153.

72 Thomas RyMER, Foedera, conventiones, litterae et cujuscunque generis acta publica inter reges Angliae et alios quosvis imperatores, reges, pontifices, principes, vel communitates ab ineunte saeculo duodecimo, viz. ab anno 1101 ad nostra usque tempora, Bd. 5, London 1727, S.311. Damit nehmen die Kardinäle unbewußt den Tenor des Briefes auf, den Edward III. am 3. Mai von Westminster aus an das Wahlkollegium gerichtet und mit dem Wunsch verbunden hatte, ut talem eligatis ad speculam celsitudinis apostolica, qui Petri naviculam, jam sine remige fluctuantem, velit et valeat feliciter gubernare et ad dirigendos pedes Catholicorum in via pacis sit fervidus et votivus, vgl. ibid., S. 310. 
Urteilen fremd und zuwider sei. Tatsächlich ging Edward III. in seinem Antwortschreiben auf diese Formulierung ein und unterstrich seinerseits die Hoffnung, quod partialis non eritis, set rectus inter Deum et homines mediator $^{73}$. In einem Brief vom 22. Mai 1342 ging er noch weiter: $\gg$ Jeder weiß, daß in euch das brennende Verlangen und der feste Wille wohnen, in Einklang mit dem Recht zu handeln und euch jeder unrechtmäßigen Handlung zu enthalten. Durch zwei Kardinäle habt ihr geruht, in mir Hoffnung zu erwecken und mein Vertrauen zu stärken. Ihr habt mir eure Unterstützung versprochen und wünscht, mich mit Zeichen eures Wohlwollens zu bedenken. Ich verspreche Euch im Gegenzug, die Rechte und Freiheiten der Kirche niemals mit Füßen zu treten und mich niemals vom Pfad des Rechts zu entfernen «74. Soweit die Absichtsbekundungen des englischen Königs. $\mathrm{Daß}$ die Kurie vor diesem Hintergrund gewisse Hoffnungen mit der Gesandtschaft verband, erstaunt nicht.

Die Nuntien verließen am 31.Juli 1342 die Kurie ${ }^{75}$ und begaben sich zunächst zu Philipp VI. von Frankreich, was Edward III. derart verärgert zu haben scheint, daß er den Nuntien auf deren Ankündigung, nach England übersetzen zu wollen, eine abschlägige Antwort erteilte: Er selbst habe vor, sich demnächst auf seine Festlandsbesitzungen zu begeben, eine Reise der Nuntien nach England sei deshalb überflüssig ${ }^{76}$. Die beiden Kardinäle sind am 15. August in Douai, am 24. August in Tournai nachweisbar. Zwei Tage später fanden in Antoing Unterhandlungen mit Jean III. von Brabant und dem Grafen von Hennegau statt. Am 28. November urkundete Annibaldo in

73 Ibid., S.313f.

74 Zit. in DÉPREZ, Préliminaires, S. 393.

75 Zuvor hatte der Papst am 12. Juni mit der Lösung der England wirtschaftlich verbundenen, nominell jedoch von Frankreich abhängigen Flamen von der Exkommunikation einen gewichtigen diplomatischen Stolperstein aus dem Weg geräumt, vgl. Lettres Clément VI, n. 156.

76 Vgl. Ulrich BÜNGeR, König Eduard III. von England und Papst Clemens VI., Berlin 1909, S. 12f. Die Ablehnung Edwards III. dürfte auch der Absicht entsprungen sein, sich der Zahlung von Prokurationen zu entziehen. Immerhin hatten die Kardinäle um Geleitbriefe für sich nebst 200 Saumrossen gebeten, was einen Eindruck vom Umfang eines derartigen Gesandtschaftstrosses ermöglicht. Den ausführlichsten Bericht liefert MURIMUTH, Continuatio, S. 126: zur Hochzeit von Lionel, dem Sohn Edwards III. im Tower zu London seien auch vier Dominikaner erschienen, missi per duos cardinales, scilicet per Petrum episcopum Penestrinum et Ambaldum, prope marchiam Flandriae commorantes, ad habendum literas regias de conductu pro se et CC. equitaturis, ad transeundum mare et Angliae regnum intrandum et ad tractandum cum rege de pace vel treuga. Et statim rex misit pro archiepiscopo, ad deliberandum cum eo de diversis et utrum essent hujusmodi literae concedendae. Et, habita / deliberatione duorum dierum, respondit quod ipse rex voluit parcere ipsorum cardinalium laboribus et expensis ac infra paucos dies in regno Franciae habere colloquium cum eisdem, praesertim cum [...] ad transeundum in Franciam se parasset, quem transitum non potuit pro dictorum cardinalium exspectatione differe. Ein weiterer Gesichtspunkt tritt hier hervor: ein allzu langes Warten auf die Ankunft der Kardinäle liefe der Staatsräson zuwider. Im Interesse Englands muß der König so bald wie möglich auf das Festland übersetzen. 
Paris ${ }^{77}$. War diese erste Phase der Gesandtschaft von hektischer, letztendlich aber ergebnisloser Reisediplomatie geprägt, kam spätestens mit der Landung Edwards III. auf dem Festland Bewegung in die Angelegenheit. Die Kardinäle wurden von diesem in sein Feldlager bei Vannes zitiert. Zeitgleich bemühte sich der französische König, Absichten und Pläne des Feindes in Erfahrung zu bringen, und bediente sich dazu der Dienste von Spionen, die für geleistete Dienste großzügig entlohnt wurden. So leistete ein Beamter der chambre des comptes, Bertrand Jobelin, auf direkte Anweisung seiner Vorgesetzten - Hugues de Pommart, Fauval de Vaudencourt, Pierre des Essars und Guillaume Balbet, der königliche Schatzmeister, werden namentlich erwähnt - vom 29. November bis zum 24. Dezember 1342 Zahlungen an Spione, die insbesondere die Bewegungen des englischen Feindes in der Bretagne überwachen sollten. Dieses gesteigerte Informationsbedürfnis auf seiten des französischen Königs machte auch vor den beiden Nuntien nicht Halt. Für den 24. Dezember 1342 ist eine Zahlung für die Beförderung von Briefen belegt, in denen über die Brandschatzung der außerhalb der Stadtmauer gelegenen Viertel von Dinant durch den Earl of Salisbury berichtet und auf die Notwendigkeit verstärkter Verteidigungsmaßnahmen für die Festung Pontorson verwiesen wurde. In diesem Zusammenhang wurde ebenfalls mitgeteilt, daß die beiden Kardinäle in Avranches und Pontorson Briefe vom König von England in Empfang genommen hätten, in denen sie dazu aufgefordert worden seien, sich zwecks Verhandlungen in das königliche Lager nach Vannes zu begeben. Über zusätzliche Details verlautete jedoch nichts ${ }^{78}$. Ebensowenig erfährt man etwas über den Verlauf der Unterredungen zwischen dem englischen König und den Kardinälen. Lediglich die Chronistik geht auf die erfolgreiche Pendeldiplomatie der Nuntien ein ${ }^{79}$. Frucht der Vermittlungstätigkeit war ein am 19. Januar 1343 in Malestroit abgeschlossener Waffenstillstand, der sich zu-

77 Vgl. zur Chronologie der Reise Marc Dykmans, Le cardinal Annibal de Ceccano (vers 1282-1350). Étude biographique et testament du 17 juin 1348, in: Bulletin de l'Institut historique belge de Rome 43 (1973) S. 145-344, hier S. 220.

$78 \mathrm{Vgl}$. LeSCOT, Chronique, S.228-230, bes. S. 230: [...] Item, le XXIIIIe jour de decembre, pour porter lettres à mesdits seigneurs, faisant mencion come les forbours de Dynan estoient ars par le conte de Sallebiere et come il estoit necessité de garnir et garder le chastel de Pontorson. Et aussi come les cardinaulx avoient eu lettres à Avrenches et à Pontorson de par le Roy d'Angleterre d'aler parler à li à Vennes ou pres d'illec [...]; vgl. umfassend Christopher Allmand (Hg.), Society at war. The experience of England and France during the Hundred Years war, Woodbridge ${ }^{2} 1998$, S. $123 \mathrm{f}$.

79 Vgl. Les Grandes Chroniques de France, hg.v. J. VIARD, Bd.9, S. 227-230, mit der wohl ausführlichsten Darstellung der Verhandlungen; auch der Wortlaut des Vertrags wird wiedergegeben, vgl. ibid., S. 231-234. Zu Entstehung und Bedeutung der Grandes chroniques handelt Bernard GuENÉE, Die Grandes Chroniques de France. Die Geschichte eines Erfolgs, in: Jean FouQuET, Die Bilder der Grandes Chroniques de France, Graz 1987, S. 71-114; Bernard Guené, Les Grandes Chroniques de France. Le Roman aux roys (1274-1518), in: Les Lieux de Mémoire, Bd.2, hg.v. Pierre NorA, Paris 1986, S. 189-214. 
nächst bis Michaelis (29. September) und darüberhinaus auf drei Jahre erstrecken sollte ${ }^{80}$. Ein erstes wichtiges Ziel auf dem Weg zu einem definitiven Friedensvertrag war mit dem vorläufigen Ende der Kampfhandlungen erreicht. Gleichzeitig kamen die Konfliktparteien darin überein, Botschafter nach Avignon zu entsenden, um dort unter Vermittlung des Papstes als Privatperson in weitere Verhandlungen einzutreten. Der für alle Parteien befriedigende Abschluß der Verhandlungen - immerhin handelte es sich um den ersten diplomatischen Erfolg des neuen Papstes - wurde allgemein gewürdigt. Edward III. schrieb den Erfolg dem Papst und den Kardinälen zu, unterstrich jedoch den privaten Charakter der päpstlichen Vermittlung81.

Die zeitgenössische Chronistik nahm das Ereignis zur Kenntnis, auch wenn überschwengliche Lobeshymnen unterblieben ${ }^{82}$. Bezeichnend für die Haltung des französischen Königs ist hingegen ein nur eine Woche nach Abschluß des Waffenstillstands verfaßter Brief an Peter von Aragon, in dem das Wirken der Kardinäle gänzlich unterschlagen, die eigene Position jedoch unterstrichen

80 Vgl. SuMPTION, I, S. 407f., 418, 423, 452-454; RYMER, Foedera, V, S. 357.

81 Vgl. RYMER, Foedera, V, S. 366.

82 Vgl. MURIMUTH, S. 129: Rex vero per totam hiemem equitavit per terram Britanniae, per iiii. dietas in longitudine et duas in latitudine, non tamen comburendo nec occidendo, sed de his quae ibi invenerant victitando; et postea fecit obsideri civitatem de Vanys [...]. Sed, dum haec omnia agerentur, duo cardinales praedicti, inter duos exercitus equitantes, unam treugam finaliter procurarunt, quae fuit cum difficultate ex parte regis Angliae concessa, decimo nono die mensis Januarii, sub hac forma [es folgt der Wortlaut des Vertrages] [...]; vgl. Chronicon comitum Flandrensium, S.214f.: Deinde anno Domini MCCCXLII, papa Clemens misit duos legatos ad Franciam et ad Angliam, ut dictum est, pro concordia facienda. Qui in principio modicum profecerunt, eo quod regis Anglie presentiam habere non potuerunt. Sed finaliter intelligentes, quod ad parvam Britanniam se transtulerat idem rex Anglie [...] illuc se transtulerunt cardinales praedicti, et invento rege Anglie in obsidione civitatis Nannetensis, colloquium habuerunt cum eo ex parte sanctissimi pontificis super pace habenda, vel saltem super treugis ineundis. Tantum profecerunt et procuraverunt dicti cardinales legati inter utrumque regem, quod sub certis conditionibus treugae fuerunt inter dictos reges et suos colligatos concessae et concordatae per terram et per maria, usque ad festum beati Michaelis, et ab hinc usque ad tres annos immediate / sequentes [...]; vgl. Chronica Aegidii li Muisis, S. 233: Anno eodem, scilicet MCCCXLII, circa natale Domini, intraverat rex Anglie in Britanniam, vastando eam rapinis et incendiis, et venit usque ad villam, quae dicitur Vane, et obsedit eam vastando undique, et dux Normanniae Johannes, primogenitus regis Franciae, erat cum ingenti exercitu ad viginti leucas prope eum, et pater ejus cum maximo exercitu sequebatur eum. Et tunc venerunt dicti duo cardinales, dominus vicecancellarius et Hanibal, et cum maximo labore et periculo tractaverunt de pace, si possent, facienda, quod minime facere potuerunt, sed potius ex utraque parte fuerunt treugae et dilationes concordatae; vgl. Ranulphus Higden, Polychronicon, Bd. 8, hg. v. Joseph Rawson LUMBY, London 1882, S. 336f.: Rex Edwardus cum navigio suo adiit Britanniam Minorem, ubi per cibos et potus inconvenientes plures amisit. Missi sunt tamen ad eum duo cardinales ex parte / papae, treugas triennales inter reges reportantes, ut sic in tanto temporis spatio de jure regis Angliae, quod in regnum Franciae vindicavit, posset ad plenum disceptari. In redeundo quoque de Britannia versus Angliam, rex Edwardus maxima incommoda per marinam tempestatem perpessus est, quae utique per nigromanticos regis Franciae dicebatur procurari $[\ldots]$. 
wird ${ }^{83}$. Der König ist sich seiner Sache sicher: vor den anstehenden Verhandlungen an der Kurie fürchte er sich nicht, sei der amtierende Papst doch ein erklärter Freund Frankreichs ${ }^{84}$. Singulär bleibt das von Knighton gezeichnete Bild, das die Kardinäle in der Rolle demütiger, den König ungemein inkommodierender Bittsteller zeigt ${ }^{85}$. Einige wenige Chronisten stellen eine ursächliche Verbindung zwischen Waffenstillstandsvertrag und verstärkten Kreuzzugsbemühungen her ${ }^{86}$.

Daß der Vertrag von Malestroit jedoch an der Kurie als möglicher Anfang vom Ende des Krieges zwischen England und Frankreich aufgefaßt wurde, daran kann kein Zweifel bestehen ${ }^{87}$. Den Kardinälen blieb außer dem ephemeren Ruhm, der mit jedem Bruch des Waffenstillstands schneller verblaßte, nur wenig. Auch in finanzieller Hinsicht erwies sich die Gesandtschaft als Fehlschlag, obwohl Clemens VI. den Fragen nach Leistung von Prokurationen bereits im Vorfeld Beachtung geschenkt hatte ${ }^{88}$. Edward III. nahm von Prokurationszahlungen Abstand - schließlich hatte er das Übersetzen der Kardinäle auf englisches Territorium erfolgreich verhindert - und vermied auch bei allen Zahlungsanweisungen zugunsten der Gesandten den Gebrauch dieses terminus technicus: die Zahlung von 200 Pfund an jeden Kardinal wurde fromm als Geschenk verbrämt ${ }^{89}$. Auch auf dem Festland lösten die Forde-

$83 \mathrm{Vgl}$. Joaquim MiRET Y SANS, Lettres closes des premiers Valois, in: Le Moyen Âge 29 (1917/1918) S. 53-83, hier S.68: le roy d'Engleterre estoit descenduz en Bretaigne [...] ses genz qui avoient prises aucunes villes en pays de Bretaigne, emsi comme il nous sentoient venir, se sont partiz et retraiz et, merci Dieu, il s'en est partiz à nostre honneur sanz riens conquester $d u$ nostre et avons trives ensemble de la Sant Michel prochaine venent en trois anz.

84 Ibid., S. 68f.: Et, pour traiter des discensions d'entre nous et li, devons nous en li envoier devers le saint Père lequel est ben nostre ami, si comme vous povez savoir.

85 Vgl. Henricus Knighton, Chronicon, hg. v. Geoffrey H. MARTIN, Oxford 1995, S. 27 : [...] statim supervenere duo cardinales missi a latere papae, et tantam instantiam supplicando fecerunt penes regem Edwardum, quod concessit eis treugas triennales, scilicet inter reges Angliae, Franciae et Scotiae. Et exinde multi Angligenae et Francigenae transierunt ad Spruciam ad bellum campestre assignatum die Parasceves proximo sequenti inter regem Hispaniae et paganos.

86 Vgl. ibid., S. 27; Hocsem, Chronique, S.311: Circa principium hujus mensis inter reges Francie et Anglie treuge publicate sunt a festo Michaelis ad triennium durature; et ex tunc multi magnates properant in adjutorium regis Granate contra Sarracenos. Tatsächlich wurde das seit 1343 von christlichen Truppen belagerte Algesiras am 25. März 1344 vom Sultan von Granada erobert.

87 Bei aller gebotenen Konzentration auf das Essentielle geht das Handbuch der europäischen Geschichte, Bd.2, S. 740 in seinem Bemühen um Reduktion zu weit. Der Waffenstillstand von Malestroit war auch in der Wahrnehmung der Öffentlichkeit mehr als ein bloßer Appendix des bereits von Benedikt XII. 1340 ausgehandelten Waffenstillstands von Esplechin.

88 Vgl. Lettres Clément VI, nn. 116, 153.

89 RYMER, Foedera, V, S.387. Immerhin erhält mit Raymundus Pelegrini ein päpstlicher Nuntius und einfacher canonicus Londoniensis bereits 7 Pfund Sterling täglich an Prokurationszahlungen, vgl. Lettres Clément VI, n. 638 (30.01.1344); bei William of Norwich, einem weiteren Nuntius, diesmal im Range eines Bischofs, werden gar 8 Goldflorin täglich 
rungen der Kardinäle keinen Jubel aus. Angesichts des großen Gefolges, das zur Steigerung der kardinalizischen Würde offensichtlich für unverzichtbar gehalten wurde, fühlte sich wohl nicht nur das Bistum Lüttich überfordert. Immerhin wagte man es aber, einen Beschwerdebrief nach Avignon zu richten, in dem man sich über die unbotmäßigen Forderungen der Purpurträger beklagte ${ }^{90}$. Allerdings sucht man solche Details in der Collatio des Papstes zu Ehren der beiden an die Kurie zurückkehrenden Nuntien vergeblich.

\subsubsection{Ibant et revertebantur: die Collatio Clemens' VI. anläßlich der Rück- kehr der beiden Kardinäle Annibaldo Ceccano und Pierre Desprez}

Als Thema seiner Begrüßungsansprache für die beiden Kardinäle Pierre Desprez und Annibaldo Ceccano wählte Clemens VI. ein Thema, das er dem ersten Kapitel des Ezechielbuches entnahm: Ibant et revertebantur in similitudinem fulguris choruscantis ${ }^{91}$. Aussendung und Rückkehr markieren Anfangs- und Endpunkt einer diplomatischen Mission, die durch die in der Pariser Handschrift enthaltene Überschrift von ihrem Ergebnis her beurteilt wird: Collatio facta per dominum Clementem papam VI. in reditu cardinalis Penestrini et Tusculani de Francia factis treugis ${ }^{92}$. Was diese Mission auszeichnete, war

fällig, vgl. ibid., n. 657 (07.02.1344). Gleichwohl scheinen Prokurationsgelder bereits eingesammelt worden zu sein, wie das Beispiel der Diözese Rochester belegt, wo der Prokurator der Kardinäle, Androuin de la Roche, dem Bischof den Empfang einer Summe von quiquaginta septem libras, duos solidos et octo denarios bestätigt, vgl. Registrum Hamonis Hethe, diocesis Roffensis (1319-1352), Bd. 1, hg. v. Charles Jornson, Oxford 1948, S. $706 f$. $90 \mathrm{Vgl}$. HocsEM, Chronique, S.310: Hoc anno contra cardinales missos pro pace inter reges Francie et Anglie procuranda, quia procurationes injuste petebant, per clerum Leodiensem extitit appellatum. Noch rund zehn Jahre später hatte sich an der kurialen Auffassung, wonach Masse ein wesentlicher Bestandteil von Klasse ist, nicht viel geändert. Gui de Boulogne, als päpstlicher Legat im Konflikt zwischen Frankreich und England vermittelnd, machte 1353 durch ein überdimensioniertes Gefolge von sich reden, vgl. JEAN LE BEL, Chronique, S. 202f.: Si y vint en plus grande pompe que oncques saint Pierre, qui fut tant amé de Dieu, n'ala par terre, car on disoit qu'il avoit bien en sa compaignie VIIc chevaulx que tous soustenoient des esglises de France; dazu auch FroIsSART, Euvres, ed. de LETTENHOVE, V, S. 223, wo »nur « von 200 Pferden die Rede ist. Auch im Reich hatte man starke Vorbehalte gegen die kostspielige Legationstätigkeit der Kardinäle, vgl. BOHMER, Acta imperii selecta, S. 740, n.1046: Scientes, quod si mittantur duos cardinales, quilibet habebit pro procuratione sua in die centum florenos, incipiendo a prima die, quando per papam et cardinales ad hoc eliguntur. Isti prelati querunt virgam ad dorsum proprium, et miserie proprie volunt addere miseriam maiorem, et se et totam Almaniam imbrigare et infamare.

91 Den folgenden Ausführungen liegt der Text der Handschrift Paris, Bibliothèque SainteGeneviève, MS 240, fol.60r-63r zugrunde. Zur Parallelüberlieferung in mindestens fünf weiteren Handschriften vgl. SCHNEYER, Repertorium, Bd.4, S.762, n.48; Mollat, Euvre oratoire, S. 256, n. 68; SchmIrz, Sermons, S. 26, n. 41; WooD, Sermon literature, S. 163-172. 92 MS 240, fol.60ra. Neben dem Verhandlungsergebnis verweist die Überschrift auch auf den exklusiven Verhandlungsort: Frankreich, was insofern erstaunt, als es um Friedensvermittlung zwischen den Königen Englands und Frankreichs geht, sich der nicht informierte Leser der Collatio also fragen muß, weshalb England als Verhandlungsort ausgeklammert wird. Die Rückkehr der Kardinäle erfolgte Ende März 1343, vgl. WEIss, Versorgung, S. 498. 
der unbestrittene Erfolg, der im Abschluß eines mehrere Jahre gültigen Waffenstillstands - factis treugis - bestand, ein Erfolg, der zum einen auf dem Verhandlungsgeschick der beiden Kardinäle beruhte, zum anderen aber auch auf die Initiative und überragende Stellung des Papstes selbst zurückzuführen war.

Das der Collatio zugrunde liegende Thema wurde vom Papst mit Bedacht gewählt ${ }^{93}$. Der im babylonischen Exil lebende Priestersohn Ezechiel hat eine Vision, die für ihn die Berufung zum Propheten bedeutet. Als Verbannter bleibt er seinem Volk verbunden, leidet mit ihm und stellt sich ganz in den Dienst Gottes. Diese Hingabe an Gott läßt ihn zum ausführenden Organ des göttlichen Willens werden: Inmitten einer Feuerwolke erkennt Ezechiel vier Tiere, die zwar menschliches Antlitz tragen, jedoch noch über zusätzliche Charakteristika verfügen. Jedes Tier hat nicht nur vier Angesichter, vier Flügel und vier Menschenhände unter den Flügeln, untereinander sind sie auch durch ihre Flügel verbunden. In jedem Antlitz erblickt Ezechiel jeweils einen Menschen, Löwen, Ochsen und Adler, Gestalten also, die Clemens VI. anderweitig auf die vier Evangelisten bezieht. Helligkeit, Flammen und Feuer werden nicht von außen an die Tiere herangetragen, sondern scheinen integraler Bestandteil ihres Wesens zu sein. Zwischen ihnen bewegt sich das Feuer unablässig hin und her, verstrahlt seinen Glanz und gewinnt an Intensität durch die Blitze, die von ihm ausgehen: fulgura, ein Zentralbegriff der Collatio.

Bereits die Nennung des Themas dürfte bei den Zuhörern eine Vielzahl von Assoziationen hervorgerufen haben. Zum einen verweist die Gestalt des Ezechiel auf die bedingungslose Unterwerfung unter den Willen Gottes mit heilbringenden Folgen für das Volk Israel - die gedankliche Übertragung auf die beiden Kardinäle und ihr spezielles Verhältnis zum Papst, der in seinem Selbstverständnis nicht nur als vicarius Christi, sondern als vicarius Dei amtiert, ist dabei durchaus intendiert -, zum anderen eröffnet der Gedanke an Evangelisten bzw. Evangelium ein Bedeutungsspektrum, das ganz auf die "frohe Botschaft « ausgerichtet ist, eine Botschaft, die die beiden Kardinäle im Auftrag des Papstes den Königen Frankreichs und Englands überbringen, die danach jedoch in Form des erzielten Waffenstillstands an die Kurie zurückkehrt.

Das Handeln der Kardinäle wird vom Papst mit einem dem Ezechielkommentar Gregors des Großen entnommenen Zitat umschrieben: "Die Staunenswertes vollbringen, sind wie der Blitz, der die Herzen der Beteiligten trifft, erschreckt, erleuchtet und entzündet «94. Mit dem Verweis auf die von den Nuntien erbrachten stupenda läßt der Papst keinen Zweifel an der positiven Bewertung ihrer Mission aufkommen, betont vielmehr deren Verhand-

93 Zentral ist Ez 1,14: Et animalia ibant et revertebantur in similitudinem fulguris choruscantis, etwa: »Und die Gestalten liefen hin und her, daß es aussah wie Blitze

94 MS 240, fol.60ra: Qui stupenda faciunt fulgur sunt, quia corda intuentium concutiunt, terrent, illuminant et accendunt. 
lungsgeschick, ihr entregent, ohne das ein Ergebnis nicht zu erzielen gewesen wäre. Scholastischer Methode folgend definiert er das, was unter fulgur zu verstehen sei: Er erzeuge Betroffenheit (stupor), verbreite Angst und Schrecken (terror), führe zu hellem Leuchten (fulgor) und erzeuge Glut und Hitze (fervor/ardor $)^{95}$. Gewagt, wenn auch durch Evangelienzitate belegt, ist der Vergleich mit der Ankunft Christi, dessen Erscheinen die Herzen der Gläubigen auf ähnliche Weise bewegt habe.

Hingewiesen sei an dieser Stelle auf ein stereotyp wiederkehrendes Kompositionsmerkmal. Geht es darum, Zentralbegriffe biblisch zu untermauern, ist das probateste Mittel zur Bewältigung dieser Aufgabe ein Griff zu Bibelkonkordanzen, die in der päpstlichen Bibliothek in großer Zahl vorhanden waren $^{96}$. Daß dies sehr oft zur Überfrachtung des Textes mit Nebensächlichem führt - nicht zuletzt ist es eben die exzessiv zur Schau gestellte Bibelkenntnis, die als Beleg für große Gelehrsamkeit gilt -, liegt auf der Hand. Wichtiges von Unwichtigem, Zentrales von Nebensächlichem trennen zu können, ist daher Voraussetzung für den sachgemäßen Umgang mit mittelalterlicher Predigt. Die gedankliche Assoziationskette innerhalb der Collatio findet mit der Erwähnung der beiden Kardinäle, die nicht irgendeinen, sondern einen auf vier Jahre gültigen Waffenstillstand vermittelt haben, ihr Ende ${ }^{97}$. Daß sich der rhetorische Ehrgeiz des Papstes nicht darin erschöpft, die Gründe für diesen diplomatischen Erfolg aufzulisten, kann nicht erstaunen. Kunstvoll verknüpft er diese mit den bereits zuvor genannten Charakteristika des fulgur. Durch das herausragende Tun (facto spectabili) der Purpurträger, ihr entschiedenes und energisches Auftreten (sono terribili), ihre zweifache, äußerst effizient und der Situation angemessen zum Einsatz gebrachte Rhetorik (suo verbo dupplici, efficaci et delectabili) und schließlich ihren staunenswerten Eifer (zelo mirabili) sei dieser Verhandlungserfolg bewirkt worden ${ }^{98}$. Interessant ist ein Blick auf den dem zweiten Punkt inhärenten Aussagegehalt. Das energische Auftreten der Kardinäle - wörtlich ihr "schrecklicher Ton " - erzeugt Furcht, Furcht vor den Konsequenzen einer Weigerung, Friedensschritte zu unternehmen, bewirkt gleichzeitig aber auch die Einsicht in die Notwendigkeit eines Waffenstillstands. Die

95 Ibid.: Quia sicut sensus et experientia docent, fulgur est inductivum stuporis, est incussivum terroris, est allativum fulgoris, est accensivum fervoris et ardoris.

$96 \mathrm{Vgl}$. die recensio des Bücherbestandes von 1369 in: EHRLE, Bibliotheca, S.316f., nn. 387-391, S. 325, n. 480, S. 323, n. 462. Bei offensichtlich allzu opulenter Zitatdichte ließe sich auch an Hinzufügungen des Reportators, bzw. des Schreibers, auf jeden Fall aber an Ergänzungen post festum denken.

97 MS 240, fol.60rb: [...] treugis pacis ymaginem gerentibus et non ad quodcumque tempus, sed fere ad quatuor annos factis [...].

98 Ibid.: Corda principum, ad quos eos principaliter misimus ymmo omnium videntium et audientium primo suo facto spectabili induxerunt in stuporem et admirationem, secundo suo sono terribili immiserunt timorem et considerationem, tertio suo verbo dupplici, efficaci et delectabili adduxerunt in fulgorem et luminationem, quarto suo zelo mirabili accenderunt in fervorem et devotionem. 
Kurie profiliert sich hierdurch als eine realpolitischem Handeln verpflichtete Institution, durch die die segensreichen Konsequenzen von "Realpolitik « überhaupt erst an die Souveräne herangetragen werden. Sie erhebt nicht nur den moralischen Zeigefinger, sondern erweist sich als Institution mit zumindest Anfang der 40er Jahre des 14. Jahrhunderts weitgehend fiktiver Staatlichkeit, die um die Bedeutung von Konzessionen weiß.

Die folgenden Abschnitte seiner Collatio richtet Clemens VI. an der Erläuterung der vier genannten Erfolgsgründe aus. Zunächst wird nach dem Grund für das Erstaunen (stupor) und die Bewunderung (admiratio) der Könige und vieler anderer gefragt. Daß zwei hochgerüstete Heere (ita fortes et terribiles), die vor dem Beginn von Kampfhandlungen standen, auf einen Waffengang verzichteten, sei Anlaß genug, erstaunt zu sein. Daß evidenter Kriegswille in Friedensbereitschaft verkehrt wurde, schreibt der Papst seinen Nuntien $\mathbf{z u}^{99}$, denen die Fähigkeit zur Vermittlung in hohem Maße gegeben sei: prudentia, labor und diligentia ${ }^{100}$. Wenn sie dann noch über die entsprechenden Vollmachten verfügten - bei den 1344 in Avignon stattfindenden Friedensgesprächen wird Clemens VI. fortwährend die unzureichenden Vollmachten der Parteien beklagen -, seien die Voraussetzungen für den Erfolg gegeben.

Erstaunlich ist in diesem Zusammenhang das Eingeständnis des Papstes, er selbst habe mit einem Kriegsausbruch gerechnet ${ }^{101}$, bedeutet dies doch eine Aufwertung der Leistung seiner Kardinäle, die er zwar anerkennt, jedoch als Ausfluß seiner eigenen plenitudo potestatis und Kompetenz verstanden wissen will. Das Prov 21,1 entnommene Zitat ${ }^{102}$ ist zwar schmeichelhaft für die Kardinäle und offensichtlich der großen Freude über das erzielte Ergebnis geschuldet, aber trotz allem ist das cor regis - wie sich bald zeigen wird - alles andere als formbar und für andere Meinungen nicht aufgeschlossen. Der Ps 76,21 eröffnet weitere Vergleichsmöglichkeiten ${ }^{103}$. Mit Pierre Desprez respektive Annibaldo Ceccano werden die biblischen Gestalten von Moses und Aaron verglichen. Die jeweilige Verbindung gründet dabei zunächst nicht in identischen Wesensmerkmalen oder abstrakten theologischen Vorstellungen, sondern im Interpretationsspektrum, das durch die Namen von Moses und Aaron selbst eröffnet wird. Moses gilt dabei nicht nur als mitissimus, mansue-

99 Vgl. Ibid., fol. 60va, wo die Kardinäle in die Fußstapfen Daniels treten und aus gefährlichen Löwen zahme Lämmer werden lassen.

100 Ibid., fol. 60rb: Sed istorum nunciorum prudentia, labore et diligentia treugas tam longi temporis inivisse et ipsos, $u t$ ad nos nuncios pro pace plenam potestatem habentes infra festum nativitatis beati Johannis proxime venturum habeant profecisse, certe stupendum est [...]. Damit verweist der Papst auf ein weiteres Verhandlungsergebnis: das Zugeständnis der Könige, bis zum 24. Juni, dem Fest Johannes' des Täufers, Bevollmächtigte an die Kurie zu entsenden, um dort über einen definitiven Friedensschluß zu verhandeln.

101 Jer 14,19: Expectavimus pacem et non est bonum tempus curationis et ecce turbatio.

102 Prov 21,1: Sicut divisiones aquarum ita cor regis in manu Domini quocumque voluerit inclinabit illud.

103 Ps 76,21: Deduxisti quasi gregem populum tuum in manu Moysi et Aaron. 
tissimus und Deo familiarissimus, sondern als de aquis assumptus ${ }^{104}$, was Clemens VI. zu der Bemerkung veranlaßt, auch der Kardinal stamme de aquis, gleichsam »aus den Wassern «, sei er doch der Diözese Aix-en-Provence (Aquensis) besonders verbunden ${ }^{105}$. Was sich der Papst hier zunutze macht, ist die identische Wurzel von aqua und Aquensis und die daraus resultierende phonetische Ähnlichkeit ${ }^{106}$. Der Vergleich des Kardinalbischofs von Tusculum mit Aaron und die in diesem Zusammenhang angeführten Beispiele zeugen von dem Bemühen Clemens' VI., das aktive, zielgerichtete Handeln des Annibaldo Ceccano als besonders lobenswert herauszustellen ${ }^{107}$. Daß damit ein Komplementärcharakter zu Pierre Desprez entworfen wird, dürfte beabsichtigt gewesen sein. Insinuiert wird, daß erst das gemeinsame Vorgehen der beiden Kardinäle, deren Charaktereigenschaften sich vortrefflich ergänzten, zu dem bereits erwähnten Erfolg geführt habe.

Der anschließende Abschnitt ist der Reflexion darüber gewidmet, weshalb die Könige und viele andere durch den sono terribili der Nuntien zu intensiverem Nachdenken angehalten worden seien. Nur wenige Grundgedanken leiten sich dabei nicht aus der Bibel her. Der Einwurf des Papstes, die Fähigkeiten guter Gesandter erwiesen sich im klug austarierten Einsatz von Schmeichelei und Drohung, steht dabei gleichberechtigt neben der Feststellung, diese Gesandten hätten als Fürsprecher der unter den Schrecken des Krieges leidenden Zivilbevölkerung zu agieren und beständig den Lobpreis des Friedens zu verkünden ${ }^{108}$. Der Weg ist das Ziel: Diplomatie beruht auf dem Einsatz des gan-

104 Vgl. IsidoR, Etymologiae, VII, 6, 46: Denique Moyses interpretatur sumptus ex aqua. Invenit eum ad ripam fluminis expositum filia Pharaonis, quem colligens adoptavit sibi; vocavitque nomen eius Moysen, eo quod de aqua sumpsisset eum; zu Isidor nach wie vor maßgeblich Jacques FonTAINE, Isidore de Seville et la culture classique dans l'Espagne wisigothique, 2 Bde., Paris 21983. Das bei Isidor explizit erwähnte Adoptionsverhältnis wird von Clemens VI. nicht weiter ausgeführt. Im gesamten, auf den Kardinalat bezogenen Predigtwerk verzichtet er des weiteren auf die Charakterisierung des Verhältnisses Papst-Kardinäle mittels Verweis auf mögliche Adoptionsakte. Kardinäle sind Kreaturen des Papstes, werden von ihm "gemacht «: Ein Verweis auf ein fingiertes Vater-(Mutter)Kind-Verhältnis läge also - auch in Hinblick auf die bei Legaten mögliche Entsendung de latere - eigentlich nahe.

105 Im September 1318 wurde Pierre Desprez von Papst Johannes XXII. zum Erzbischof von Aix-en-Provence ernannt.

106 Diese Art von Wortspielerei kann als eines der Hauptcharakteristika mittelalterlicher Predigt gelten; vgl. MS 240, fol.60vab: [...] in psalmo vel in manu Moysi et Aaron, id est domini Penestrini Moysi quidem mitissimi, Moysi mansuetissimi, Moysi Deo familiarissimi, Moysi, id est de aquis assumpti. Ad litteram enim de aquis, id est de ecclesia Aquensi ad cardinalatus apicem est assumptus.

107 Dieser Vorstellung zugrunde liegt die etymologische Herleitung des Namens Aaron, der mit mons fortis und mons fortitudinis gleichgesetzt wird. Mons, Berg, wird dabei zum Ausgangspunkt einer Assoziationskette, die die Energie und Aktivität des Kardinals unterstreicht, vgl. IsIDOR, Etymologiae, VII, 6, 47.

108 MS 240, fol.60vb: Isti enim sunt boni nuncii, quia nunc alliciebant blandis, nunc deterrebant asperis [...]. Oportet enim, qui vult ad pacem inducere, nunc lamentationes exponere populorum propter guerras gravissime afflictorum, nunc carmen continere propter bonum 
zen Spektrums an Willensbekundungen, das nach Clemens von der Schmeichelei bis hin zur Drohung reicht. Der Hinweis auf die den Gesandten zur Verfügung stehenden spirituellen Waffen dient zur Überhöhung seiner eigenen Stellung als Papst. Er allein kann Könige exkommunizieren: Lediglich die von ihm den Gesandten übertragene potestas - die stets eine zeitlich begrenzte ist - setze diese in den Stand, in seiner Stellvertretung zu handeln. Diese beschränkte Machtteilung kann jedoch keinen Zweifel daran aufkommen lassen, daß es letztendlich er allein ist, der Furcht in die Herzen der Könige senkt ${ }^{109}$.

Den folgenden Abschnitt widmet der Papst Gedanken über die Macht des Wortes, da allein das Wort - verbum dulce et delectabile - es vermag, die im Frieden begründeten bona gegen die aus dem Krieg resultierenden incommoda abzugrenzen ${ }^{110}$. Gleichsam als Appell an das Gewissen der kriegführenden Könige fungiert der Hinweis auf die Verletzung des Eides, den die Könige bei ihrer Krönung geschworen haben. Jeder kriegerische Akt stelle eine Verletzung des Schwurs dar, Schaden vom eigenen Volk abzuwenden. Wenn die Könige bei der Einhaltung ihrer eidlichen Versprechen versagten, sei der Papst zum Handeln gezwungen. Die Kardinäle amtieren anstelle des Papstes und werden zu Friedensengeln, durch die sich die Wahrheit Bahn bricht ${ }^{111}$. Wahrheit ist Erleuchtung: Diese Gleichsetzung führt zu einer Flut von der Bibel entnommenen Belegstellen, durch die der Begriff fulgur beleuchtet werden soll. Ziel ist die theologische Rechtfertigung und Überhöhung der durch weltliche Politik und Diplomatie erzielten Ergebnisse anhand eines biblischen Zentralbegriffs: fulgur.

Das vierte, abschließende Element, der bewundernswerte Eifer nämlich, mit dem die Kardinäle die Herzen der Könige in fervorem et devotionem führten, wird auf den Begriff der devotio verkürzt. Freilich fokussiert Clemens VI. seine Ausführungen weniger auf die spirituell-religiöse Seite des Begriffs, spricht also weniger von Frömmigkeit oder Andacht als vielmehr von Ehrerbietung und Ergebenheit, die er selbstverständlich auf sich selbst bezieht. Die Klausel des Waffenstillstandsvertrags, in der die Entsendung von Gesandtschaften Englands und Frankreichs an die Kurie enthalten ist, wird zu einem Akt der Devotion, also der Ehrerbietung gegenüber dem Papst. Kein Wort wird darüber verloren, daß die Vermittlungsdienste, die Clemens VI. erbrin-

pacis, que exuperat omnem sensum [...]. Es schließt sich die Bemerkung an, daß mit dem Arsenal geistlicher Waffen, mit der Angst vor Höllenstrafen durchaus gedroht werden dürfe.

109 Der Abschnitt wird mit diesem Psalmvers beschlossen, vgl. Ps 103,7: A voce enim tonitrui tui formidabunt.

110 MS 240, fol. 61 ra: Dico tertio, quod corda regum et aliorum suo verbo dulci et delectabili adduxerunt in fulgorem et illuminationem ostendendo scilicet eis et bona, que ex pace provenerunt, et incommoda, que ex guerris secuntur, et dampna, in quibus se etiam omnibus subditis suis submittunt.

111 Ein Vergleich mit dem Engel, der am Morgen den entsetzten Frauen die Auferstehung des Herrn verkündete, liegt dabei nahe, vgl. Mt 28,2f. Ein Vorteil insbesondere von Mt 28,3 - erat autem aspectus eius sicut fulgur et vestimentum eius sicut nix - besteht darin, daß mit diesem Vers erneut ein Zentralbegriff der Collatio transportiert wird. 
gen will, von ihm nicht als Papst, sondern als Privatperson eingefordert werden. Der gut dokumentierte Verlauf der Verhandlungen in Avignon im Jahre 1344 sollte zeigen, daß Clemens VI. tatsächlich Schwierigkeiten hatte, der von ihm geforderten Rolle als unparteiischer Vermittler gerecht zu werden.

Eine erste Zusammenfassung der geäußerten Gedanken schließt sich an das bisher Gesagte an ${ }^{112}$. Das Augenmerk richtet sich nun auf die bereits eingeführten animalia des Ezechiel-Zitats, deren enger Bezug zu den vier Evangelisten verdeutlicht wird. Wenn die Evangelisten als Überbringer der »Frohen Botschaft « gelten, dürften auch die Kardinäle das Prädikat »Evangelisten « für sich in Anspruch nehmen, seien sie es doch, die ausgesandt wurden, um Frieden in nah und fern zu verkündigen ${ }^{113}$. Von dieser grundsätzlichen Feststellung ausgehend, schafft Clemens VI. in kaum überraschender Vorgehensweise die rhetorische Grundlage für weitere Ausführungen. Dazu blickt er auf Aussehen und Eigenschaften der animalia. Sie verfügen 1. nicht nur über Augen an mehreren Stellen des Körpers (multipliciter oculata) und 2. jeweils sechs Flügel (excellenter alata et pennata), sondern sind 3. auch untereinander verbunden (iugiter copulata et sociata) und 4. zu aktivem Handeln (fortiter et indefectibiliter preparata et non fatigata ${ }^{114}$ ) bereit.

In Analogie zum bereits beschriebenen Vorgehen wird nun jeder der vier Punkte um zusätzliche Elemente erweitert und anschließend näher erläutert. Bei der Zuweisung und Verbindung der einzelnen Elemente ist eine der Redesituation geschuldete Beliebigkeit nicht von der Hand zu weisen. Weshalb Klugheit und Einsicht (prudentia et discretio) dem ersten, Weisheit und Einsicht (sapientia et consideratio) dem zweiten Punkt, weshalb wahre Freundschaft und Liebe (vera amicitia et dilectio) dem dritten und schließlich Sorgfalt und beharrliches Mühen (diligentia et prosecutio) dem vierten Punkt zugewiesen werden, ist wohl nur aus der Tatsache heraus zu erklären, daß der Papst positiv konnotierte Elemente benötigt, um die Arbeit seiner Nuntien angemessen zu würdigen ${ }^{115}$.

112 MS 240, fol.61rb: Habemus ergo duo: primum, quod fulgur est inductivum stuporis, incussivum terroris, allativum fulgoris, accensivum fervoris et ardoris. Habemus secundo, quod isti nostri nuntii corda regum, principum et aliorum suo facto spectabili induxerunt in stuporem et admirationem, suo sono terribili immiserunt in stuporem et considerationem, suo verbo dulci et delectabili adduxerunt in fulgorem et illuminationem, suo zelo mirabili accenderunt in fervorem et devotionem.

113 Ibid.: Isti autem missi sunt evangelizare pacem et hiis, qui prope sunt et hiis, qui longe.

114 Wie negativ das Adjektiv fatigatus für den Papst belegt ist, wird sich bei der Bewertung der von Kardinal Bertrand de Deux 1348 im Königreich Sizilien ausgeführten Legation erweisen.

115 Ibid., fol.61va: Ergo merito, quod de sanctis animalibus dictum est, de eis dici potest. Mit prudentia und consideratio sind freilich auch zwei Eigenschaften angesprochen, denen Bernhard von Clairvaux in seiner Schrift De consideratione zentrale Bedeutung beimißt, vgl. Ernest Martineau, Prudence et considération - un dessin philosophique de saint Bernard, in: Études philosophiques (1980), S. 23-46. Der Papstspiegel wurde von Clemens VI. insbesondere in der Collatio Assumpsi michi duas virgas herangezogen. 
Die bereits zu diesem Zeitpunkt recht komplexe Predigtstruktur wird in der Folge nochmals erweitert. Ins Blickfeld gerät einmal mehr das Thema Ibant et revertebantur in similitudinem fulguris choruscantis, das in seine Bestandteile aufgelöst und mit weiteren Elementen verbunden wird. Bezeichnet ibant als Verb der aktiven Fortbewegung das rühmenswerte und wirksame Fortschreiten (progressus commendabilis et virtuosus) der Kardinäle, dessen Ergebnis der Waffenstillstand ist, verweist das Verb revertebantur auf die ersehnte frohe Rückkehr (regressus desiderabilis et gaudiosus) der Gesandten. Den im dritten thematischen Element - in similitudinem fulguris choruscantis - bemühten Vergleich will der Papst schließlich vor dem Hintergrund des akzeptablen Legationsergebnisses (legationis fructus acceptabilis) verstanden wissen $^{116}$. Gleich einem ausschlagenden Baum verästelt sich die Predigtkonstruktion noch stärker. In Rückgriff auf das eben Erwähnte werden nun die zentralen Nomina, d.h. progressus, regressus und fructus, näher beleuchtet. Besteht der progressus in der großen Sorgfalt, mit der die Kardinäle den ihnen gestellten Aufgaben nachgekommen sind, so spiegelt sich in deren regressus die Freude über ein Ergebnis wider, das seine Entstehung nicht unwesentlich der guten Zusammenarbeit, dem gegenseitigen Einvernehmen der Gesandten untereinander verdankt. Das frei von Konkurrenzdruck erzielte Ergebnis fructus - ehrt die Kardinäle, mit ihnen freut sich die gesamte Kurie.

Die Erwartungen der Zuhörer bzw. der Leser, mehr über den Verhandlungsverlauf erfahren zu können, werden enttäuscht. Mit der knappen Bemerkung: Non prosequor causa brevitatis ${ }^{117}$ bricht der Papst ab. Ob ihn tatsächlich Zeitmangel dazu veranlaßte, oder ob es das Gespür für die begrenzte Aufnahmekapazität seiner Zuhörer war, muß offen bleiben. Festzustellen bleibt, daß ein Perspektivwechsel erfolgte. Ohne Überleitung wird das Feld biblischer Textkritik betreten, indem der Papst - die Worte des Themas stets vor Augen - auf einen scheinbaren Widerspruch im biblischen Text verweist. Spricht Ez 1,14 von animalia, die ibant et revertebantur, so findet sich in $\mathrm{Ez} 1,9$ in Hinblick auf die Beschreibung eben dieser animalia die Bemerkung: non revertebantur cum incederent. Wie können die beiden, sich widersprechenden Aussagen miteinander in Einklang gebracht werden? Clemens VI. bemüht eine Phalanx von Autoritäten, die sich mit diesem und anderen in der Bibel enthaltenen Widersprüchen beschäftigen, und führt schließlich Hieronymus als $\mathrm{Ge}$ währszeugen dafür an, daß aufgrund des Unterschiedes von Zeit und Personen scheinbar widersprüchliche Aussagen doch miteinander in Einklang zu bringen seien ${ }^{118}$. Wie Regen und Schnee vom Himmel fielen, so verließen die

116 Auch der Papst trennt offensichtlich nicht streng zwischen dem Tun von Legaten und demjenigen von Nuntien.

117 MS 240, fol.61va.

118 Ibid., fol. 61vb: [...] tamen non est contrarium ymmo utrumque pro temporum et personarum diversitate concordatur. Ita in proposito nostro. Konkret auf den Fall bezogen heißt dies: Primo, quod ibant et non revertebantur ante negocii eis impositi perfectionem. Sed ibant et revertebantur post predicti negocii consumationem. 
Nuntien die Kurie und feuchteten durch ihre diplomatische Aktivität die Erde 119 - so der Papst.

Ziel war zunächst die Schaffung einer akzeptablen Ausgangsposition für die Verhandlungen, wozu unbedingt eine Art atmosphärischer Reinigung, herbeigeführt durch dulcor und compunctio, Süße und Reue, gehörte. Reue und Zerknirschung seien die unabdingbaren Voraussetzungen für die Vergebung der Sünden ${ }^{120}$ : Wer anders als von der Kurie ausgesandte Kleriker könnte dazu in der Lage sein, die Herzen der Könige entsprechend zu bereiten und sie - dies jedoch in einem zweiten Schritt - mit Zuneigung und Liebe zu erfüllen? Wer könnte dem Prinzip der Lebenskraft durch besonnenes Handeln zum Durchbruch verhelfen außer die beiden Nuntien, für die ja die Meßlatte des Vergleichs durch den Verweis auf imber und nix bewußt hoch gesetzt wurde $^{121}$ ? Faßbares Ergebnis all dieser Bemühungen war der Waffenstillstand fructum optimum treugarum in re -, der durch die Aussicht auf fest vereinbarte Friedensverhandlungen noch zusätzlich aufgewertet wurde. Die Arbeit der Nuntien war nicht vergeblich ${ }^{122}$. Die von ihnen in Kauf genommenen Anstrengungen und Entbehrungen wurden nicht zuletzt anhand der erbrachten Reiseleistungen konkretisiert. Frankreich, das Gebiet um Boulogne, Brabant und die Bretagne werden ausdrücklich genannt - die Arbeit, der labor der Kardinäle, bestand also tatsächlich vor allem in ihrer kontinuierlichen Reisetätigkeit, wobei auch auf ihre Bereitschaft hingewiesen wird, England anzusteuern $^{123}$. Als umsichtiger, diplomatisch erfahrener Prälat wußte Clemens um die Bedeutung rhetorischer Leerstellen: Ihm genügte es, England zu erwähnen, ohne dabei ausdrücklich auf die Ablehnung Edwards III., die Gesandten auf seinem Territorium zu empfangen, hinzuweisen. Das Verschweigen dieses Sachverhalts war an dieser Stelle ebenso explizit wie es seine Erwähnung gewesen wäre ${ }^{124}$. Worauf der Papst verwies, war nicht nur seine

119 Zentral Jes 55,10f.: Et quomodo descendit imber et nix de caelo et illuc ultra non revertitur, sed inebriat terram et infundit eam et germinare eam facit et dat semen serenti et panem comedenti, sic erit verbum meum, quod egredietur de ore meo non revertetur ad me vacuum, sed faciet quaecumque volui.

120 Vgl. Nikolaus Paulus, Geschichte des Ablasses im Mittelalter vom Ursprunge bis zur Mitte des 14. Jahrhunderts, Paderborn 1922 (ND Darmstadt 2000).

121 MS 240, fol. 62ra: Terram humectaverunt ad dulcorem et compunctionem, inebriaverunt ad amorem et dilectionem, fecundaverunt ad vigorem et bonam operationem. Idcirco non revertentur ad me vacui [...]. Non vacuos quidem nec sine fructu ymmo afferentes fructum optimum treugarum in re et pacis in spe.

122 Verwiesen wird auf Phi 2,16: Non in vacuum cucurri nec in vacuum laboravi.

123 MS 240, fol.62rb: Isti enim quasi ex quo recesserunt fuerunt in discursu continuo et labore. Unde de eis potest dici illud Ez. primo: Per quatuor partes euntes ibant, ad litteram per partes Francie, per partes Bolonie et Brabantie et ultimo per partes vaste Britanie. Parati etiam si necesse fuisset transire ad partes Anglie.

124 Ein Psalmvers dient dem Papst jedoch dazu, indirekt gewisse Rückschläge im Laufe der Vermittlungsbemühungen einzuräumen. So sei eine mala responsio Grund für Bitterkeit und Schmerz bei den Nuntien gewesen - gemeint sein kann nur der abschlägige Bescheid des englischen Königs, durch den die Kardinäle an der Überquerung des Kanals 
Mitwirkung an der Mission, sondern auch seine stete Einflußnahme auf den Verlauf der Verhandlungen. Er war es, der den ursprünglichen Auftrag, den Abschluß eines für beide Parteien verbindlichen Friedensvertrags, modifiziert und als zweitbeste Lösung einen Waffenstillstandsvertrag angestrebt hatte. So waren es nicht nur die Nuntien, die sich den erzielten Erfolg zuschreiben konnten, sondern auch Clemens VI. selbst ${ }^{125}$. Der Stolz der Kardinäle auf das Ergebnis wurde in klar definierte Schranken gewiesen - Ruhm darf niemals dem eigenen Tun zugeschrieben werden ${ }^{126}$. Die Collatio schließt mit einer auf Gregor den Großen zurückgehenden Definition des bonus nuntius, der erst dann seine volle Wirksamkeit entfalte, wenn er die Herzen der Zuhörenden erreiche und entzünde ${ }^{127}$. Genau dies hätten die Nuntien erreicht, weshalb ihre Rückkehr hocherwünscht und für die Gesamtkirche mit großer Freude verbunden sei.

\subsubsection{Dominum papam et totum collegium provocarunt: erste Verhandlungsschritte an der Kurie}

Weniger Freude als vielmehr Mühen und Beschwernis bescherte dem Papst die Verwirklichung der im Vertrag von Malestroit enthaltenen Verpflichtung zu Friedensgesprächen an der Kurie.

Bei seinem Versuch, eine diplomatische Lösung des Konfliktes zwischen England und Frankreich, der Europa - mit mehreren längeren Perioden ohne direkte Kampfhandlungen - ab 1338 fast 100 Jahre lang in Atem hielt, herbeizuführen, war der Papst nicht nur auf die Verhandlungsbereitschaft der kriegführenden Parteien, sondern auch auf die Mitarbeit der Kardinäle angewiesen. Deren Beteiligung an der Vermittlung ist besser belegt als in anderen Fällen, wie z.B. dem Kampf gegen Ludwig den Bayern, in den das Papsttum ebenfalls direkt einbezogen war. Überliefert sind nicht nur viele der Instruktionen, die der Papst seinen nach England und Frankreich entsandten Kardinallegaten erteilte ${ }^{128}$. Zur Beantwortung der Frage, in welchem Maße die Purpurträger an den Verhandlungen beteiligt waren, wieweit sie dabei auch eigenverantwortlich handelten, muß die Urkundenüberlieferung der in ihrer

gehindert wurden. Die diplomatische Erfolgsgeschichte wird somit durch die Erwähnung realpolitisch begründeter Rückschläge gebrochen, in ihrer Wirkung jedoch nicht minimiert.

125 MS 240, fol.62va: Quia enim videbatur michi difficile, ymmo quasi impossibile, quod ibi pax fieret, eis iniunxeram, ut treugas longas facerent et ad praesentiam nostram partes reducerent, sicut et fecerunt.

126 Ibid., fol.62vb: [...] sed vadunt et revertentur quando totum Deo vel mittenti referunt. Mit dem mittenti ist niemand anderes als Clemens VI. gemeint.

127 Ibid., fol. 63ra: Boni enim nuncii, sicut dicit Gregorius ibidem, et flumina sunt et fulgura sunt. Quando enim corda audientium rigant flumina, quando vero accendunt fulgura nuncupantur.

128 Hingegen müssen alle von den Kardinälen an die Kurie abgehenden Briefe als verloren gelten. 
Bürokratisierung weit fortgeschrittenen Nationalstaaten miteinbezogen werden. Die Verhandlungen, in denen der Papst von September bis November 1344 in Avignon als Privatperson vermittelte, sind ausgesprochen gut dokumentiert: Neben den von den englischen Gesandten verfaßten und an Empfänger in England gerichteten Briefen verdient der Ende November des Jahres verfaßte Bericht, in dem der Verlauf der Verhandlungen aus englischer Sicht beschrieben und beurteilt wird, besonderes Interesse. Zwei Collationes, mit denen der Papst seine Kardinallegaten nach erfolgter Gesandtentätigkeit an der Kurie willkommen heißt, ergänzen das Bild und nuancieren den Sachverhalt. Dasselbe gilt auch für die Chronistik, in der die Auseinandersetzungen zwischen England und Frankreich je nach nationaler Zugehörigkeit dargestellt und beurteilt werden ${ }^{129}$.

Das im Januar in Malestroit ausgehandelte Abkommen wurde an der Kurie offiziell ratifiziert. Erhalten geblieben ist das am 21. Dezember 1343 in Avignon vom Kammerkleriker Guillelmus de Bos ausgestellte Notariatsinstrument ${ }^{130}$, in dem die wichtigsten Vereinbarungen von allen Vertragspartnern bestätigt werden ${ }^{131}$. Für den Pontifikat Clemens' VI. sind derart genaue An-

129 Vgl. beispielsweise Andrew AYTon, Crécy and the chronicles, in: The battle of Crécy (1346), hg. v. Andrew Ayton, Philip Preston, Woodbridge 2005, S. 287-350.

$130 \mathrm{Vgl}$. zu den wenigen, erhalten gebliebenen Notariatsinstrumenten und ihrer Bedeutung für die Stellung einzelner Kardinäle an der Kurie Kap. 2.

131 Vgl. A.A. Arm. I-XXVIII, n. 5014, fol.110r: Nota super prorogatione termini super tractatu pacis inter Reges Francie et Anglie

In nomine domini Amen. Noverint universi et singuli, quod anno a nativitate domini MCCCXLIII, indictione XI, pontificatus sanctissimi patris et domini nostri Clementis pape $V I$ anno secundo et die $X X I$ mensis decembris in camera ipsius domini nostri pape et in qua idem dominus noster papa presens erat, necnon reverendi patres domini P. Penestrinus, Gaucelmus Albanensis, Johannes Portuensis et Anibaldus Tusculanus episcopi ac Bertrandus tit. S. Marci presbyter S.R.E. cardinales, cum secundum pactiones et conventiones initas et concessas in indictione seu impositione treugarum inter serenissimos principes dominos Philippum Francie et Odoardum Anglie et Ibernie reges illustres fuisse dicatur expresse, actum et conventum, quod prefatus dominus noster papa sub certis modis et formis posset tractare de pace et concordia inter reges eosdem usque ad proximum festum Nativitatis Domini nostri. Et ipsorum dominorum regum quilibet teneretur pro dicto tractatu prosequendo et exequendo mittere infra certum tempus ad presentiam ipsius domini nostri papae certos ambaxatores et nuncios speciales, inter quos saltim esset unus de sanguine cuiuslibet ipsorum dominorum regum. Et tandem prefati domini reges pro premissis exequendis et complendis iam diu est, destinassent suos ambaxatores et nuntios speciales ad dicti domini nostri pape presentiam videlicet dominus Francie rex magnificum et potentem virum dominum Humbertum Dalphinum Viennensem cum nonullis aliis suis collegis. Et prefatus dominus Anglie et Ibernie rex magnificum et potentem virum dominum Johannem de Gres militem consanguineum suum hinc est, quod cum tam propter occupationes multiplices ipsius domini nostri pape quam ipsorum dominorum regum non fiunt processum in dicto tractatu et instaret finis dicti termini dicti tractatus, prefatus dominus Johannes de Gre(s) miles ambaxator et nuntius predictus consanguineus, ut dixit domini Anglie regis dictis die et loco personaliter constitutus coram eodem domino nostro papa habens, ut dixit, ad infrascripta facienda potestatem, de certa scientia ipsius domini regis Anglie et Ibernie terminum dicti tractatus a dicto festo Nativitatis domini proxime futuro usque ad subsequens festum eius- 
gaben über die bei der Abfassung des Instruments anwesenden Personen äußerst selten. Wüßte man bei Unterhandlungen von solcher Tragweite gerne mehr über die Beteiligung insbesondere der Kardinäle, lassen die überlieferten Registereinträge diesen Wunsch durchweg unerfüllt. Anders in diesem Fall: aufgelistet werden fünf Kardinäle, neben Bertrand de Deux als einzigem Kardinalpriester vier Kardinalbischöfe, Pierre Desprez, Gaucelme de Jean, Jean de Comminges und Annibaldo Ceccano. Diese Nennung hat ihren Grund keineswegs nur in der zufälligen Präsenz der Kardinäle an der Kurie. Der weitere Verlauf der Verhandlungen wird zeigen, daß sie es waren, auf deren Vermittlungsbemühungen der Papst vertraute. Was die personale $\mathrm{Zu}$ sammensetzung der im Dezember 1343 in Avignon anwesenden Gesandtschaften angeht, bestand ein eklatantes Ungleichgewicht. Auf englischer Seite findet lediglich eine Person, Johannes de Gre(s), ein consanguineus Edwards III., Erwähnung. An der Spitze der französischen Gesandtschaft steht mit dem Dauphin von Vienne, Humbert II., einer der prominentesten Adligen des Königreichs. Die Zusammensetzung der unzureichend aufeinander abgestimmten Gesandtschaften sollte im weiteren Verlauf der Verhandlungen noch eine Rolle spielen.

Einer der wichtigsten Punkte des in Malestroit geschlossenen Waffenstillstandsvertrags bestand in der für beide Parteien verbindlichen Übereinkunft, Gesandte nach Avignon zu entsenden, um dort - den Waffenstillstand gleichsam als diplomatische Zwischenetappe nutzend - über einen abschließenden Friedensvertrag zu verhandeln: "Aufgrund der Ehrerbietung gegenüber der

dem Nativitatis Domini in personam eiusdem domini nostri papae sub eisdem modis et formis, sub quibus in dictis treugis fuit et est conventum et promissum, porrogavit (sic!) pro parte ipsius domini Anglie et Ibernie regis, qua porrogatione sic facta dominus noster papa predictus dictam porrogationem sic factam in se recipiens cum / prout dixit ad presens sit quamplurimis arduis negociis occupatus, assignavit domino Johanni predicto et domino Anglie regi in personam dicti domini Johannis terminum ad inchoandum tractatum dicte pacis et concordie vespera festi proximi Ramis Palmarum cum diebus sequentibus ad hoc commodis et etiam oportunis, de quibus omnibus dictus dominus noster papa precepit michi Guillelmo de Bos clerico sue camere auctoritate apostolica notario, quod facerem unum aut plura publica instrumenta dicto domino militi etiam hoc idem requireret. Acta fuerunt hec anno, mensis et die predictis et testibus presentibus prout supra.

Siquidem die et loco et presentibus quibus supra venerunt ad presentiam dicti domini nostri pape magnificus vir dominus Humbertus Dalphinus Viennensis cum venerabilibus patribus Johanne Belvacensis et Petro Claromontensis episcopis et magistris Jacobo Roceliti archidiacono Remensis, Siccardo de Montealto archidiacono et Fermino de Corelio. Dicti domini frater regis clericis et ibidem prefatus dominus Humbertus Dalphinus ambaxator et de sanguine domini Francie Regis coram dicto domino nostro papae personaliter constitutus habens, ut dixit, ad infrascripta facienda potestatem de certa scientia ipsius domini Francie Regis terminum dicti tractatus a proximo venturo festo Nativitatis domini usque ad subsequens festum eiusdem Nativitatis domini in personam eiusdem domini nostri pape sub eisdem modis et formis, quibus in dictis treugis fuit et est conventum et promissum, porrogavit pro parte et vice domini Francie Regis ob reverentiam dicti domini nostri pape et S.R.E. sicut dixit. Qua porrogatione sic facta et per dominum nostrum papam recepta idem dominus noster papa assignavit terminum ad inchoandum sicut supra. 
Kirche und um der bedrängten Christenheit, insbesondere aber um den Untertanen der Könige von Frankreich und England zu helfen, nicht zuletzt auch aufgrund der Ehre, die den Kardinälen gebührt, die zwischen den Königen Frieden und Eintracht vermittelt haben, wurde die Übereinkunft erzielt, daß beide Parteien Gesandte sowohl königlichen Geblüts als auch anderen Stands mit allen nötigen Vollmachten an die Kurie entsenden, um dort über alle Meinungsverschiedenheiten und Streitfragen zu verhandeln « ${ }^{132}$. Grundsätzlich sollten alle Fragen Gegenstand der Verhandlungen sein und dem Papst unterbreitet werden dürfen, ohne eine abschließende richterliche Sentenz des Pontifex befürchten zu müssen ${ }^{133}$. Mit dem Beginn der Verhandlungen waren untrennbar Fragen der Ehre verbunden: spürbar war die Sorge um den honor cardinalium. Man fürchtete um die Glaubwürdigkeit der kurialen Diplomatie. Vor diesem Hintergrund mußte der Papst die Hinhaltetaktik des englischen Königs als entwürdigend empfinden. Über Monate zogen sich die Auseinandersetzungen um Geleitbriefe hin, wurde der personale Kern der englischen Gesandtschaft ständigen Modifikationen unterworfen ${ }^{134}$.

Erst am 4. August 1344 erteilte Edward III. dem Bischof von Norwich und John d'Offord, dem Dekan von Lincoln, die nötigen Vollmachten und entsandte sie nach Avignon. Dort kamen sie am 3. September 1344 an ${ }^{135}$. Welche

132 MuRIMUTH, S. 130: Concordatum est quod, ob reverentiam Ecclesie, et ad succurrendum malo statui Christianitatis, et subveniendum indempnitati subjectorum dictorum regum Franciae et Angliae, et propter honorem dominorum cardinalium tractantium pacem et concordiam inter dictos reges, quod super omnibus controversiis et dissensionibus mittantur aliqui de sanguine dictorum regum et aliqui alii ad curiam Romanam, potestatem habentes concordandi, firmandi, et roborandi super praedictis, secundum tractatum domini nostri papae et tractatorum praedictorum. Der Frage einer königlichen Abstammung eines Teils der Gesandten wird auch im Notariatsinstrument große Bedeutung beigemessen.

133 Ibid., S. 130: Poterunt autem partes rationes suas coram dicto domino papa dicere et proponere, non ad finem decisionis et ferendae sententiae sed melioris tractatus et pacis fiendae.

134 Rymer, Foedera, V, S. 366 (20. Mai 1343). Darin wird ausdrücklich betont, die Verhandlungen fänden coram dicto Domino Summo Pontefice, non ut judice, set ut privata persona et tractatore et mediatore communi, non in forma nec figura iudicii, set extrajudicialiter et amicabiliter statt; vgl. des weiteren ibid., S. 381f. (29. August 1343), S. 394 (29. November 1343), S. 419 (3. August 1344); Lettres Clément VI, nn. 315, 326-329, 420, 439, 449, 451, 581, 593, 594. Der Registereintrag vom 23. Juni 1344, der auf eine Entsendung zweier weiterer Kardinäle hindeutet, darf als Irrläufer gelten, vgl. Lettres Clément VI, n. 920. Die beiden apostrophierten Kardinäle Petrus, tit. S. Praxedis und Bertrandus, tit. Sanctae Mariae in Aquiro, waren tatsächlich als Nuntien zur Beilegung des englisch-französischen Konflikts entsandt worden, allerdings schon 1336, vgl. Lettres Benoît XII, n. 379. Daß der Brief an dieser Stelle registriert wurde, mag als Beleg für ein verbreitetes Bedürfnis nach weiterer hochrangiger Vermittlung dienen, ist letztendlich jedoch auf das Versehen eines Schreibers zurückzuführen.

${ }^{135}$ In seinem ersten, an den englischen König gerichteten und auf den 13. September 1344 datierten Brief spricht der Dekan von Lincoln von einer Ankunft en Avinion le vendredy proschein devant la feste de la Nativité de Nostre-Dame. Die Briefe finden sich abgedruckt in FroISSART, Euvres, Bd. 18, S. 202-233 [fortan zitiert als Lettres]. 
Hoffnungen der König und mit ihm seine Gesandten mit diesen Verhandlungen verbanden, ob von ihnen tatsächlich ein dauerhafter Frieden mit Frankreich angestrebt wurde, wird nirgendwo explizit vermerkt. Die tradierten Briefe liefern Informationen und dienen der Selbstlegitimierung der Gesandten: Eigenständige Bewertungen von Ereignissen, konkrete Vorschläge zur effizienteren Gestaltung der Verhandlungen treten demgegenüber zurück.

Der erste Kontakt mit Clemens VI. wurde schnell hergestellt. Bereits am 5. September wurden die Gesandten zu einem Essen mit dem Papst gebeten: Bei dieser Gelegenheit wurden sie über Vorstellungen und Hoffnungen in Kenntnis gesetzt, die der Papst mit der von ihm initiierten Unterredung verband ${ }^{136}$. Die eigentlichen Verhandlungen begannen mit der Aufforderung des Papstes an die Gesandten, ihm und den zu diesem Zweck versammelten Kardinälen die Position des englischen Königs darzulegen. Die vom Papst ausgewählten Purpurträger waren der Vizekanzler Pierre Desprez, daneben Annibaldo Ceccano, Gaucelme de Jean, Pedro Gomez, Raymond de Farges und Bertrand de Deux. Über die Kriterien, die für die Zusammensetzung dieser Kommission bestimmend waren, erfährt man nichts. Es steht jedoch fest, daß die meisten ihrer Mitglieder im Laufe ihres Kardinalats Gelegenheit gehabt hatten, sich in der einen oder anderen Fom mit der politischen Situation in England und Frankreich vertraut zu machen. Als Kenner der Materie durften in erster Linie diejenigen gelten, die zu einem früheren Zeitpunkt als Legaten vor Ort agiert hatten. An erster Stelle zu nennen sind Pierre Desprez und Annibaldo Ceccano, die im Mai 1342, also unmittelbar nach dem Pontifikatsbeginn Clemens' VI., als Nuntien nach England und Frankreich entsandt worden waren und mit der Vermittlung des Waffenstillstands von Malestroit einen ersten diplomatischen Erfolg erzielt hatten. Die Verbindungen des Kardinals Gaucelme de Jean mit England datieren weiter zurück: Er fungierte ab März 1317 als Legat sowohl in England als auch in Schottland und Irland. Bertrand de Deux, der unter Clemens VI. zum bevorzugten päpstlichen Legaten werden sollte, hatte seine ersten Schritte auf der diplomatischen Bühne in Südfrankreich 1329 gemacht, war also zumindest über Ursachen und Art des Aquitanien-Problems im Bilde. Pedro Gomez war 1337 zur Friedensvermittlung nach England und Frankreich entsandt worden ${ }^{137}$. Einzig für Raymond de Farges sind keine vergleichbaren Aktivitäten belegt. Allerdings unterhielt er - und analog alle aufgeführten Kardinäle - andere Verbindungen mit England. Er verfügte über lukrativen, durch die Politik des englischen Königs massiv bedrohten Pfründenbesitz auf englischem Boden, was bei ihm zu einem gesteigerten Interesse an einem positiven Ausgang der Verhandlungen geführt

136 Vgl. ibid., S.203, wo die besondere Redegabe des Papstes Erwähnung findet: il teynt ovesque nous un grant collation de nos besoignes.

137 Im Brief taucht er als Johan d'Espayne auf, vgl. ibid. Da zu diesem Zeitpunkt nur ein Vertreter Spaniens im Kollegium vertreten war, muß es sich hierbei um Pedro Gomez handeln. 
haben dürfte. Bei der Zusammensetzung der Kardinalskommission dürften den Papst noch andere Gründe geleitet haben: die im Laufe der kurialen Karriere erworbene Sachkompetenz. Mit 34 Dienstjahren führte Raymond de Farges den Reigen an, gefolgt von Gaucelme de Jean mit 28 und Pierre Desprez mit 24 Dienstjahren. Annibaldo Ceccano und Pedro Gomez trugen seit 17 Jahren den Purpur. Lediglich Bertrand de Deux blieb mit seinem erst sechs Jahre währenden Kardinalat hinter seinen Kollegen zurück. Alle, nicht zuletzt der Papst, selbst ehemaliger Berater des französischen Königs, waren also bestens gerüstet, um die zunächst in genereller Form vorgebrachten Beschwerden der englischen Gesandten zu hören.

Neben der fortgesetzten Verletzung des Waffenstillstands in der Bretagne durch Frankreich wurde auch die Frage der päpstlichen Reservationen und Provisionen behandelt. Die Anklagen richteten sich also sowohl gegen Frankreich als auch gegen den Papst. Durch dieses Vorgehen wurde der Papst in die Defensive gedrängt und seine Rolle als unparteiischer Vermittler in Frage gestellt ${ }^{138}$. Als Oberhaupt der Kirche war von ihm Unparteilichkeit in Benefizialangelegenheiten nicht zu erwarten. Immerhin ließ er Konzessionsbereitschaft erkennen. In einer ersten Stellungnahme bekundete er die Absicht, in Zukunft überlegter bei der Pfründenvergabe vorgehen zu wollen - ohne freilich sein Verfügungsrecht über diese Benefizien preiszugeben ${ }^{139}$. Wie die Absicht, Frankreich zur Einhaltung des Waffenstillstands aufzufordern, veranlaßten andere Äußerungen des Papstes die Gesandten zu der im weiteren Verlauf der Gespräche so nicht mehr beibehaltenen Einschätzung, der Pontifex habe die englische Sache zu seiner Herzensangelegenheit gemacht ${ }^{140}$. Die Kardinäle blieben zu diesem Zeitpunkt noch im Hintergrund.

Aus einem nur einen Tag später, am 14. September, an den Erzbischof von Canterbury gerichteten Brief wird ersichtlich, daß England an der Kurie zumindest einen Verbündeten in Kardinalsrang besaß, der die Gesandten bereits vor deren Ankunft in Avignon über die aktuelle Lage und die an der Kurie herrschende Betriebsamkeit in Kenntnis gesetzt hatte ${ }^{141}$. Die Identität dieses Informanten wurde nicht enthüllt, allerdings deutet die Erwähnung von

138 Auf die durchaus nicht immer spannungsfreien Beziehungen zu Frankreich verweist Guillaume Mollat, Le Saint-Siège et la France sous le pontificat de Clément VI, in: RHE 55 (1960) S. 5-24.

139 Vgl. FROISSART, Lettres, S. 204: [...] et dist finalment qu'il ferroit modération resonable sauns arcer son powar apurtenant à lui come à chief de Seinte-Eglise [...].

$140 \mathrm{Vgl}$. ibid., S. 205: [...] Et semble à moy, sire, qu'il prent meynetenant vos besoignes mult à queor $[\ldots]$.

141 Vgl. ibid., S.206: [...] antequam intrarem curiam, cum tamen essem prope eam videlicet apud Sanctum-Spiritum, praemonitus fui per unum dominum cardinalem amicum nostrum [...] quod facti fuerant processus nedum contra dominum nostrum regem solummodo, sed etiam contra reges alios occasione modernis temporibus attemptatorum contra primatum Ecclesiae [...]; des weiteren wird unterstrichen, daß dominus noster papa et confratres sui per tres septimanas antea multa sua, licet vacationis tempore, tenebant consistoria et fuerant occupati $[\ldots]$. 
Schulden, die der englische König gegenüber Kardinal de Farges zu begleichen hatte, darauf hin, daß es sich um dieses Mitglied der Kommission handelte ${ }^{142}$. Einen sicheren Beleg für die im Vergleich zu seinen Mitbrüdern privilegierte Stellung des Kardinals liefert ein Brief, den Edward III. bereits am 13. April 1342 an die königlichen Amtsträger in England gerichtet hatte. Darin wurde festgestellt, daß insbesondere die Prokuratoren des genannten Kardinals unter besonderem königlichen Schutz stünden, eine Verfügung, die gleichermaßen für die in England gelegenen terras, res, redditus et omnes possessiones gelte. Alle Amtsträger wurden nachdrücklich aufgefordert, Schaden von dessen Besitzungen fernzuhalten und von widerrechtlichen Besetzungen und Konfiskationen abzusehen ${ }^{143}$. Diese Verfügung rief der König seinen Amtsträgern drei Jahre später nochmals in Erinnerung ${ }^{144}$. In einem Schreiben vom 22. Mai 1342, gerichtet an einen reverendus pater et amicus carissimus, bei dem es sich nur um Raymond de Farges handeln kann, bekundete Edward III. sein absolutes Vertrauen in den Kardinal und dessen Einsatz für englische Belange an der Kurie ${ }^{145}$. Bereits 1340 hatte der König die Dienste des Kardinals in Anspruch genommen, als es darum ging, das Ansehen der Krone bei der Kurie, das durch Verleumdungen in starke Mitleidenschaft gezogen worden war, zu heben ${ }^{146}$.

Wenige Kardinäle profitierten von Edwards Wohlwollen: dazu gehörte Pedro Gomez, der Kardinalbischof von Sabina, dem im Juni 1342 das Privileg verliehen wurde, auf Lebenszeit jedes Jahr 60 Sack Wolle in England kaufen und ausführen zu dürfen, ohne dafür Steuern entrichten zu müssen ${ }^{147}$. Edward benannte mit ihm explizit einen Verteidiger englischer Interessen an der

142 Vgl. Brief des Dekans von Lincoln an einen Ratgeber des englischen Königs vom 18. Oktober 1344, ibid., S.212-215, bes. S.215: Sire, jeo entenks que vous aiderets que le conseil pense par temps de moy, et auxint de la dette du cardinal des Farges, de Piers de Seint-Marcel et de Piers de Poddinghake, cum estoit acordé devaunt mon départir.

143 Vgl. RYMER, Foedera, V, S. 309.

144 Vgl. C.P.R., V, S. 379; RYMER, Foedera, V, S. 439 (21/1/1345); ibid., S. 479 (6/10/1345); C.P.R., VII, S. 37, S. 269, S. 409.

145 Rymer, Foedera, V, S.314. Eine Identifizierung des Adressaten mit Raymond de Farges liegt deshalb nahe, weil im Brief auf nicht näher spezifizierte Gerüchte Bezug genommen wird, die Kardinal Anibaldus und der Verfasser des Briefes Edward III. haben zukommen lassen. Der Brief der beiden Kardinäle, in dem der englische König von der Wahl Clemens' VI. in Kenntnis gesetzt worden war, datiert vom 8. Mai, vgl. ibid., S. 311.

$146 \mathrm{Vgl}$. DÉPREZ, Préliminaires, pièces justificatives, $\mathrm{n}$.X. Der Brief an den reverendo patri et amico suo datiert vom 18. April 1340.

147 Vgl. RyMer, Foedera, V, S. 321. Adressiert ist der Brief, der die Kunde von der Verleihung des Privilegs enthält, an die Zollbeamten im Hafen von London. Zur Begründung äußert sich Edward III. wie folgt: Cum nuper, attendentes magnum locum, quem venerabilis pater, Petrus episcopus Sabinensis, Sanctae Romanae Ecclesiae Cardinalis, nobis in nostris agendis tenuit a iamdiu, necnon benivolentiam continuam, quam ipse penes nos gessit et gerit jugiter hiis diebus, ad ea, quae nostros honores et commoda concernunt, exhibendo se paratum, ac volentes, eo praetextu, ipsius precibus, nobis oblatis, favorabiliter inclinare [...]; zu weiteren Privilegien vgl. C.P.R., VII, S. 245. 
Kurie, der die honores et commoda des Königreichs seit langem befördert habe ${ }^{148}$. Der Kardinalbischof von Tusculum, Annibaldo Ceccano, konnte sich desselben Privilegs wie Pedro Gomez erfreuen, sah sich aber bei seiner Geltendmachung vor große Schwierigkeiten gestellt, da später ein Beschluß des Parlaments die Entrichtung der Summe von 40 solidi für jeden Sack exportierter Wolle zwingend vorschrieb. In einem am 2. Juli 1343 an seinen Schatzmeister gerichteten Brief bemühte sich Edward III., diesen Beschluß zu umgehen. $\mathrm{Da}$ er einen offenen Konflikt mit seinem Parlament scheute, wählte er aus wohlverstandenem Eigeninteresse - der Kardinal sollte England gegenüber gnädig gestimmt bleiben - den Weg des geringsten Widerstands: Er wies seinen Schatzmeister an, dem königlichen Schatz die Summe von 200 Pfund zu entnehmen, um die vom Kardinal geschuldete Steuer zu zahlen und damit dem Parlamentsbeschluß gerecht werden zu können ${ }^{149}$.

Auch Kardinal Galhard de la Mothe darf zum Kreis derjenigen Purpurträger gerechnet werden, die in Avignon wenn nicht als Verbündete des englischen Königs, so doch als Förderer seiner Interessen agierten. Wegen seiner affectio grata, seines großen Wohlwollens gegenüber Edward III., wurde ihm im August 1342 das zeitlich befristete Privileg zuteil, keine Steuern auf die Erträge seiner in England gelegenen Benefizien entrichten zu müssen ${ }^{150}$. Die Kardinalbischöfe Gaucelme de Jean und Pierre Desprez wurden am 14. Mai 1343 von der Abgabe ausgenommen, die Edward III. zur Landesverteidigung auf Zehnterträge erhob ${ }^{151}$. Die Privilegienverleihungen des Königs folgten demselben Prinzip. Sie dienten als Anerkennung für bereits geleistete Dienste, waren aber auch als Investitionen in die Zukunft gedacht. Ewards Verhalten gegenüber bestimmten Mitgliedern des Kardinalskollegs war alles andere als altruistisch: das subtile Gleichgewicht von Geben und Nehmen nahm beide Parteien in die Pflicht. Sicherlich nicht zufällig profitierten diejenigen Kardinäle von der Gunst des Königs, die später als Mitglieder der vom Papst eingesetzten Kommission über die Situation zwischen England und Frankreich

148 Im Verlauf der Verhandlungen sollte das Beharren auf den königlichen honores und commoda wesentlicher Bestandteil der Argumentationslinie durch die englischen Gesandten werden.

149 Vgl. C.P.R., V, S. 122; RYMER, Foedera, V, S. 373.

150 Ibid., V, S. 337. Diese Verfügung wird in ihrer Bedeutung allerdings durch einen Brief Edwards III. an den Vizegrafen von Leicester vom 27. Januar 1343 relativiert, in dem ein allgemeiner Schuldenerla $\beta$ hinsichtlich der Besteuerung kardinalizischer Benefizien verkündet wird, vgl. ibid., S. 356. Stärker noch als in den bereits erwähnten Briefen kommt hier das Element einer Investition in die Zukunft zum Tragen: Considerantes specialem affectionem quam venerabiles patres, Ecclesiae Romanae Cardinales, in regno nostro Angliae beneficiati, ad coronam Angliae habuerunt et bonum locum quem nobis et progenitoribus nostris tenuerunt et nobis et haeredibus nostris tenere poterunt in futurum, pardonavimus eisdem cardinalibus omnia debita [...]; zu weiteren Privilegien vgl. C.P.R., VII, S. 264.

$151 \mathrm{Vgl}$. ibid., S. 364. Gaucelme profitiert auch noch 1345 vom Wohlwollen des Königs, der ihm die Erträge aus der Kirche von Stebenheth (Diöz. London) garantiert, vgl. C.P.R., V, S. 464 . 
zu urteilen hatten, sich also auf höchster diplomatischer Ebene für die Belange des Königreiches einsetzen konnten.

Im Vergleich zum ersten, an Edward III. gerichteten Brief besticht der eben behandelte an den Erzbischof von Canterbury durch ein Mehr an Information. Insbesondere die Passagen, in denen in wörtlicher Rede die konzise Positionsbestimmung des Papstes referiert wird, gestatten Einblicke in Art und Verlauf der Verhandlungen. Der Anteil der sechs anwesenden Kardinäle scheint lediglich in ihrer Anwesenheit bestanden zu haben. Still hörten sie der flammenden Verteidigungsrede, die Clemens VI. für die libertas Ecclesiae hielt, zu und waren auch dann nicht aus der Reserve zu locken, als das Vorgehen Edwards III. gegen die Prokuratoren einiger ihrer Mitbrüder zur Sprache kam. Das Schicksal dieser Prokuratoren, ihre schmachvolle Behandlung durch den König wird anschaulich geschildert ${ }^{152}$ - allenfalls der Vergleich mit der Leidensgeschichte Christi wirkt etwas überzogen ${ }^{153}$. Die Grenzen zwischen Rhetorik und Schauspiel waren fließend: Wie in einem Brennspiegel bündelte der Papst seine erregten Auführungen in dem melodramatischen Ausruf Certe, certe mallemus mori quam excessus et errores hujus tollerare! 154 In einem verbalen Rundumschlag wurde nicht nur Edward III. für die Verschärfung der Situation verantwortlich gemacht, auch die übrigen hohen Prälaten gerieten ins Blickfeld des Papstes ${ }^{155}$. Die Replik der Gesandten - ausdrücklich wurden die Kardinäle miteinbezogen - beschränkte sich auf die Schilderung des Volkszorns, der aufgebrachten öffentlichen Meinung in England, die nur schwer zu beherrschen sei ${ }^{156}$. Darauf wurde nicht weiter eingegangen: An der Kurie herrschte die Meinung vor, Untertanen hätten zu ge-

152 Vgl. FroISSART, Lettres, S. 207: et coepit inter alia cum magna cordis anxietate [...] recitare totum factum concernens arrestationem procuratorum cardinalium [...] eorum captionem et adductionem ante tribunal justiciariorum quasi ad praetorium, attractionem eorum ad vilissimum carcerem in quo etiam latrones et homicidae recluduntur, retentionem ipsorum procuratorum per triduum in eodem, extractionem ipsorum et reductionem ad praetorium ac clamationem popularium procuratam per nonullos clericos quorum nomina habet [...] ut poenarum generibus torquerentur ad similitudinem, ut dixit, passionis Christi . 153 Die Predigten und Ansprachen Clemens' VI. bestechen durch ein hohes Maß an bildhafter Anschaulichkeit. Am eindrücklichsten kommt dies in der Konsistorialansprache zum Ausdruck, in der Clemens VI. die Ermordung des Andreas von Ungarn in verstörender Detailfreude schildert und es auch dort nicht versäumt, Parallelen zwischen dem Meuchelmord von Aversa und der Passio Christi zu ziehen; ein Teilabdruck der nach wie vor noch nicht kritisch edierten Collatio Vox sanguinis fratris tui vom 1. Februar 1346 findet sich in BALUZE/MOLLAT, Vitae II, S. 368f.

154 Frolssart, Lettres, S. 207.

155 Dies eröffnet den Gesandten die willkommene Möglichkeit, ihre Verteidigungsbemühungen in strahlendsten Farben zu schildern - der Brief ist an den Erzbischof von Canterbury gerichtet!

156 Vgl. ibid., S. 208: Et dixi quod totus populus de effusis gratiis factis duobus cardinalibus motus fuerat in excessu, et, quod difficillimum fuit et est effrenatos impetus commoti populi refrenare et quod remediari non poterit nisi per Sanctitatis Vestrae debitum moderamen [...]. 
horchen und von unbotmäßigen Willensbekundungen Abstand zu nehmen. Zuletzt wurde noch einmal auf die von allen anderen Nationen akzeptierte Notwendigkeit hingewiesen, den Kardinälen für ihren Lebensunterhalt Pfründen zuzuweisen. Unterstrichen wurde, daß alle christlichen Nationen gemeinsam diese Last zum Wohl der Kirche zu tragen hätten ${ }^{157}$.

Ein Vier-Augen-Gespräch mit dem Dekan von Lincoln, das am folgenden Tag, dem 7. September, stattfand, diente dazu, die zwischen Papst und englischem König strittigen Punkte nochmals zu erörtern. Es ging dabei um die freien kanonischen Wahlen, die Provisionen von Ausländern mit ertragreichen Benefizien, den Umgang mit den an der Kurie vakant werdenden Benefizien, die vom Papst in England vorgenommenen Reservationen und schließlich als Sonderfall um die englischen Pfründen von Kardinal Adhémar Robert ${ }^{158}$. Päpstlicherseits waren Eingriffe in das freie Wahlrecht von Domkapiteln oder anderen Institutionen unter Berufung auf die plenitudo potestatis vorgenommen, das Recht, als unumschränktes Oberhaupt der Kirche auch deren Personalangelegenheiten an sich ziehen zu können, durchgesetzt worden. Daß dabei dieser Vollbesitz der Macht je nach Maßgabe der politischen Situation gehandhabt wurde, verstand sich von selbst. Clemens VI. wies denn auch darauf hin, daß er der von Edward III. an die beiden Kardinäle Annibaldo Ceccano und Pierre Desprez anläßlich ihrer Legation gerichteten Bitte, der Krone die Ernennung von zwei oder drei Bischöfen zuzugestehen, stattgegeben und damit auf die Durchsetzung seiner plenitudo potestatis verzichtet habe ${ }^{159}$. Auch im zweiten der erwähnten Punkte war die Kurie zu Konzessionen bereit: Die Provision von Ausländern mit in England gelegenen Kuratbenefizien sollte beendet und auch Kardinäle von dieser Regelung nicht ausgenommen werden ${ }^{160}$. Kompromißbereitschaft wurde auch hinsichtlich der

157 Vgl. ibid.: Dixit etiam quod creaverat ad certum numerum cardinales, et oportuit quod viverent de ordinatione Ecclesiae et quod divisit eos ad victum percipiendum per provincias atque regna, et quod nullibi inventa fuerat resistentia nisi in regno Angliae; vgl. hierzu auch Jean FAVIER, Temporels ecclésiastiques et taxation fiscale: le poids de la fiscalité pontificale au XIVe siècle, in: Journal des savants (1964) S. 102-127.

158 Vgl. ibid.: [...] cum discurissem per puncta videlicet de liberis electionibus, de non promovendo alienigenas infra regnum, de beneficiis vacantibus in curia et alibi per mortem capellanorum suorum, de reservationibus beneficiorum virorum ecclesiasticorum notabiliter in Anglia promotorum, de gratia domini Ademari Roberti cardinalis et de moderatione facienda quoad gratias iam factas indigenis linguae nostrae [...]; vgl. Kap. 5.1.7.

159 Vgl. FroISSART, Lettres, S. 209f.: Dixit etiam quod dominus rex, quando fuerat in Britannia post treugas captas et comederunt cum eo duo domini cardinales, supplicari fecit sibi per eosdem quatinus duos episcopatus vel tres / etiam nominatos pro certis suis clericis etiam tunc nominatis promovendis faceret reservari [...].

160 Vgl. ibid., S.210: [...] quod non intendebat infra regnum Angliae ad beneficia curata alienigenas promovere, nec intendebat, ut dixit, excludere dominos cardinales. Die Klage der Gesandten hatte auf die Gesamtheit der Benefizialverleihungen abgezielt: Der Papst zeigt sich also grundsätzlich konzessionsbereit, fokussiert die Bereitschaft zum Einlenken jedoch auf eine Pfründengruppe, die zur Versorgung von hohen Prälaten, insbesondere den Kardinälen, ohnehin nur sehr bedingt in Frage kommt. 
durch Tod des Pfründeninhabers an der Kurie vakant gewordenen Benefizien bekundet - allerdings mit einer gewichtigen Einschränkung: Edward solle sich nur pro bonis personis et idoneis ${ }^{161}$ einsetzen, der Papst würde diese schon berücksichtigen, wobei er sich allerdings die Entscheidung, wer als idoneus und bonus zu gelten habe, selbst vorbehielt.

Ein weiterer Brief, von Hugo Neville an Edward III. adressiert und auf den 17. Oktober 1344 datiert, beschreibt die insgesamt unsichere, von gegenseitigem Mißtrauen geprägte Verhandlungssituation ${ }^{162}$. Eine wie auch immer geartete Partizipation von Kardinälen an den Unterredungen bleibt unerwähnt, dafür wurde die Klage des Papstes über die Angriffe gegen die Freiheit der Kirche in England wiederholt ${ }^{163}$. Hugo Neville wurde darauf hingewiesen, daß der französische König eine hochkarätige Gesandtschaft zusammengestellt und nach Avignon entsandt habe ${ }^{164}$. Er machte damit auf das rangmäßige Ungleichgewicht der einzelnen Gesandtschaften aufmerksam, ein Problem, das auch dem Papst - allerdings zu einem späteren Zeitpunkt - schmerzhaft bewußt werden sollte und ihn zu der durch den Wortlaut des Waffenstillstandsvertrags legitimierten Aufforderung veranlaßte, die englische Gesandtschaft durch die Entsendung von Unterhändlern königlichen Geblüts aufzuwerten.

In einem vom Dekan von Lincoln an den Erzbischof von Canterbury gerichteten Schreiben vom 28. Oktober $13444^{165}$ fanden die bereits bekannten Punkte Erwähnung, durch die Wiedergabe in wörtlicher Rede geschah dies jedoch in sehr viel direkterer und unmittelbarerer Form. So gab der Papst zu verstehen, daß er aufgrund der Vorhaltungen, die ihm die Kardinäle wegen seiner duldsamen Haltung gegenüber England gemacht hatten, gar nicht anders könne als sein Vorgehen zu verschärfen und mit geistlichen Waffen gegen Edward III. vorzugehen ${ }^{166}$. In scharfer Form wies er einen englischen Ge-

161 Ibid.

162 Ibid., S. 211f.

163 Vgl. ibid., S. 211: Toutesvoies, sire, ledit Seint-Pière se pleint grevousment des choses attemptées en Engleterre contre li et l'Église, queles, à ceo qu'il dist, il ne puyt suffrir sauns ceo qu'eles soient en autre poynt que unqore ne sont. Auch der am 18. Oktober abgefaßte Brief des Dekans von Lincoln an einen Ratgeber Edwards III. zeugt zum einen von der Angst, der Papst könne bereits vorbereitete Prozesse gegen den englischen König und sein Reich publizieren, unterstreicht zum anderen aber auch sein als aufrichtig bewertetes Bemühen, zu einer Verständigung zu gelangen, vgl. ibid., S. 212-215.

164 Namentlich aufgeführt werden der Erzbischof von Clermont, Pierre de Cuignières, der Dekan von Paris, Louis d'Espagne, Louis de Poitiers und Simon de Buissi.

165 IBID., S. 215-219.

166 IBID., S. 216f.: Der Papst bekennt: Intollerabiles injurias contra primatum Ecclesiae sustinuimus jam per biennium, et sumus tam a nostris fratribus quam ab aliis adeo notabiliter inculpati quod non poterimus, neque volumus haec ulterius tollerare/ [...] Et sciat dominus tuus et etiam consilium suum quod nisi fuisset zelus quem habemus ad reformandam pacem inter ipsum et regem Franciae, non sustinuissemus per tam longa tempora injurias hujus impunitas, et certe processus, diu est, sunt facti et completi, nec restat nisi publicatio facienda $[\ldots]$. 
sandten mit dem Argument zurecht, er, der Papst, stehe über dem König. So wie Gott über die Engel, Erzengel, Throne und Gewalten herrsche, stehe er über den Menschen: das Vorgehen des englischen Königs sei deshalb nicht weiter hinnehmbar ${ }^{167}$. Spätestens an dieser Stelle wurde die Rolle des Papstes als unparteiischer Vermittler ad absurdum geführt. Von englischer Seite dazu gedrängt, agierte er als Vertreter einer in die Verhandlungen miteinbezogenen Partei - nicht aber als über den Parteien stehender Vermittler. Vor dem Hintergrund dieses übersteigerten und - der Verlauf der Verhandlungen macht dies deutlich - nicht mehr zeitgemäßen Machtanspruchs mußte die kurz zuvor gemachte Bemerkung, die Kardinäle würden ihn zu einer schärferen Gangart anhalten, als das wirken, was sie war: ein vorgeschobenes Argument, das der von ihm allein bestimmten und verantworteten kurialen Politik größeres Gewicht verleihen sollte. Der Papst glaubte, seine Autorität weiterhin durch den Verweis auf die Lehnsabhängigkeit Edwards III. vom Heiligen Stuhl aufwerten zu können. Damit wurde auch die Problematik der seit Jahrzehnten nicht mehr geleisteten Census-Zahlungen angeschnitten ${ }^{168}$.

Die Gesprächssituation verdüsterte sich daraufhin zusehends. Einem Einspruch des Gesandten wurde harsch begegnet - et incoepit aspere loqui ${ }^{169}$ und offen mit der Macht der Kurie gedroht. Clemens VI. redete sich in Rage und forderte als Vorbedingung für sein Einlenken in Fragen der Provisionen und Reservationen den Widerruf eines königlichen Erlasses, durch den die Entgegennahme päpstlicher Bullen und die Durchsetzung von Ansprüchen auf Benefizien unter Strafe gestellt wurden. Der Rat des Gesandten an den Erzbischof war kurz und einfach: Um Exkommunikation und Interdikt vorzubeugen, müsse der König auf die Bedingungen des Papstes eingehen. Der Dekan von Lincoln machte den König in einem am 28. Oktober abgefaßten Schreiben ${ }^{170}$ auf diese Gefahr aufmerksam und riet ihm zu einem wohlwollenden Empfang der an seinen Hof entsandten Nuntien, des Erzbischofs von Ravenna und des Bischofs von Astorga ${ }^{171}$. Verschwiegen wurde, daß die Entsen-

167 Ibid., S. 217: Nos sumus superior suus, non ipse noster. Angeli, Archangeli, Troni, Dominationes et Potestates habent caput in coelis, et nos a Deo sumus in terris. Credis tu quod ego faciam ea quae per partem vestram petuntur et quod postmodum expectem quod vos quae volueritis faciatis? Certe non. Vgl. zur Bedeutung des Hauptes gegenüber den Gliedern den klugen Beitrag von Ioan PÂNZARU, Caput mystice. Fonctions symboliques de la tête chez les exégètes de la seconde moitié du XII ${ }^{e}$ siècle, in: Le Moyen Âge 107 (2001) S. 439-453.

168 Die Szene gerät zum Musterbeispiel für das durch sorgsame Registerführung garantierte historische Gedächtnis der Kurie. Zur Untermauerung seiner Aussagen läßt sich der Papst einen Registerband bringen und liest complete tenorem litterarum Innocentii Tertii et litterarum regis Johannis vor, vgl. FROISSART, Lettres, S. 217.

169 Ibid., S. 218.

170 Ibid., S. 219-223.

171 Vgl. Lettres Clément VI, nn.1216, 1217, 1265-1271, 1325, 1909. Das Kardinalskolleg stimmt dieser Entsendung ausdrücklich zu, vgl. FroIsSART, Lettres, S. 250: [...] nostre SeintPère avoit ordoné par délibération et assent du collège de envoier à vous, sire, ses messages [...]. Dabei dürfte es sich jedoch lediglich um die statische de consensu fratrum nostrorumFormel handeln, die nichts über die tatsächliche Beteiligung der Kardinäle aussagt. 
dung der beiden Nuntien als direkte Reaktion der Kurie auf das Eintreffen eines gegen Kardinal Galhard de la Mothe gerichteten königlichen Breve anzusehen war. Das Breve, das nicht nur aufgrund des Inhalts, sondern auch wegen seines Tons einen Sturm der Entrüstung bei Papst und Kardinälen hervorgerufen hatte, war sicherlich nicht dazu angetan, die angespannte Situation zu entkrampfen. Und tatsächlich verletzte die »Grußadresse « an einen der höchsten Würdenträger der Kurie, der sich als $A$ toy Gaillard de La Mote ${ }^{172}$ apostrophiert sah, nicht nur die diplomatischen Usancen, sondern mußte als bewußt in Kauf genommene Unverschämtheit gelten ${ }^{173}$. Erwähnung fand ebenfalls die Ankunft der französischen Gesandten. Deren erste Tätigkeit bestand wie selbstverständlich in einem am Lukastag (18. Oktober) dem Papst abgestatteten Besuch. Bereits am folgenden Tag wurde der Gesamtheit der Kardinäle Aufwartung gemacht. Man kann sich fragen, ob in der Reverenz gegenüber den Kardinälen mehr als die Erfüllung von Vorgaben des päpstlichen Zeremoniells zu sehen ist, nämlich die Absicht, die Kardinäle für die Belange des französischen Königs günstig zu stimmen. Wäre dem tatsächlich so, würde dies für ein stärkeres Gewicht der Purpurträger bei den Verhandlungen sprechen - ein Gewicht, das über die Angaben aus der Gesandtenkorrespondenz nicht zu erschließen ist. Auf weitere Inhalte des Schreibens wird wegen identischer Angaben in der Denkschrift der englischen Gesandten weiter unten eingegangen ${ }^{174}$. Der am 12. November 1344 an den Erzbischof von Canterbury gerichtete Brief ${ }^{175}$ legte einmal mehr Zeugnis von den hervorragenden Informationsquellen ab, die den Gesandten zur Verfügung standen

172 Ibid., S. 226: [...] et ore tard si est envoyé un brief de prohibition au cardinal de la Mote, dont nostredit Seint-Pière et tut le collège sount esmuts et ennuyés si bien de la matire dudit brief come de la manière du parler, en taunt que est dit en meysme le brief: A toy Gaillard de La Mote, sauns plus cortoysement parler, et hier fust leu ledit brief en consistoire [...]. Das Breve erreicht die Kurie am 26. Oktober und wird am folgenden Tag im Konsistorium vorgelesen und behandelt.

173 Auch in anderen Schreiben vom 28. Oktober 1344 thematisiert der Dekan von Lincoln diesen Vorfall, vgl. ibid., S. 222: Hesterna die lectum fuit in consistorio praedictum breve regium domino cardinali de Mota et magistro Raymundo Peregrini procuratori suo directum, cujus materia et loquendi modus, attenta dicti domini cardinalis dignitate, ad indignationem magnam, prout dicitur, propter irreverentiam, dominum papam et totum collegium provocarunt [...]; vgl. auch ibid., S. 225, gerichtet an einen Berater des englischen Königs: [...] et hier fust leu un brief directé au cardinal de La Mote come à cardinal, dequele jeo vous envoye la copie enclose deins ceste, lequele brief est molt dure chalange si bien endroit de la matire come de la manère de parler qui puist avoir esté plus curteise [...].

174 Das Schreiben des Dekans von Lincoln diente wohl als Vorlage für den ersten Abschnitt der Denkschrift, hatte jedoch den großen Vorteil, aufgrund der französischen Sprache vom König unmittelbar verstanden worden zu sein. So wirkt denn auch die Schlußbewertung bezüglich des päpstlichen Verhandlungswillens sehr viel eindringlicher als in der lateinischen, quasi offiziellen Fassung, vgl. ibid., S.223: En bone foy, sire, nostredit seint-Pière, à ceo que nous semble et pooms sentir, se monstre de bone voluntée dever nous, sire, et grant diligence met pur l'esploit de nos besoignes [...].

175 Ibid., S. 227-229. Als Verfasser darf ebenfalls der Dekan von Lincoln gelten. 
und mit deren Hilfe sie Kenntnis von den im Rahmen der consistoria secreta behandelten Angelegenheiten erhielten. Auszugehen ist dabei wohl von der Unterstützung des bereits zu einem früheren Zeitpunkt als amicus noster apostrophierten Kardinals, der jetzt als unus dominus et amicus in Erscheinung tritt. Befürchtet wurde von Papst und Kardinälen ein schlechter Empfang der päpstlichen Nuntien durch den englischen König. Angesichts dieser Tatsache soll - so die Gesandten - ein Kardinal im Konsistorium den Vorschlag unterbreitet haben, die sich an der Kurie aufhaltenden englischen Gesandten im Falle einer Verhaftung der päpstlichen Nuntien in Gewahrsam zu nehmen ${ }^{176}$. Die für erfolgreiche diplomatische Verhandlungen unverzichtbare Immunität und Unverletzlichkeit von Gesandten schien also auf beiden Seiten nicht mehr gewährleistet zu sein - zumindest argwöhnte dies eine Partei von der anderen ${ }^{177}$.

\subsubsection{Et petivimus quod placeret eis tangere effectualiter: die Verhandlungen in Avignon 1344 und das Tagebuch der englischen Gesandten}

Über die von Clemens VI. und einigen Kardinälen in Avignon unternommenen Bemühungen, einen dauerhaften Frieden zwischen England und Frankreich zu vermitteln, informiert neben den Gesandtenbriefen ${ }^{178}$ eine Quelle, die als einzige über viele wichtige Vorgänge unterrichtet. Die Rede ist von dem in lateinischer Sprache abgefaßten Tagebuch der englischen Gesandten, das alle Verhandlungsschritte minutiös protokolliert und so einen genauen Einblick in das diplomatische Procedere um die Mitte des 14. Jahrhunderts ermöglicht ${ }^{179}$.

176 Ibid., S. 228: Praemunitus sum etiam per unum dominum et amicum quod unus maximus homo debuit heri dixisse in consistorio haec verba: Si isti prelati qui mittuntur in Angliam in ambassatia, non recipiantur et capiantur, faciemus illud idem de suis qui in curia hic existunt. Der Dekan von Lincoln verhehlt seine Angst nicht: Istis consideratis videtur michi quod nec est michi benevolus, nec amicus, qui erit illius sententiae quod, ingruente guerra inter sacerdotium et regnum, in romana curia debeam tantis subici periculis et inutiliter commorari.

177 Die Verzweiflung des Dekans scheint verständlich, vgl. ibid., S. 229: Grossa facta scripsi et scribam. Consilia nulla dabo.

178 Vgl. Kap. 5.1.5.

179 Abgedruckt in FroisSART, Euvres, Bd. 18, S.235-256, dort mit dem Titel Journal des conférences d'Avignon (fortan: Journal); vgl. Karsten Plöger, England and the Avignon Popes. The practice of diplomacy in late medieval Europe, London 2005, S. 184-186; zur Struktur der trilateralen Verhandlungen ibid., S. 203-208; DERS., Englische Gesandte und die Festkultur am Papsthof in Avignon, in: Höfische Feste im Spätmittelalter, hg.v. Gerhard Fouquet, Harm von SEgGern, Gabriel ZeILINGER, Kiel 2003, S.105-111; vgl. des weiteren Eugène DÉPREZ, La conférence d'Avignon (1344). L'arbitrage pontifical entre la France et l'Angleterre, in: Essays in medieval history presented to Thomas Frederick Tout, hg.v. Andrew George LiTTLE, Frederick Maurice Powicke, Manchester 1925, S. 301-320; Pierre CHAPLAIs, Règlement des conflits internationaux franco-anglais au XIVe siècle, in: Le Moyen Âge 57 (1951) S. 269-302; DERS., English diplomatic practice in the Middle Ages, London, New York 2003. 
Den ausführlichen, die Zeitspanne vom 22. Oktober bis zum 29. November 1344 abdeckenden und für den englischen König ${ }^{180}$ bestimmten Bericht führte Hugh Neville, einer der Gesandten, mit sich, als er Avignon Anfang Dezember verließ, um am englischen Hof neue Instruktionen einzuholen. Edward III. sollte über die bisherigen Verhandlungsschritte und die von der Gegenpartei vertretenen Positionen informiert werden. Daß dabei auch das Wirken der Gesandten eine positive Deutung erfuhr, liegt auf der Hand. Als Nuntien des englischen Königs fungierten William Bateman, der Bischof von Norwich $^{181}$, John Offord, der Dekan von Lincoln, sowie der Erzdiakon von Norwich, Hugh Neville, und Nicolino dei Fieschi. Wie viele Personen der Gesandtschaft der gegnerischen französischen Partei angehörten, bleibt im Dunkeln. Dem Papst, der tanquam coram privata persona et amicabili mediatore ${ }^{182}$ vermittelte, standen sechs Kardinäle zur Seite: Gaucelme de Jean, Jean de Comminges, Annibaldo Ceccano, Pedro Gomez, Bertrand de Deux und der Vizekanzler Pierre Desprez. Clemens VI. sollte also in Ausübung seiner Vermittlertätigkeit zur Privatperson Pierre Roger werden und dabei - die vornehmste Pflicht eines Mediators - unparteiisch wirken. Allen dürfte jedoch klar gewesen sein, daß dies reines Wunschdenken war, stand doch für das Papsttum zu Beginn des Hundertjährigen Krieges politisch einiges auf dem Spiel. Clemens VI. - bezeichnenderweise ist von ihm stets als dominus papa die Rede - agierte als auf Ausgleich bedachter Vermittler und verzichtete auf peremptorische Verurteilungen. Was seine Unparteilichkeit betrifft, fällt auf, $\mathrm{da} ß$ von den englischen Gesandten in dieser Hinsicht keinerlei Klagen laut wurden. Clemens VI., der im allgemeinen als in hohem Maße von Frankreich abhängig diskreditiert wird ${ }^{183}$, handelte unabhängig und versuchte in Ausübung seines Hirtenamtes, das nicht zuletzt darin bestand, Kriegsgegner zum Wohle der ganzen Christenheit zusammenzuführen, einen akzeptablen Kompromiß zu vermitteln. $\mathrm{Da}$ er dies als amicabilis mediator tat, als beiden Parteien nicht nur indifferent, sondern wohlwollend gegenüberstehender Vermittler, unterstreicht sein Interesse an einem positiven Ausgang der Verhandlungen.

Einsichtsfähigkeit in das politisch Machbare war in hohem Maße vorhanden. Bereits zu Beginn der Verhandlungen wies Clemens VI. die englischen

180 Der Adressat wird nicht genannt. Da die Niederschrift jedoch vor dem Hintergrund notwendiger Konsultationen mit dem englischen König verfaßt wird, liegt es nahe, im König selbst oder seinem engsten Beraterkreis den Empfänger der Schrift zu sehen. Da einzelne Mitglieder der Gesandtschaft sich normalerweise auf französisch an den König wenden, verweist die lateinische Form evtl. auf den letzterwähnten Empfängerkreis. Eine kurze Schilderung der Verhandlungen liefert SuMPTION, I, S. 438-444.

181 Vgl. zum diplomatischen Personal des englischen Königs Plöger, England, S. 65-123.

182 FroissarT, Journal, S. 235; vgl. auch FroISSART, Lettres, S. 231, mit der Bemerkung, die Parteien verhandelten vor dem Papst non pas com devant juge, mès come devant privé persone et médiatour eslu par assent de parties [...].

183 Vgl. Barraclough, The medieval papacy, S.154; ReITer, Das Papsttum in Avignon, S. 22. 
Gesandten darauf hin, daß ihre französischen Kollegen über die entsprechenden Vollmachten verfügten, um einen dauerhaften Friedensvertrag unterzeichnen zu können. Und er tat gut daran, der englischen Seite ins Gedächtnis zu rufen, daß das zu erzielende Verhandlungsergebnis stark von den jeweiligen Vollmachten abhing ${ }^{184}$. Subtil deutete er an, daß beschränkte Vollmachten ein beschränktes Ergebnis, wenn nicht gar ein vollständiges Scheitern der Unterhandlungen zur Folge haben könnten. Auch die zweite Mahnung des Papstes verdeutlichte diese Gefahr. Eindringlich wurde davor gewarnt, die Verhandlungen mit Maximalforderungen zu belasten ${ }^{185}$. Die Antwort der Engländer konnte angesichts dieser Mahnungen nur als Provokation verstanden werden. Zwar wurde cum reverentia betont, daß dem englischen König nichts wichtiger als ein stabiler Friede sei, daß auch sie multum voluntarios ad pacem seien, doch darf dies getrost als introduktives Geplänkel, als eine ungeschickte Form der captatio benevolentiae, angesehen werden. Vom Papst gedrängt, zur Sache zu kommen, wurde denn auch kein Zweifel daran gelassen, von welcher Voraussetzung alle weiteren Verhandlungen auszugehen hätten, nämlich der, daß die Krone Frankreichs dem englischen König gehöre, Philipp VI. damit als Usurpator anzusehen sei. Die Vorstellung, Unmögliches zu fordern, um Mögliches zu erreichen, entspricht einer Form diplomatischen Vorgehens, die Clemens VI. wegen der damit verbundenen Unwägbarkeiten offensichtlich nicht schätzte. An diese Maximalforderung schloß sich die Bitte an den Papst an, einen Lösungsweg aufzuzeigen. Immerhin überließ man ihm damit die inhaltliche Ausgestaltung des weiteren Verhandlungsverlaufs. Die sarkastische Bemerkung Clemens' VI., daß es sich hierbei wohl um keinen guten Anfang handle ${ }^{186}$, lässt seinen ausgeprägten Sinn für das politisch Machbare erkennen.

Trotz dieser Einschränkungen wird deutlich, daß dem Papst an einem $\mathrm{Zu}$ standekommen eines Dialogs lag. Zu diesem Zweck riet er, die Forderung Edwards III. auf die französische Krone, deren Rechtmäßigkeit er weder bestätigte noch bezweifelte, vorerst unbeachtet zu lassen und sich zunächst leichter verhandelbaren Gegenständen zuzuwenden ${ }^{187}$. Der englische Vorschlag, in Erörterungen über die fortgesetzte Verletzung des Waffenstillstands einzutre-

184 FroIsSART, Journal, S. 235f.: [...] et dixit quod praedicti nuntii sibi dixerunt quod habent plenam et sufficientem potestatem tractandi de pace praedicta et quod / habent pleniorem voluntatem ad reformationem bonae pacis [...].

185 Ibid., S. 236: [...] et quod faceremus petitiones quae non forent nimis excessivae, et quae forent inductivae bonae pacis, et voluit quod diceremus.

186 Ibid.: Et dominus papa tunc respondit quod hujus petitio non foret forsitan initium boni tractatus.

187 Ibid., S. 237: [...] dixit dominus papa quod nuntii partis adversae nullo modo consentirent quod regnum Franciae poneretur in discussione seu disputatione, nec ius ad regnum. Quapropter videbatur sibi, ut dixit, plus expedire pro tractatu, quod quasi dormitaret petitio de regno dum tractabitur de viis pacis quae possent esse de ducatu Acquitanniae et de matrimoniis [...]. 
ten, wurde zugunsten zweier anderer Probleme zurückgewiesen: Im Mittelpunkt sollten zunächst die Besitzrechte in Aquitanien und die Möglichkeit einer Befriedung durch Heiratspolitik stehen.

Das zweite Zusammentreffen am 24. Oktober verlief ähnlich, vermittelt jedoch den Eindruck zunehmenden gegenseitigen Mißtrauens. Warf der Papst den Nuntien vor, mit ihren wahren Absichten hinter dem Berg zu halten ${ }^{188}$, forderten diese ihn dazu auf, die tatsächlichen Vollmachten der Gegenpartei offenzulegen. In dieser Situation erging der erste konkrete Auftrag an eines der Mitglieder der sechsköpfigen Kardinalskommission. Der Vizekanzler Pierre Desprez wurde damit betraut, Klarheit über die Vollmachten beider Seiten zu gewinnen, um damit die Verhandlungen zu erleichtern. Die dritte Verhandlungsrunde zwei Tage später - auch dieses Mal bestand der Teilnehmerkreis aus dem Papst, sechs Kardinälen und den Gesandten Englands fand in gespannter Atmosphäre statt. Bereits bekannte Forderungen wurden wiederholt, was Clemens VI. erneut zu der Feststellung veranlaßte, die Gesandten würden ihre Karten nicht offen auf den Tisch legen. Immerhin wurde dieser Vorwurf auch den Vertretern der französischen Gegenpartei, mit denen separat verhandelt wurde, gemacht ${ }^{189}$. Eine neue Situation ergab sich, als die englische Seite den Vorschlag des Papstes, über Aquitanien zu verhandeln, entrüstet von sich wies und historische Argumente ins Feld führte, die den Anspruch des englischen Königs auf das Herzogtum belegen sollten. Ob sie dabei auf eine ebenfalls 1344 im Umfeld Edwards III. entstandene Denkschrift ${ }^{190}$ zurückgriffen, in der das Problem um Aquitanien eine zentrale Stellung einnahm, ist mit letzter Sicherheit nicht zu belegen. Immerhin tauchten sehr viele der Argumente, auf die in den mündlichen Verhandlungen rekurriert wurde, in der Denkschrift auf ${ }^{191}$. Ihre Argumentation verdeutlichte, daß sich die Voraussetzungen, unter denen einst zwischen den Vorgängern der jetzigen Könige über Aquitanien verhandelt wurde, grundlegend geändert hatten und nicht mehr der politischen Realität des Jahres 1344 entsprachen. Wenn Clemens VI. seine bereits gegenüber den Vertretern der Gegenpartei geäußerten Befürchtungen artikulierte, legte er einmal mehr diplomatisches Feingefühl und eminent politisches Denken an den Tag. Die Antwort der

188 Ibid.: Bene video quod non vultis vos aperire, sed vos tenetis vos clausos.

189 Ibid., S. 238: Vos tenetis vos multum clausos, et ita se tenent clausos nuntii alterius partis.

190 FroissarT, Euvres, Bd. 18, S. 256-272. Die Denkschrift findet sich dort unter dem Titel Mémoire sur les prétentions d'Édouard III à la couronne de France (fortan: Mémoire).

191 Vgl. FroissarT, Mémoire, S. 258-260. Darin wird betont, Edward III. habe den Lehnseid gegenüber dem französischen König nicht nur unter Zwang geleistet, sondern gleichzeitig auch auf einer Salvationsklausel bestanden - salvis sibi juribus. Des weiteren wird unterstrichen, daß sich das homagium auf das gesamte Gebiet Aquitaniens bezogen habe, ein Territorium, von dem der französische König zum Zeitpunkt der Eidleistung einige Teile besetzt gehalten habe. Das Versprechen Philipps VI., diese Teile zurückzuerstatten, sei nicht realisiert worden, so daß folglich auch Edward III. nicht mehr an diesen Eid gebunden sei. Auch andere Bedingungen habe der Lehnsherr nicht erfüllt, vielmehr gegen den minderjährigen englischen König durch Bündnisse intrigiert. 
Engländer hatte er vorausgesehen und ihre Forderung nach der Krone Frankreichs lediglich als taktisches Manöver eingeschätzt ${ }^{192}$.

Daß die sechs Purpurträger als Beratergremium des Papstes bisher im Hintergrund geblieben waren und man sich des Eindrucks kaum erwehren kann, sie hätten lediglich als Staffage gedient, wird angesichts der vom Papst ausgehenden Verhandlungsinitiativen und seiner beherrschenden Stellung verständlich. So konnte es auch kaum erstaunen, daß Clemens VI. die Kardinäle zum Verlassen des Raumes aufforderte ${ }^{193}$, um ungestörter mit den Gesandten verhandeln zu können und die Übermittlung von Informationen an die Gegenpartei zu verhindern. Auch dieses Vorgehen führte zu keinem Durchbruch. Die Zwischenbilanz nach vier Tagen angestrengter Konsultation fiel insbesondere für den Papst negativ aus. Angesichts dieser Tatsache entschied er sich, die Fortführung der Verhandlungen den Kardinälen zu überlassen. Als Verhandlungsführer stand nicht allein die von ihm eingesetzte Kardinalskommission zur Verfügung. Er zeigte sich bereit, lediglich zwei Kardinäle, deren Verhandlungsgeschick 1343 zum Abschluß des Waffenstillstands von Malestroit geführt hatte, zu benennen: Annibaldo Ceccano und Pierre Desprez. Unbestritten handelte es sich bei ihnen um die besten Kenner der französisch-englischen Problematik. Als sich die englische Seite uninteressiert zeigte, entschied der Papst selbst und rief alle Gesandten nebst den beiden Kardinälen am 3. November zur Wiederaufnahme der Verhandlungen in den Konsistorialsaal zusammen.

Erst zu diesem Zeitpunkt, rund zehn Tage nach Beginn der Verhandlungen, wurde den Kardinälen ein eigenverantwortliches Vorgehen gestattet, was für die englische Seite zunächst von einer Zurücksetzung begleitet war. An den Separatverhandlungen hielten auch die beiden Kardinalbischöfe fest und führten zunächst mit der französischen Seite Gespräche. Diese nahmen so viel Zeit in Anspruch, daß die Engländer - nobis ad partem existentibus ${ }^{194}$ - nicht mehr zum Zuge kamen. Erst am folgenden Tag, dem 4. November 1344, konnten sie zu den Vorschlägen der Kardinäle, die nicht neu waren, Stellung nehmen, sollte doch Aquitanien wiederum ganz oben auf der Tagesordnung stehen. Nochmals wurde der englische Standpunkt dezidiert vertreten und darauf hingewiesen, daß die Aquitanien-Frage angesichts des Streites um die Krone Frankreichs - discordia mota occasione coronae ${ }^{195}$ - nur von untergeordneter Bedeutung sei ${ }^{196}$. Die bereits zu diesem Zeitpunkt spürbar von Re-

192 Vgl. FroIsSART, Journal, S.239: Et dominus papa tunc statim dixit nobis: Certe nos istud idem diximus praedictis nuntiis quod talem responsionem forsitan vos daretis. Et diximus plus eis [...] quod petitio vestra de regno Franciae non est facta sine colore, nec sine magno consilio.

193 Ibid., S. 240: Et tunc dixit dominus cardinalibus quod traherent se ad partem.

194 Ibid., S. 241.

195 Ibid.

196 Dabei wird die rechtlich interessante Feststellung getroffen, daß sich mit dem Tod Karls IV. 1328 die bisher in den Bahnen des Lehnsrechts kanalisierten Ansprüche des englischen Königs auf Aquitanien in ihrem Wesensgehalt geändert hätten und nun eine Einheit mit dem erbrechtlich begründeten Anspruch auf ganz Frankreich bildeten. 
signation geprägte Antwort der Kardinäle über die Zwecklosigkeit solcher Unterredungen wird verständlich: Vos ergo vultis persistere in petitione regni et non alterius rei. Sic nunquam erit utilis tractatus pacis ${ }^{197}$. Jetzt lag es an den Gesandten selbst, die Initiative zu ergreifen und einen Vorschlag zu machen, der auf die völlige Loslösung Aquitaniens von der französischen Krone abzielte. Die lehnsrechtliche Bindung sollte gekappt und Aquitanien allein der Verfügungsgewalt des englischen Königs unterstellt werden. Daß mit diesem Vorschlag der Boden der Realität verlassen wurde, erkannten die Kardinäle genau. Ein stabiler und dauerhafter Friede war damit jedenfalls nicht zu erreichen ${ }^{198}$ : Nicht nur der französische König, sondern auch die Bevölkerung würde einer solchen Lösung niemals zustimmen - so die Kardinäle ${ }^{199}$. Im Mittelpunkt der Unterredungen stand nun die Frage, wie eine communio quae parit discordiam ${ }^{200}$ vermieden und das Problem der englischen Festlandsbesitzungen bewältigt werden konnte. Deutlich zeigt sich, daß von den Kardinälen eine Lösung favorisiert wurde, wonach der englische König auf alle Festlandsbesitzungen verzichten und dafür adäquat entschädigt werden sollte. Als Rekompensation wurden die in England gelegenen Besitzungen der Johanniter, die vollständig dem König übereignet werden sollten, in Erwägung gezogen. Die Gesandten reagierten auf diesen Vorschlag mit einem klaren Nein: Die Ehre und das politische Interesse des englischen Königs ließen eine solche Lösung nicht $\mathrm{zu}^{201}$. Auch der kardinalizische Alternativvorschlag fand vor ihren Augen keine Gnade: Schottland könne als Entschädigung nicht akzeptiert werden, weil bereits rechtliche Ansprüche des englischen Königs auf dieses Gebiet bestünden. Angesichts dieser Weigerungen war auch der letzte Vorschlag, nämlich derjenige eines finanziellen Ausgleichs, zum Scheitern verurteilt. Niemals würde der englische König seine Ansprüche durch Geldzahlungen ablösen lassen. Finanzielle Transaktionen dieser Art seien ehrenrührig und würden der Tragweite der Ansprüche nicht gerecht.

Die Position der Kardinäle war denkbar schwierig. Nachdem alle konkreten Vorschläge von der englischen Seite zurückgewiesen worden waren, erschien es ihnen sinnvoll, die Frage nach möglichen Eheverbindungen zwischen den Königshäusern zum Gegenstand einer der nächsten Verhandlungs-

197 Ibid., S. 242.

198 Unterstrichen wird, daß auch von den Kardinälen bereits an diese Möglichkeit gedacht, sie jedoch vor dem Hintergrund der Unmöglichkeit eines Eingriffs in die territoriale Integrität Frankreichs verworfen worden sei.

199 Die Antwort der Engländer verdeutlicht, daß das Element der Bevölkerung, der Untertanen, im politischen Kalkül der Herrscher wenig zählt: die Untertanen hätten sich den Entscheidungen der Herrscher bedingungslos zu unterwerfen: [...] verumptamen si partes principales ad hoc essent concordes, incolae ducatus sustinere haberent concordiam hujus, vellent nollent, ibid., S. 243.

200 Ibid., S. 244.

201 Ibid.: Respondimus quod ista via non esset pro honore domini nostri regis, nec pro ejus commodo. 
runden zu machen. Die Thematik wurde lediglich angerissen - tangebant etiam de matrimoniis in genere ${ }^{202}$-, nach einer kurzen, alles andere als positiven Stellungnahme der englischen Verhandlungspartner jedoch auf den 6. November vertagt ${ }^{203}$. Zum vereinbarten Zeitpunkt mußten die Gesandten eine weitere Zurückweisung hinnehmen. Erneut zeigten sich die Kardinäle so stark beschäftigt, daß eine Wiederaufnahme der Gespräche nicht möglich war. Das nächste Treffen fand erst einen Tag später statt, diente jedoch nur dazu, der englischen Seite nach verordneter Zwangspause Gelegenheit zu einer Bewertung der bisherigen Verhandlungspunkte zu geben. Das Ergebnis war niederschmetternd: Der Eifer der Kardinäle wurde zwar lobend hervorgehoben, die Verhandlungen insgesamt aber als wenig fruchtbar bezeichnet. Bereits für den nächsten Tag beraumte man eine weitere Gesprächsrunde an. Doch auch hier wurde nur Altbekanntes hin- und hergewälzt.

Diplomatischer Erfindungsreichtum kann sich zwar in rhetorischem Raffinement verwirklichen, diese Art von Raffinement gehörte jedoch zu einer Welt, die den Kardinälen offensichtlich fremd war. Erneut lenkten sie den Blick auf Aquitanien, gaben damit den Gesandten jedoch nur einmal mehr Gelegenheit zu einer breit angelegten Selbstdarstellung: Der englische König sollte davon überzeugt werden, da $\beta$ in Avignon die Interessen Englands mit aller Schärfe und Deutlichkeit verteidigt würden. Der Gedanke, daß Diplomatie in hohem Maße die Kunst bezeichnet, Kompromisse einzugehen, schien den Gesandten fremd zu sein. Selbstzweifel an ihrer Rolle sind jedenfalls an keiner Stelle feststellbar. Verständlicherweise reagierten die beiden Kardinalbischöfe zunehmend gereizt auf eine Haltung, die durch Opposition und Negation gekennzeichnet war. Die Diskussion um den geschichtlichen Aspekt des Problems der englischen Erbansprüche samt dem von den Engländern in seiner Rechtmäßigkeit bestrittenen Lehnseid Edwards III. gegenüber dem französischen König mündete in einer Zurechtweisung der Gesandten. Wer einen dauerhaften Frieden erhalten wolle, müsse von Extremforderungen abrücken ${ }^{204}$ - so der Tenor. Immerhin hatten die Gesandten dank ihrer Obstruktionspolitik eines erreicht: Aquitanien als politischer Brenn- und eigentlicher Ausgangspunkt der territorialen Besitzansprüche des englischen Königs wurde fortan nicht mehr als diplomatische Manövriermasse behandelt, sondern als Territorium, dessen Zugehörigkeit zu England außer Zweifel stand. Verhandelbar blieb deshalb nur der rechtliche Status dieser Festlandsbesitzung. $\mathrm{Da} B$ die Kardinäle mit dem Vorschlag, Aquitanien wie bisher unter französischer Oberherrschaft zu belassen, um damit einen seit Jahrzehnten mehr

202 Ibid.

203 Die Gesandten unterscheiden zwischen principalia et accessoria media der Verhandlungen, verkürzt ausgedrückt zwischen wichtigen und weniger wichtigen Themen. Das Gespräch de matrimoniis zählt dabei eindeutig zu letzteren.

204 Ibid., S. 247: Propterea videbatur eis, ut dixerunt, quod expediret loqui de viis pacis perpetuae, non tangendo talia extrema de toto regno et de contrario [...]. 
schlecht als recht funktionierenden status quo zu sanktionieren, scheitern würden, war vorauszusehen. Die Gesandten wehrten sich energisch gegen eine inakzeptable Lehnsabhängigkeit, die mit dem Einverständnis Edwards III. gleichzusetzen wäre, ein rechtlich fragwürdiges Ziel mit militärischen Mitteln verfolgt zu haben, und forderten die Umwandlung des Gebiets in ein Allodium, ein der vollen Verfügungsgewalt durch den englischen König unterstehendes Gut ${ }^{205}$. Die Kardinäle wurden so einmal mehr mit einer Maximalforderung konfrontiert, deren Unverhandelbarkeit allen Parteien klar vor Augen stehen mußte. Ihre Zwischenanalyse trug deshalb weniger Züge übergroßen Scharfsinns, sondern verwies auf eher bodenständige Konzeptionen von Politik. Ein dauerhafter Friede - die Kardinäle sprachen von bona pax ${ }^{206}$ - sei durch das beständige Betonen von Über- und Unterordnung nicht zu erzielen, auch die vollständige rechtliche Loslösung Aquitaniens vom Rest Frankreichs sei zum Erreichen dieses Ziels ungeeignet. Hoffnungen auf einen neuen diplomatischen Vorstoß, mit dem der gordische Knoten hätte durchschlagen werden können, wurden von den Kardinälen zunichte gemacht.

Der Begriff einer eher bodenständigen Politikkonzeption wurde ja bereits bemüht: Der nun folgende Vorschlag der beiden Experten für anglo-französische Probleme an der Kurie war erneut dazu angetan, diese Feststellung zu belegen, brachte er doch keinen neuen Gesichtspunkt in die Verhandlungen ein, sondern bemühte nur einmal mehr bereits angerissene und für nur begrenzt sinnvoll erachtete Konzepte. Konkret ging es um die Vermittlung von Eheschließungen als Mittel der Politik. Würde nämlich einer der Söhne des englischen Königs eine Tochter Philipps VI. heiraten, dann könnte Aquitanien in dessen Hände übergehen - die Kardinäle versäumten nicht zu betonen, daß Aquitanien dann auch der Oberhoheit des englischen Königs unterstellt werden könnte. Ein eklatanter Denkfehler der Purpurträger tritt hier klar zutage: Beide gingen von einem im Kern personalisierten Konflikt aus, in dem ausschließlich die persönliche Ehre und Integrität der jeweiligen Könige auf dem Spiel stünden. Die rechtliche und transpersonale Seite des Problems wurde dabei aber nur ansatzweise berücksichtigt. Es ging um Ansprüche von Nationen, die in Personen ihre Konkretisierung fanden. Verständlicherweise wurde der Vorschlag von den Gesandten abgelehnt ${ }^{207}$ und erneut auf den rein akzidentellen Charakter eines solchen Vorgehens verwiesen ${ }^{208}$. Auch jetzt zeigten sich die Kardinäle noch nicht entmutigt. Ein weiteres Mal wurden

205 Ein mögliches Zugeständnis in diesem Bereich wird vor dem Hintergrund sehr viel weiterreichender Besitzansprüche als bonum initium partiale bezeichnet, vgl. ibid.

206 Vgl. ibid.

207 Gleichsam mundgerecht zubereitet durfte sich Edward III. an den Worten erfreuen: [...] et jam per viam istam nichil sibi remaneret, et sic perderet commodum et honorem et dicere posset quod malos tractatores haberet, vgl. ibid., S. 248.

208 Ibid.: Sed diximus quod primo cogitare deberent facere conditionem ipsius domini nostri regis bonam et honorificam, et tunc loqui de matrimoniis quantum ad condimentum rei pro pleniori amicitia copulanda. 
Zahlungen an Edward III. als Entschädigung für den Verlust von Aquitanien diskutiert - zum großen Erstaunen aller Beteiligten schien die englische Seite diesen Vorschlag nicht wie üblich gänzlich abzulehnen. Im Bericht klingt zumindest deren Hoffnung an, für Aquitanien mit anderen, auf französischem Territorium gelegenen Gebieten entschädigt zu werden. Sie sollte sich aber bereits am nächsten Verhandlungstermin, dem 10. November, als unberechtigt erweisen. Nach separaten Gesprächen der Kardinäle mit der Delegation des französischen Königs schien dieser Weg nicht gangbar, das Projekt möglicher Rekompensationsleistungen wurde somit endgültig begraben ${ }^{209}$.

Aquitanien wurde von der englischen Seite als major causa behandelt, die freie Überlassung des Gebietes zur >Chefsache` erhoben und mit dem Hinweis tanquam rem partialem cooperativam ad pacem ${ }^{210}$ taktisch klug verbrämt. Das Verhalten der Verhandlungsführer schien defensiv zu sein: Frankreich würde nie einem Ergebnis zustimmen, an dessen Ende die freie Verfügungsgewalt Englands über Aquitanien stünde. Vor diesem Hintergrund mußte die Frage nach möglichen Eheverbindungen als das erscheinen, was sie tatsächlich war: ein aus Verzweiflung geborener Akt. Die Reaktion der von der Nutzlosigkeit solcher Demarchen überzeugten Engländer war denn auch entsprechend harsch: Die Kardinäle sollten sich endlich um Effizienz bemühen ${ }^{211}$. Eine neue Sitzung wurde am 13. November anberaumt, von den Kardinälen jedoch um eine weitere Woche verschoben.

Die nächste Verhandlungsrunde fand so nach zehntägiger Pause erst am 20. November statt und erhielt durch die Präsenz des Papstes und des auf die alte Zahl von sechs Mitgliedern erweiterten kardinalizischen Beratergremiums zusätzliches Gewicht. Nachdem sich der Papst durch einen Bericht der Kardinalbischöfe von Tusculum und Palestrina über den aktuellen Stand der Verhandlungen informiert hatte, ließ er sowohl Engländer als auch Franzosen zu sich kommen - ein bemerkenswertes Novum, hatte man sein Vertrauen bisher doch auf Separatverhandlungen gesetzt und den direkten verbalen Austausch der Gesandten geflissentlich vermieden. Das direkte Eingreifen des Papstes wird vor dem Hintergrund der ins Stocken geratenen und kurz vor dem Abbruch stehenden Verhandlungen verständlich. Als oberster, weisungsbefugter Vertreter kurialer Diplomatie trug der Papst zwar Schuld an deren desaströser Bilanz, doch war er es auch, der das Ruder noch einmal hätte herumreißen

209 Ibid., S. 249: Finaliter diximus eis quod insistere circa compensationem hujus non foret expediens quia per viam compensationis hujus haberemus nedum carere portione predicti ducatus extra manus nostras existente, immo haberemus perdere portionem dicti ducatus quam habemus.

210 IBID.

211 IBID., S. 249f.: [...] et petivimus quod placeret eis tangere effectualiter / quid facere velit pars adversa domino nostro regi [...]; man versäumte auch nicht, auf das baldige Auslaufen des aktuell noch gültigen Waffenstillstands an Weihnachten hinzuweisen. Auch eine Abberufung durch Edward III. wegen ineffizient geführter Verhandlungen erschien den Gesandten denkbar. 
und seinen ganzen Einfluß hätte geltend machen können, um die Konzessionsbereitschaft der Verhandlungsparteien zu verstärken. $\mathrm{Zu}$ Beginn stand das mahnende Wort: alle hätten sich zwar redlich bemüht, es letztendlich aber an ehrlichem Willen zum Friedensschluß fehlen lassen ${ }^{212}$ - so der Papst. Schuld sei eine von beiden Seiten eingenommene Haltung, die sich darin gefalle, klare Aussagen zu vermeiden, Verhandlungsziele und -ergebnisse nicht deutlich zu benennen, sondern mit dem Schleier der Ungewißheit zu verhüllen. Clemens VI. zeigte sich entschlossen: als Verantwortlicher für das Gelingen der Unterredungen sei er nicht länger bereit, sich derartiges bieten zu lassen, und fordere deshalb die Vertreter beider Parteien dazu auf, ihn persönlich - falls gewünscht ohne Beteiligung der Kardinäle - in Kenntnis über die Vorstellungen und Pläne der jeweiligen Herrscher zu setzen. Der englischen Seite wurde überdies noch in vertraulichem Gespräch ins Gewissen geredet: Grund allen Übels sei und bleibe der Streit um Aquitanien. In den von den beiden Kardinälen unterbreiteten Vorschlägen liege der Schlüssel zur Lösung des Problems. Kurz und knapp, mit großer Eindringlichkeit wurden die Engländer dazu aufgefordert, die in den letzten Tagen diskutierten Sachfragen zu überdenken und den Papst am folgenden Tag über das Ergebnis zu informieren.

Auf dem Treffen am 21. November befand sich der Papst jedoch erneut in der Defensive. An die Stelle der erbetenen Erläuterungen trat die einfache Frage, ob die erwähnten Rekompensationsleistungen, die höchstwahrscheinlich von Edward III. nicht akzeptiert werden würden, nur für den momentan von den Engländern kontrollierten Teil oder ganz Aquitanien gelten sollten. Der Papst wurde damit gezwungen, als Sprachrohr der französischen Seite zu fungieren und zu unterstreichen, daß deren Konzessionsbereitschaft nur so weit ginge, den unter Edward II. gültigen status quo wieder herzustellen, Aquitanien jedoch keinesfalls aus dem französischen Kronverband zu entlassen. Den Vorschlag bezüglich möglicher Entschädigungsleistungen konnte Clemens in seiner Tragweite nicht durchdacht haben: anstelle kirchlicher Besitzungen in England wurde als mögliche territoriale Entschädigung das $\mathrm{Ge}-$ biet von Flandern genannt, ein Territorium, dessen starke Unabhängigkeitsbestrebungen der Kurie bereits seit langem Probleme bereiteten. Verhalten war denn auch die Reaktion der Gesandten: Eine Entschädigung durch Gebiete innerhalb Englands käme nicht in Frage, über alles andere müßte mit dem Souverän, nämlich Edward III., Rücksprache gehalten werden.

Der Papst schien Licht am dunklen Verhandlungshorizont zu sehen und unterrichtete die Gesandten über die Einstellung des französischen Königs, der non sine maxima difficultate ${ }^{213}$ einer Lösung zustimmen würde, die den Engländern Rechte an Aquitanien beließe. Gleichsam en passant ließ er die

212 IвID., S. 250: Laudo vos quia laboratis et zelatis, ut credimus, pro bona pace; sed in hoc non laudo vos quod ex una parte et ex altera vos tenetis vos nimis clausos, nec vultis aperire aliquam viam pacis in specie.

213 Vgl. ibid., S. 253. 
Bemerkung fallen, daß sich Philipp VI. sicherlich konzilianter zeigen würde, könnte Edward III. sich dazu entschließen, höherrangige Gesandte - wenn möglich von königlichem Geblüt - nach Frankreich zu entsenden. Diese für die aktuellen Gesandten wenig schmeichelhafte Bemerkung erzielte eine vom Papst nicht beabsichtigte Wirkung. Die Engländer erklärten: »Obwohl wir nicht ausdrücklich den besprochenen Weg einer Rekompensationsleistung zurückweisen, betonen wir dennoch, da $\beta$ wir uns, konfrontiert mit der Aussage, unser König könne innerhalb des französischen Territoriums nichts in völliger Unabhängigkeit vom französischen König besitzen, außer Stande sehen, mit den Verhandlungen weiter fortzufahren ohne zuvor unseren König konsultiert zu haben [...] « 214. Der Papst erkannte die Brisanz dieser Worte. Ein Abbruch der Verhandlungen war nicht mehr auszuschließen, zumal gleichzeitig drei englische Gesandte um die Erlaubnis zur Abreise baten. In einer weiteren, am 24. November stattfindenden Unterredung zog Clemens VI. die Notbremse: lediglich einer Person wurde die Reise nach England zwecks Konsultation mit Edward III. gestattet. Eine entsprechende Anweisung erging an die französische Seite. Damit hielt die Kurie vor den Augen der Öffentlichkeit den Schein aufrecht, in Avignon würde weiterverhandelt. Diese Entscheidung wurde in Abstimmung mit vier Kardinälen getroffen ${ }^{215}$.

Auch die Ankunft zweier Nuntien aus England, Johannes de Thoresby und Richard Sprygonell, die dem Papst Briefe Edwards III. überreichten, änderte nichts an der Situation. Lediglich der zu Weihnachten ablaufende Waffenstillstand wurde bis in die Mitte der Fastenzeit des folgenden Jahres verlängert. Das letzte Zusammentreffen der Verhandlungsparteien fand am 29. November statt: Hugh Neville dürfte nur wenig später in dem Bewußtsein abgereist sein, daß weitere Verhandlungen unter der Prämisse, daß Philipp VI. weiterhin auf einer subiectio, also der Lehnsabhängigkeit Edwards III. für Aquitanien bestehe, zum Scheitern verurteilt seien ${ }^{216}$. Tatsächlich verliefen die Verhandlungen im Sande. Hugh Neville erreichte England kurz nach Weihnachten. Bald darauf machte sich auch William Bateman zurück auf den Weg in sein Bistum Norwich. Fieschi begab sich nach Italien, schließlich verließ mit

214 Ibid.: Licet non recusemus expresse viam recompensationis praetactam, dicimus tamen vobis quod post datum nobis tale principium videlicet quod nichil omnino tenere deberet dominus noster rex infra regnum Franciae nisi in subjectione, nolumus ex nunc super viis tactis tractare inconsulto domino nostro rege [...].

215 Ibid., S. 254: Qua hora adveniente fecit primo vocari dominos cardinales tunc praesentes in palatio, videlicet dominos Penestrensem et Tusculanum, Albanensem et Covenarum, et diffusum cum eis habuit tractatum [...]. Die Kardinäle Pedro Gomez und Bertrand de Deux scheinen verhindert gewesen zu sein.

216 In einem Brief vom 26. November 1344 informierte der Bischof von Norwich den englischen König über die bevorstehende Abreise des Hugh Neville und kündigte dabei auch die in lateinischer Sprache abgefaßte Denkschrift an, FrorssarT, Lettres, S. 231f.: Si envoyons à vostre Haute Seignurie la copie de l'avant-dit tretée en latin pur ceo que en latin se fist, issint, sire, que, le tretée de pées examiné et entendu, nous puissons hastivement estre certifiés de vostre entention et de vostre volenté [...]. 
John Offord, dem Dekan von Lincoln, Anfang März auch der letzte Vertreter der ursprünglichen Verhandlungsdelegation Avignon. Die Konferenz von Avignon war gescheitert 217 .

\subsubsection{Der Fall Adémar Robert:}

\section{kuriale Benefizialpraxis und die Reaktion des englischen Königs}

Mit Adémar Robert, Kardinalpresbyter tit. S. Anastasiae, tritt eine Persönlichkeit ins Blickfeld, über deren kuriale Tätigkeit nur sehr wenig bekannt ist und die auch nur deshalb ein gewisses Interesse beanspruchen darf, weil sich in ihr die Anklagen des englischen Königs gegen die Benefizialpolitik der Kurie bündeln und verdichten ${ }^{218}$. Bereits 1343 erscheint Adémar Robert in den päpstlichen Registern. In einem Brief vom 28. August des Jahres wurde der englische König von Clemens VI. dazu aufgefordert, die gegen die in England tätigen Prokuratoren des Kardinals verfügten Maßnahmen rückgängig zu machen ${ }^{219}$. Grund für das an der Kurie mit Empörung registrierte Vorgehen des Königs gegen den Kardinal war die Entscheidung des Papstes, nach der im Dezember 1342 erfolgten Kreation zwei Mitgliedern des Kollegiums umfangreichen Benefizialbesitz in England zuzuweisen. Die Kardinäle teilten mit ihm Arbeit und Lasten - so der Papst - und benötigten deshalb ein entsprechendes Einkommen, das nur durch sichere Pfründen zu erzielen sei. Außerdem habe er nicht irgendwelche Kardinäle mit englischen Pfründen ausgestattet, sondern darauf geachtet, daß zwei Prälaten zum Zuge kämen, die in Aquitanien, mithin im Herrschaftsgebiet des englischen Königs, geboren seien 220 .

Mit dem Verweis auf die Lasten der Kardinäle reihte sich Clemens VI. in eine Traditionslinie ein, die die Vergabe von Pfründen an den Grundsatz beneficium propter officium gebunden wissen wollte. Damit wurde nicht nur auf die enge Verzahnung von spiritueller Leistung und materieller Gegenleistung verwiesen, sondern auch auf die Vorstellung, daß den Klerikern ein Einkommen zu gewähren sei, das ihrer Stellung innerhalb der kirchlichen Hierarchie entspräche. Im Vertrauen auf die Wirksamkeit der päpstlichen Verfügungen wurden Prokuratoren entsandt, die die Interessen der Kardinäle in England wahrnehmen sollten. Über diesen Auftrag dürfte bei ihnen allerdings nicht allzu große Freude aufgekommen sein, wurden sie doch nicht nur durch königliche Beamte an der Wahrnehmung ihres Auftrags gehindert, sondern sogar gefangengenommen und mit Schimpf und Schande des Landes verwie-

217 Vgl. Lettres Clément VI, nn. 1574, 1590, 1591; RYMER, Foedera, III, 32.

218 Vgl. generell Geoffrey Barraclough, Papal provisions, Oxford 1935; Plöger, England, S. 42-51; Kap. 5.1.5., 5.1.6.

219 Lettres Clément VI, n. 375.

220 Ibid.: Cum autem duobus ex eis de ducatu Aquitanie oriundis, videlicet dilectis filiis nostris Ademaro tituli Sanctae Anastaiae, et Geraldo tituli Sancte Sabine presbiteris cardinalibus, de hujusmodi beneficiis in regno et terris tuis [...] gratias hujusmodi providerimus faciendas $[\ldots]$. 
$\operatorname{sen}^{221}$. Clemens VI. appellierte an das Ehrgefühl Edwards III. und betonte, $\mathrm{da} ß$ er sich - insbesondere vor dem Hintergrund der problemlosen $\mathrm{Zu}$ sammenarbeit mit seinen Vorfahren - beim besten Willen nicht vorstellen könne, daß der König dieses Vorgehen angeordnet habe oder gar billige ${ }^{222}$. Außerdem sei England die einzige Nation, die sich gegen solcherart Verfügungen sperre. Nachdrücklich wurde Edward III. darauf hingewiesen, welche Nachteile ihm aus seinem Verhalten erwachsen könnten: Ganz zweifellos sei es doch so, da $\beta$ in England bepfründete Kardinäle ihren Einfluß an der Kurie zugunsten seiner Nation geltend machen würden ${ }^{223}$. Der Hinweis auf möglicherweise fehlende Fürsprache an der Kurie wurde durch die unverhüllte Drohung, im Notfall auch Kirchenstrafen über ihn zu verhängen, relativiert. Angesichts dieser Perspektiven beschwor der Papst den englischen König, einzulenken und die getroffenen Verfügungen zu widerrufen. Zeitgleich gingen Schreiben an Isabella, die englische Königin, deren Tochter Philippa und an die Ratgeber Edwards III., in denen diese dazu aufgefordert wurden, den englischen König entsprechend zu beeinflussen ${ }^{224}$. Raymundus Pelegrini, Kanoniker in London und päpstlicher Kollektor, erhielt den Auftrag, die Briefe an die entsprechenden Empfänger weiterzuleiten ${ }^{225}$.

Es wird deutlich, daß hier die Interventionsmöglichkeit des Papstes mit der des Königs auf dem Gebiet der Pfründenverleihungen kollidiert ${ }^{226}$. Die Verfü-

221 Walsingham, Chronica, S. 255: Eodem anno [1343], Papa Clemens iterum fecit in Anglia provisiones duobus Cardinalibus de beneficiis proximo vacantibus, praeter episcopatus et abbatias, ad extentam duorum millium marcarum. Quod Rex et tota regni nobilitas pati noluit; sed procuratores dictorum cardinalium, sub poena carceris, Angliam exire coegit, zur Bewertung der Chronik vgl. WalsIngham, Chronica, S. IX-XXIII; Antonia Gransden, Historical writing in England, Bd. 2, London 1996, S. 118-156; John TAYLOR, English historical literature in the $14^{\text {th }}$ century, Oxford 1987, S. 59-89.

${ }^{222}$ Lettres Clément VI, n. 375: [...] ea de tua processisse consciencia faciliter non valemus.

223 Ibid.: [...] quod cardinales et illi maxime qui naturaliter afficiuntur ad honores et commoda tua regia, in regno et terris tuis beneficia obtineant ecclesiastica, quia ex hoc proculdubio libencius et fervencius ad promovendos profectus regios inducuntur [...].

224 Ibid., n. 376 (28.08.1343). Rund zwei Wochen später nutzte der Papst noch einmal die Gelegenheit, einem Dankesschreiben an die englische Königin die dringende Bitte hinzuzufügen, zur Lösung des Problems beizutragen, ibid., n. 393 (08. 09.1343).

225 Ibid., n. 377 (28.08. 1343).

${ }^{226} \mathrm{Zu}$ den Pfründenklassen, deren Kollation sich der Papst vorbehielt vgl. William LuNT, Financial relations of the papacy with England 1327-1534, Cambridge/Ma. 1962, S. 320-323 und Guillaume Mollat, La Collation des bénéfices ecclésiastiques à l'époque des Papes d'Avignon, in: Lettres communes de Jean XXII, Bd.2, S. 11 (introduction). Neben Pfründen, die nur deshalb vom Papst weiterverliehen werden konnten, weil der ordentliche Kollator, zumeist der Ortsbischof, zu lange mit der Weitervergabe wartete und denen, die durch den Tod des Inhabers an der Kurie oder im Umkreis von zwei Tagesreisen davon entfernt frei wurden, traten seit Clemens V. generell die durch den Tod von Kardinälen, päpstlichen Kaplänen und anderen Offizialen vakant werdenden Benefizien. Die von Johannes XXII. am 21. November 1317 erlassene Apostolische Konstitution Execrabilis (FrIEDBERG, II, Sp. 1207) zielte klar gegen die Pluralität von Benefizien und bescherte der päpstlichen Kammer eine neue Reservationsklasse. Verständlich wird das päpstliche Vorgehen jedoch erst 
gung über Benefizien galt nicht nur als Prärogativ der Herrscher und als probates Mittel, Getreue für geleistete oder noch zu leistende Dienste zu entlohnen. In England kam ein weiterer Gesichtspunkt hinzu: Die Stifter einer geistlichen Institution, der ein zu vergebendes Benefizium zugeordnet war, konnten ein Mitspracherecht bei der Vergabe dieser Pfründe geltend machen ${ }^{227}$. Wirklich begehrenswert waren nur wenige Pfründen: daß diese vom Papst für seine Getreuen reklamiert wurden, mußte den Zorn des englischen Königs erregen ${ }^{228}$. Bereits am 8. September verließ ein neuer Brief die Kurie in Richtung Westminster. Nochmals wurde der König zum Einlenken aufgefordert ${ }^{229}$. Über ein Jahr fließen in der Folge die über päpstliche Registereinträge eruierbaren Informationen spärlich ${ }^{230}$, auch wenn mittels eines Statuts vom Januar 1344 Clemens VI. noch einmal seine Ansprüche bekräftigte, gleichzeitig jedoch gewisse Exzesse von seiten der Prokuratoren einräumte ${ }^{231}$ und im Juli noch einmal grundsätzlich auf seine aus der päpstlichen plenitudo potestatis resultierende Verfügungsgewalt nicht nur über die strittigen Benefizien verwies ${ }^{232}$.

vor dem Hintergrund der angespannten finanziellen Lage, in der sich das Papsttum zu Beginn seines Pontifikats 1316 befunden hatte. Um die Einkünfte der Camera apostolica zu steigern, hatte der Papst damals mittels der Bulle Si gratanter adverteritis (vgl. THEINER, Monumenta Hungariae, I, S. 446-448) am 8. Dezember 1316 eine an die Weltkirche gerichtete Generalreservation verfügt. Sie sollte der Kurie die Annaten aller freien und innerhalb einer Frist von drei Jahren frei werdenden Pfründen sichern. Bald wurde vor dem Hintergrund nur verhalten steigender Einnahmen deutlich, daß das "natürliche«, d.h. durch den Tod des jeweiligen Pfründeninhabers motivierte Freiwerden von Pfründen auch in Zukunft zusätzliche Mittelzuflüsse nur in bescheidenem Umfang garantierte. Die Lösung konnte also nur darin bestehen, schnell viele Pfründen freiwerden zu lassen, auf die dann die Bestimmungen von Si gratanter adverteritis Anwendung finden sollten. Die Konstitution Execrabilis ermöglichte dieses Freiwerden und führte in der Tat zur Konsolidierung der päpstiichen Finanzen. Neben diesen zentralen fiskalischen Aspekten sollte jedoch auch die seelsorgerisch-moralisch motivierte Stoßrichtung gegen eine Akkumulation von Kuratbenefizien nicht vergessen werden.

227 Vgl. allgemein Kathleen WOOD-LEGH, Studies in church life under Edward III, Cambridge 1934 .

228 Nicht unerwähnt bleiben soll die Tatsache, daß es neben Papst und König zumindest theoretisch auch noch Mitspracherechte der ordentlichen Kollatoren, beispielsweise der Bischöfe oder Äbte, gab. In der Zurückdrängung und Beschneidung dieser Ansprüche waren sich Papst und König wiederum einig.

229 Lettres Clément VI, n. 394 (08.09.1343): Que autem, fili dilectissime, super ipsis novitatibus, quas non minui sed augeri displicibiliter nimis percipimus, egeris et intendas agere, rescribere nobis, quesumus, non omittas.

230 Ibid., nn. 519, 520 (13.11.1343).

231 Ibid., n. 637 (28.01.1344): [...] nonnulli procuratores [...] extendentes avidas manus suas [...] super quibus questiones et scandala in aliquibus partibus, sicut intelleximus, sunt exorta.

232 Ibid., n. 957 (11.07.1344): Nos, qui ecclesiarum omnium tamquam pastor universalis earum invigilamus commodis, uti non intendimus nec intendamus reservationibus et provisionibus huiusmodi, nisi quantum utilitatibus et necessitatibus ecclesiarum ipsarum crediderimus expedire [...]. Attende fili, ipsam Ecclesiam Romanam, cuius pastorali regimini, licet meritis insufficientibus, praesidemus, non ab Apostolicis, sed ab ipso domino Salvatore nostro primatum super omnes mundi ecclesias obtinere; ipse quidem solus eandem fundavit Ecclesiam dicento domino Petro: Tu es Petrus [...]. 
Erst mit einem Brief vom 11.September 1344 schien wieder Bewegung in die Sache zu kommen. Der Papst forderte den Bischof von Exeter auf, den Prokurator von Kardinal Robert darin zu unterstützen, die Benefizialerträge der im Bistum gelegenen Pfarrkirche von Exminster einzuziehen ${ }^{233}$. Damit fand eine Pfründe Erwähnung, die sich in den Supplikenregistern Clemens' VI. erst im Juni 1345 nachweisen läßt. Sie muß Teil der gratia beneficialis gewesen sein, die der Papst zu Beginn seines Pontifikats gewährt hatte. Leider weisen die Register, die ansonsten mit großer Akribie geführt wurden, für diese ersten Monate entscheidende Lücken auf. Dennoch kann davon ausgegangen werden, daß bereits zu diesem Zeitpunkt die Entscheidung des Papstes ergangen war, dem neu kreierten Kardinal in der Kirchenprovinz York Pfründen im Wert von 1000 Mark Sterling zu übertragen, eine Verfügung, die in der (Neu-) Providierung des Kardinals vom Juni 1345 bestätigt wurde ${ }^{234}$.

233 Ibid., n. 1100 (11.09.1344).

234 Vgl. Mollat, Collation, S.254-258; LuNT, S. 229f.; RS 9, fol.54r-v. Aufgrund ihrer eminent politischen Bedeutung sei der Text dieser extrem umfangreichen Supplik hier vollständig wiedergegeben:

Dudum attendentes, quod dilectus filius noster Ademarus tit. S. Anastasie presbyter cardinalis, quem tunc ad cardinalatus dignitatem suis exigentibus meritis duximus promovendum, ad supportandam expensarum onera, que ipsum oportebat de neccessitate subire, decenter non affluebat habundancia facultatum et propterea volentes sibi de oportune subventionis auxilio providere beneficia ecclesiastica, etiam si prioratus conventuales, decanatus, prepositure, archidiaconatus, archipresbyteratus et quecumque alie dignitates non tamen episcopales nec abbatiales regulares necnon personatus et officia, canonicatus et prebende, parrochiales ecclesie et quecumque alia beneficia ecclesiastica cum cura vel sine cura, secularia vel regularia Clunacien., Cistercien., Premostraten., Grandimonten., Sancti Benedicti, Sancti Augustini, Camaldunen. aut aliorum quorumcumque ordinum aut status preeminentie vel cuiuscumque condicionis, etiam si in cathedralibus vel quibusvis aliis ecclesiis existerent, etiam si unum, duo, tria, plura et quotcumque et qualiacumque forent, etiam si ad beneficia ipsa consuevisset quis per electionem assumi dummodo dignitates ipse in cathedralibus maiores post pontificales et in collegiatis secularibus ecclesiis non essent principales, quibus tamen maioribus et principalibus dignitatibus canonicorum ecclesiarum ipsarum cura imminet animarum ad cuiuscumque seu quorumcumque collationem, provisionem, electionem, presentationem seu quamvis aliam dispositionem in provincia Eboracensi comuniter vel divisim spectant, quorum fructus, redditus et proventus mille marcharum Sterlingorum argenti secundum taxationem decime valorem annuum non excedant, si qua in eadem Eboracensi provincia tunc vacabant vel cum simul aut successive vacarent, que per ipsum Ademarum vel procuratorem suum legitimum infra certi temporis spatium postquam eidem Ademaro vel procuratori suo de illorum vacatione constaret, duxeret acceptanda conferenda sibi post acceptationem huiusmodi cum omnibus iuribus et pertinentiis suis motu proprio non ad ipsius Ademari vel alterius pro eo nobis oblate petitionis instanciam, sed de nostra mera liberalitate donationi apostolice duximus reservanda cum inhibitione decreti, interponitione, dispensatione ac certarum condicionum et penarum appositione prout in nostris super hiis confectis litteris plenius continetur certis super hiis per alias nostras litteras executorias deputare. Cum autem sicut accepimus prefatus cardinalis vigore huiusmodi nostre gratie non nisi archidiaconatum Estrindungensem et canonicatum et prebendam de Warchill in ecclesia Eboracensi una cum ecclesia de Axemynsti., Exoniensis diocesis, eidem prebende annexa, ac canonicatum et prebendam Beate Marie in ecclesia S. Johannis Beverlaten., Eboracensis 
Bereits im November des Jahres schärfte der Papst dem englischen König ein, dieses Mal die Arbeit der Prokuratoren nicht zu behindern ${ }^{235}$. Clemens VI. hatte nach massiven Protesten aus England die Situation dadurch zu entschärfen versucht, daß er das für die Benefizien relevante Gebiet, also die Kirchenprovinz York, modifizierte, genauer: zusätzlich um die Kirchenprovinz Canterbury erweiterte. Konnte sich der Kardinal zumindest während dreier Jahre der Einkünfte aus seinem Archidiakonat in York und der Pfarrkirche von Wimbledon im Bistum Winchester erfreuen, hatte er sich spätestens seit 1347 der Konkurrenz zweier vom König mit denselben Pfründen Providierter zu erwehren. Noch schlimmer: Ungeachtet seiner Würde wurden er bzw. seine Prokuratoren vor das Parliament zitiert, um dort auf die Anschuldigungen zu reagieren und sich zu verteidigen. Nicht allein die de facto-Enteignung des Kardinals und damit die Mißachtung des päpstlichen Kollationsrechtes, sondern auch das vom König gewählte prozessuale Verfahren stießen an der Kurie auf schärfsten Widerstand. In seinem Brief versuchte Clemens VI., den englischen König zum Einlenken zu bewegen. Er führte dafür das immer wieder bemühte Argument an, die Kardinäle benötigten Pfründen, um ihren Lebensunterhalt angemessen bestreiten zu können, bemerkte jedoch ergänzend, daß die so Bepfründeten gleichzeitig auch als Fürsprecher des Landes an der $\mathrm{Ku}-$ rie wirken könnten, aus dem sie ihre Einkünfte bezögen ${ }^{236}$. Insgesamt also wenig Neues in einem Streit, der sich bereits über fünf Jahre hinzog.

diocesis, de qua prebenda idem cardinalis in palacio apostolico causarum noscitur litigare, quorum quidem beneficiorum fructus, redditus et proventus centum triginta marcharum sterlingorum secundum taxationem decimae valorem annuum non excedit, acceptaverit nec acceptare alia certis supervenientibus iustis impedimentis potuerit, Nos volentes dictam gratiam ampliare et, ut citius et facilius suum consequatur effectum, ad provinciam Cantuariensem extendi beneficia ecclesiastica, quecumque, quotcumque et qualiacunque prout superius singulariter sunt expressa prioratibus conventualibus et beneficiis ordinis Grandimontensis dumtaxat exceptis, que in huiusmodi gratia nolumus comprehendi ad cuiuscumque seu quorumcumque collationem, provisionem, electionem, presentationem seu quamvis aliam dispositionem etiam in dicta provincia Cantuariensi comuniter vel divisim spectantia, quorum fructus, redditus et proventus computatis illis, que pro ipso cardinali in illa provincia Eboracensi vigore prefate gratie acceptari continget octingentarum septuagintarum marcharum sterlingarum secundum taxationem decimae valorem annuum non excedant [...]. Fiat motu proprio ut petitur per omnia $R$. Villamnovam $X$ kl. Julii anno IV (22. Juni 1345).

235 Lettres Clément VI, n. 2143 (06.11.1345).

236 Ibid., n. 3536 (23.10.1347): [...] licet igitur cunctorum gravamina moleste feramus venerabilium tamen fratrum nostrorum S.R.E. cardinalium tanto ferentes molestius, quanto ipsi universalis Ecclesie onera nobiscum indefessis sollicitudinibus partiuntur [...] et quantum prefatus cardinalis tibi et regno tuo in tuorum apud Sedem eandem promotione favorabili agendorum et directione consilii, ac impensione favoris esse poterit [...]. Es entbehrt nicht einer gewissen Ironie, wenn der Papst in zeitgleich abgefaßten Schreiben neben Heinrich, dem Grafen von Lancaster und dem königlichen Kämmerer Bartholomäus de Burgassh auch die beiden Nuntien dazu auffordert, die Sache Kardinal Roberts vor dem König zu vertreten. Von unparteiischen Vermittlungsversuchen scheint man sich endültig verabschiedet zu haben, vgl. ibid., n. 3537. 
In immer neuen Variationen wurden von Papst und König dieselben Argumente hin- und hergewälzt, wurden die jeweiligen Standpunkte umrissen, ohne dabei wahre Konzessionsbereitschaft zum Ausdruck zu bringen. In dieser Hinsicht bemerkenswert ist der Brief Edwards III. an den Papst, datiert in Westminster am 26. September 1343, in dem die Position der englischen Seite argumentativ untermauert wurde, der König jedoch auch nicht davor zurückschreckte, die moralischen Qualitäten der Pfründeninhaber in schwärzesten Farben zu schildern ${ }^{237}$. Die fettesten Pfründen - so der König - würden unwürdigen und fremden Personen verliehen, für die Residenzpflicht ein fremdes Wort sei, die die Schafe ihrer Herde niemals zu Gesicht bekämen, der Landessprache nicht mächtig seien, insgesamt also die cura animarum vernachlässigten und wie Händler nur auf schnöden weltlichen Gewinn aus seien ${ }^{238}$. Die Kardinäle erschienen in der Darstellung des Königs nicht als Vertreter der höchsten innerhalb der catholitas zu erwerbenden Würde, sondern als unwürdige Krämer, deren Streben allein auf Gewinn ausgerichtet sei - ein zugegebenermaßen wenig schmeichelhaftes Bild der päpstlichen »Senatoren «.

Der Papst tat gut daran, die Opposition aus England nicht allein als Ausfluß königlicher Entscheidungsgewalt zu betrachten. Bereits in der Sitzung des Parliament vom 28. April 1343 hatten sich die Commons darüber beklagt, $\mathrm{daB} z \mathrm{zu}$ viele Ausländer Pfründen innehätten und dadurch nicht nur den Schatz der Nation verringerten, sondern auch Staatsgeheimnisse an deren Feinde verraten würden. Verbittert wurde bemerkt, daß es englischen Klerikern nur mit größten Anstrengungen gelänge, in den Besitz von Pfründen zu kommen ${ }^{239}$. Der König, offiziell zur Behebung dieses Mißstandes aufgefordert, war jedoch klug genug, den Vertretern des Parliament den Ball erneut zuzuspielen. Sie selbst - so der König - sollten für Abhilfe sorgen und den Papst über die getroffenen Verfügungen in Kenntnis setzen ${ }^{240}$. Unter Bezugnahme auf eine dieser bereits 1307 ergangenen Verfügungen über den Mißbrauch von Provisionen ${ }^{241}$ wurde eine Petition erlassen, die neben der Verurteilung der päpstlicherseits geübten Praxis auch konkrete Bestimmungen darüber enthielt, wie diese Mißstände zu beseitigen seien: Königliche Hafenbeamte wurden angewiesen, päpstliche Bullen oder Briefe, die dem engli-

237 Vgl. Walsingham, Chronica, S. 255-258. Der Brief präsentiert sich als Antwort auf das päpstliche Schreiben vom 28. August (Lettres Clément VI, n. 375; der Brief findet sich vollständig abgedruckt bei MURIMUTH, Continuatio, S. 149-151).

238 WALSINGHAM, Chronica, S. 256: [...] indignis ac alienigenis, plerumque nobis suspectis, qui non resident in dictis beneficiis, et vultus commissorum eis pecorum non agnoscunt, linguam non intelligunt, sed animarum cura neglecta, velut mercenarii solummodo temporalia lucra quaerunt.

239 Der Bischof von Exeter, John de Grandisson, hatte den Papst bereits im November 1342 auf die Mißstände aufmerksam gemacht, vgl. dazu LUNT, Financial relations, S. 327.

240 Rot. Parl., II, 141.

241 Vgl. Rot. Parl., I, 207, 219-221. Die Rede ist vom sog. Statute of Carlisle, vgl. dazu BARRELL, Papacy, S.131-133. 
schen Volk zum Schaden gereichten, keinesfalls ins Land zu lassen und deren Überbringer festzusetzen. Keiner dürfe mehr aufgrund päpstlicher Provisionen in den Besitz von Benefizien gelangen ${ }^{242}$. Der offizielle Brief an den Papst, datiert vom 18. Mai 1343 und in französischer Sprache abgefaßt, wies ausdrücklich auf den Schaden hin, der der Kirche Englands insbesondere im Bereich der cura animarum aus der obenerwähnten Praxis erwachsen sei. Nebenbei gab man dem Papst auch zu verstehen, daß das kollektive Gedächtnis der Nation doch so gut funktioniere, um mit Erstaunen das Anschwellen von Provisionen unter seinem Pontifikat zur Kenntnis zu nehmen ${ }^{243}$. Im Februar 1344 versuchte man aus dieser Petition ein statute, d.h. eine bindende Gesetzesverfügung, zu machen ${ }^{244}$.

Offensichtlich ging es also darum, an den Prokuratoren des Kardinals ein Exempel zu statuieren, der Kurie ins Bewußtsein zu rufen, daß exzessiver päpstlicher Machtanspruch im Bereich von Provisionen nicht unwidersprochen bleiben würde. Mit Kardinal Adémar Robert hatte man den Schuldigen gefunden: Purpurträger der Römischen Kirche ohne Bezug zur englischen Nation, Kardinal der zweiten Garnitur, d.h. ohne größere Einflußmöglichkeiten in Hinblick auf englische Belange, eine Kreatur des Papstes, bei der antienglisches Ressentiment vorausgesetzt wurde. Nicht vergessen werden sollte in diesem Zusammenhang, daß die gewählte Form des harschen, mit konkreten Maßnahmen verbundenen Protests dazu geeignet war, den aufgebrachten Volkszorn in die richtigen Bahnen zu lenken, die öffentliche Meinung also zugunsten des englischen Königs zu beeinflussen: politisch kluges Taktieren angesichts der geplanten Ausweitung kriegerischer Unternehmungen auf dem Festland. Tatsächlich zeigt ein Blick in die Fortsetzung der Chronik von Murimuth, in der der Bericht von der Festsetzung der Prokuratoren unmittelbar auf die Wiedergabe des an Clemens gerichteten Briefes folgt, daß dieser Bericht als Exempel für die unhaltbare Situation fungierte und die Notwendigkeit eines Einschreitens rechtfertigen sollte. Der Bericht klingt weniger dramatisch als die unmittelbare Reaktion des Papstes auf die Neuigkeit. Insbesondere die von den Prokuratoren erlittene Unbill wird mit nüchternen Worten beschrieben ${ }^{245}$.

242 Vgl. Rot. Parl., II, 144f.; am 20. Juli 1342 war den nicht aus England stammenden Empfängern päpstlicher Gratialbriefe für Pfründen in England verboten worden, auf Ausführung ihres verbrieften Anspruchs zu bestehen, vgl. C.P.R. 1343-1345, S.164f.; vgl. Andrew D. M. BARRELL, The ordinance of provisors of 1343, in: Historical Research 64 (1991) S. 264-277.

243 MURIMUTH, Continuatio, S. 138-142; Robert of AVESBurY, De Gestis mirabilibus regis Edwardi tertii, hg.v. Edward Maunde THOMPSON, London 1889, S. 353-355.

244 Vgl. C.P.R. 1343-1345, S. 279; vgl. hierzu auch Thomas ECKERT, Nichthäretische Papstkritik in England vom Beginn des 14. bis zur zweiten Hälfte des 15. Jahrhunderts, in: Annuarium Historiae Conciliorum 23 (1991) S. 116-359.

245 MURIMUTH, Continuatio, S. 142f.: Et quia papa providit duobus cardinalibus, nepotibus suis, uni videlicet de beneficiis vacaturis in Cantuariensi provincia usque ad mille marcas, et in provincia Eboracensi alteri de vacaturis beneficiis tantae summae, ac procuratores desti- 
Ein Appendix zu Murimuth liefert darüber hinaus einen Einblick in das, was unter der schwer faßbaren Rubrik "öffentliche Meinung " verbucht werden kann. Neben den beiden Kardinälen Adémar Robert und Gérard de Daumard rückt mit Élie Talleyrand de Périgord ein kardinalizisches Schwergewicht ins Blickfeld des Interesses. Der Wahrheitsgehalt des Berichts darf getrost als äußerst gering veranschlagt werden. Wahrheit wird auf einer anderen Ebene widergespiegelt: der Ebene des rumor ${ }^{246}$. Hier ist es die Darstellung eines zeitgenössischen »So könnte es gewesen sein «, wodurch der ansonsten schwer faßbare Bereich der öffentlichen Meinung zugänglicher wird. John of Shoreditch soll 1343 - so der Bericht - als Gesandter Briefe des Königs nach Avignon überbracht ${ }^{247}$ und die Verfügungen Edwards III. gegen die aspera et dura verba des Papstes verteidigt haben ${ }^{248}$. Auf die - nachweislich falsche Behauptung Clemens' VI., er habe überhaupt nur zwei Ausländern Benefizien in England zugewiesen, soll der Gesandte geantwortet haben: "Heiliger Vater, ihr habt dem Herrn Périgord das Dekanat von York übertragen, einem Mann, den der König und alle Adligen Englands als Hauptfeind des Königreichs betrachten $\aleph^{249}$. Die geschilderte Aufregung auf seiten von Papst und Kardinälen über diesen allen diplomatischen Usancen zuwiderlaufenden Vor-

nati per cardinales eosdem nonulla beneficia, virtute hujus gratiae, acceptarunt, fuerunt dicti procuratores coram cancellario regis et aliis justiciariis regisque concilio convocati, et ad responsionem positi quomodo et qua audacia et quibus literis de conductu Angliam intrarunt et tam prejudicialiter regi et regno temere acceptarunt. Qui respondebant quod auctoritate domini papae et literarum / ipsius, pro negociis dictorum cardinalium prosequendis, regnum intrarunt et beneficia, de quibus ut premittitur, acceptarunt. Et, quia praefata responsio non fuit sufficiens reputata, fuerunt ipsi attachiati et custodiae vicecomitis Londoniarum deputati. Sed finaliter fuit eis inhibitum ne talia de cetero attemptarent, et mandatum eisdem quod infra certum diem sub salvo conductu regnum exirent. Quod et factum fuit circa festum sancti Jacobi apostoli. Die Angelegenheit des anderen betroffenen Kardinals Gérard de Daumar erledigte sich auf natürlichem Weg: er starb hochverschuldet bereits 1343, vgl. Lettres Clément VI, n. 482 (23.10.1343); vgl. des weiteren zur Angelegenheit ibid., nn. 375-377, 393f., 485, 1169.

246 Dieser rumor ist Gegenstand eines weitverbreiteten Verses in England, der innerenglische Befindlichkeiten widerspiegelt und Einblick in die Vorstellungswelt einer breiteren Öffentlichkeit gewährt: Ore est le Pape devenu Franceys, E Jesu devenu Engleys. Ore serra veou que fra plus, Ly Pape ou Jesu, zit. in William Abel Pantin, The English Church in the fourteenth century, Cambridge 1955, S. 82.

247 Vgl. MURIMUTH, Continuatio, S. 143f.; vgl. William CAPES, The English Church in the fourteenth and fifteenth centuries, London 1909, S.88.

248 Auch im Bericht der englischen Gesandten von 1344 ist von einem aspere loqui des Papstes die Rede. Das Beharrungsvermögen der englischen Seite läßt Clemens VI. emotionaler als gewohnt reagieren.

249 MURIMUTH, Appendix, S. 230: Et dictus dominus Johannes, in praesentia omnium cardinalium, respondit: „Pater sancte, providistis de decanatu Eboracensi domino Petragoricensi, quem rex et omnes proceres regni Angliae reputant capitalem inimicum regis et regni*. Die Bedeutung dieses Vorfalls wird noch dadurch unterstrichen, daß omnes cardinales anwesend sind. Die Provision Talleyrands mit dem Dekanat von York und die Durchsetzung seiner Ansprüche gegen den königlichen Kandidaten Philip de Weston gehört sicherlich nicht zu den Glanzleistungen des Pontifikats Clemens' VI., vgl. Rot. Parl., II, S. 154. 
fall ist verständlich. Während der Papst von angemessener Antwort raunt, ziehen es die Kardinäle vor, aufgeregt und bestürzt von dannen zu ziehen. Auch der Gesandte fühlt sich nicht mehr wohl in seiner Haut: Um Schwierigkeiten aus dem Weg zu gehen, verläßt er umgehend Avignon ${ }^{250}$. Als Quintessenz dieses Berichts kann somit die Feststellung gelten, daß man der Kurie vieles zutraute, man sogar so weit ging, ihr einen solchen $\mathrm{Ha} \beta$ gegenüber England zu unterstellen, daß selbst Todfeinde der Nation von ihr für würdig befunden wurden, sich am sprudelnden englischen Benefizienquell zu erquicken. Murimuth erwähnt eine Sentenz, die die englischen Befindlichkeiten deutlich macht. Unter den Kurialen des Heiligen Stuhls - so der Chronist - habe sich das Bonmot verbreitet, die Engländer seien gutmütige Esel, denen man bedenkenlos die schwersten Lasten auferlegen könne ${ }^{251}$.

Alle getroffenen Maßnahmen richteten sich gegen Ausländer: Die Angriffe auf Kardinal Robert waren im Grunde genommen nicht ad personam gerichtet, sondern reichten in ihrer Tragweite sehr viel weiter. Adémar Robert hatte lediglich das Unglück, zur Unzeit mit lukrativen Pfründen bedacht worden zu sein, aus Südfrankreich (wenn auch aus Aquitanien) zu stammen und dem Kardinalskollegium anzugehören. Er wurde zur Zielscheibe von Angriffen, nicht weil er Adémar Robert war, sondern weil sich mit ihm als Kardinal Adémar Robert gezielt Angriffe gegen das komplexe System kurialer Pfründenvergabe richten ließen ${ }^{252}$. Warum stieß die unter Clemens VI. geübte Praxis auf besonderen Widerstand, wo doch sein Vorvorgänger Johannes XXII. in sehr viel umfangreicherem Maße von päpstlichen Reservationsrechten $\mathrm{Ge}$ brauch gemacht hatte? Es gibt dafür mehrere Gründe: England lag mit Frankreich seit 1338 im Krieg, einer Nation, der sich der Papst in besonderer Weise verbunden fühlte; daneben war seine Freigiebigkeit in beneficiis weitaus gröBer als die seines Vorgängers Benedikt XII. Schließlich waren einige seiner Provisionen, die unter Umgehung der örtlichen Bischöfe und Kapitel vorgenommen wurden, unklug und gaben zu Widerspruch Anlass.

Daß Edward III. an einer grundsätzlichen Änderung päpstlicher Provisionspolitik gelegen war, darauf deutet eine weitere Verfügung hin. Am 8. Juli

250 MURIMUTH, Appendix, S. 230: Cardinales vero, his auditis, de palatio recesserunt, quasi commoti et desolati. Ac idem dominus Johannes, capta domini papae licentia, exivit similiter a camera, et absque mora aliqua festinavit se ab Avinione [...].

251 MURIMUTH, Chronica, S. 175: Unde inter curiales sedis apostolicae vertitur in proverbium quod Anglici sunt boni asini, omnia onera eis imposita et intolerabilia supportantes.

252 BARRELL, Papacy, S. 137, urteilt treffend: "[...] the scale of the problem was exaggerated by contemporaries. It was the high profile of some of the beneficiaries, and their reputedly anti-English attitude, which explain the strength of feeling against them «; WAUGH, England in the reign of Edward III, S.136-153. Deutlich wird aus den Untersuchungen von Waugh, daß das ausländische Element von Edward III. bewußt instrumentalisiert und in seiner Bedeutung übertrieben dargestellt wurde, allerdings mit einer Ausnahme: den Kardinälen. Zwischen 1305 und 1334 erhielten 29 Kardinäle 103 Benefizien, darunter 39 Pfarrkirchen. Zwischen 1349 und 1378 waren 38 Kardinäle im Besitz von 128 Benefizien, darunter nur 14 Pfarrkirchen, vgl. ibid., S. 145. 
1343 wies er seine Bischöfe an, Listen mit den Namen all derjenigen Ausländer zu erstellen, die in England bepfründet waren ${ }^{253}$, was seinem Vorgehen einen durchaus xenophoben Anstrich gab. Er ging jedoch noch weiter: Bald wurde auch die Rechtmäßigkeit päpstlicher Provisionen für englische Benefiziaten bestritten und die Vorlage entsprechender Dokumente unter Strafe gestellt $^{254}$. Nur noch aufgrund spezieller königlicher Mandate sollten die Bischöfe Benefizien verleihen. Der Anspruch Edwards III. ging weit. In allen folgenden Sitzungen des Parliament stand die genannte Problematik weit oben auf der Tagesordnung. Ihre tatsächliche Konkretisierung mittels rechtlicher Verfügungen war jedoch stets maßgeblich von der politischen Großwetterlage abhängig. Pfründenvergaben an Kardinäle waren durchaus noch möglich - auch wenn wenig Aufhebens davon gemacht wurde ${ }^{255}$. Selbst Kardinal Robert konnte von der Ende 1345 einsetzenden Entspannung profitieren. 1349 wurde ihm die Erlaubnis erteilt, den Archidiakonat von East Riding durch Prokuratoren visitieren $\mathrm{zu}$ lassen und die entsprechenden Einkünfte daraus zu beziehen ${ }^{256}$.

Als Folge der Pest war von 1348 bis 1350 nicht nur militärisches Operieren sinnlos geworden ${ }^{257}$. Erst gegen Ende des Pontifikats Clemens' VI. wurde der alte Streit erneut virulent. Mit dem Statute of Provisors, verabschiedet im Februar 1351, erreichte die antipäpstliche Gesetzgebung in England einen neuen Höhepunk $\mathrm{t}^{258}$. Wie diese Verfügung in Avignon aufgenommen wurde, ist angesichts fehlender Registereinträge, insbesondere jedoch wegen des Schwei-

253 C.C.R. 1343-1346, S.224; zu den anderen Maßnahmen C.P.R. 1343-1345, S.164f.; C.C.R. 1343-1346, S. 220 (erneuert am 30. Januar 1344), vgl. C.C.R. 1343-1346, S.356f.

254 C.C.R. 1343-1346, S. 247.

255 Vgl. die Beschwerde der Commons im Parliament vom Januar 1348, in: Rot. Parl., II, 171. Die Beschwerde richtete sich höchstwahrscheinlich gegen die Providierung von Kardinal Annibaldo Ceccano mit der Thesaurarie der Kathedrale von York, vgl. RYMER, Foedera, III, S. 190; C.P.R. 1348-1350, S. 408f. Als pragmatisch denkender Politiker kümmerte sich Edward III. nur wenig um die Befürchtungen der Commons. Im September 1348 gewährte er dem Kardinal von Beaufort, d.h. Pierre Roger de Beaufort, dem neukreierten Neffen des Papstes, die Erträge des Archidiakonats von Canterbury, vgl. C.P.R., VIII, S. 191.

256 C.P.L., III, S. 289.

257 William M. ORMroD, The English Government and the Black Death of 1348-49, in: England in the $14^{\text {th }}$ century, hg. v. William M. ORMROD, Bury St. Edmonds 1986, S. 175-189; vgl. hier auch die eindrückliche Beschreibung der in Avignon und im Comtat Venaissin wütenden Pest durch den Leibarzt des Papstes GuY DE CHAuliac, Inventarium sive Chirurgia magna, hg. v. Michael R. MCVAUgH, 2 Bde., Leiden, New York u.a. 1997.

258 Vgl. Cecily Davies, The statute of provisors, in: History 38 (1953) S. 116-133; Frederic CheyeTte, Kings, courts, cures and sinecures. The statute of Provisors and the common law, in: Traditio 19 (1963) S. 295-349. Die Bestimmungen des Statute of Provisors - schwere Strafen für all diejenigen, die beabsichtigten, zum Nachteil der königlichen Rechte ein Verfahren an fremden, d.h. päpstlichen Gerichtshöfen, anzustrengen - wurden 1353 durch das Statut Praemunire ergänzt, das all denjenigen Ächtung und Verlust sämtlicher Besitzungen androhte, die nicht innerhalb von zwei Monaten überzeugend darlegen konnten, weshalb sie außerhalb des Landes um Rechtsmittel nachgesucht hatten. 
gens der chronikalen Überlieferung, nicht mehr auszumachen ${ }^{259}$. Man ließ sich auf jeden Fall mit einer entsprechenden Reaktion Zeit. Härteres Vorgehen ist erst ab Juni 1352 belegbar ${ }^{260}$. Der Tod Clemens' VI. am 6. Dezember 1352 machte die Drohungen mit Interdikt und Exkommunikation obsolet.

\author{
5.1.8. En ce temps traveillerent les II cardinaulx: \\ die Kardinäle Annibaldo Ceccano und Étienne Aubert als Vermittler \\ im Konflikt zwischen England und Frankreich (1345-1347)
}

Nachdem die Konferenz von Avignon ohne Ergebnisse geblieben, ja im Sande verlaufen war, zogen sich die beiden verfeindeten Parteien indigniert zurück. Verletzungen des Waffenstillstands auf beiden Seiten waren zwar an der Tagesordnung und zogen stereotype Protestnoten nach sich ${ }^{261}$, insgesamt waren die Jahre 1344 und 1345 jedoch eine Zeit des Stillhaltens und des Lauerns, die zu verstärkter Rüstung, aber auch zur Beeinflussung der öffentlichen Meinung genutzt wurde ${ }^{262}$. Der Ausbruch neuer Kampfhandlungen in der Guyenne im Juni 1345 bedeutete das Ende des 1343 in Malestroit ausgehandelten Vertrags ${ }^{263}$. Edward III. nutzte die Gunst der Stunde, landete am 12. Juli 1346 bei Cherbourg, verwüstete die Normandie, rückte bis in die Nähe von Paris vor und errang - vom französischen König verfolgt und von diesem am 26. August des Jahres zur Entscheidungsschlacht gedrängt - bei Crécy einen überwältigenden Sieg über die Truppen Frankreichs. Die Verluste auf französischer

259 Vgl. Barrell, Papacy, S. 141-143.

260 Vgl. Lettres Clément VI, nn. 5431 (15.10.1352), 5448 (02.11.1352); LUNT, Financial relations, S. 337. Eine Art »Zwangsverwaltung « der Pfründenmasse einiger Kardinäle ist ab 1351 belegbar, vgl. C.P.R, IX, S. 178, 301f., 362.

261 Vgl. RyMER, Foedera, V, S. 448f. (24.04.1345), S.453f. (26.05.1345): Edward III. unterstreicht hier zum einen seine Gutwilligkeit vor dem Hintergrund einer vermeintlichen Falschheit des französischen Königs, verweist zum anderen jedoch auch auf die Rolle des Papstes beim Zustandekommen des Waffenstillstands, impliziert damit also eine Verantwortung der Kurie für die Einhaltung des Abkommens über die eigentliche Unterzeichnung hinaus: Et cum ibidem in expeditione guerrae nostrae ageremus, supervenerunt, reverendi patres, $P$. Penestrini et $A$. Tusculani, episcopi cardinales, vestri et sedis apostolicae nuncii, de treugis, cum praefato Philippo ad tempus, infra quod coram Sanctitate vestra tractari posset de pace finali, ineundis, ex parte dictae Sanctitatis, cum instantia nos rogantes, aicientesque quod eadem Sanctitas crederet invenire viam, per quam pax posset commode reformari. Auch die an der Unterzeichnung des Vertrags beteiligten Nuntien, Annibaldo Ceccano und Pierre Desprez, werden von Edward III. an ihre Verantwortung erinnert, vgl. ibid., S. 454f. (26.05.1345). Interessanterweise werden sie, zusammen mit Talleyrand de Périgord und Raymond de Farges, als amici nostri bezeichnet.

262 Ibid., S. 496-498 (15.03.1346), wo Edward III. dem Provinzial der englischen Dominikaner die Gründe für den Krieg gegen Frankreich erläutert. Die Pflege der öffentlichen Meinung durch den König war insbesondere in Hinblick auf die Orden von größter Wichtigkeit, weil sie es waren, die aufgrund ihrer supranationalen Ausrichtung und dem daraus resultierenden Informationsvorsprung am ehesten Zweifel an der Legitimität des königlichen Vorgehens hätten artikulieren können.

263 Vgl. Lettres Clément VI, nn. 1969, 2018-2026. 
Seite waren immens: Mehrere tausend Männer fielen in einem Kampf, in dem die Überlegenheit der englischen Bogenschützen über ihre traditionell bewaffneten Gegner wirkungsvoll unter Beweis gestellt wurde 264 .

Die Kurie wurde von dieser Entwicklung nicht überrascht. Bereits im April 1345 hatte Edward III. den französischen König angeklagt, den unter Vermittlung des Papstes zustande gekommenen Waffenstillstand in der Bretagne gebrochen zu haben ${ }^{265}$. In Avignon reagierte man schnell, denn wollte man ein Übergreifen der Kämpfe auf andere Gebiete verhindern, war in der Tat energisches Handeln gefragt. Daß man sich dazu entschloß, erneut zwei Kardinäle im Range von Nuntien zu entsenden, kann kaum erstaunen. Die Tatsache, daß man mit Annibaldo Ceccano auf einen Diplomaten zurückgriff, der als Vermittler des Waffenstillstands von Malestroit besser als jeder andere sowohl die Schwierigkeiten als auch die Möglichkeiten zu ihrer Beseitigung kannte, muß als kluge Personalentscheidung gewertet werden. Ihm zur Seite gestellt wurde Kardinal Étienne Aubert, der von Clemens VI. am 20. September 1342 zum Kardinalpresbyter tit. SS. Johannis et Pauli kreiert worden war. Die Übernahme dieser Gesandtschaft war für ihn die erste Bewährungsprobe im Dienste der Kirche. Die Gründe dafür, daß ausgerechnet Étienne Aubert an die Stelle des erfahrenen Vizekanzlers Pierre Desprez trat, werden weder in der kurialen noch in der chronikalen Überlieferung genannt. Gesundheitliche

264 An Spezialuntersuchungen zur Schlacht von Crécy sind zu nennen: Jean VIARD, La campagne de juillet-aout 1346 et la bataille de Crécy, in: Moyen Âge 27 (1926) S. 1-84; Alfred Burne, The Crecy War. A military history of the Hundred Years War from 1337 to the Peace of Brétigny, London 1955; Philippe ConTamine, Crécy (1346) et Azincourt (1415): une comparaison, in: Divers aspects du Moyen Age en Occident. Actes du Congrès Calais (sept. 1974), Paris 1977, S.29-44; John F. FulleR, Les batailles de l'Écluse et de Crézy, in: Les batailles décisives du monde occidental, Paris 1980, S. 211-230; SUMPTION, II, S.527-536; Andrew AYton, Philip Preston (Hg.), The battle of Crécy (1346), Woodbridge 2005; zur Darstellung in der Chronistik allgemein AYTON, Crécy and the chronicles, S. 287-350; Walsingham, Chronica, S.267-269 und vor allem FroissarT, Euvres, V, S.27-75, dem wir die ausführlichste Darstellung des Kampfgeschehens verdanken. Vgl. zu Person und Werk Froissarts v. a. Michel Zink, Froissart et le temps, Paris 1998; des weiteren Christopher T. Allmand, Historians reconsidered: Froissart, in: History Today 16 (1966) S. 91-113; Georg JÄGER, Aspekte des Krieges und der Chevalerie im XIV. Jahrhundert. Untersuchungen zu Jean Froissarts Chroniques, Bern 1981; Peter F. AINSwORTH, Jean Froissart and the fabric of history. Truth, myth, and fiction in the Chroniques, Oxford 1990. Die Beschreibung Froissarts wurde von Shakespeare bei der Abfassung seines Stükks über den englischen König benutzt, vgl. William SHAKESPEARE, Edward III., hg. v. Giorgio MelCHIORI, Cambridge 1998; dt. Übersetzung von Ludwig TIECK, Neuausgabe Buchholz 1998. Auf der Bühne werden nicht nur zeitlich weit auseinanderliegende Ereignisse eng zusammengerückt, sondern auch die handelnden Personen geschichtswidrig gruppiert. Shakespeare - bzw. mit ihm mehreren anonymen Verfassern - geht es um Massenwirksamkeit: deshalb liegt die Betonung auf Aspekten wie Kriegsverherrlichung, Diskreditierung anderer Personen oder dem Preis von Heldenmut und Opferbereitschaft.

265 Vgl. RYMER, Foedera, III, S. 36; vgl. auch Martin Jones, Edward III's Captains in Brittany, in: England in the $14^{\text {th }}$ century, hg. v. William M. ORMROD, Bury St. Edmunds 1986, S. 99-118. 
Gründe dürften jedoch nicht den Ausschlag gegeben haben: Der Vizekanzler versah sein Amt noch bis 1361, dem Jahr seines Todes. Eher drängt sich der Gedanke auf, der Papst habe dem machtbewußten und ungemein einflußreichen Kardinal nicht noch mehr an Ansehen und Einfluß zugestehen wollen. Der Papst bediente sich mit Étienne Aubert einer seiner eigenen "Kreaturen«, griff also auf das von ihm selbst geschaffene personelle Reservoir zurück.

Die Ernennungsbulle datiert vom 31. Oktober $1345^{266}$. Bereits drei Tage zuvor waren der König und die Königin von Frankreich und deren Sohn Jean, Herzog der Normandie, von der Entsendung in Kenntnis gesetzt worden ${ }^{267}$, wobei im Brief ap die Königin die Tatsache unterstrichen wurde, daß es sich bei Étienne Aubert um eine der Sache Frankreichs ergebene Persönlichkeit handle ${ }^{268}$. Die Frage liegt nahe, weshalb der Papst meinte, ausgerechnet diesen Aspekt betonen zu müssen. Die Bemerkung, sollte sie mehr als ein rhetorischer Allgemeinplatz sein, gewinnt erst dann an Aussagekraft, wenn man aus ihr schließen darf, daß der zweite Gesandte, Kardinal Annibaldo Ceccano, dem französischen König reservierter gegenüberstand ${ }^{269}$. Die Ernennung des Étienne Aubert könnte dann der Absicht des Papstes entsprungen sein, das politische Gleichgewicht an der Spitze der Gesandtschaft auszubalancieren oder gar zugunsten Frankreichs zu verschieben.

Die den Kardinälen übertragenen Aufgaben waren dreifacher Natur: Die aktuellen kriegerischen Akte sollten unterbunden, ein dauerhafter Friedensvertrag vermittelt und in jedem der beiden Staaten Angriffe gegen kirchliche Freiheiten verhindert werden ${ }^{270}$. Wie bereits 1342 verzichtete der Papst auf eine Ernennung der beiden zu Kardinallegaten: ihre Aufgaben sollten sie im Range von Nuntien wahrnehmen. Ein breitgefächerter Bestand an Fakultäten sollte den Spielraum der Mission erweitern ${ }^{271}$. Um den Nuntien eine Demütigung wie diejenige zu ersparen, die Edward III. 1343 den Gesandten durch das Verbot der Einreise nach England zugefügt hatte, sandte Clemens VI. am 26. Oktober 1345, also vier Tage vor Veröffentlichung der Ernennungsbulle, ein Schreiben an Raimundus Pelegrini, seinen Nuntius in London, und bat ihn, beim englischen König freies Geleit für die beiden Kardinäle zu

266 Lettres Clément VI, n. 2076.

267 Ibid., nn. 1850-1852.

268 Ibid., n. 1850: Scimus quidem ab experto prefatum Stephanum cardinalem, esse, ac fuisse honoris et comodi regii fervidum zelatorem.

${ }^{269}$ Immerhin hatte Edward III. Annibaldo bereits $1334 \mathrm{zu}$ seinem consiliarius mit dem Anrecht auf eine jährliche Rente von 50 Mark Sterling ernannt, vgl. DyKMANS, Annibal de Ceccano, S. 179.

270 Lettres Clément VI, nn. 2077-2081.

271 Ibid., nn. 2082-2135, 2194-2196, 2201f. Gleichzeitig werden sämtliche politisch einflußreichen Persönlichkeiten der beiden Königreiche und Flanderns in gesonderten Schreiben dazu aufgefordert, den beiden Nuntien jedwede Unterstützung zukommen zu lassen, ibid., nn. 2158-2169, 2190. 
erwirken $^{272}$. Am 28. Oktober wurde Edward noch einmal aufgefordert, von weiteren kriegerischen Akten in der Guyenne zumindest so lange Abstand zu nehmen, bis die beiden Kardinäle zu einer persönlichen Unterredung mit ihm in der Lage gewesen seien ${ }^{273}$. Dabei wurde davon ausgegangen, ein Übersetzen des Königs auf das Festland stünde unmittelbar bevor. Mit der Abreise von der Kurie hatten es die Kardinäle nicht eilig. Erst am 26. November verließen sie Avignon in Richtung Norden 274.

In einem drei Tage später vom Papst verfaßten Schreiben wurde ihnen nochmals eingeschärft, zunächst alles dafür zu tun, den brüchigen Waffenstillstand wiederherzustellen. Deutlich wird, daß der Papst nicht allein aus realpolitischen Erwägungen die Bedeutung dieses Abkommens - seines ersten diplomatischen Erfolgs - überschätzte. Sein Bruch mußte die diplomatischen Fähigkeiten und den politischen Einfluß der Kurie in ein ungünstiges Licht rücken und die Ausgangsbasis für zukünftige Verhandlungen erschüttern, wenn nicht gar zerstören. Explizit wurden die Kardinäle auf die processus, im Extremfall sogar auf Kirchenstrafen wie Interdikt und Exkommunikation, die durchaus auch gegen die jeweiligen Souveräne Anwendung finden sollten, hingewiesen ${ }^{275}$. Das Engagement des Papstes in epistolis, die flankierende Begleitung und Unterstützung der Mission mittels päpstlicher Schreiben, präsentierte sich im Vergleich zu 1343 sehr viel umfangreicher und zielgerichteter. Clemens VI. schien aus der Erfolglosigkeit und den Schwierigkeiten der bis dato von der Kurie initiierten Gesandtschaften und Legationen gelernt zu haben. Er war es selbst, der den englischen König um freies Geleit für seine Gesandten bat ${ }^{276}$, allerdings vergeblich: Am 11. März 1346 mußte er ihnen entschuldigend mitteilen, Edward III. habe auf das Ausstellen von Begleitbriefen verzichtet und sein baldiges Übersetzen auf das Festland angekündigt ${ }^{277}$. Das

272 Ibid., n. 2070. Ob mit Raimundus Pelegrini die Wahl des Papstes auf die richtige Persönlichkeit fiel, muß bezweifelt werden, hatte sich Edward III. doch bereits am 26. Mai über die nicht näher ausgeführten excessus dieses Nuntius bitter beklagt, vgl. RYMER, Foedera, V, S. 453f.: [...] ut taceamus de excessibus per nuncium Sanctitatis vestrae, prium pro conservatione treugarum predictarum missum in Britanniam, perpetratis; qui quod sedasse debuit diffidium propensius excitavit, non conservatorem treugarum, sed partem contra nos et nostros potius se ostendens; super quo Sanctitas vestra (salva pace sua) remedium non adhibuit [...]. Der englische König hatte also keinen Grund, dem Papst irgendwelche Gefälligkeiten zu erweisen.

273 Lettres Clément VI, n. 2074.

274 Vgl. Dykmans, Annibal de Ceccano, S. 222.

275 Lettres Clément VI, n.2173f. Zum Begriff processus vgl. DDC 7 (1965), Sp. 309-311 (R. NAZ); Lexicon mediae et infimae latinitatis Poloniae, Bd. 7, Sp. 1211-1216.

${ }^{276}$ Lettres Clément VI, n. 2177 (01.12.1345). Der Papst betont seine eigene Bescheidenheit und reiht sich in eine Traditionslinie ein, wenn er unterstreicht, daß er lediglich mit denjenigen Briefen um freies Geleit nachsuche, die in forma solita olim aliis cardinalibus illuc missis gewährt worden seien. Auf das Jahr 1343 kann er sich hier wohl kaum beziehen. 277 Ibid., n.2358: [...] regem excusavit prefatum, asserens quod ex eo litteras vobis de conductu non miserat nec mittebat, quia ipse in propria persona intendebat in proximo citra mare transire. 
bereits bekannte Muster wiederholte sich: Mit allen Mitteln versuchte der englische König, die päpstlichen Diplomaten von seinem Territorium fernzuhalten. $\mathrm{Da} \beta$ er dies mit sehr fadenscheinigen Gründen tat - immerhin erfolgte die Landung erst vier Monate später - dürfte nicht dazu beigetragen haben, die Bereitschaft der Kurie, zu seinen Gunsten zu vermitteln, zu fördern. Die Kardinäle ließen sich nicht entmutigen und ergriffen selbst die Initiative, ohne dabei freilich ein anderes Ergebnis zu erzielen: auch ihnen wurde derselbe Bescheid gegeben $^{278}$. Dabei vermied es Edward III., die Nuntien vor den Kopf zu stoßen. Er entschuldigte sich mit dem Hinweis auf große Arbeitsüberlastung und auf die notwendige, aber noch nicht erfolgte Abstimmung mit den Verbündeten gemeint waren insbesondere die Flamen -, ohne die verbindliche Friedensgespräche nicht möglich seien ${ }^{279}$. Einer Bitte war jedoch bereits zuvor entsprochen worden: Aus rein informativen Gründen hatte Edward III. in die Entsendung einfacher Nuntien ohne jede Verhandlungsvollmacht eingewilligt ${ }^{280}$. Daß jedoch einer persönlichen Unterredung mit Edward III. vom Papst höchste Priorität eingeräumt wurde, wird aus einem an die Gesandten gerichteten Brief vom 22. März des Jahres deutlich. Da Edward genausogut in der Guyenne wie in Flandern an Land gehen könne - der Papst gesteht ein Informationsdefizit ein, das ein unmittelbares Handeln der Gesandten erschwere -, halte er es für besser, die Gesandten würden nicht in Arras bleiben ${ }^{281}$, sondern sich nach Chartres begeben, das nicht nur auf halbem Wege zwischen Flandern und der Gascogne, sondern auch näher an der Bretagne und der Normandie liege ${ }^{282}$.

Noch rund drei Monate später zeugen die Briefe des Papstes von Unsicherheit und Ratlosigkeit hinsichtlich der zu wählenden Verhandlungsstrategie.

278 Brief vom 2. Juli 1346, in: RYMER, Foedera, III, S.84.

279 RYMER, Foedera, V, S.517f. (02.07.1346), vgl. zum Bedeutungsspektrum des Begriffs »alliance«, insbesondere zur Zeit des Hundertjährigen Krieges, die Dissertation von Nathalie NABERT, Les réseaux d'alliance en diplomatie aux XIVe et XVe siècles. Étude de sémantique, Thèse université de Paris-Sorbonne 1994.

280 RYMER, Foedera, V, S.511 (20.04.1346): [...] ad insinuandum et exponendum eisdem ordinatam voluntatem nostram in hac parte, et ad audiendum, reportandum et referendum nobis quae dicti patres dicere, facere vel ostendere voluerint in praemissis. Den Flamen wird zwei Tage später mitgeteilt, die Kardinäle hätten deshalb um Entsendung dieser Nuntien gebeten, weil ihnen der Weg nach England selbst verwehrt sei und sie schon zu viel Zeit mit unnützem Warten vergeudet hätten, ibid., S. 512.

281 Aegidius li Muisis, Chronica, in: Corpus Chronicorum Flandriae, hg. v. Joseph Jean de SMET, Bd. 2, Brüssel 1841, S. 218-289, hier S. 239: Anno MCCCXLVI venerunt duo cardinales, dominus Hannibal et dominus de Claromonte, et fecerunt moram per longum tempus Attrebati, euntes pluries ad regem Franciae et regem Angliae, laborantes et tractantes de pace et longo tempore ibi remanentes.

282 Lettres Clément VI, n. 2390. Strategisch relevante Informationen werden auf englischer Seite vertraulich behandelt. Das hilflose Agieren der Kardinäle, die in dieser Situation anstelle eigenverantwortlichen Handelns eine zeitaufwendige Rückbindung an die Kurie vorziehen - a nobis quid vos velimus ulterius facere petiistis -, zeugt vom eklatanten Mangel an informationstechnischen Möglichkeiten, anders ausgedrückt: über Spione im näheren Umfeld des englischen Königs schien man nicht zu verfügen. 
Man meint, einen verärgerten Unterton herauszuhören, wenn Clemens VI. unterstreicht, auch andere politische Probleme hätten Anrecht auf seine Aufmerksamkeit ${ }^{283}$. Erst Anfang August - die Nachricht von der Landung des Königs war durch Briefe der Kardinäle bis nach Avignon gedrungen - entfaltete die Kurie wieder ernstzunehmende diplomatische Aktivitäten. Edward III. wurde über das Kommen der Kardinäle unterrichtet ${ }^{284}$, die Gesandten zu besonnenem und eigenverantwortlichem Handeln, das jedoch nicht in völlige Beliebigkeit ausarten dürfe, aufgefordert ${ }^{285}$. Diplomatie mußte - so zumindest die Auffassung der Kurie - berechenbar sein und hatte auf alles Sprunghafte zu verzichten. Sie hatte sich in von der Tradition vorgezeichneten Bahnen zu bewegen, mußte also bereits ergangene Entscheidungen und vollzogene Entwicklungen in die anstehenden Überlegungen miteinbeziehen. Um dies den Gesandten noch einmal ins Gedächtnis zu rufen, verfaßte der Papst ein umfangreiches Memorandum, in dem der Verlauf des Konflikts und die von der Kurie bereits unternommenen Schritte knapp dargestellt und bewertet wurden ${ }^{286}$. Angesichts des rhetorischen Aufwands erstaunt es, daß der historische Rückblick des Papstes selektiv ausfiel. Die Konferenz von Avignon 1344, deren Scheitern spätestens jetzt, gleichsam ex silentio, eingeräumt wurde, fand mit keinem Wort Erwähnung. Deutlich wurden jedoch antienglische Ressentiments, die sich in aussagekräftigen Worten verdichteten. Die Hauptschuld am Bruch des Waffenstillstands wurde der englischen Seite zugeschrieben: als Aggressor galt der englische König. Dennoch wollte der Papst eingedenk seines Amtes als Friedensbringer wirken: Er bediente sich seiner Nuntien als ausführender Organe ${ }^{287}$.

${ }^{283}$ Lettres Clément VI, n. 2596: Super hiis [...] per nos diligentius intellectis certis causis suadentibus, deliberare omisimus, et etiam respondere presertim quia eramus, sicut adhuc sumus, magnis diversis arduis aliis negociis, propter guerras et dissensiones que in Alamannia, Sicilia, Lombardia et aliis diversis mundi partibus ingruunt multipliciter impediti [...].

284 Ibid., n. 2694 (03.08.1346).

285 Ibid., n. 2695. Die Kardinäle müssen sich erneut hilfesuchend an den Papst gewandt haben, antwortet dieser doch mit Entschiedenheit: Super aliis vero que dicte littere continebant breviter respondemus, quod vos, qui estis in scola experientie constituti, melius scire potestis, quid sit, secundum illa que occurrunt, presentialiter in illis partibus faciendum, quamobrem juxta potestatem vobis traditam secundum datam vobis a Deo prudentiam, sicut utilius et expedientius, attentis statu et qualitate negociorum emergentium videritis, procedatis.

286 Ibid., n. 2726 (14.08.1346).

287 Ibid.: Nichilominus pervigili studio pacis et concordie reformande inter reges prefatos invicem vacaturi negocio et circa id sedulis ministerii vestri efficaces opem et operam, prout vobis Altissimus ministraverit, et facultas adherit impensuri [...]. Verum quia negocium reformationis pacis et concordie hujusmodi adeo insidet cordi nostro quod nullo modo, quantum in nobis, auxilio assistente divino, fuerit, relinquere volumus imperfectum, reges prefatos tenore presentium requirimus ac per vos etiam verbaliter aut litteraliter, prout expedire cognoveritis, requiri, rogari, moneri et obsecrari volumus et mandamus ut innumerabile bonum pacis ac guerrarum et dissensionum dispendia innumera, quibus irritatur majestas divina graviter, diligentius attendentes ad reformationem ejusdem pacis et concordie inter vos mutue benignis animis et piis mentibus se inclinent effectualiter, et disponant. 
Das nächstliegende Ziel war die Verlängerung des alten bzw. der Abschluß eines neuen Waffenstillstands, der als Grundlage für weitere Friedensverhandlungen dienen sollte. Konkrete Ausführungsbestimmungen gab der Papst seinen Gesandten nicht mit auf den Weg. Daß er an eine parallele Verhandlungsführung dachte - ein Kardinal führt die Verhandlungen auf englischer, der andere auf französischer Seite -, wird aus dem Memorandum ersichtlich $^{288}$. Der Hypothese, die Kardinäle hätten eine vom Papst intendierte gegenseitige Kontroll- und Überwachungsfunktion wahrnehmen sollen, dürfte damit der Boden entzogen sein. Zum Zeitpunkt der Abfassung des Memorandums hatte bereits bei Lisieux ein Treffen der Nuntien mit dem französischen König stattgefunden ${ }^{289}$. Als am französischen Hof Zweifel an den Fähigkeiten der Kardinäle laut wurden, fühlte sich Clemens VI. genötigt, ihnen zur Seite zu stehen. In einem Brief vom 27. August 1346, den er drei Tage nach der Katastrophe von Crécy an die Königin von Frankreich richtete, gab er seinem Unwillen darüber Ausdruck, da $\beta$ die verfahrene Situation den Kardinälen angelastet werde ${ }^{290}$. Der Papst war klug genug, zu wissen, daß die gegen die Nuntien erhobenen Vorwürfe gleichzeitig auch die Kurie, damit ihn selbst, $\operatorname{trafen}^{291}$. Die Schuld an der gegenwärtigen Lage wollte er weder sich selbst

288 Ibid.: [...] vobis quos ad tam grandis tamque necessarie utilitatis opus ferventibus una nobiscum desideriis affici novimus, de ipsorum fratrum nostrorum consilio, per apostolica scripta committimus et mandamus quatinus vos vel alter vestrum eumdem regem Anglie, premissis circa ipsum exhortationibus et monitis, de quibus et prout rationabiliter expedire videritis $[\ldots]$.

289 Vgl. ibid., n. 2727 (14.08.1346; nur Regest). Der in RV 140, fol. 91, n. 381 überlieferte Text deutet auf eine mögliche Ausweitung der Vollmachten hin: [...] si qua vobis forsitan occurrerent in hac parte utilia vel necessaria facienda que iuxta potestatem vobis attributam ut premittitur facere non possetis deliberare super illis et deliberationem vestram super hoc nobis mittere studeretis, ut consule adhibito consilio vobis respondere ac facere, sicut nobis videretur expediens, valeremus; verum cum postmodum audiverimus et per vestras etiam percepimus litteras vos, qui cum rege predicto Lexonie multum perplexos et variis sollicitudinibus, super quibus nobis compatimur, occupatos quandam commissionem recitativam veraciter illorum, que gesta circa negocium predictum sunt, hactenus faciendam, vobis de fratrum nostrorum consilio providimus quam cum presentibus destinamus, ut super contentis in ea, sicut expedire cognoveritis, deliberatione provida previa procedatis. Auch Edward III. hatte den Nuntien freies Geleit zugesichert, vgl. C.P.R., VII, S. 474 (03.08. 1346, Lisieux).

290 Lettres Clément VI, n. 2760: Porro, dilectissima filia, displicenter nimis audivimus quod ab aliquibus popularibus, seu indiscretis hominibus predictis cardinalibus improperatur plerumque imponendo eisdem imperfectionem reformationis pacis predicte [...]. Briefe desselben Wortlauts gehen an Philipp VI. und die Herzogin der Normandie, ibid., nn. 2761-2762. Die Kunde von der Niederlage des französischen Heeres war zu diesem Zeitpunkt noch nicht nach Avignon gedrungen, verläßt doch noch zwei Tage später ein an den gefallenen König Johann von Böhmen gerichteter Brief die Kurie, ibid., n. 2767.

291 Unterstrichen wurde, die Kardinäle täten ihr Möglichstes - faciunt continue posse suum -, um ihrer Aufgabe als Friedensengel gerecht zu werden: Quamobrem non est eis ulterius si rectum teneatur judicium imputandum, nec eadem irreverentia solum cardinales eosdem, sed Sedem prefatam non immerito multum ledit. 
noch anderen Prälaten anlasten ${ }^{292}$. Könnte man den Ton dieser Briefe als vorsichtig zurechtweisend charakterisieren ${ }^{293}$, muß angesichts des Briefes, der zur gleichen Zeit an Edward III. abging, von einer harschen Zurechtweisung gesprochen werden. Diplomatische Usancen vergessend, brandmarkte Clemens VI. den König als Aggressor und forderte ihn auf, von allgemeinen Absichtserklärungen gegenüber den Nuntien Abstand zu nehmen. Verba generalia seien beileibe nicht dazu angetan, die Spirale der Gewalt zu beenden ${ }^{294}$. Dabei verkannte der Papst, daß es auch gar nicht in der Absicht des Königs lag, die für England ungemein günstig verlaufenden kriegerischen Handlungen zu unterbrechen. Offensichtlich spitzte sich die Lage zu, geriet die päpstliche Diplomatie zwischen die Mühlsteine nationaler Realpolitik. Die Besorgnis des Papstes richtete sich dabei nicht nur auf die gegen die Nuntien geführte Verleumdungskampagne, sondern sehr viel unmittelbarer auf deren körperliche Unversehrtheit. Die Situation stellte sich zumindest in Avignon als derart prekär dar, daß die Nuntien eindringlich vor gefährlichen Alleingängen gewarnt wurden und ihnen empfohlen wurde, sich der Dienste von Leibwächtern zu versichern ${ }^{295}$. Mit der Aufforderung, alle Dinge schriftlich zu fixieren, schwang auch etwas Kritik an der bisherigen Arbeitsweise der Nuntien mit, hatten sich doch deren Widersacher augenscheinlich das Prinzip Quod non est in actis, non est in mundo zunutze gemacht.

Angesichts dieser teils selbst verschuldeten, teils von außen herbeigeführten Schwächephase päpstlicher Diplomatie wurde zu einem Gegenschlag ausgeholt, der einer breiten Öffentlichkeit die Funktions- und Reaktionsfähigkeit der Kurie vor Augen führen sollte. Einmal mehr traf der päpstliche Bann-

292 Offensichtlich begann man am französischen Hof noch vor der eigentlichen Niederlage mit der Suche nach Schuldigen. Nach Crécy verstummten die gegen die Kurie gerichteten Vorwürfe vollständig: das Desaster wurde nun als Strafe Gottes für - wahlweise oder im Konglomerat - den Hochmut des Adels, die Gier nach Reichtümern oder den exzessiven Kleiderluxus begriffen, vgl. Grandes Chroniques, V, S. $462 f$.

293 Bereits einen Tag später bedauerte der Papst in einem Schreiben an die Kardinäle den zu freundlichen Ton des Briefes, vgl. Lettres Clément VI, n. 2766: [...] sed non sic, ut deceret, aspere, sicut exigebat rei qualitas, scripsimus [...]. Gleichzeitig versicherte er die Nuntien seines fortgesetzten Wohlwollens und bedauerte, daß die Angriffe auf ihre persönliche Integrität ausgerechnet von Frankreich ausgegangen seien.

294 Ibid., n. 2763: [...] prefatis cardinalibus, quibus respondisti generaliter ut intelleximus, te velle pacem rationabilem, si tibi offerretur habere ad aliqua descendendo specialia per que paci eidem dari possit aditus aperire, sicut fuerit honestum et expediens, intentionem mentis tue, nosti nempe, fili precarissime, quod per verba generalia obtineri votivus super predictis exitus non valerent.

295 Ibid., n. 2766: Ceterum volumus vobisque, quantum possumus, inhibemus, quod nullo modo personas vestras periculis imminentibus exponatis; scitis namque quod exinde, si sinistrum, quod absit, contingeret, preter dampnum irreparabile, nostra et dicte Sedis maxima confusio sequeretur, et tam pungitivus dolor infigeretur nostris precordiis, qui animam nostram pertransiens nullo unquam tempore ab inde valeret dilui vel avelli. Et omnino credimus expedire quod unum vel duos servientes armorum pro securiori custodia, et ad mittigandum, si oporteret, rumorem populi vobiscum continue habeatis. 
strahl die Flamen: den Kardinälen oblag es, deren Exkommunikation öffentlich zu verkünden und damit das der Kurie zur Verfügung stehende Korrektivpotential ins allgemeine Bewußtsein zurückzurufen ${ }^{296}$. $\mathrm{Da}$ die Verkündigung der processus vom Papst bereits eine Woche später verschoben wurde, hing mit der zwischenzeitlich bekannt gewordenen Niederlage von Crécy zusammen ${ }^{297}$. Ein an die Königin von Frankreich gerichteter Trostbrief zeugt von dem Bemühen Clemens' VI., Schuldzuweisungen zu vermeiden, um so die militärischen und menschlichen Vorzüge Philipps VI. in um so hellerem Licht erstrahlen lassen zu können - auf den insbesondere von der französischen Ritterschaft entrichteten Blutzoll wird mit keinem Wort eingegangen ${ }^{298}$. Mit fast identischen Worten wandte sich der Papst am selben Tag an den französischen König, vergaß jedoch nicht, seinem Schreiben die dringende Aufforderung hinzuzufügen, die Nuntien nicht nur anzuhören, sondern ihre Ratschläge auch zu beherzigen ${ }^{299}$. Die Informationen, die bisher an die Kurie gedrungen waren, schienen das Informationsbedürfnis des Papstes noch nicht befriedigt zu haben. Seine Nuntien wies er jedenfalls an, ihm genauere Mitteilung über die Vorfälle zu machen ${ }^{300}$.

Die Niederlage, deren genaues Ausmaß noch nicht bekannt war, wurde von der Kurie als Chance für den Neubeginn von Friedensverhandlungen angesehen. In der Tat hatte insbesondere Frankreich großes Interesse an einem Ende der Kampfhandlungen, was die Verhandlungs- und Konzessionsbereit-

296 Ibid., n. 2773 (01.09.1346). Die offizielle Exkommunikation erfolgte erst am 13. Mai 1347 in Tournai, vgl. Aegidius Li Muisis, Chronica, S. 268.

297 Lettres Clément VI, n. 2789 (08.09.1346).

298 Ibid., n. 2790 (08.09.1346): Profecto, filia carissima, extimamus indubie quod ex hiis rex prefatus majoris fulguris claritatem in sui nominis gloria posuit, ac corda subditorum suorum quorumlibet sibi ad amplioris fidelitatis et dilectionis augmentum atraxit [...]. Auch die Philipp VI. ansonsten kritisch bewertende Chronique des quatre premiers Valois bemerkt: Le roy Philippe en sa hastiveté se porta celui jour comme tres bon chevalier et y fit merveilles d'armes, mais fortune tourna contre lui, in: Chronique des quatre premiers Valois, hg.v. Siméon LuCE, Paris 1862, S. 16.

299 Lettres Clément VI, n. 2791 (nur Regest); vgl. RV 140, fol.113v, n. 480: Sane quia ipse Rex pacificus pacem diligit et in viris pacificis delectatur, exhortationibus nostris adicimus, ut cardinales, qui ad pacis serenda semina missi sunt, favorabiliter et honeste ipsorum monitis et persuasionibus salubribus super reformatione pacis tibi regnaque tuo honorabili et congrue affectu benignitatis regie acquiescas.

300 Lettres Clément VI, n. 2792 (08.09.1346): [...] vos itaque nobis plene rei geste circa conflictum predictum seriem, que forsan per scribentes, sic celeriter scribi non poterat, et que ulterius contingerint rescribatis. Vom päpstlichen Informationsdefizit war ohne Zweifel die Rolle Philipps VI. an den Kampfhandlungen betroffen: Auch in diesem Brief bekundete der Papst Trauer über die Niederlage, äußerte jedoch auch Freude über die Stärkung der königlichen Position: [...] tristia et leta simul nostris precordiis inducentem [...] leta tamen in eo quod prefatus rex Francie in tanto discrimine custoditus a domino sit, constanter, viriliter et strenue se gessisse describitur, quod fama sui nominis et honoris exinde grandia suscipit et suscipiet incrementa [...]. Zu einer solchen Art Zweckoptimismus hatte der Papst im Brief an seine Kardinäle keinen Grund: er schien zu diesem Zeitpunkt also tatsächlich von der Richtigkeit seiner Bemerkungen überzeugt. 
schaft ungemein befördert haben dürfte. Anders England: auf einer Erfolgswelle ohnegleichen schwimmend, bestand hier das Interesse eher darin, die eigene Position auf Kosten des geschwächten Frankreich auszubauen. Immerhin gelang es den Nuntien, mit beiden Souveränen in persönlichen Kontakt zu treten. Nachdem Edward III. bei Lisieux seinen Verhandlungswillen bekundet und die Ernennung von tractatores, Verhandlungsführern, zugesagt hatte, beeilte sich auch Philipp VI., den gleichen Eifer an den Tag zu legen. Die Mahnung des Papstes an die Kardinäle fiel deutlich aus: energisch, jedoch mit aller gebotenen Vorsicht sollten die Verhandlungen in Angriff genommen werden. Favorisiert wurde als erstes Verhandlungsziel der Abschluß eines weiteren Waffenstillstands ${ }^{301}$. Wie nicht anders zu erwarten, war es Edward III., der kein Interesse an einer schnellen Problemlösung an den Tag legte. Obwohl von der Kurie die Anweisung erging, mit beiden Souveränen so oft wie möglich Kontakt aufzunehmen, gelang es den Nuntien nicht, substantielle Fortschritte zu erzielen ${ }^{302}$. Einmal mehr war es die an der Kurie hinlänglich bekannte Hinhaltetaktik Edwards III., waren es seine verba generalia, die für Verzweiflung sorgten: wenigstens insgeheim solle er den Kardinälen brauchbare Informationen zukommen lassen - so der Papst an den König ${ }^{303}$.

Anfang Januar hatte Annibaldo Ceccano Gelegenheit zu einer Unterredung mit dem König gehabt: doch auch dabei war außer allgemeinen Absichtserklärungen wenig Konkretes über den einzuschlagenden Friedensweg in Erfahrung zu bringen gewesen ${ }^{304}$. Genauso unverbindlich blieb die Anweisung des Papstes, mit allen Mitteln auf den Abschluß eines Waffenstillstands zu dringen. Mitunter eignet den päpstlichen Briefen ein ungeduldiger Unterton: einfallsreicher (virtuosius) sollten die Nuntien vorgehen, niemals das

301 Ibid., n. 2844 (03.10.1346): [...] exhortantes quatinus circa reformationem dicte concordie vel saltem treugas ineundas vel indicendas inter reges prefatos, sicut fuerit expediens, laborare operosis sollicitudinibus, ut cepistis, continuatione infatigabili $[. .$.$] , ut de vestris labo-$ ribus fructus gloriosi et desiderati proveniant.

302 Ibid., n. 3053 (15.01. 1347; nur Regest); vgl. RV 140, fol. 203v, n. 895: Sane quia eiusdem negocii diligens prosecutio et fidelis, velut toti christianitati necessaria et perutilis, grandis apud Deum mercedis premium et apud homines magne laudis preconium secum trahit, nostre circumspectionis prudentiam in domino attentius exhortamur, quatinus labores, solicitudines et studia vestra circa prosecutionem huiusmodi nostris non deficientes animis, sed eis pocius vestros indefessos supponentes humeros, spe remunerationis eterne continuare curantes ad eosdem Reges et eorum quemlibet, sicut secure ac commode fieri poterit, pro querendis et aperiendis viis pacis huiusmodi, quociens oportunum fuerit et expedire prudencie nostre videbitur, accedatis instando pro pacis eiusdem concordia oportune ac importune, prout necessitas vel utilitas exegerit apud eos.

303 Lettres Clément VI, n. 3054 (15.01. 1347; nur Regest); vgl. Raynaldi, Annales ecclesiastici a.a. $1347, \S 23$.

304 Lettres Clément VI, n. 3100 (05.02.1347; nur Regest); vgl. RV 140, fol.225, n. 975: Et quia tu frater Episcope, qui ad Regem prefatum Anglie non vitatis laboribus et periculis accessisti, eum ad ineundas treugas diceris dispositum reperisse, si ad pacem mutuam non potestis attingere, de presenti videtur admodum expediens, quod circa easdem ineundas / treugas sub modis, formis et conditionibus oportunis et decentibus laboretis. 
kurzfristige Ziel aus den Augen verlieren ${ }^{305}$. Die Kurie wirkte als Vermittler, verlor ihr eigenes Interesse jedoch nicht aus den Augen. Ab April 1347 war es die Pfründenproblematik, die sich wie ein roter Faden durch die Korrespondenz des Papstes sowohl mit seinen Nuntien als auch den beiden Souveränen zog. Dabei handelte es sich keinesfalls um ein neues Problem. Bereits 1344 während der Konferenz von Avignon hatte sich Clemens VI. bei den englischen Gesandten wortgewaltig über die Eingriffe Edwards III. in die Freiheiten der Kirche, worunter an der Kurie zuvorderst das Recht der Bischofsernennungen und Pfründenprovisionen verstanden wurde, beklagt ${ }^{306}$. Neu war allerdings, daß Edward III. insbesondere mit seinem vom Februar 1346 datierenden Vorgehen gegen die Benefizien der Kardinäle ${ }^{307}$ beispielgebend für den französischen König gewirkt zu haben scheint, hatte dieser sich doch ebenfalls für eine gegen die Benefizien der Purpurträger und ihrer Familiaren gerichtete Gesetzgebung entschieden. Als Verteidigerin kurialer Interessen am französischen Hof wirkte die Königin, Jeanne de Bourgogne, bei der sich der Papst denn auch für ihr Engagement bedankte, hatte sie doch dafür gesorgt, daß der Erlaß, der sich seit Beginn des Jahres 1347 gegen die Benefizien derjenigen gerichtet hatte, die nicht in Frankreich residierten, also v.a. die Kardinäle und die an der Kurie in Avignon Beschäftigten, zumindest teilweise zurückgenommen worden war ${ }^{308}$. Eine Bitte der Königin wurde jedoch ab-

305 Lettres Clément VI, n. 3223 (11.04.1347; nur Regest); vgl. RV 140, fol.266v, n. 1195: Quocirca vestram prudentiam attentius in domino exhortamur, quatinus labores nostros quantum comode poteritis et proficere circa dictum negocium credideritis continuare virtuosius procuretis. Eine weitere Schwierigkeit, die sich aus der räumlichen Distanz von Haupt und Gliedern, d.h. von Papst und Nuntien, ergibt, wird ebenfalls benannt: das Kommunikationsproblem. Aufgrund der unsicheren Lage erreichten Briefe nur unregelmäßig oder gar nicht ihr Ziel, benötigten auf alle Fälle mehr als zwei Wochen, um von Lisieux nach Avignon zu gelangen. Angesichts dieser Situation scheinen es die Nuntien vorgezogen zu haben, den Briefverkehr auf das absolute Minimum zu beschränken: Rursus cum intellexerimus prefatum Regem Anglie quasdam clausas nobis directas suas litteras nobis assignare fecisse, quas nobis mittere propter viarum discrimina ommisistis, volumus eas per vos aperiri et diligenter videri nobisque transcriptum earum sub nostris interclusam litteris postmodo destinari.

306 Vgl. Froissart, Euvres, ed. de LetTEnhove, S. 204; vgl. Kap. 5.1.3, 5.1.5, 5.1.6 .

307 Vgl. RYMER, Foedera, III, S.68; MURIMUTH, Appendix, S.245: Eodem anno [1346], circa Quadragesimam, rex percepit in manu sua omnes proventus et emolumenta quae cardinales habuerunt in Anglia, nolens eos tanto gaudere beneficio, eo quod pro majori parte favent papae et Philippo de Valoys, qui se dicit regem Franciae. Damit gibt der Chronist ohne Zweifel die vorherrschende öffentliche Meinung wieder, vgl. auch Kap. 5.1.2.

308 Lettres Clément VI, n. 3227 (13.04.1347) ; vgl. dazu auch BaLUZE/Mollat, Vitae IV, S.78. Clemens VI. hatte eigens Pasteur de Sarrats und Guillaume Lamy als Nuntien in dieser Angelegenheit nach Frankreich entsandt: Er untersagte ihnen eine Rückkehr an die Kurie, so lange kein Erfolg erzielt worden sei und begründete diese Entscheidung damit, daß eine Abreise als »entehrend « für den Heiligen Stuhl angesehen werden würde und deshalb im Konsistorium verworfen worden sei, vgl. Lettres Clément VI, n. 3363 (10.07.1347); vgl. zur »Benefizienaffäre« Guillaume MoLlat, Clément VI et le chancelier Firmin de Cocquerel, in: BEC 122 (1964) S.257-261; Elizabeth BROWN, Taxation and 
schlägig beschieden, nämlich die offizielle Verurteilung des englischen Königs durch die Kurie. Clemens VI. unterstrich, daß ihn einzig und allein die Friedensliebe (amor pacis) und die Hoffnung auf einen positiven Ausgang der Verhandlungen von diesem Schritt abhielten, er aber gewisse processus vorbereite, die bei Bedarf auch eingesetzt würden ${ }^{309}$.

Am 28. April 1347 ergingen konkrete Handlungsanweisungen an die Kardinäle ${ }^{310}$. Annibaldus solle sich zum englischen König, Étienne zu Philipp VI. begeben, um gegen die fortgesetzten Angriffe auf kirchliche Freiheiten zu protestieren und auf die vollständige Zurücknahme der antikurialen Gesetzgebung zu drängen. Die Analyse des Papstes war zutreffend: Edward III., der unter dem Vorwand, das Edelmetall würde knapp, jedwede Ausfuhr von Geldern aus dem Königreich verboten und damit der vermeintlichen Finanzierung des Krieges gegen England mit englischen Geldern entgegengewirkt habe, sei beispielgebend für den französischen König gewesen. Damit wurden die Aussagen wiederholt, die Edward in einem bereits im Februar an den Papst gerichteten Brief gemacht hatte ${ }^{311}$. Unglücklicherweise implizierte diese Feststellung eine gegen das Wirken der Nuntien gerichtete Rüge. Dieses eine Mal hatten sie Eigeninitiative ergriffen, Briefe des Papstes, in denen das englische Vorgehen scharf verurteilt wurde, zurückgehalten, um - so die entschuldigende Antwort - den Fortgang der Verhandlungen nicht zu gefährden - und mußten nun dafür Kritik einstecken. Hätte man nämlich - so der Papst - den Anfängen gewehrt, wäre Philipp VI. sicherlich von seinem Vorgehen abzubringen gewesen. Ohne Zweifel handelte der Papst in diesem Falle unter

morality in the thirteenth and fourteenth centuries: conscience and political power and the kings of France, in: French Historical Studies 8 (1973) S. 1-28; vgl. zum Verhältnis PapstKönigin auch Guillaume MOLLAT, Clément VI et Jeanne de Bourgogne, reine de France, in: Comptes rendus de l'Académie des inscriptions et belles-lettres 20 (1957) S.412-419, bes. S. 414f.; Pierre GaSNault, Une lettre missive de Clément VI à la reine Jeanne de Bourgogne, in: MEFR 73 (1961) S.365-373; allgemein Jean GAUDEMET, La collation par le roi de France des bénéfices vacants en régale des origines à la fin du XIVe siècle, Paris 1935.

309 Lettres Clément VI, n. 3227: Porro super hiis, que de faciendis processibus contra regem Anglie nuper tua excellentia nobis scripsit, breviter respondemus quod amore pacis quam desideravimus et desideramus ferventibus desideriis, et ne ipsius posset impediri tractatus, per cardinales nuncios a processibus, prout nobis scripserunt, cessatum extitit usque modo; nunc vero aliquos ordinari de novo facimus diligenter, quibus breviter ordinatis, illorum tibi mittemus copiam, et eos absque cunctatione faciemus nichil aliud expectando ulterius expediri.

310 Ibid., n. 3253 (28.04.1347). Erinnert sei daran, daß Annibaldo bereits unter Johannes XXII. Gelegenheit hatte, sich in den Großkomplex kurialer Pfründenpolitik einzuarbeiten. Seine Teilnahme am Prozeß, der zur Verurteilung der Lehren Thomas Waleys, eines scharfen Kritikers eben dieser Politik, führte, ist belegt, vgl. DYkmans, Annibal de Ceccano et la Vision Béatifique, S. $351 \mathrm{f}$.

311 Vgl. RyMER, Foedera, V, S. 490f.; LunT, Financial relations, S. 334-337; Edward III. berief sich auf eine nationale Notlage, in der alle ihren Beitrag zur Verteidigung Englands zu leisten hätten. Immerhin wurde die Rückerstattung der einbehaltenen Erträge und Einkünfte zu einem späteren Zeitpunkt angekündigt. 
Druck, saßen ihm doch die Kardinäle im Nacken, die beim Verlust der Einkünfte aus den wohldotierten Pfründen in England und Nordfrankreich um ihr wirtschaftliches Wohlergehen bangten ${ }^{312}$. Konkrete Handlungsanweisungen ergingen ebenfalls für den Fall einer Weigerung der Könige, auf die Forderungen der Kurie einzugehen. Da diese Anweisungen jedoch Teil von dem offiziellen Brief beiliegenden cedulae waren, diese aber nicht mitüberliefert wurden, kann lediglich vermutet werden, daß die Kardinäle darin über die anzuwendenden processus in Kenntnis gesetzt wurden ${ }^{313}$. Zumindest das Vorgehen von Étienne Aubert beim französischen König wurde durch flankierende Maßnahmen in epistolis unterstützt. Nicht nur Philipp VI. wurde aufgefordert, den Kardinal familiariter et secrete anzuhören ${ }^{314}$, Briefe mit der Bitte um Unterstützung gingen auch an zwölf weitere Persönlichkeiten Frankreichs ${ }^{315}$.

Die Situation in England gestaltete sich ungleich schwieriger, ja wurde noch dadurch verschärft, daß sich die Vorwürfe Edwards III. gegen die Benefizialpolitik des Papstes auf eine Person konzentrierten: Kardinal Adémar Robert, Kardinalpresbyter tit. S. Anastasiae. Bereits zu einem früheren Zeitpunkt hatte die Entscheidung des Papstes, dem neu kreierten Kardinal in der Kirchenprovinz York Pfründen im Wert von 1000 Mark Sterling zu übertragen, für Empörung gesorgt ${ }^{316}$. Durch einen Brief versuchte Clemens VI. den englischen König zum Einlenken zu bewegen. Er führte dabei das immer wieder vorgetragene Argument an, die Kardinäle benötigten Pfründen, um ihren Lebensunterhalt angemessen bestreiten zu können, bemerkte jedoch ergänzend, daß die so Bepfründeten gleichzeitig auch als Fürsprecher des Landes an der Kurie wirken könn-

312 Zur Sorge bestand Anlaß. Vom königlichen Erlaß betroffen waren: der Archidiakonat von Richmond (Jean de Comminges), vgl. C.P.R. 1348-1350, S. 425; die Thesaurarie von York mit der zugehörigen Pfründe von Wilton (Annibaldo Ceccano), vgl. C.P.R., 1348-1350, S.51, 202, 582; die Kirche von Hemingbrough (Gaucèlme Jean); der Archidiakonat von York und die Pfründe von Wistow (Pierre Desprez), vgl. C.C.R. 1349-1354, S.431, vgl. C.P.L., II, S. 213. ${ }^{313}$ Zur Bedeutung von cedulae im diplomatischen Briefverkehr Clemens' VI. vgl. Guillaume Mollat, Correspondance de Clément VI par cédules, in: Bullettino dell'Archivio paleografico italiano, n.s., II-III (1956-1957) S.175-178; Yves RENOUARD, Comment les papes d'Avignon expédiaient leur courrier, in: Revue historique 180 (1937) S. 1-29.

314 Lettres Clément VI, n. 3254 (28.04.1347; nur Regest); vgl. RV 140, fol.256v, n.1141: Super quibusdam salutem tuam, fili carissime, ac statum tuum et Regni tui prosperum concernentibus, dilectum filium nostrum Stephanum tit. SS. Johannis et Pauli presbiterum cardinalem apostolice sedis nuncium tui et Regni predicti specialem sincerum et fervidum zelatorem pro parte nostra volentes tecum, fili carissime, colloqui familiariter et secrete, tuam rogamus excellentiam attentius in domino et hortamur, quatinus ipsum cardinalem plene, pacienter et benigne audias eidemque super explicandis fidem adhibeas credulam ac sic prudenter et clementer ea que tibi suaserit percipias et in effectum deducas, quod omnia dante domino succedant prospere, periculis et scandalis evitatis. Vgl. auch Lettres Clément VI, n. 3266 (02.05.1347) im Umfang eines kleineren Memorandums, durch das Philipp VI. zum Einlenken bewogen werden sollte; zur weiteren Entwicklung nn. 3272, 3299, 3363, 3401-3403.

315 Ibid., n. 3255.

316 Vgl. Mollat, Collation, S. 254-258; LuNT, Financial relations, S. 229f.; RS 9, fol. 54r-v; vgl. insbesondere Kap. 5.1.5. 
ten, aus dem sie ihre Benefizialeinkünfte bezögen ${ }^{317}$. Letzteres Argument war noch weniger als das erste dazu angetan, Edward III. zu beeindrucken, wußte er doch bereits seit längerem um die Vorzüge solcher Fürsprecher innerhalb des Konsistoriums. Für ihre Vermittlerdienste im Interesse Englands wurden diese großzügig entlohnt, mit Privilegien bedacht und von den gegen ihren Benefizialbesitz gerichteten Verfügungen ausdrücklich ausgenommen. Deutlich zeigt sich die Absicht Edwards III., diesen Kreis nicht, oder zumindest nicht um die Person des Adémar Robert, zu erweitern. Der englische König war auch wenig geneigt - dies in Analogie zur ersten Gesandtschaft 1342/1343 -, die Verbindlichkeit der kurialerseits immer wieder eingeschärften Verpflichtung zur Leistung von Prokurationszahlungen anzuerkennen ${ }^{318}$. Von ihm wohlwollend gedeckt, waren es insbesondere Bischöfe und Äbte, die es ablehnten, sich an den »Unkosten « der Nuntien zu beteiligen ${ }^{319}$. Am 27 . Januar 1348 erhielten die Gesandten die ausdrückliche Vollmacht, Kirchenstrafen gegen diejenigen zu verhängen, die sich diesen Verpflichtungen entziehen wollten ${ }^{320}$.

317 Lettres Clément VI, n. 3536 (23.10.1347): [...] licet igitur cunctorum gravamina moleste feramus venerabilium tamen fratrum nostrorum S.R.E. cardinalium tanto ferentes molestius, quanto ipsi universalis Ecclesie onera nobiscum indefessis solicitudinibus partiuntur [...] et quantum prefatus cardinalis tibi et regno tuo in tuorum apud Sedem eandem promotione favorabili agendorum et directione consilii, ac impensione favoris esse poterit [...].

318 Am 12. April 1347 wurden Prokurationszahlungen ausdrücklich mit der Begründung untersagt, die Kardinäle hielten sich außerhalb Englands auf, vgl. RYMER, Foedera, III, S. 117. Zahlungen wurden 1348 und 1350 gestattet, jedoch teilweise anderslautend deklariert, vgl. ibid., S. 167, 204; C.P.R., VIII, S. 562. Ein Chronist überliefert gar die Nachricht, Edward III. habe 1350 beim Papst um Ernennung eines englischen Kardinals mit der Begründung nachgesucht, England habe seit langem keinen entsprechenden Vertreter im Kollegium besessen, müsse jedoch fortgesetzt Zahlungen für den Unterhalt von Kardinälen leisten, vgl. Geoffroy le Baker, Chronicon, S. 111f. Prokurationszahlungen in Höhe von rund 108 Pfund sind beispielsweise für das Bistum Rochester überliefert, vgl. Registrum Hamonis Hethe, Bd. 1, S. $848 f$.

319 Immerhin war es den Prokuratoren der beiden Nuntien erlaubt worden, die Interessen ihrer Klienten in England zu vertreten, vgl. C.P.R., VII, S. 562 (05.10.1347), C.P.R., VIII, S. 288 (16.02.1348); C.P.R., VIII, S. 132 (01.07.1348); C.P.R., VIII, S. 137 (06.08.1348), S. 139, S. $408(25.10 .1348)$, S. 448 (23.01.1350), S. $482(10.03 .1350)$, S. $549(02.07 .1350)$. ${ }^{320}$ Lettres Clément VI, n. 3707 (nur Regest); vgl. RV 181, fol.6, n.14: Quanto Romanam ecclesiam, cuius honorabilia membra estis, amplius honorare vestrorum magnitudine meritorum, tanto decentius fore conspicimus, ut in hiis, que quitati sunt, consona et incrementa commodi vestri respiciunt, nos reperiatis favorabiles et benigne. Sane dudum cum vos ad Francie et Anglie regna pro magnis et arduis negociis duximus destinandos, ut incumbentia vobis expensarum onera possetis facilius supportare, vobis ambobus recipiendi huiusmodi negociorum vestra prosecutione durante similes procurationes, quas unus de cardinalibus Sancte Romane Ecclesie apostolice sedis legatus vel nuncius in eisdem Regnis pro suis procuratoribus recipere consuevit, que videlicet ad maiorem summam ascendere noscebantur a venerabilibus fratribus nostris archiepiscopis et episcopis ac dilectis filiis abbatibus [...] et carissimis in Christo filiis nostris Francie et Anglie regibus necnon contradictores per censuram ecclesiasticam appellatione postposita compescendi vobis et cuilibet vestrum plenam et liberam concessimus per nostras litteras facultatem [...]. Da sich diese Fakultät als wenig schlagkräftig erwies, wurden die Vollmachten entsprechend erweitert. 
Die Kardinäle zeigten Präsenz, eine Tatsache, die insofern erstaunt, als die Gesandtschaft ein halbes Jahr zuvor am Rande des Scheiterns gestanden hatte. Nur eindringliches Zureden des Papstes konnte die Nuntien damals davon abhalten, angesichts der verfahrenen Situation - nicht zuletzt aus wohlbegründetem Sicherheitsdenken heraus - die Gesandtschaft ohne konkretes Ergebnis abzubrechen. Nach eingehenden Beratungen mit den Kardinälen sei er so der Papst - zu dem Schluß gelangt, daß die Gesandtschaft um jeden Preis aufrechtzuerhalten sei, um so den Weg zum Frieden nicht ganz zu verbauen. Selbst wenn sie bereits auf dem Weg zurück nach Avignon seien, ergehe jetzt seine Anweisung, auf jeden Fall umzukehren ${ }^{321}$. Als schwacher Trost konnte da nur die ergänzende Bemerkung dienen, das eigene Leben nicht unnötig zu gefährden. Eine ähnliche Argumentation war bereits in Zusammenhang mit den Angriffen Philipps VI. gegen die Pfründen von nicht in Frankreich residierenden Klerikern vorgenommen worden. Auch damals wurde die Rückkehr der Nuntien untersagt, damals wie jetzt stand das Ansehen der Kurie auf dem Spiel. Den vor der Schwere der Aufgabe kapitulierenden Kardinälen hielt der Papst die Bedeutung und das Ansehen kurialer Diplomatie vor Augen, wog die bis dato katastrophale Ergebnisbilanz der Gesandtschaft in situ gegen das Interesse der Kurie zumindest an einem Waffenstillstand ab und ließ in seine Erwägungen zwar unausgesprochen, nichtsdestoweniger wahrnehmbar die Sorge um den honor ecclesiae miteinfließen ${ }^{322}$.

$\mathrm{Zu}$ diesem Zeitpunkt lagerten beide Armeen bereits vor Calais, so daß die Hauptaufgabe der Nuntien in einer Art Pendeldiplomatie bestand, durch die ein kriegerisches Aufeinandertreffen der Heere vermieden werden sollte ${ }^{323}$. Schweigen sich die kurialen Quellen über den Verlauf dieser Vermittlungstätigkeit aus - auch der Papst nahm in seinen Briefen nicht auf mögliche zuvor an ihn gerichtete Schilderungen der Kardinäle Bezug -, so ist es doch die Chronistik, die ein für die Nuntien durchaus vorteilhaftes Bild entwirft ${ }^{324}$.

321 Lettres Clément VI, n. 3373 (15.07.1347): Subsequenter autem cum fratribus nostris S.E.R. cardinalibus deliberationibus prolixis et diligentibus [...] habitis, tandem post deliberationes et opiniones diversas nostra et fratrum ipsorum in hoc deliberatio consulta resedit, quod cum reges prefati appropinquare ad congressus bellicos hinc inde, dispositis aciebus dicantur, vos ad obviandum periculis, sicut commode fieri poterit, et pacem procurandam, si ad eam apperiret aditum pacis auctor, adhuc remanere in illis partibus debeatis, quia etiam si iam essetis in itinere veniendi vel applicuissetis ad curiam illuc vos redire super tante necessitatis articulo decens esset.

322 Der Begriff des honor ecclesiae harrt im Gegensatz zu dem des honor imperii noch der wissenschaftlichen Aufarbeitung, vgl. einstweilen Knut GörICH, Die Ehre Friedrich Barbarossas. Kommunikation, Konflikt und politisches Handeln im 12. Jahrhundert, Darmstadt 2001, S. 92-185; Heinz KRIEG, Herrscherdarstellung in der Stauferzeit, Sigmaringen 2003, S. 175-196, 247-250.

323 Vgl. Sumprion, I, S. 535-543; zur weiteren Entwicklung SumPTION, II, S. 1-51.

324 Vgl. Chronique Normande du XIVe siècle, hg. v. Auguste MolinIER, Paris 1882, S. 89, wo allerdings nicht auf den Waffenstillstand nach dem Fall von Calais, sondern auf eine von den Kardinälen vermittelte Kampfpause von drei Tagen verwiesen wird; vgl. Grandes 
Dies ändert jedoch nichts an der Tatsache, daß auch dort die Vermittlung als eher reaktiv denn präventiv dargestellt wird. Der Papst jedenfalls lobte das unter maßgeblicher Mitwirkung seiner Nuntien erzielte Ergebnis: die Verhinderung von Krieg ${ }^{325}$. Nur wenige Tage später sollte dieser unsichere, da rechtlich nicht fixierte Schwebezustand in Sicherheit überführt werden.

Am 28. September nahm der Papst auf einen Brief der Kardinäle vom 20. desselben Monats Bezug, in dem er über den Abschluß eines neuen Waffenstillstands informiert worden war ${ }^{326}$. In die Freude mischte sich jedoch die Befürchtung, daß dessen Dauer - als Expirationsdatum war der 8. Juli $1348^{327}$ vorgesehen - nicht ausreichen könnte, um einem stabilen Frieden den Weg zu ebnen. Die von den Kardinälen geäußerten Rückkehrabsichten wurden von Clemens VI. positiv beschieden, der regressus jedoch verschoben. Auch wenn die Kurie nur mehr mühsam der Präsenz der beiden Purpurträger entbehren könne, so legitimiere doch der mögliche Abschluß eines Friedensvertrages ihr weiteres Verweilen vor Ort - so der Papst in einer Mischung aus Schmeichelei

Chroniques de France, IX, S. 311; FroIsSarT, Euvres, S. 194f.; Aegidius Li Muisis, Chronicon, S. 271; Chronicon comitum Flandrensium, in: Corpus Chronicorum Flandriae, Bd.1, hg. v. Joseph Jean DE SMET, Brüssel 1837, S. 200-233, hier S. 223; Jean le Bel, Chronique, S.159, S. 170, mit besonderer Betonung der Pendeldiplomatie: En ce temps traveillerent les II cardinaulx, et alerent tant d'ung costé et d'aultre que treves furent acordées [...]. Vgl. zur Bedeutung Jean le Bels als Chronist Diana TYson, Jean le Bel, portrait of a cronicler, in: Journal of Medieval History 12 (1986) S.315-322, und Nicole ChAREYRON, Jean le Bel, le maître de Froissart, grand imagier de la guerre de Cent Ans, Brüssel 1996, bes. S. 108-119, wo die Autorin unterschiedliche Sichtweisen der englischen und französischen Chronistik bezüglich der Schlacht von Crécy Revue passieren läßt.

325 Lettres Clément VI, n. 3415 (24.08.1347; nur Regest); vgl. RV 141, fol. 65v, n. 289: Litteris vestris paterna nuper caritate susceptis, solicitudinis nostre studia in eo precipue quod bellum, quod inter carissimos in Christo filios nostros Francie et Anglie Reges illustres et utriusque ipsorum exercitum, procurante pacis emulo, parabatur, ne tantus sanguis populi christiani funderetur, fuit per operationis vestre ministerium fructuosum, auxiliante domino, impeditum et illis de Calesio, quibus vite discrimen et periculum iminebat, vestre interventionis obtentu extitit clementer indultum admodum commendamus. Den Beitrag des Papstes am Zustandekommen des Waffenstillstands unterstreicht WaLsingHaM, Chronica, S. 271: [...] Papa vero, considerans rem contigisse contrariam votis suis, et jam Regem Angliae effectum celeberrimum inter omnes reges, interposuit partes suas, ut treuga fieret inter regna.

326 Lettres Clément VI, n. 3486 (28.09.1347). Die Datierung muß vor dem Hintergrund der im Brief selbst enthaltenen Angaben nach hinten korrigiert werden. Clemens VI. bezieht sich darin nämlich auf drei Schreiben der Kardinäle vom 20., 23. und 28. September. Da der Waffenstillstand überhaupt erst am 28. September offiziell geschlossen wurde, ist eine Abfassung dieses Briefes am selben Tag unmöglich. Wahrscheinlich ist eine Datierung um den 14 . Oktober, ergeht unter diesem Datum doch ein kurzgefaßtes Schreiben der Kurie an die Kardinäle mit dem Verweis auf cedulae, die die nötigen Informationen bezüglich des regressus enthielten, vgl. Lettres Clément VI autres que la France, n. 1518 (14.10.1347). Die entsprechenden cedulae sind nicht überliefert.

${ }^{327}$ [...] usque ad XV diem post festum beati Johannis Baptiste proxime futurum [...]. Der Text des Abkommens findet sich bei RYMER, Foedera, III, S. 136-138. 
und realpolitischen Erwägungen ${ }^{328}$. Nach Abschluß des Waffenstillstands am 28. September war die offizielle Mission der Nuntien erfüllt. Auch wenn ein Friedensvertrag noch in weiter Ferne lag, war das von der Kurie selbst definierte Minimalziel erreicht worden. Zwischen dem 24. November und dem 1. Dezember kehrten die beiden Kardinäle nach Avignon zurück. Dies legt ein Blick in die päpstlichen Rechnungsbücher nahe, wo Ausgaben für ein Festessen aufgeführt sind, das der Papst zu Ehren der Nuntien veranstaltete ${ }^{329}$. Doch damit nicht genug der offiziellen Würdigungen: In einer Ansprache anläßlich ihrer Rückkehr wurden die im Auftrag des Papstes vollbrachten Leistungen auch verbal gewürdigt.

\subsubsection{Hii sunt viri: die Collatio Clemens' VI. anläßlich der Rückkehr der beiden Kardinäle Annibaldo Ceccano und Etienne Aubert}

Mit der Wahl eines Themas aus dem Buch Esra ${ }^{330}$, in dessen Mittelpunkt der Bericht über den Wiederaufbau des Tempels in Jerusalem und dessen Weihe steht, verfolgte Clemens VI. zwei Absichten. Zum einen wurde ihm durch das Thema die Möglichkeit geboten, das Spannungsverhältnis Jerusalem-Babylon in allegorischem Sinn auszudeuten, zum anderen auf die Geschichte einer »Reformation « samt eines echten biblischen »Reformators « zu verweisen. Die im Buch Esra aufscheinende Theologie impliziert, daß rechte Erneuerung nicht nur des göttlichen Wortes, sondern auch seiner Verkündigung bedarf. Erneuerung gründet sich somit auf die verba Dei in Gestalt der vox predicatoris, bedient sich des Gebets als Waffe und zielt auf mehr als äußere Veränderungen $a b^{331}$. Zentral sind Reinigung und Läuterung als Prozesse, an deren Ende die Abkehr von der Sünde steht. Die praktisch-rhetorische Verwertbarkeit der in diesem Buch aufscheinenden Theologie und die Übertragung auf

328 Lettres Clément VI, n. 3486: Ceterum quia de regressu vestro ad nos concedi licentiam petiistis scire vos volumus quod ferventi et grandi desiderio vestrum, sicut operariorum fidelium et quorum invite caremus presentia, desideramus adventum, ut solicitudinibus atque laboribus quos multifarie multisque modis in prosecutione negociorum subiistis hujusmodi fine imposito quietem aliquam resumatis. Sed [...] attendentes utrum vester utilis regressus, nam treugarum hujusmodi durante tempore tractari poterit de pace commodius, maxime si prefatus rex Anglie vel aliqui pro eo propter causam hujusmodi remaneant citra mare, consideretis etiam quod tempus est modicum quo treuge hujusmodi sunt durature [...].

329 Vgl. SCHÄFER, Ausgaben Klemens VI., S.360: Comederunt cum papa omnes dd. cardinales et multi alii prelati propter eventum dd. Claromont. et Neapolitan.

330 Den profundesten Überblick über das biblische Esra-Buch liefert Martin SAEBO, Art. Esra, in: TRE 10 (1982), S. 374-386. Das gesamte Mittelalter hindurch ist seine Stellung eher marginal, vgl. Pierre RichE, Guy LoBRICHON (Hg.), Le Moyen Âge et la Bible, Paris 1984, S. $155,368,525$.

331 Bezeichnenderweise zeigt eine Miniatur des Codex Amiatinus Cassiodor in Gestalt des Esra mit drei in den Institutiones erwähnten Bibelexemplaren. In einem Bücherschrank ist zusätzlich eine neunbändige Bibel zu erkennen. Der Codex liegt heute in Florenz, Biblioteca Medicea Laurenziana, Amiat. 1, fol.5v (entstanden vor $716 \mathrm{n}$. Chr.). 
aktuelle politische Probleme stellten keine allzu hohen Anforderungen an den versierten Orator ${ }^{332}$.

Hii sunt viri qui ascenderunt de captivitate quam transtulerat Nabugonodosor Rex Babilonis in Babilonem et reversi sunt in Jherusalem ${ }^{333}$ - ohne weitere einführende Worte steht dieses Thema am Anfang der Begrüßungsansprache, die der Papst anläßlich der Rückkehr der beiden Kardinäle Annibaldo Ceccano und Étienne Aubert Ende November/Anfang Dezember 1347 in Avignon hielt ${ }^{334}$. Die das Thema kennzeichnenden Toponyme dienen dabei als Ausgangspunkt breitgefächerter Überlegungen, die um die Darstellung des Gegensatzpaares Jerusalem und Babylon kreisen ${ }^{335}$. Neben Bernhard von Clairvaux ist es Augustinus, der als Kronzeuge herangezogen wird: Jerusalem als civitas Dei steht in denkbar stärkstem Kontrast zu Babylon, das als civitas diaboli, damit als confusio bezeichnet wird ${ }^{336}$. Nach einem weiteren Überblick über einige der prominentesten Bibelstellen, die das Begriffspaar JerusalemBabylon als Gegensatz zweier einander feindlich gegenüberstehender Prinzipien, genauer des Unrechts und der Gerechtigkeit, benennen ${ }^{337}$, konkretisiert Clemens VI. diesen Gegensatz in zehn Punkten (condiciones): 1. Verwirrung Ordnung (confusio-ordinatio); 2. Unruhe - Frieden (perturbatio-quietatio);

332 Das dem alttestamentarischen Buch Esra entnommene Thema wird von Clemens VI. als Ausgangspunkt eigener Überlegungen bezüglich einer Bewertung der allgemeinen politischen Lage herangezogen. Der geschichtliche Kontext freilich - das Volk Israel richtet nach der Zeit der Verbannung unter Führung der Propheten Esra und Nehemia die alten Institutionen wieder auf und beschert Juda, das fortan als Provinz dem Perserreich untersteht, relative Autonomie - spielt als Vergleichsrahmen keine Rolle. Der Papst begegnet damit der Gefahr, definieren zu müssen, welche der beiden Nationen, Frankreich oder England, das herrschende Perserreich und das unterlegene Juda repräsentiert.

333 Esra 2,1, etwa: »Und das sind die Einwohner der Provinz [Juda], die aus der Gefangenschaft hinaufzogen, die Weggeführten, die Nebukadnezar, der König von Babel, nach Babel weggeführt hatte und die nach Jerusalem und Juda zurückgekehrt sind, jeder in seine Stadt $\ll$.

${ }^{334}$ Den folgenden Ausführungen liegt der Text der Handschrift Paris, Bibliothèque Sainte-Geneviève, MS 240, fol.449r-454r zugrunde. Zur Parallelüberlieferung vgl. SCHNEYER, Repertorium, Bd. 4, S. 762, n. 45 ; Mollat, Euvre oratoire, S. 256, n. 66; ScHMIIZ, Sermons, S. 25, n. 38; Wood, Sermon literature, S. 163-172.

335 MS 240, fol.449rb: Videtur michi, quod scriptura sacra licet multas civitates commemoret, tamen specialiter duas enumerat, que sibi valde adinvicem adversantur, scilicet civitatem Babilonis et civitatem Jherusalem.

336 Augustinus, De civitate Dei, hg. v. Bernardus DombarT, Leipzig 1908, lib. XVII, cap. 16, S. 239f.: Ipsa est et Hierusalem eodem modo spiritaliter, unde multa iam diximus. Eius inimica est civitas diaboli Babylon, quae confusio interpretatur; ex qua tamen Babylone regina ista in omnibus gentibus regeneratione liberatur et a pessimo rege ad optimum / regem, id est a diabolo transit ad Christum; vgl. auch Augustinus, In Psalmum CXXXVI enarratio. Sermo ad plebem, in: PL 37, Sp. 1761-1774, hier Sp. 1761f.; die Verwendung des Babylon-Mythos durch Clemens VI. diskutiert Wood, Political theory, S. 466.

337 Z. B. Ps 136,1f. (Super flumina Babylonis), Jer 50,8 (Recedite de medio Babylonis). In lediglich vier Bibelstellen wird Babylon zum alleinigen Gegenstand der Betrachtungen gemacht, vgl. I Petr 5,13; Apc 14,8; Apc 17,5; Apc 18,10. 
3. Weinen - Trost (lacrimatio-consolatio); 4. Qual - Jubel (vexatio-exultatio); 5. Raub - Besitz (spoliatio-possessio); 6. Gefahr - Sicherheit (periclitatio-assecuratio); 7. beständiger Kampf - gegenseitige Liebe (continua impugnatiomutua dilectio); 8. teuflische Tyrannei - göttliche Herrschaft (dyabolica tirannizatio-divina dominatio); 9. Gefangenschaft - Befreiung (captivatio-liberatio); 10. Verdammnis - Errettung (dampnatio-salvatio) ${ }^{338}$. Er verzichtet aufgrund der Kürze der Zeit darauf, die von ihm angeführten Gegensatzpaare einer weitergehenden Deutung zu unterziehen, unterstreicht jedoch deren enge Anbindung an den biblischen Text ${ }^{339}$. Immerhin dürfte ihm jedoch mit dieser ermüdenden Nominalreihung eines gelungen sein: beim Zuhörer bzw. Leser eine Ahnung davon aufkommen zu lassen, wo das biblisch überhöhte Jerusalem heute zu finden sei. Das himmlische Jerusalem findet seinen Fortsatz im irdischen Jerusalem, wird widergespiegelt am Sitz der Kurie, die als Aufenthaltsort des vicarius Christi nicht die Wohnstatt des Teufels sein kann ${ }^{340}$.

Der Papst konzentriert sich nun auf ein Gegensatzpaar, das alle genannten Punkte in zwei Zustandsbeschreibungen bündelt, nämlich die von Krieg und Frieden (bellica commotio-pacis adeptio) ${ }^{341}$. Begründet wird dies in drei Unterpunkten. Zunächst richtet sich der Blick auf die Herrschaftsform (ratione similis dominationis). Der Blick auf die Herrschaft Babylons verdeutliche so Clemens VI. - doch nur eines: Babylon könne als Wohnstatt des Teufels, als eine dem Bösen unterworfene Stadt, nicht anders handeln, als Unfrieden zu stiften $^{342}$. Das in Rückgriff auf Augustinus gezeichnete Bild evoziert eine

$338 \mathrm{Vgl}$. MS 240, fol. 449vb.

339 Ibid., fol. 449va: Et videtur michi quantum possum colligere, quod iste due civitates habent $X$ contrarias condiciones, que optime possunt probari per scripturam, sed non prosequor.

340 Kritische Geister wie Petrarca oder William von Ockham argumentieren in entgegengesetzter Richtung. Vergleiche mit Babylon sind nicht nur auf den engeren Bereich der Kurie beschränkt. Opicinus de Canistris, ein in Avignon tätiger Kleriker, belegt so beispielsweise seine Heimatstadt Pavia mit dem wenig schmeichelhaften Begriff Babilonia, vgl. Richard SALOMON, Das Weltbild eines avignonesischen Klerikers, in: Vorträge der Bibliothek Warburg 6 (1930) S. 145-189; DeRS., A newly discovered manuscript of Opicinus de Canistris, in: Journal of the Warburg and Courtauld Institutes 16 (1953) S. 45-57; vgl. auch Guy Roux, Muriel LAHAIR, Art et folie au Moyen Âge. Aventures et énigmes d'Opicinus de Canistris (1296-vers 1351), Paris 1997.

$341 \mathrm{Vgl}$. MS 240, fol. 449vb.

342 Zur Illustration und autoritativen Absicherung führt der Papst den bei Augustinus (De civitate Dei, lib. 2, cap. 25) überlieferten Bericht über den Kampf von Dämonen an, um gleich zu lib. 16, cap. 23 überzuleiten, wo Augustinus eine in Gen 15,9-12 überlieferte Erzählung allegorisch interpretiert: Abraham, unsicher, ob er das ihm von Gott verheißene Land tatsächlich besitzen wird, bittet Gott um ein Zeichen. Auf sein Geheiß hin bringt Abraham Kuh, Ziege, Widder, Turteltaube und Taube herbei, tötet alle Tiere und zerteilt sie - ausgenommen die Vögel - in der Mitte. Raubvögel fallen danach auf das Aas, werden von Abraham jedoch vertrieben. In Augustinus' Interpretation werden nun die unzerteilten Vögel zu den gottesfürchtig lebenden Menschen, den viri spirituales, während die zerteilten Tiere für diejenigen Menschen - homines carnales - stehen, die sich in Krieg und Zwietracht bekämpfen. Die Raubvögel schließlich, die auf das Aas niederstoßen, reprä- 
Trias - der Mensch, der auf Gottes Wegen wandelt, der Mensch, der Gottes Gebote missachtet, und die Dämonen -, die vom Papst später noch einmal aufgegriffen werden sollte. Die Bewertung der in Jerusalem praktizierten Herrschaftsform unterliegt jedoch keinerlei Zweifel: allein der Friede (pax) lenke dort die Geschicke und sei Garant für das gedeihliche Zusammenleben aller Menschen. Im zweiten Unterpunkt wird auf Fragen der Deutung (ratione interpretationis) verwiesen, was insofern einen Pleonasmus bezeichnet, als Interpretationsfragen bereits seit Beginn der Collatio eine zentrale Rolle gespielt haben. Noch einmal wird Babylon als allumfassende confusio interpretiert, die nicht nur Sachen und Körper, sondern auch Herzen und Seelen umfasse, und damit gegen Jerusalem, Sinnbild einer visio pacis, abgegrenzt ${ }^{343}$.

Auch der dritte Unterpunkt (ratione similis condicionis) erschöpft sich in der Wiederholung von bereits Gesagtem. Sämtliche bereits zu Beginn angeführten Gegensatzpaare finden noch einmal Erwähnung. Immerhin bringt der Abschluß dieses Gedankengangs die erste konkrete Bezugnahme auf das Wirken der Kardinäle, die am eigenen Leibe den vom König von Babylon, dem Teufel, bewirkten kriegerischen Aufruhr (bellica commotio) miterlebt hätten. Erst durch ihre diplomatische Intervention habe der König von Jerusalem, Christus, dazu bewegt werden können, einen Waffenstillstand gutzuheißen. Somit erweise sich denn auch das Thema als geeignet, um das Tun der Nuntien zu charakterisieren ${ }^{344}$.

Der folgende Abschnitt steht unter dem Leitgedanken der tribulatio und wird mittels einer geschickten Verbindung von Neuem und Altem Testament eingeleitet. Die in Apc 7,13 formulierte Frage: Hii qui amicti sunt stolis albis, qui sunt et unde venerunt? ${ }^{345}$ läßt der Papst in die vom Thema vorgegebene Antwort münden: Hii sunt viri qui ascenderunt de captivitate. Esra als antique legis doctor ${ }^{346}$ wird damit in das bibelinterne Verweissystem eingegliedert, durch das Ereignisse im Neuen Testament bereits im Alten Testament aufscheinen und so eine enge Verbindung zwischen Altem und Neuem Bund hergestellt wird. Die in der Apokalypse vorgegebene Antwort auf die gestellte

sentieren die Dämonen, die ihre Nahrung allein der menschlichen Zwietracht verdanken. Dieser ausgesprochen dichte Gedankengang wird den Zuhörern in verkürzter Form dargeboten und beschränkt sich auf diejenigen Punkte, die zum Verständnis des Gesagten absolut notwendig sind. Zur allgemeinen Bedeutung von De civitate Dei im Mittelalter vgl. Giuseppina CANnIzzo, Eternità del mondo: su alcune letture medievali del De civitate Dei, in: Il De civitate Dei. L'opera, le interpretazioni, l'influsso, hg. v. Elena CavalcanTr, Rom, Freiburg, Wien 1996, S. 405-435.

$343 \mathrm{Vgl}$. MS 240, fol. 450rb.

344 Ibid., fol.450vb: Concludendo ergo, quia venerabiles fratres nostri veniunt de bellica commotione, quam operatus est dyabolus rex Babylonis et eorum ministerio rex Jherusalem, Jhesus Christus, pacem seu treugas representans pacis ymaginem operatus est. Merito de eis possum dicere verba thematis preassumpta [...].

345 Luther übersetzt: »Wer sind diese, mit den weißen Kleidern angetan, und woher sind sie kommen? «

346 Ibid. 
Frage, nämlich: Hii sunt qui venerunt ex magna tribulatione et laverunt stolas suas in sanguine agni. Ideo sunt ante thronum dei et serviunt ei die ac nocte in templo eius et qui sedet in throno habitabit super illos ${ }^{347}$, ist für die weitere Entfaltung des Gedankengangs in mehrfacher Hinsicht von Bedeutung. Die Gesandten sind nicht nur aus der babylonischen Gefangenschaft zurückgekehrt: ihnen wird jetzt die Freude zuteil, in Jerusalem zu sein, um dort vor dem Thron Gottes zu sitzen ${ }^{348}$. Selbst den Prälaten, die mit den plenitudo potestatis-Vorstellungen Clemens' VI. bereits vertraut waren, dürfte bei diesen Aussagen unwohl geworden sein. Die Assoziationskette mündet nicht nur in einem schlichten Vergleich Jerusalem - Rom - Avignon, sondern wird ins Extrem gesteigert. Avignon repräsentiert nicht nur das zwangsläufig mit Makeln behaftete irdische Jerusalem, sondern kommt dem himmlischen Jerusalem gleich. Allerdings thront in Avignon nicht Gottvater, sondern der Papst. Können die Gesandten also vor dem Thron Gottes sitzen, sitzen sie als Vertreter der Kurie vor dem Thron des Papstes und dienen ihm - wie dereinst die in der Apokalypse bemühten Gestalten - Tag und Nacht. Das lebenspendende Zentrum ist also Avignon. Mittelpunkt des Zentrums ist der Papst als Stellvertreter Christi. Der päpstliche Primat wird einmal mehr durch den Verweis auf seine christozentrischen Grundlagen untermauert.

Das Bemühen des Papstes, die von den Gesandten erbrachten Leistungen entsprechend zu würdigen, muß hinter diesen Äußerungen zwangsläufig verblassen. Man bewegt sich zwar auch weiterhin auf der Ebene der Superlative, doch geht der Ausschließlichkeitscharakter der Aussagen verloren. Auch wenn er nicht ausschließe - so der Papst -, daß andere Legaten oder Nuntien eine intensivere Drangsal erlitten hätten, so halte er es doch für ausgeschlossen, daß ihnen eine extensivere Drangsal zuteil geworden sei ${ }^{349}$. Durch das Adjektiv extensivus wird nicht nur auf die zeitliche Dauer der Gesandtschaft ${ }^{350}$, sondern auch und insbesondere auf ihre politische Dimension verwiesen. Doch auch das im Adjektiv intensivus aufscheinende Bedeutungsspektrum geht nicht ganz verloren. Andere Legaten haben mehr gelitten: Diese Aussage impliziert doch, daß ganz konkret auch Annibaldo Ceccano und Étienne Aubert gelitten haben. Erinnert sei an den Briefwechsel zwischen

347 Apc 7,14f. Luther übersetzt: »Diese sind's, die kommen sind aus großer Trübsal und haben ihre Kleider gewaschen und haben ihre Kleider hell gemacht im Blut des Lammes. Darum sind sie vor dem Stuhl Gottes und dienen ihm Tag und Nacht in seinem Tempel. Und der auf dem Stuhl sitzt, wird über ihnen wohnen «.

${ }_{348}$ MS 240, fol. 451 ra: Quid est enim venire de magna tribulatione nisi venire de captivitate babilonica? Quid est sedere ante thronum Dei nisi reversum esse in Jherusalem, id est ad istam sanctam sedem, ubi habent servire Christo et eius vicario die ac nocte?

349 Ibid.: Audeo dicere, quod licet forte audiverim aliquos legatos seu sedis apostolice nuncios forte passos fuisse unam maiorem tribulationem intensive, tamen de nullis legi nec audivi passos fuisse maiores tribulationes extensive.

350 Immerhin halten sich die beiden Kardinäle über zwei Jahre, von November 1345 bis Dezember 1347, fern der Kurie auf. 
Papst und Nuntien, in dem mehr als einmal auf die von den Nuntien geäußerte Furcht um ihr eigenes Leben verwiesen wurde. Die Bedeutungsvielfalt des Begriffs tribulatio war von den Gesandten also in all seinen Schattierungen wahrgenommen worden ${ }^{351}$. Eben diesen Ausformungen von tribulatio nimmt sich der Papst nun näher an, beschränkt sich dabei jedoch auf die durch das Vorbild Hiob ${ }^{352}$ vorgegebene Siebenerzahl. Explizit benannt werden der Überdruß durch allzu umfangreiche und überfordernde Arbeiten (tedium magnorum laborum), die Fülle an großem Schmerz (profluvium multorum dolorum), der aus zu großer Ermattung resultierende Schaden (dispendium gravium languorum), die Zerstörung des eigenen Besitzes (excidium suorum bonorum), das Seufzen aufgrund gerechtfertigter Angst (suspirium iustorum timorum), der Einbruch drängender Gefahren (incursum ingruentium periculorum), die Lippen böser Verleumder (labium malorum detractorum). Zur rhetorischen Entfaltung gelangt jedoch nur der letzte Punkt. Der Papst räumt ein, daß seine Nuntien den Angriffen von Verleumdern ausgesetzt gewesen seien, durch die nicht nur ihre Verdienste, sondern auch ihre moralische Integrität in Zweifel gezogen worden seien ${ }^{353}$. Clemens VI. nutzt die Predigtsituation, um für seine Gesandten einzutreten und seine eigene Haltung durch den Verweis auf eine biblisch fundierte »der Gerechte muß leiden«-Konstante zu verdeutlichen ${ }^{354}$.

Vor dem Hintergrund der bis dahin getroffenen Feststellungen zögert Clemens VI. nicht, zum Ausgangspunkt seiner Überlegungen, d.h. zum Thema selbst, zurückzukehren. Der Gestaltungswille ist dabei unverkennbar, findet diese Rückwendung zum Esra-Zitat doch genau in der Mitte der Collatio statt. Das Thema wird - streng scholastischer Praxis folgend - in vier Bestandteile aufgespalten: 1. Hii sunt viri, 2. qui ascenderunt, 3. de captivitate, 4. quia reversi sunt in Jherusalem. Aus diesen Worten werden vier Arten von Bewegung extrahiert, wobei zwischen fremdbestimmten und eigenverantworteten moventia unterschieden wird, die jedoch alle insofern einem passiven Prinzip unterliegen, als der eigentliche Anstoß für die Bewegung von außen kommt. "Movetur« verweist so einmal mehr auf die Vorgabe von Handlungen, das »Auf-den-Weg-bringen«, ein Vorgehen, das der Papst für sich in Anspruch nimmt. Die Betrachtungen beziehen sich zum einen auf die Sache, die bewegt wird (mobile quod movetur), auf die Art der Bewegung (motum quo movetur), auf den Ausgangspunkt der Bewegung (terminum a quo movetur), zum anderen auf deren Zielpunkt (terminum ad quem movetur) ${ }^{355}$. Erst durch die

351 Vom Papst werden, wie nicht anders zu erwarten, die entsprechenden Bibelstellen zitiert: 2 Cor 6,4f.; 2 Cor 11,10; Ps 114,3f.

352 Iob 5,19: In sex enim tribulationibus liberavit eos dominus et in septima non tetigit eos malum.

353 Vgl. Lettres Clément VI, nn. 2760 (27.08.1346), 2766 (28.08. 1346).

354 Dazu werden zwei aussagekräftige Stellen des AT und NT miteinander in Beziehung gesetzt: I Cor 4,9-13 und Jer 38,4f.

$355 \mathrm{Vgl}$. MS 240, fol. 451va. 
weitere Spezifizierung verliert das rhetorische Vorgehen etwas von seiner künstlich-bemüht wirkenden Sprödigkeit. Die zuerst erwähnte Sache - und kein Zweifel kann daran bestehen, daß damit das Wirken der Kardinäle gemeint ist - besticht durch Entschlossenheit (strenuitas) und Exzellenz (excellentia). Steilheit (arduitas) und Heftigkeit (vehementia) sind diejenigen Charakteristika, mittels derer der Papst die Bewegung selbst, d.h. die Gesandtschaft, zu umreißen sucht. Mit dem Ausgangspunkt der Bewegung ist die politisch ausweglos erscheinende Lage zu Beginn der Gesandtschaft gemeint, deren Unheil (calamitas) und Elend (miseria) für alle mit Händen zu greifen waren. SchlieBlich verweist der Zielpunkt der Bewegung auf das während der Gesandtschaft erzielte Ergebnis, in dem sich Sicherheit (securitas) und Gefälligkeit (complacentia) widerspiegeln ${ }^{356}$. Müßte diese komplexe Argumentationsstruktur in einem Satz zusammengefaßt werden, würde das Ergebnis wohl wie folgt lauten: Durch ihre hervorragenden Eigenschaften waren die Nuntien des Apostolischen Stuhls in der Lage, durch selbstlosen Einsatz eine politische Krise größten Ausmaßes zu bewältigen und ein für alle Parteien befriedigendes Ergebnis zu erzielen.

Ohne Übergang schließt sich an die Gliederung des Themas in vier Elemente eine andere, diesmal auf nur drei Elementen basierende Divisionsformel an, durch die freilich nur die zuvor unter 2. und 3. noch separierten Elemente miteinander verbunden werden. Den Gesandten wird ein Geist himmlischer Kraft zugeschrieben (spiritum celici vigoris), ein Gespür für das Schnauben des Kriegstreibers nachgesagt (fremitus bellici hominis) und ein Ertrag an aus Frieden resultierender Süße (reditus pacifici dulcoris) bescheinigt. Den einzelnen Elementen dieser Trias werden in bereits bekannter Manier charakteristische Substantive zugeordnet. Festigkeit und Kraft (constantia et fortitudo) reihen sich an Verzagtheit und Bitterkeit (angustia et amaritudo), um in Ruhm und Ehre (gloria) zu münden. Doch damit nicht genug. Jedem der drei Divisionselemente des Themas wird noch ein weiteres Charakteristikum zugewiesen, durch welches das konkrete Handeln der Nuntien stärker in den Blickpunkt rückt. Sie zeigen sich nicht nur diplomatisch einfallsreich zu Beginn ihrer Gesandtschaft (in aggressu virtuosi) und bedecken sich im weiteren Verlauf mit Ruhm (in processu gloriosi), sondern kehren auch frohen Herzens an die Kurie zurück (in regressu gaudiosi). Die Freude über die Rückkehr dürfte dabei in der Vorstellung des Papstes jedoch eher aus der Befriedigung über den erzielten Waffenstillstand denn aus der Erleichterung darüber, einer lebensgefährlichen Situation entronnen zu sein, resultieren. Die komplexe gedankliche Struktur hat damit den höchsten Grad ihrer Entfaltung erreicht.

Für jedes der drei Divisionselemente 1. Hii sunt viri, 2. qui ascenderunt, 3. reversi sunt in Jherusalem verfügt der Papst nun über ein Konglomerat 
charakteristischer Adjektive und Substantive ${ }^{357}$. Als wollte Clemens VI. seine Meisterschaft im Umgang mit unterschiedlichen Dilatationsformeln unter Beweis stellen, geht er - nach wie vor die Division in drei Elemente berücksichtigend - zur Diskussion der grammatikalischen Struktur des Themas über ${ }^{358}$, um danach erneut auf Eigenschaften überleiten zu können, die er seinen Nuntien zubilligt. Ihr Erfolg erweise sich nicht nur an der Qualität der erzielten Ergebnisse (excellentia operum), deren Entstehung der mentalen Festigung (mentium constantia) der Gesandten geschuldet sei, sondern auch am Übermaß der von ihnen ausgehenden Tugenden (virtutum affluentia).

Die Beschreibung der excellentia operum nutzt Clemens VI. erneut zu einer Darstellung der eigenen Beteiligung am Verhandlungsergebnis. Eingebettet in eine Vielzahl biblischer Belege ${ }^{359}$ wird der Nachweis erbracht, da 3 die Kardinäle ihr Dasein allein dem Papst verdanken. Wenn sie Erfolge erzielten, könnten sie dies nur tun, weil sie dem Herrscher der Welt - dominus terre zugeordnet seien, weil sie »aus seiner Seite « hervorgingen ${ }^{360}$. Auffällig immerhin, daß Clemens VI. hier die Kategorien der Nuntien und Legaten um diejenige von nuncii a latere erweitert, eine kirchenrechtlich nicht definierte Funktion, deren Beschreibung man in offiziellen kirchenrechtlichen Sammlungen vergeblich sucht. Die unmittelbare Zuordnung zum Papst - man ist pars corporis papae - läßt in diesem Falle die insbesondere auf dem Gebiet der Vollmachten angesiedelten Abgrenzungen zwischen Nuntien und Legaten verschwimmen. Clemens VI. wird anhand zweier Zitate noch deutlicher: Die nuncii a latere seien es, die dem Herrn der Welt, somit ihm selbst, dienten. Sie seien ausführende Organe in dem Bestreben, über das eigene Volk zu wachen, um damit das Einfallen fremder Truppen zu verhindern ${ }^{361}$. Ihre Befugnisse habent potestatem claudere celum et aprire ${ }^{362}$ - seien Ausfluß der päpstlichen plenitudo potestatis. Im konkreten Fall werden damit ihre Vollmachten angesprochen, Exkommunikationen auszusprechen und einen Waffenstillstand zu

${ }^{357}$ Für das erste Divisionselement Hii sunt viri ergibt sich somit laut MS 240, fol.451vb folgendes Ergebnis: Dico primo, quod video in istis strenuitatem et excellentiam multiplicius commendandas. Habuerunt enim spiritum celici vigoris, ex quo fuerunt constantia et fortitudine roborati, ut essent in aggressu tanti negocii virtuosi. Agressi enim sunt cum magna constantia et ardore.

358 Ibid.: Et videtur michi, quod hic sunt tres dictiones, pronomen demonstrativum (Hii), verbum substantivum (sunt), nomen virtutis expressivum (viri).

359 Apc 11,4; Apc 11,6; Zach 4,14; Jer 11,16; Lc 11,33; II Chr 4,7; Zach 4,14; Zach 9,8; Zach 9,10; Mt 10,1; Lc 10,19; Sap 5,1.

360 MS 240, fol.452ra: Videte tertio nuncios complacentes assistentia et propinquitate ad attrahendum, quia dicitur, quod sunt in conspectu domini terre stantes, ad litteram nuncii de latere nostro.

361 Zach 4,14: Assistunt domini terrae; Zach 9,8: Circumdabo domum meam ex hiis qui militant michi euntes et revertentes. Und Clemens VI. verdeutlicht: Circumdabo domum meam, id est ecclesiam, ex hiis, qui militant michi, id est ex hiis, qui michi serviunt in ecclesia in variis ministeriis et ad meum imperium huc illucque discurrunt (MS 240, fol. 452ra).

362 Ibid. 
vermitteln ${ }^{363}$. Der Papst sieht sich selbst als pater familias, die Kardinäle hingegen als in allen Dingen unmittelbar von ihm abhängige servi ${ }^{364}$.

Der Blick des Papstes richtet sich nun auf die mentale Disposition der Kardinäle, genauer auf ihre mentium constantia. Dabei wird ganz auf eigene Bemerkungen verzichtet. Durch die Aneinanderreihung von Bibelzitaten wird aber unterstrichen, daß die Hand des Herrn auf dem Tun der Kardinäle geruht habe, sich nicht zuletzt deshalb die Anschuldigungen ihrer Verleumder in nichts aufgelöst hätten 365 .

Die des weiteren angeführte virtutum affluentia wird von Clemens VI. auf die günstige Grunddisposition seiner Gesandten zurückgeführt. Ihre Überlegenheit gründe auf dem mannhaften Vorantreiben der Aufgaben, auf dem starken Widerstand, den sie ungerechtfertigten Forderungen gegenüber leisteten, auf ihrem beharrlichen Insistieren, auf dem gleichmütigen Hinnehmen auch demütigender Beleidigungen und schließlich auf dem am Nutzen der Kurie orientierten Verhandlungsergebnis ${ }^{366}$. Doch damit ist die Charakterisierung des idealen Kuriendiplomaten noch nicht an ihrem Ende angelangt. Überragende Klugheit (prudentie certitudo), Beharrungsvermögen (constantie fortitudo), Ausdauer (perseverantie longitudo), Geduld (patientie magnitudo) und schließlich göttliche Gnade (gratie plenitudo) vervollständigen das »Anforderungsprofil $\aleph^{367}$. Die Nuntien werden zu Auserwählten, zu viri electi, und

363 Ibid.: Et habent potestatem super aquas. Ad litteram per sententiam excommunicationis et aliter indicendo treugas et aliter compellendo. Clemens VI. läßt es sich nicht nehmen, mit Mt 10,1 ein weiteres Bibelzitat anzuführen, durch das die potestas der Kardinäle auch im spirituellen Bereich umrissen wird: Cum Christus misit apostolos dedit eis potestatem spirituum immundorum, ut eos eicerent et curarent omnem languorem et omnem infirmitatem. Die Macht, bösen Geistern wirkungsvoll zu begegnen, war bereits 1345 von Kardinal Bertrand du Pouget zum Thema einer vor Papst und Kardinälen gehaltenen Predigt gemacht worden. Die heute in einer Handschrift des Pembroke-College überlieferte Predigt, der das Thema Erat Jhesus demonium eicens (Lc 11,14) zugrundeliegt, weist interessante Bezugspunkte zur Collatio des Papstes auf und soll deshalb weiter unten kurz besprochen werden, vgl. Kap. 5.1.10.

364 MS 240, fol.452ra: Unde pater familias mittens servos dedit eis potestatem cuiusque operis. Der Vergleich mit der korrespondierenden Bibelstelle Mc 13,34 offenbart Erstaunliches: ist es dort ein Hausvorstand, der vor seiner Abreise sein Haus ordnet, jedem Sklaven bestimmte Arbeiten zuweist und dem Pförtner befiehlt, wachsam zu sein, bleibt im Falle Clemens' VI. der Hausvorstand zwar vor Ort, sind es die Sklaven, die ausgesandt werden, und dennoch wird in der Vorstellung des Papstes die biblische Aussage nicht umgekehrt. Da die servi, d.h. die Kardinäle, im Range von nuncii a latere agieren, ist es ohne Belang, ob sie oder der Papst selbst das Haus, d.h. die Kurie, verlassen. Pater familias und servi agieren - der Vorstellung vom pars corporis papae sei Dank - als eine Person.

365 Vgl. MS 240, fol.452rb. Zitiert werden folgende Stellen: Sap 5,3f.; Apc 14,4f.; Sap 10,14; II Chr 20,17.

366 MS 240, fol. 452rb: Vir enim dicitur a virtute. Et ad litteram isti fuerunt bene viri. Viri, inquam, viriliter prosequentes, fortiter resistentes, immobiliter insistentes, equanimiter sustinentes, utiliter proficientes.

367 Ibid., fol. 452va: Viriliter, inquam, prosequentes regulati prudentie certitudine, fortiter resistentes roborati constantie fortitudine, immobiliter insistentes animati perseverantie longi- 
der Papst unterstreicht: zu Auserwählten, die die Wahrheit lieben und die Habsucht verabscheuen ${ }^{368}$. Auch hier werden in einem Halbsatz Vorwürfe entkräftet, die im Laufe der Gesandtschaft gegen die Nuntien erhoben worden waren. Eigenständiges Handeln wird ihnen ebenfalls bescheinigt - gleichsam ein Paradoxon, weil in und mit ihnen der Papst selbst handelt, ein nicht von ihm gesteuertes und verantwortetes Handeln also eigentlich ein Ding der Unmöglichkeit ist. Und dennoch sind die diplomatischen Initiativen von Erfolg gekrönt - stets jedoch unter der Prämisse einer engstmöglichen Rückbindung an die Kurie ${ }^{369}$. Clemens VI. verleiht dem erzielten Ergebnis zusätzliches spirituelles Gewicht, indem er all denen einen $A b l a ß$ von zehn Tagen gewährt, die für den Bestand der Vereinbarungen beten ${ }^{370}$. Die Völker Frankreichs und Englands könnten mit den Leistungen der Kardinäle zufrieden sein - so der Papst mittels eines Zitats aus dem ersten Samuelbuch, das auch seine eigene Zufriedenheit widerspiegelt, war die päpstliche Diplomatie doch mit der erklärten Absicht angetreten, das Blutvergießen, unter dem insbesondere die gemeine Bevölkerung zu leiden hatte, zu beenden ${ }^{371}$. Eine weitere Spielart der rhetorischen Dilatatio schließt sich an: die comparatio. So werden die

tudine, equanimiter sustinentes armati patientie magnitudine, sed utiliter proficientes decorati gratie plenitudine. Bene ergo viri, id est virtuosi. Die Subdivision folgt den Vorgaben der Gleichheit von Endsilben. Dieser concordantia in voce bedient sich Clemens VI. recht häufig, gilt sie doch als Merkmal rhetorischer Verfeinerung und virtuoser Sprachbeherrschung.

368 Ibid.: Isti enim sunt viri electi iuxta consilium Jetro, viri inquam potentes et timenes Deum, in quibus fuit veritas et qui oderunt avaritiam, Exo. XVIII, qui ex se treugas fecerunt. Der Bezug auf Ex 18,21 eröffnet eine weitere Vergleichsebene, was ein Blick auf die Fortsetzung des Verses bestätigt: [...] et constitue ex eis tribunos et centuriones et quinquagenarios et decanos, qui iudicent populum omni tempore, quicquid autem maius fuerit, referant ad te. Übertragen auf die Kurie bedeutet dies, daß der Papst sein Spitzenpersonal nach Kriterien auswählt, die im Bereich sowohl moralischer Integrität als auch absoluter Untergebenheit zu verorten sind.

369 Ibid.: Sed quod maius fuerit [und hier erfolgt der Bezug auf Ex 18,21f.] ad nos retulerunt, scilicet pacem proficiendam, pro qua tantam dispositionem fecerunt, quod utraque pars debet propter hoc ad nos infra festum purificationis mittere suos nuncios sollenes et placeat, quod ille velit introducere formam pacis. Angesprochen wird hier also eine mögliche Neuauflage der Konferenz von Avignon. Wie wichtig dem Papst der enge Kontakt mit seinen Gesandten war, verdeutlicht eine Passage aus der Collatio Et iste bonus est nuntius, gehalten 1343 anläßlich der Rückkehr von Kardinal Bernard d'Albi, vgl. ibid., fol.69ra: Dico quarto, quod noster nuncius habuit veritatem iusticie in gestorum relatione veraci et ideo reportavit seriose. Ad litteram enim, quod in ipsis regibus et eorum consiliariis reperit nulli parcendo, nullum palpando, fideliter scripto retulit et verbo seriosius reportavit.

370 Ibid., fol. 452va: Et ut dignetur omnibus, qui oraverint omni die, concedimus decem dies de indulgentia ultra indulgentias solitas.

371 Ibid.: Ut de eis dicat populus Francorum et Anglie illud primum Regum XXV: Viri isti boni satis fuerunt nobis; pro muro erant nobis tam in nocte quam in die; vgl. auch Joseph FunKENSTEIN, Samuel und Saul in der Staatslehre des Mittelalters, in: Archiv für Rechtsund Sozialphilosophie 11 (1952/1953) S.129-140; Paul KIRN, Saul in der Staatslehre, in: Staat und Persönlichkeit. E. Brandenburg zum 60. Geburtstag, hg. v. August DoEN, Leipzig 1928, S. 28-47. 
beiden Kardinäle nicht nur mit Caleph und Josua, sondern mit Moses und Elias $^{372}$ verglichen.

Die übergeordnete Struktur, welcher die Ausführungen des Papstes folgten, dürfte in der Zwischenzeit aus dem Bewußtsein der Zuhörer wie der Leser verschwunden gewesen sein. Dennoch wird sie in dem Augenblick wieder aktuell, als sich Clemens VI. in Rückbindung an die Divisionstrias deren zweitem Element nähert und es samt allen Verästelungen aktualisiert ${ }^{373}$. Eine zentrale Stellung nimmt vor diesem Hintergrund die Reflexion über Babylon als Hort des Bösen und die Mission der Kardinäle als Friedensengel daselbst ein. Friedensengel verzichteten auf jegliche Gewaltanwendung, wirkten durch das Wort, das durch sie jedoch zur Waffe (iacula) umfunktioniert werden könne $^{374}$. Im Gegensatz zu allen anderen, die sich im Umkreis Babylons, d.h. der Hölle, bewegten, stiegen sie nicht dorthin hinab, in Umkehrung der Verhältnisse gerate ihnen im Gegenteil der Abstieg zum Aufstieg ${ }^{375}$. Diese Bewegung nach oben wird als Bewegung nach innen beschrieben, die sich in vier Schritten vollzieht. Einem stereotypen »ascenderunt « werden so unterschiedliche grammatikalische Formen des Begriffs cor zugeordnet. Diese paronomastische Spielerei ist nichts anderes als eine neue Zurschaustellung rhetorischer Fertigkeiten, die im Bereich der Concordantia in voce anzusiedeln sind ${ }^{376}$. Dem Papst bietet dieses Vorgehen die Möglichkeit, den Blick stärker auf die moralisch-spirituelle Ebene zu lenken und damit die Niederungen zwar wichtiger, jedoch inferiorer Realpolitik an die darüber hinausgehenden Zielsetzungen des Papsttums zu koppeln. Doch auch hier mag er sich nicht ganz vom konkreten Hintergrundgeschehen lösen, vergleicht er doch die Bewegung supra cor mit der bewußten Inkaufnahme von Gefahren für Leib und Leben.

372 Maria M. WrTTE, Elias und Henoch als Exempel, typologische Figuren und apokalyptische Zeugen. Zur Verbindung von Literatur und Theologie im Mittelalter, Frankfurt a.M., Bern, New York 1987. Auch die Figur des Josua war typologisch einschlägig besetzt: sie wurde als historische Realprophetie Christi interpretiert, vgl. AUERBACH, Typologische Motive, S. 7-9.

373 MS 240, fol.452vb-453ra: Dicebam II., quod isti sentierunt fremitum bellici horroris. Unde fuerunt in congressu gloriosi, quia congressi sunt cum magna prudentia et labore. Ipsi enim ex bellico fremitu fuerunt angustia et amaritudine circumdati vel circumvallati / et tamen gloriosi sunt congressi, qui ascenderunt de captivitate quam transtulerat etc.

374 Ibid., fol.453rb: Debet enim quilibet angelus pacis contra Babilonem, id est bellicam commotionem, se preparare, per debitam sollicitationem archum intendere, per scripturarum inductionem eam debellare, per ratiocinationem et argumentationem iacula mittere, per malorum, que ex ea veniunt, detestationem clamare adversus eam per bonorum, que per eam perduntur. Der Bezug zu Jer 50,14f. - in der Collatio auch angeführt - liegt auf der Hand.

375 Ibid.: Nostri ergo pacis angeli sicut virtuosi, sicut gloriosi, sicut fructuosi non habuerunt in ista Babilone motum descensus, sed motum ascensus. Diese Bewegung wird mittels Adverbien - deren uniforme Endung auf -liter sich hervorragend für eine concordantia in voce eignet - näher erläutert.

376 Ibid., fol. 453va: Ascenderunt ad cor, ascenderunt in corde, ascenderunt de corde, ascenderunt supra cor. Ascenderunt de corde opere et indeficienti animo insistendo, ascenderunt inquam ad cor Deum exorando, ascenderunt in corde vias et remedia cogitando, ascenderunt supra cor etiam vitam propriam periculis exponendo. 
In Fortführung der dem ersten Divisionselement zugeordneten Personenvergleiche finden sich die beiden Kardinäle jetzt in den Gestalten des Paulus und des Barnabas personifiziert. Zum ersten Mal erfährt man Dinge, die den Bereich allgemein gehaltener Charakteristika übersteigen. Wie Paulus könne Annibaldo als großer Theologe gelten - sei freilich auch kahlköpfig wie dieser. Mit diesem humoristisch gefärbten Kompliment leitet der Papst zur Gestalt des Étienne Aubert über, dessen eminente Qualitäten als Jurist Erwähnung finden ${ }^{377}$. Ein zweifaches Schwert gehe aus dem Mund der Kardinäle hervor: das des göttlichen und das des positiven Rechts ${ }^{378}$. Mit diesem Schwert richteten sie über die beiden Nationen England und Frankreich. Der Papst unterstreicht, daß kriegerisches Verhalten diesen Nationen wesensfremd sei $^{379}$, deshalb der Grund für die Auseinandersetzungen beim König von Babylon, dem Teufel, gesucht werden müsse ${ }^{380}$. Die Analyse der aus dem Kriegszustand resultierenden Auswirkungen ist luzide. Betroffen seien nicht nur die beiden Königreiche, sondern die gesamte Christenheit. Nicht nur die Verarmung weiter Teile Europas sei eine Folge des Krieges, sondern die Erhebung der Ungläubigen über die Gläubigen. Auch am desolaten Zustand der christlichen Position im Heiligen Land seien die Auseinandersetzungen nicht ganz unschuldig 381 .

Das Ungleichgewicht in der Behandlung des zweiten gegenüber dem ersten Divisionselement verstärkt sich in Hinblick auf das abschließende dritte, für das in der Collatio temporis causa nur noch wenig Raum bleibt ${ }^{382}$. Clemens VI. nutzt die Gelegenheit, um abschließend noch einmal seiner Freude darüber Ausdruck zu verleihen, daß die Nuntien nach ihrem Sieg über die Dämonen glücklich nicht an irgendeinen Ort, sondern nach Jerusalem, d.h. an die Kurie nach Avignon, zurückgekehrt seien. Die Collatio schließt mit der Bitte um die Schau des himmlischen Jerusalem: Ad quam nos perducat qui est benedictus in secula seculorum, Amen $^{383}$.

377 Ibid.: Paulus quidem Anibaldus noster magnus theologus et calvus, sicut et Paulus, et Barnabas noster Stephanus, doctor in iure egregius, filius quidem consolationis quasi alter [...]. Humoristisch gefärbte Schlußwendungen finden sich auch in anderen Collationes, vgl. Collatio Egrediebatur et intrabat.

378 Ibid.: Unde de ore eorum procedebat gladius bis acutus: iuris scilicet divini et etiam positivi. (Bezugnahme auf Apc 1,16).

379 Die stattliche Anzahl von zwanzig positiv konnotierten Substantiven dient zur Überhöhung der beiden Königreiche, vgl. ibid., fol. 453vb.

380 Ibid.: Ergo ista bellica commotio non est ibi naturaliter, sed magis ex translatione regis Babilonis, id est dyaboli propter aliqua occulta indicia Dei.

381 Ibid.: Ex hoc enim quasi sequitur totius christianitatis commotio et depauperatio et infidelium contra fideles erectio et totius christianitatis in partibus orientalibus desolatio.

382 Ibid., fol. 454ra: Dico III. et ultimo, quod ipsi hodie obtinuerunt reditum pacifici dulcoris, unde sunt in regressu gaudiosi, quia reversi sunt in Jherusalem, id est ad istam sanctam sedem, a qua missi fuerant certe cum tristitia et dolore. Sed hodie reversi sunt letitia et amore.

383 Ibid., fol. 454rb. 


\subsubsection{Bertrand du Pouget und sein Sermo Erat Jhesus eiciens}

Der in Form einer Reportatio überlieferte Sermo von Kardinal Bertrand du Pouget $^{384}$, gehalten in der Fastenzeit des Jahres 1345 in der Kapelle des päpstlichen Palastes zu Avignon, bietet sich insofern als Vergleich zur Collatio des Papstes an, als auch in ihm eine durch das Thema vorgegebene starke Bezugnahme zur Welt der unheilbringenden, nur durch die Kirche zu besiegenden Dämonen stattfindet. Inwieweit sich im überlieferten Sermo der originale Sprachduktus des Kardinals widerspiegelt, kann aufgrund der Überlieferungssituation nicht geklärt werden ${ }^{385}$; immerhin scheint das der Predigt zugrundeliegende gedankliche Gerüst jedoch ohne Brüche niedergeschrieben worden zu sein.

Bertrand eröffnet seinen Sermo mit der Feststellung, daß sich die Macht Jesu in keinem anderen Wunder so deutlich gezeigt habe wie bei der Austreibung der Dämonen. Gerade dort manifestiere sich am offensichtlichsten seine Macht über die bösen Geister ${ }^{386}$, wobei göttliche virtus und potentia ineinanderflössen. Der Bezug auf virtus und potentia führt zur ersten großen Aufgliederung des Gedankengangs: beide Elemente zeigen sich sowohl auf seiten dessen, der die Dämonen austreibt, als auch auf seiten dessen, der Opfer dieser Austreibung ist: primo ex parte eicientis, secundo ex parte eiecti $i^{387}$. Der erste Untersuchungsgegenstand erfährt eine nochmalige Auffächerung in drei Unterpunkte: Primo per modum eiciendi, secundo per modum disputandi, tercio per modum committendi ${ }^{388}$. Von großer Wichtigkeit ist hier der dritte Unterpunkt, in dem von der Übertragung der Macht, Wunder zu wirken, die Rede ist. Christus übergibt nach seiner Auferstehung den Aposteln die Vollgewalt der Predigt und der Dämonenaustreibung.

384 Der Sermo findet sich in einer im Pembrok College zu Cambridge aufbewahrten Handschrift, vgl. JAMES, A descriptive catalogue, n. 98 , fol. $94 \mathrm{v}-98 \mathrm{v}$ : Reportatio fratris Berardini de urbe veteri fratris heremitarum sancti Augustini ordinis de sermone facto in capella papae per reverendum in Christo patrem et dominum dominum Bertrandum episcopum Hostiensem et Vellatrencensem cardinalem in tercia dominica $X L$ in civitate Avinionensi anno domini MCCCXLIIII tempore sanctissimi in Christo et domini Clementis divina providencia papae VI sui pontificatus anno tercio etc.; vgl. auch BEATTIE, A curial sermon. Von Berardus (Bernardus) von Orvieto ist eine weitere reportatio in mehreren Handschriften überliefert, vgl. z.B. Adolar ZuMKeller, Manuskripte von Werken der Autoren des Augustiner-Eremitenordens in mitteleuropäischen Bibliotheken, Würzburg 1966, S. 92 , n. 187: Reportatio responsionis nuntiis seu ambassatoribus Romanorum per Clementem VI. anno Domini 1343 in civitate Avinionensi die vicesima septima mensis Januarii factae. Hierbei handelt es sich um die berühmte Ansprache Clemens' VI. an die Gesandtschaft der Römer Desidero videre vos; Anneliese MAIER, Codices Burghesiani Bibliothecae Vaticanae, Rom 1967, S. 47.

385 Zur aktuellen Forschungsdiskussion bezüglich reportationes vgl. Kap. 1, 3.2.

386 Vgl. Mt 17,14-21 mit dem Bericht von der Heilung des mondsüchtigen Knaben.

387 Pembrok, MS 98, fol. 94v.

388 Ibid. 
Die Bischöfe als Nachfolger der Apostel - und Bertrand spricht als herausgehobener Vertreter des bischöflichen Ordo innerhalb des Kardinalskollegs in eigener Sache -, sehen sich gleichermaßen mit dieser Macht begabt: Subtil stärkt Bertrand hier die bischöfliche Vollgewalt und unterstreicht durch die Verschränkung von Predigt und Dämonenaustreibung die Bedeutung der vornehmsten bischöflichen Aufgabe, der Predigt, die freilich um 1345 nur noch in Schwundstufen vorhanden und von den Vertretern der Bettelorden schon seit langem unterminiert worden war. Nach einer nochmaligen Betonung der Tatsache, daß in den messianischen Dämonenaustreibungswundern die göttliche potentia wohl am stärksten zur Verwirklichung strebe ${ }^{389}$, wendet sich der Autor dem zweiten übergeordneten Punkt zu. Gegenstand der Betrachtungen wird derjenige, der Opfer einer Austreibung ist, nämlich der Dämon selbst. Bertrand unterstreicht die biblisch legitimierte Sicht vom Teufel als princeps mundi ${ }^{390}$, dessen Gewalt nur von Christus bzw. von den von ihm beauftragten Personen gebrochen werden könne - Christus selbst erweise sich erst durch diese Macht als wahrer Weltenherrscher. Auch hier findet anschließend eine inhaltliche Gliederung in drei Unterpunkte statt, die jeweils eine Art von Dämonen behandeln: primum genus est mutum, secundum genus vocatur legio, tercium genus vocatur lunaticum ${ }^{391}$. Der erste Unterpunkt wird anhand eines Exempels illustriert. Vom Hörensagen kenne er, Bertrand, die Geschichte einer Frau - audivi [...] non dico quod viderim -, die, obwohl sie lediglich des Provenzalischen hätte mächtig sein dürfen, plötzlich in fließendem Ungarisch sicut homo de mundo zu reden begann ${ }^{392}$. Dieses Beispiel aus der Alltagswirklichkeit - vergessen wir nicht, daß insbesondere die Kurie zu diesem Zeitpunkt durch Vermittlungsbemühungen zwischen Johanna von Neapel und dem König von Ungarn mehr als in Anspruch genommen war - sollte die Fremdbestimmung des Menschen durch den Dämon vor Augen führen. Sprachlich fremdgeleitete Menschen entbehrten jedweder Persönlichkeit und Bertrand unterstreicht diesen Gedanken anhand des Blicks auf einerseits

${ }^{389}$ Ibid. fol.95r: Habetis ergo per istud, quod Christus ostendit plus de potentia in eiectione demoniarum, quam in alio miraculo. Der Hinweis fehlt nicht, daß sich diese Macht adhuc hodie in ecclesia finde.

$390 \mathrm{Vgl}$. Hiob 1,7; Joh 14,30.

391 Pembrok, MS 98, fol. 95v.

392 Ibid.: Primum genus vocatur mutum et ratio est, quia ille, qui talem spiritum habet, non loquitur nisi secundum quod demon movet sibi linguam. Audivi, quod in terra ista fuit quedam mulier de partibus istis, non dico, quod viderim, que nesciebat aliam linguam loqui vel aliud ydioma et facta demoniaca loquebatur ungaricum. Ivit quidam episcopus vulgarus ad loquendum secum, qui dixit, quod illa mulier loquebatur ita bonum ungaricum sicut homo de mundi posset loqui. Nicht nachgewiesen bei Frederic C. TUBACH, Index Exemplorum. A Handbook of medieval religious tales, Helsinki 1969; vgl. allgemein zu Exempla WELTER, L'exemple; Brémond, Le GoFf, SchmitT, L'exemplum; Jean Claude SchmiTt (Hg.), Prêcher d'exemples. Récits de prédicateurs du Moyen Age, Paris 1985; Jacques BerLIoz, Marie Anne Polo de BeAulieu (Hg.), Les Exempla médiévaux. Introduction à la recherche, suivie des tables critiques de l'Index exemplorum de F.C. Tubach, Carcassonne 1992. 
die muti prelati, die stummen Geistlichen, und die muti subditi, die stummen Untergebenen, andererseits. Dabei kommt hier dem Adjektiv mutus sicherlich nicht das Bedeutungsspektrum von physisch stumm zu: vielmehr wird auf eine Art psychische Stummheit abgehoben, die die prelati dazu verleitet, auf Tadel und Besserung ihrer Untergebenen durch predicatio publica und correctio spiritualis zu verzichten ${ }^{393}$. Geistliche sind dem Prinzip der Wahrheit verpflichtet, das sie dazu zwingt, auch Unbequemes offen auszusprechen. Schwache und fremdgeleitete Persönlichkeiten verzichten auf diese Verbalisierung von Wahrheit entweder aus purer Angst (timor), aus Trägheit (pigricia) oder Unwissenheit (ignorancia) ${ }^{394}$. Angst kann unterschiedliche Formen annehmen, ist jedoch besonders tadelnswert, wenn sie aus der Befürchtung resultiert, eigene Verfehlungen könnten durch das Tadeln anderer ans Tageslicht gelangen. In enger Verbindung hierzu steht der consiliarius-Gedanke: Freunde und gleichzeitig gute Ratgeber sind diejenigen, die der Wahrheit folgend ohne Ansehen des Freundschaftsgrades konstruktiv kritisieren, niemals jedoch diejenigen, die durch permanentes Lob lediglich ihren Partikularinteressen zum Durchbruch verhelfen wollen.

Das zweite, legio genannte Dämonengeschlecht wird anhand der Erzählung aus Lc 8 charakterisiert ${ }^{395}$. Dort heilt Jesus den besessenen Gerasener von seinem bösen Geist, der auf die Frage Jesu »Wie heißest Du?« wegen der Vielzahl der Geister antwortet: »Legion«. Der den Lastern von Luxuria und Gula verfallene Mensch wird von Bertrand mit dem unreinen Schwein verglichen ${ }^{396}$. Bertrand nutzt die Gelegenheit, um durch die Irruption klerikaler Alltagsrealität innerhalb der Textexegese zu einer Klerikerschelte überzuleiten. Er tadelt diejenigen Kleriker und Ordensleute, die sich nicht an ihre Gelübde gebunden glauben und sich hemmungslosen Ausschweifungen hingeben. An dieser Stelle findet sich denn - wohl durch den weiter oben entfalteten Topos des guten Ratgebers motiviert - auch der erste und einzige Hinweis auf das Kardinalskollegium. Es unterstützt den Papst beim Urteil über einen Bischof, der, in den Stricken der vom Dämon ausgehenden Luxuria gefangen, sich mehr als zwanzig Konkubinen gleichzeitig hält ${ }^{397}$. Auffällig, daß der Papst und seine confratres, die Kardinäle, richten, selbst jedoch nicht gerichtet

393 Somit ist der Ausspruch des Humbertus de Romanis nach wie vor aktuell: Praedicator vox Christi debet abundare verbis, in: HUMBERTUS DE ROMANIS, De eruditione Praedicatorum, in: Maxima Bibliotheca Veterum Patrum, Lyon 1677, S. 426-567, hier S. 434.

394 Pembrok, MS 98, fol.96r. Die Begriffe sind in der Handschrift durch Unterstreichungen besonders hervorgehoben.

$395 \mathrm{Vgl}$. Lc 8,30.

396 Ibid., fol. 97r: Nudus porcus est animal in mundum et significat homines immundos per immundiciam luxurie et gule et dicitur, quod stabat iste homo in monumentis, ubi ponuntur cadavera, que sunt fetida.

397 Ibid.: Et dicitur, quod iste demon [...] significat cleros, qui non tenentur ligamento sacri ordinis vel potest dici, quod quidam faciunt legionem concubinarum, quia eis non sufficit una vel due, sed volunt habere infinita sicut fuit nuper allegatum in consistorio de quodam episcopo, qui habebat $X X$ concubinarias. 
werden - implizit wird hier auf die Reinheit und moralische Vorbildlichkeit des kardinalizischen Standes verwiesen.

Luxuria als hervorstechendes klerikales Laster wird von einem zweiten Laster flankiert. Bertrand nennt es carnabilitas, meint damit aber nichts anderes als schrankenlosen Nepotismus, die Bevorzugung der eigenen Verwandten bei der Vergabe von Posten und Pfründen ${ }^{398}$. Bertrand verurteilt diese Praxis nicht nur, sondern verfällt in heiligen Zorn, wenn er verkündet, daß der gerechte Gott hier nicht nur korrigierend eingreifen, sondern die Unsitte mit Brachialgewalt durch Tötung aller Nepoten samt ihres Förderers beseitigen werde. Mit Augustinus kann er sagen: Dyabolus non potest noscere quantum vult sed quantum noscere permissus est ${ }^{399}$. Die Erlaubnis zum Wirken des Teufels in der Welt erteile nicht allein Gott - man denke hier an den Beginn der Hiob-Erzählung -, sie resultiere auch aus dem freien Willen des Menschen, der sich gegen die Versuchungen des Bösen mit dem ihm eigenen Glauben (fides) zur Wehr setzen müsse.

Die dritte und letzte Erscheinungsform des Dämon, der demon lunaticus, bietet schließlich erneut die Gelegenheit zur Klerikerschelte. Dabei wird auf die Heilung des mondsüchtigen Knaben durch Jesus verwiesen. Spricht die biblische Wundererzählung jedoch klar von einem Knaben, der unter epileptischen Anfällen zu leiden hatte, richtet Bertrand sein Augenmerk auf die zweite Bedeutung des Adjektivs lunaticus im Sinne von »kurz andauernd, flüchtig «. Vir duplex animo inconstans est in omnibus viis suis ${ }^{400}$. Fast ist man versucht, in dieser Aussage einen Vorläufer des Goetheschen "Zwei Seelen wohnen, ach! in meiner Brust « $\mathrm{zu}$ sehen ${ }^{401}$. Auch dort kommt der Mensch, der sich seiner selbst und seiner Stellung in der Welt nicht sicher ist, vom geraden Weg ab, läßt sich versuchen, geht dadurch der überzeitlichen Werte verlustig und gewinnt doch nur ephemere Befriedigung. Bertrand verweilt weiterhin bei der Erzählung aus Matthäus. Deutlich steht ihm die aus den Autoritäten eines Beda Venerabilis oder Hrabanus Maurus gespeiste Antwort auf die Frage vor Augen, weshalb die Jünger Jesu nicht in der Lage gewesen seien, den mondsüchtigen Knaben zu heilen: quia non habuerunt fidem ${ }^{402}$.

Der gesamte Schlußabschnitt ist so vom Spannungsverhältnis Glauben-Unglauben geprägt. In einem eindrücklichen Vergleich werden fides und das granum sinapis gegenübergestellt. So wie das Senfkorn die überflüssigen Dinge aufgrund der Erwärmung aus dem Gehirn vertreibe, so vertreibe der Glaube alle Zweifel durch die Erwärmung des affectum. Dabei sei jedoch zu beachten,

398 Ibid.: Alia est carnabilitas, ut in clero sunt aliqui, qui cum sunt prelati statim faciunt legionem, statim vocant omnes consanguineos et affines, omnes beneficiant, omnes ditant, omnia ipsorum facta tacent et lites et questiones et matrimonia in cameris suis.

399 Ibid., fol. $97 \mathrm{v}$.

400 Ibid.

401 Johann Wolfgang von GoETHE, Faust. Eine Tragödie, hg.v. Erich Trunz, Hamburg 1959 (Hamburger Ausgabe, 3), S. 41.

402 Der Text Mt 17,20 bietet hier ein incredulitas vestra. 
daß sich der Glaube recht eigentlich nur in Zeiten der Verfolgung bewähre: So wie ein Senfkorn erst zertreten werden muß, um die in ihm enthaltene Hitze offenbar werden zu lassen, so muß auch der Glaube zuerst angegriffen werden, um sich zu beweisen. Die modica fides lasse den Menschen nicht nur zweifeln, sondern auch straucheln, und treibe ihn in die Hände des Teufels.

Bertrand postuliert den Unglauben als zentrales Grundübel innerhalb der Kirche: Sic est hodie in ista sancta ecclesia, nam sancta ecclesia habet suam auctoritatem et potestatem, et habet usum clavium et quidam non facit, que vellet facere et cum non potest venire ad finem eius, quod vult et vero est propter modicam confidenciam, quam sumimus de Deo ${ }^{403}$. Dort jedoch, wo reiner Glaube vorhanden sei, ermögliche dieser den Sieg der Sache Gottes. Bertrand verweist auf den vor kurzem errungenen Sieg gegen die Türken bei Smyrna und die Sarazenen in Spanien ${ }^{404}$. Infinita enim miracula facta sunt propter fidem: dieser Bekräftigung schließt sich ein Aufruf zum Beharren in Kreuzzugsangelegenheiten an. Die im 4. Buch Mose überlieferte Erzählung von der Verteilung des Ostjordanlandes an die Stämme Ruben, Gad und Manasse soll an die Pflicht zum Kampf erinnern ${ }^{405}$. So wie diese Stämme für ein Land, das verheiBene Israel, kämpften, in dem sie nicht leben wollten, durch ihr kämpferisches Engagement jedoch das Gebot Gottes erfüllten, so sollten auch die ytalicos et alios orientales 406 ein stärkeres Bemühen an den Tag legen. Auffällig ist, daß Bertrand durch die Verbindung der Ytalici mit den übrigen Orientales das Bild einer großen räumlichen Distanz entstehen läßt, so als sei Italien nicht zentraler Kernbereich des Abendlands und von entscheidender Bedeutung für das Papsttum. Auch wenn schon viele Siege errungen worden seien, die an Wunder gemahnten, so harrten doch viele Projekte noch ihrer Verwirklichung. Propter defectum fidei seien diese Projekte jedoch in ihrer Substanz bedroht. Der Sermo endet offen: Einerseits wird die Leistungsfähigkeit des Glaubens durch aktuelle Beispiele illustriert, andererseits auf die aus Unglauben resultierenden Gefahren des Stillstands oder gar des Rückgangs und damit auf den Verlust bereits erzielter Siege verwiesen. Als Mittel zur Hebung von fides wer-

403 Pembrok, MS 98, fol. 98r.

404 Ibid.: Sed ubi nos plene confidimus, tunc consequimur bonum, quod optamus, sicut patet de victoria noviter contra turcos habita et similiter de victoria concessa de Sarracenis in Yspania. Zum Sieg des Kreuzfahrerheers bei Smyrna vgl. Lettres Clément VI, nn. 1350 (23.12.1344), 1351, 1462, 1464, 1570, 1571, 1669, 1670, 1674, 1676, 1844, 3728, 4661, 4865, 5053, 5056. Zum Sieg von Algeziras, vgl. ibid., nn. 898, 981(Glückwunschschreiben an den König von Kastilien, 19.07.1344), 3256. Algeziras war von einem Kreuzfahrerheer unter Leitung Alfons' XI. von Kastilien nach 19 Monaten Belagerung am 26. März 1344 erobert worden; zu den Kreuzzugsanstrengungen des Papstes vgl. allgemein Anthony LUTTRELL, The crusade in the fourteenth century, in: Europe in the late Middle Ages, hg. v. John Rigby Hale, John R. Highfield, Beryl Smalley, London 1965, S. 122-155; Housley, The Avignon Papacy; Kenneth M. SETton, The Papacy and the Levant, 4 Bde., Philadelphia 1976-1984, hier Bd. 1, S. 162-194; DeMURGER, Le pape Clément VI et l'Orient.

405 Num 32,25ff.

406 Pembrok, MS 98, fol. $98 \mathrm{v}$. 
den an vorderster Stelle Gebet und Fasten genannt, oratio und ieiunio. Das Zusammenspiel dieser beiden christlichen Tätigkeiten führe - so will es Kardinal Bertrand de Pouget zumindest seine Zuhörerschaft glauben machen zur Hebung von fides und damit zum Vertreiben aller das Menschengeschlecht bedrohender Dämonen.

Im Laufe der Interpretation der Hii sunt viri-Collatio wurde darauf hingewiesen, daß die Kardinäle den Ausführungen hinsichtlich der Wirkmacht der päpstlichen plenitudo potestatis wohl eher reserviert gegenüberstanden. Zugegebenermaßen fanden sich im Text der Collatio selbst keinerlei explizite Belege, die diese Annahme hätten bestätigen können. Wird jedoch der Sermo von Kardinal Bertrand de Pouget in die Betrachtungen miteinbezogen, wird das, was als bloße Annahme formuliert war, zur Gewißheit. Die Tatsache, daß die Person des Papstes vom Kardinal an keiner Stelle genannt wird, ist allein noch nicht dazu angetan, Verwunderung hervorzurufen. Wenn Bertrand de Pouget jedoch postuliert, göttliche Macht zeige sich dort am stärksten, wo Dämonenaustreibungen vorgenommen werden, er diese Macht aber von Christus nicht an einen Apostel allein, sondern an die Gesamtheit der Apostel übertragen wissen will, bleibt von der exklusiven Stellung des Papstes nicht mehr allzu viel übrig. Nicht dem Nachfolger des Apostels Petrus allein, sondern allen Bischöfen in ihrer Eigenschaft als successores apostolorum sei diese Macht zueigen.

Die exklusive Stellung des vicarius Christi wird auch an anderer Stelle subtil unterminiert. Gegen Ende des Sermo verdeutlicht der Kardinal, daß es die Kirche sei, die über die potestas clavium, die Schlüsselgewalt, verfüge. Wenn die Kirche aufgrund von Unglauben bei vielen Unternehmungen scheitere ${ }^{407}$, legt dies doch eigentlich den Schluß nahe, auch der Papst sei miteingeschlossen. Bertrand de Pouget benannte mit Luxuria und Carnabilitas zwei kuriale Laster par excellence ${ }^{408}$. Auch wenn ein direkter Angriff auf Clemens VI. kaum intendiert gewesen sein dürfte, fällt die Tatsache ins Auge, daß damit diejenigen Laster Erwähnung fanden, die dem Papst von seinen zeitgenössischen Kritikern mit ermüdender Regelmäßigkeit unterstellt wurden. Walsingham ersetzte in seiner Chronik beispielsweise luxuria durch prodigalitas profusissima und schuf so eine Verbindungslinie zum Benefiziengebaren des Papstes $^{409}$. Dessen Hang, eigene Familienmitglieder zu begünstigen, hatte nicht zuletzt in der Zusammensetzung des Kardinalskollegs seinen Ausdruck gefun-

407 Bezeichnenderweise bedient sich der Kardinal hier der 2. Person Plural: [...] propter modicam confidentiam, quam sumimus de Deo, ibid., fol. $98 \mathrm{r}$.

408 Erinnert sei an Petrarca, Rerum familiarum libri, ed. RossI, lib. VI, cap. 1, S. 47-54: $A d$ Anibaldum Tusculanum epyscopum cardinalem contra avaritiam pontificum.

409 Walsingham, Chronica, S. 254: Eodem anno [1342], Clemens Sextus, quondam Rothomagensis Archiepiscopus, successit Benedicto Duodecimo. Iste Clemens vir insignis litteraturae fuit, sed prodigalitatis profusissimae; adeo ut dignitates ecclesiasticas, vacantes in Anglia, suis conferret cardinalibus, novosque pro eis in Anglia titulos moliretur imponere; qua de causa Rex Anglie offensus, provisiones per Dominum Papam factas cassavit. 
den ${ }^{410}$. Der Kontrast zur päpstlichen Collatio Hii sunt viri könnte größer nicht sein. Clemens VI. äußert sich im Bewußtsein der ihm durch sein petrinisches Amt übertragenen Vollgewalt. $\mathrm{Ob}$ es eine Persönlichkeit, für die der $\mathrm{Ge}$ brauch unumschränkter Macht eine Selbstverständlichkeit ist, tatsächlich nötig hat, derart ostentativ auf die eigene plenitudo potestatis zu pochen, ob hier vielleicht nicht doch eher reale Unsicherheit durch den Schleier verbaler Sicherheit verhüllt werden soll, mag dahingestellt bleiben. Der textuelle Befund ist eindeutig: Clemens VI. sieht sich in einer Traditionslinie stehend, die von Gott und Christus zum Apostelfürsten und schließlich zu ihm selbst führt. Diese Stellung wird von ihm als exklusiv in dem Sinne begriffen, da $B$ alle relevanten Entscheidungen der Kurie, insbesondere die im politisch-diplomatischen Bereich, seiner höchsten Befehlsgewalt und seinem Gestaltungswillen unterliegen. Er ist nicht nur in der Lage, die Grundlinien der Politik vorzugeben, sondern diese durch das Konstrukt der pars corporis papae auch in absentia entscheidend zu gestalten. Kardinäle können vor diesem Hintergrund nicht viel mehr als bloße Erfüllungsgehilfen päpstlicher Politik sein. Dies ist die Botschaft der päpstlichen Collatio.

Die Bewertung der politischen Aktivitäten Clemens' VI. im Hundertjährigen Krieg fällt zwiespältig aus. Unbestritten ist die Tatsache, daß sein Vermittleramt nicht nur von den beiden kriegführenden Parteien zumindest grundsätzlich akzeptiert wurde - auch wenn England wiederholt die Begünstigung Frankreichs fürchtete, auch wenn sich Philipp VI. mitunter des Papstes allzu sicher wähnte. Als vermittelnde Instanz, die, eingebunden in ein politisches Interessengeflecht, zwar Unparteilichkeit für sich reklamieren, de facto jedoch nicht verwirklichen konnte, war die Kurie auch noch nach 1348 gefragt. Anfang 1350 forderte so beispielsweise der König von Kastilien Clemens VI. in einem öffentlichen Konsistorium durch seinen Gesandten dazu auf, sich weiter um Eintracht zwischen England und Frankreich zu bemühen ${ }^{411}$. Die Bitte entprang zwar wohlverstandenem Eigeninteresse - für die Rückgewinnung Gibraltars war Kastilien an einem befriedeten Hinterland gelegen -, zeugte aber von einem Grundvertrauen in die Wirksamkeit kurialer Diplomatie.

In Hinblick auf das untersuchte Quellenmaterial drängt sich der Eindruck auf, daß auch Clemens VI. von der Effizienz kurialer Diplomatie überzeugt war. Die Fülle der während seines Pontifikates in alle Richtungen ausgehenden Gesandtschaften - die wenigsten wurden dabei von Kardinälen angeführt -

410 Folgende Verwandte wurden zu Kardinälen kreiert: Hugues Roger (Bruder), Guillaume de la Jugée (Neffe), Nicolas de Besse (Neffe), Pierre Roger (Neffe), Guillaume d'Aigrefeuille (Cousin), Pierre de Cros (Cousin).

411 Vgl. VINCKE, Bernat Miquel, S. 150: Primo quod dominus papa dignaretur illustribus dominis Francie et Anglie regibus et ad ipsos mittere pro pace et concordia asserens quod dictus dominus rex Castelle de ipsorum dominorum guerra et discodia erat totus turbatus et desolatus et quod toto suo desiderio optabat pacem et concordiam inter eos. 
sprechen in dieser Beziehung eine deutliche Sprache. Die längiährige Vermittlungstätigkeit im Konflikt zwischen England und Frankreich verdeutlicht jedoch, daß dem Papst außerordentlich an der Betonung seiner eigenen Position gelegen war. In gedanklicher Engführung sieht er sich angesichts der nach Frankreich und England abgehenden kardinalizischen Gesandtschaften als eine Art unbewegten Beweger, dem in absentia die Steuerung der Abläufe obliegt. Bezeichnend ist sein Rückzug aus den Verhandlungen mit den englischen Gesandten genau zu dem Zeitpunkt, als er angesichts ihrer mit Hartnäckigkeit verfochtenen Positionen allen Grund dazu hatte, an seinen eigenen Fähigkeiten zu zweifeln. Dieses auf Vorstellungen von unbeschränkter päpstlicher plenitudo potestatis aufbauende gedankliche Konstrukt erwies sich - anders als beabsichtigt - als kontraproduktiv. Ein Blick auf die Tätigkeit der Kardinäle verdeutlicht, daß es in Zeiten wichtiger Legationen das Bemühen um stete Rückbindung an den Papst war, das zielgerichtetes und situationsgebundenes Handeln und Vermitteln ungemein erschwerte. Das in den beiden Collationes entfaltete Bild des Schöpfers, dem seine Kreaturen zu- bzw. untergeordnet sind, zeugt in sehr viel stärkerem Maße als die päpstlichen litterae vom atemberaubenden Machtanspruch eines Papstes, der durchaus dazu in der Lage war, Kompetenz bei seinen engsten Mitarbeitern zu erkennen und zum Wohle der Gesamtkirche einzusetzen und zu fördern. Daß dieser unbestreitbaren Kompetenz jedoch nur wenig Raum zur freien Entfaltung gelassen wurde, darin bestand der eigentliche Fehler des Papstes. Neben allen realpolitischen Unwägbarkeiten war es dieses Verhalten, das der päpstlichen Diplomatie wenig mehr als ephemere Erfolge bescherte. 


\subsection{Die päpstliche Diplomatie in Oberitalien und im Königreich Neapel}

\subsubsection{Die Legation von Kardinal Guillaume Court in Oberitalien (1342-1343)}

\subsubsection{Die Legation im Spiegel kurialer Registerüberlieferung}

Nur zwei Monate nach der Krönung Clemens' VI. erfolgte mit der Entsendung von Kardinal Guillaume Court ${ }^{412}$ - aufgrund seiner Zugehörigkeit zum Zisterzienserorden auch cardinalis albus genannt - in die Lombardei und andere namentlich genannte Städte in Oberitalien der erste, insgesamt noch verhaltene Versuch einer direkten Einflußnahme auf das politisch außerordentlich instabile System im genannten Gebiet ${ }^{413}$. Das Legationsgebiet war mit den Patriarchaten von Aquileia und Grado, weiteren Kirchenprovinzen wie

412 Vgl. Kap. 9.2.22.

413 Einen groben Überblick über das politische Engagement Clemens' VI. in Italien liefert Mollat, Papes d'Avignon, S. 212-220; vgl. auch Giovanni Tabacco, Programmi di politica italiana in età avignonese, in: Aspetti culturali della società italiana nel periodo del papato avignonese, Todi 1981, S. 49-77; Lettres Clément VI autres que la France, n. 4 (nur Regest); vgl. Reg. Vat. 152, fol.27r: [...] Ideoque gerentes de tuis claris meritis fiduciam in domino spiritualem, quamvis nos et fratres nostri tanti viri presentia nobis et Ecclesie Romane necessaria et perutili careamus inviti, tamen propter urgentem et evidentem necessitatem predictarum partium Lombardie, quibus speramus per tuam providentiam circumspectam, illo tibi auxiliante, qui potest omnia in premissis salubriter consuli et utiliter subveniri, te ad partes illas videlicet Aquilegen[sem] et Grandien[sem] patriarchatus necnon Mediolanen[sem], Januen[sem], Judien[sem], Spalaten[sem], Ragusinen[sem], Creten[sem] et Antibaten[sem] provincias ac Papien[sem], Ferrarien[sem], Placentinen[sem], Parmen[sem], Mutinen[sem] et Reginen[sem] civitates ac diocesi tibi in eisdem patriarchatibus, provinciis, civitatibus et diocesibus vices nostras ac plene legationis officium committendo, ut in eis evellas et destruas et dissipes et disperdas [...], de dictorum fratrum nostrorum consilio destinamus tibi, ut in patriarchatibus, provinciis, civitatibus et diocesibus prelibatis inter ecclesiasticas mundanasve personas, duces, principes, marchiones, barones et nobiles, comunitates, universitates ac populos et alios universos et singulos discordes bonum pacis studeas reformare ac concordes in fraterne dilectionis glutino confirmare ac agere nichilominus et tractare quecumque ad cultum Dei exaltationem, catholice fidei apostolice sedis honorem, observantiam ecclesiastice sanxionis et reintegrationem ecclesiastice libertatis, honestatis ac morum cultum relevationem ecclesiarum et locorum ecclesiasticorum et pauperum animarum salutem, tranquillitatem corporum ac robur status prosperi patriarchatum, provinciarum ac civitatum et diocesum predictorum quomodolibet pertinebunt, convocando ad tuam presentiam Venetos et alios quoscumque, de quibus pro utilitate dicti negotii expedire videris ac cum eis tam de armata quam de aliis oportunis remediis contra ipsos Turchos adhibendis tractando et ordinando, quibus viis et modis dictum negotium, quod nos etiam realibus subsidiis ac indulgentiis et remissionibus iuvare intendimus, contra dictos Turcos possit, actore Domino, prosperari $[. .$.$] , nobisque rescribendo particulariter et distincte, quicquid tractandum et ordi-$ nandum duxeris in premissis et nichilominus universos et singulos partium premissarum ex parte nostra salubribus persuasionibus inducas pariter et horteris ipsosque unias, confederes et coniungas, ut eidem Ludovico, qui Sanctam Romanam Ecclesiam et eius honorem ex indurata sibi pertinacio offendere ipsosque afficere nititur iniuriis, scismatibus et scissuris ac 
Mailand und Genua und den Bistümern Ferrara, Piacenza, Parma, Modena und Reggio ausgesprochen umfangreich. Im Entsendungsschreiben wurde aber nicht nur das Legationsgebiet umrissen, sondern auch auf die mit der Legation verbundenen Zielsetzungen verwiesen. Vorrangig sollte es um die Vermittlung des bonum pacis gehen, sollte zu einer friedlichen Verständigung zwischen den miteinander verfeindeten Parteiungen in Oberitalien nicht zuletzt deshalb beigetragen werden, um einen Durchzug Ludwigs des Bayern zu erschweren. Davon getrennt sollten Verhandlungen insbesondere mit Venedig in Hinblick auf eine wirksame Bekämpfung der Türkengefahr stattfinden ${ }^{414}$.

Zeitgleich mit dem Entsendungsschreiben erging am 19. Juli 1342 eine Anzahl von Fakultäten, durch die die Arbeit des Legaten unterstützt und erleichtert werden sollte ${ }^{415}$. Die 47 an Guillaume Court gerichteten Fakultäten lassen sich dabei einzelnen Themenbereichen zuordnen ${ }^{416}$. Unbestritten an der Spitze stand der Komplex der Verleih- und Dispensvollmachten, durch die der Legat in die Lage versetzt werden sollte, zu einem positiven äußeren Erscheinungsbild der diplomatischen Mission beizutragen. Damit war die Möglichkeit verbunden, geleistete Hilfe aus dem Reservoir päpstlicher Gnadenerweise $\mathrm{zu}$ vergelten ${ }^{417}$. Ein nicht $\mathrm{zu}$ unterschätzendes Korrektivpotential enthielten die zehn Zensurfakultäten, die den Legaten in die Lage versetzten, Vergehen gegen seine Person oder Ziel und Zweck seiner Legation angemessen zu ahnden ${ }^{418}$. Ein weiterer Fakultätenkomplex war auf die Situation vor Ort hin ausgerichtet. Für das erfolgreiche Gelingen einer Legation konnte es beispielsweise entscheidend sein, ob der Kardinal in der Lage war, mit Exkommunizierten unterhandeln zu dürfen, ob man ihm gestattete, von der Kurie verhängte Interdikte aufzuheben, um damit Verhandlungen überhaupt erst zu ermöglichen ${ }^{419}$ - dies insbesondere in Oberitalien, wo keine Kommune vor dem päpstlichen Bannstrahl gefeit war. Numerisch weit abgeschlagen, dennoch von besonderem Interesse waren die ganz auf die persönliche Situation des Legaten zugeschnittenen Fakultäten. Behandelt wurden darin Fragen der zu leistenden Prokurationszahlungen ${ }^{420}$, die - der Fall England hat es bereits

statum ipsorum et aliorum fidelium parcium Italie perturbare, fideles ipsos subvertere ac eos in profundum, in quo ipse diversus est, demergere malignorum, ne partes Lombardie predictas ingredi aut aliquid contra honorem eiusdem Romane ecclesie atque nostrum in partibus illis quoquomodo attemptare valeat, resistant et obvient remediis opportunis [...].

414 Clemens VI. betont nachdrücklich, der Kardinal solle ihn particulariter et distincte über diese Verhandlungen auf dem laufenden halten; vgl. allgemein Klaus ARNOLD, De bono pacis - Friedensvorstellungen in Mittelalter und Renaissance, in: Überlieferung - Frömmigkeit - Bildung als Leitthemen der Geschichtsforschung, hg.v. Jürgen PETERSOHN, Wiesbaden 1987, S. 133-154.

415 Lettres Clément VI autres que la France, nn. 5-53.

416 Ibid., nn. 7, 9-55.

417 Ibid., nn. 15, 20, 21, 22, 26, 28, 29, 31-33, 36, 41-44, 46, 52.

418 Ibid., nn. 7, 9, 13, 14, 16, 25, 27, 30, 34f.

419 Ibid., nn. 18f., 23f., 49-51. 
gezeigt - auf seiten der Prokurationsgeber fast durchgängig auf Anfechtung und Ablehnung stießen. Wichtig war deshalb das Privileg, Prälaten - selbst wenn diese gewisse ihnen einstmals vom Heiligen Stuhl verliehene Exemptionsprivilegien vorweisen konnten - ad contribuendum in procurationibus [...] infra tue legationis terminos constitutos zu zwingen. Ausdrücklich versichert wurde, daß ihm als Legaten des Heiligen Stuhls die üblichen, einem Kardinal zu leistenden Prokurationen zustünden. Konkrete Zahlenangaben sucht man freilich vergeblich ${ }^{421}$.

Am 5. Oktober 1342 wurden zwei Fakultäten nachgeschoben. Durch die eine erhielt Guillaume Court vorab die Erlaubnis, nach Ablauf von drei Jahren an die Kurie zurückzukehren ${ }^{422}$. Die andere garantierte ihm die Rückerstattung der in seiner Abwesenheit "zweckentfremdeten «, d.h. mit anderen Personen belegten Livrée in Avignon ${ }^{423}$. Man geht wohl nicht fehl in der Annahme, daß sich in den eben erwähnten Fakultäten ein gewisses Unbehagen des Kardinals hinsichtlich der ihm aufgetragenen Legation artikuliert. Abgeschnitten vom kurialen Versorgungssystem, seiner Livrée beraubt, damit also faktisch temporär enteignet und angewiesen auf mehr als unsichere Prokurationsleistungen, erblickte der Zisterzienserkardinal in der Legation wohl eher eine Last als eine Ehre. Mit der Abreise aus Avignon hatte er es denn auch nicht allzu eilig. In den Protokollbüchern der päpstlichen Kammerkleriker taucht er noch als Teilnehmer an dem berühmten Konsistorium vom 27. Januar 1343 auf, in dem Clemens VI. das ihm von der Stadt Rom angebotene Senatoriat, Kapitaneat und Syndikat akzeptierte und gleichzeitig für 1350 ein Heiliges Jahr verkündete ${ }^{424}$.

Die Registereinträge zeugen vom verhaltenen Engagement des Guillaume Court in seinem Legationsgebiet. Administrative Akte ergingen im Bistum Vercelli ${ }^{425}$. Lucas, dem Elekten von Lodi, sollte er gegen einen Konkurrenten zum Bischofsstuhl verhelfen ${ }^{426}$. Immerhin gelang ihm die Vermittlung eines Waffenstillstands, in den als verfeindete Parteien die Visconti von Mailand, Johanna I. von Neapel, Jacobus von Savoyen und die Kommune Asti eingebunden waren ${ }^{427}$. Diese Erfolgsbilanz scheint in Avignon als nicht ausrei-

420 lbid., nn. $7,48$.

421 Ibid., n. 48 (nur Regest); vgl. RV 152, fol.34v: Cum [...] destinemus nos, ut incumbentia tibi expensarum onera possis facilius supportare, volentes tibi de opportuno subventione auxilio providere, tibi recipiendi huius tua legatione durante similes procurationes, quas unus cardinalis Sancte Romane Ecclesie apostolice sedis legatus in dictis partibus pro suis procurationibus recipere consuevit [...].

422 Lettres Clément VI autres que la France, n. 54.

423 Ibid., n. 55.

424 Vgl. SCHRÖDER, Protokollbücher, n. 74.

425 Lettres Clément VI autres que la France, n. 193, 194 (18.06.1343).

426 Ibid., n. 205 (08.07.1343). Guillaume Court ist in einen weiteren Bistumsstreit involviert. Am 20. September 1343 ergeht die Aufforderung, den Bischof von Acqui bei der Rückgewinnung der vom Markgrafen von Montferrat eroberten Besitzungen zu unterstützen, vgl. ibid., n. 284. 
chend empfunden worden zu sein. Ein Schreiben des Papstes vom 8. August 1343 zeugt von einer durch Verleumdungen angespannten Atmosphäre ${ }^{428}$. Deutlich wird, daß von Personen, die aus dem Legationsgebiet selbst stammen mußten, Klage gegen den Kardinal und sein Vorgehen erhoben worden war. Der Papst versicherte zwar, daß er diesen Anklagen keinen Glauben

427 Vgl. RaYNALdi, a. a. 1342, \$17. Clemens VI. nimmt zum ersten Mal in einem an Giovanni und Luchino Visconti gerichteten Schreiben vom 29. Juli 1343 auf diesen Waffenstillstand Bezug, nachdem er den Kardinal noch Ende Mai zur Integration des Jacobus von Savoyen aufgefordert hatte (Lettres Clément VI, n. 196); vgl. auch Lettres Clément VI autres que la France, n. 230 (nur Regest); vgl. RV 137, fol. 67: Ad reformandum statum pacificum Lombardie laborans et intendens solerter et fideliter, dilectus filius noster Guillelmus tit. SS. Quatuor Coronatorum presbiter cardinalis in partibus ipsius apostolice sedis legatus, pridem, sicut intelleximus, inter carissimam in Christo / filiam nostram Johannam Reginam Sicilie Illustrem ipsiusque vassallos et sequaces partium predictarum, inter quos dilecti filii nobiles viri Jacobus de Sabaudia et Forenses Civitatis Asten[sis] esse noscantur ex parte una et vos et sequaces vostros ex altera treugas pacis representantes ymaginem sub certis modis, formis et penis provident indicendas, vos attentius requirimus et hortamur, quatinus inviolabiliter treugas observantes predictas, ab omni offensione dictorum nobilis et forensium aliorumque vasallorum et sequacium regine predicte desistatis vestrosque stipendiarios desistere penitus faciatis, quosvis offensores eorum in terris vobis subditis nullatenus admissuri vel quomodolibet defensuri publice vel occulte pro certo scituri, quod contrarium si attemptaretur - quod absit - quomodolibet nobis admodum displicibile redderetur et molestum valde gessimus et gerimus, si quod nobis relatum est, veritate fulcitur, videlicet quod in civitate Astensi gentem armigeram fecistis ad offendendum partem alteram congregari cum predictas treugas, ex quibus vobis et aliis de partibus illis totique patrie bona innumera proventura speramus, velimus tenaciter observari; vgl. auch Carlo CIPOLLA, Clemente VI e casa Savoia, in: Miscellanea di storia italiana 5 (1900) S. 89-178; Bruno Galland, Les papes d'Avignon et la maison de Savoie (1309-1409), Rom, Paris 1998, S. $256 f ., 262$.

428 Lettres Clément VI autres que la France, n. 246 (nur Regest); vgl. RV 137, fol. 77v: Presentatas nobis litteras tuas, per quas te super quibusdam sinistris, que contra te nostris auribus perceperas instillata excusans tue puritatis innocentiam ostendisti multis causis et rationibus super eis solita benignitate recepimus et que continebantur in eis pleno collegimus intellectu. Sane, dilectissime fili, licet aliqui super nonnullis, que in tuis predictis recitabantur litteris fuerint oblocuti, Nos tamen, qui dudum alias dum Nos et te status haberet inferior et etiam postmodum sinceritatem tuam probavimus, aures non accomodavimus credulas quamquam referentibus negare nequiverimus decenter auditum. Scire namque te volumus, quod de partialitate tua nobis inter cetera mentio facta fuit, sed quia mores hominum partium illarum, qui ad obloquendum super talibus consueverunt esse multum prompti, frequenter audivimus de te, quem virum iustum et prudentem reputamus, merito non credimus, sed forsitan de aliquibus, qui iuxta te sunt penitus non negamus. De muneribus autem turpibus, quae per te recepta fuerint, nichil nobis suggestum fuisse meminimus, nec cuiquam eciam fidem credulam super hoc dedissemus. Porro super emolumento sigilli tui multa Nobis quam super aliis sunt suggesta et quamquam personam tuam innocentem super hiis indubie supponamus, aliquos tamen, qui iuxta te sunt, non excusamus omnino, quominus absque tua conscientia, ymmo pocius contra eam dicantur aliquociens super talibus excesisse, quamobrem honori et fame tue multum videtur expediens, quod circa premissa et eorum singula prudenter et vigilanter tua circumspectio temperando et corrigendo que temperamento, correctione ac reformatione indiguerint cum effectu circumspiciat, quid agendum [...]. Auf die harsche Kritik am Vorgehen des Legaten verweist auch BISCARo, Le relazioni dei Visconti, S. 56 . 
schenke - man wisse um die mehr als zweifelhaften mores der Verleumder -, $\mathrm{da} B$ er im Kardinal weiterhin den moralisch integren Prälaten erblicke, dem Parteilichkeit fremd sei, von dem er sich auch nicht vorstellen könne, daß er ehrenrührige Geschenke (munera turpia) angenommen und sich damit des Vergehens der Bestechlichkeit schuldig gemacht habe ${ }^{429}$. Als reine Phantasieprodukte böswilliger Geister wollte der Papst die Anklagen denn aber auch nicht verstanden wissen. Deshalb erging die dringende Aufforderung, in $\mathrm{Zu}-$ kunft mehr Sorgfalt auf die Auswahl der ihn unmittelbar umgebenden Personen zu legen. Den Anklagen mußte also doch ein so hohes Maß an Glaubwürdigkeit geeignet haben, daß der Papst sich dazu entschließen konnte, Schuldige im Umfeld des Kardinallegaten zu benennen.

$\mathrm{Zu}$ einer Erfolgsgeschichte entwickelte sich die Legation auch in der Folge nicht. Bereits am 21. September wurde dem Kardinal mitgeteilt, er selbst möge darüber befinden, ob er weiterhin seine Legation ausüben oder nicht doch lieber an die Kurie zurückkehren wolle. Clemens VI. nahm in diesem Brief auf ein Schreiben des Kardinals Bezug, in dem dieser nachdrücklich (cum instantia et ferventi desiderio) um Erlaubnis zur Rückkehr nachgesucht hatte. Guillaume Court wurde zwar noch einmal aufgefordert, seine eigenen Interessen hinter dem Wohl der christlichen Gemeinschaft zurückzustellen, doch dürfte die Kurie an den Präferenzen des Legaten keinerlei Zweifel gehegt haben. Guillaume Court entschied sich scheinbar selbst für seine Abberufung und wahrte damit das Gesicht. Der vorliegende singuläre Fall einer Abberufung, über die der amtierende Legat in situ selbst befinden konnte, liefe dem ansonsten durchgängig feststellbaren Bemühen des Papstes zuwider, diplomatische Abläufe selbst zu steuern. Andererseits wäre eine durch den Papst verfügte Abberufung wohl als scharfe Sanktion gewertet worden, die das Kardinalskolleg als Ganzes in eine Protesthaltung hätte versetzen können ${ }^{430}$. Durch diplomatisch geschicktes Taktieren stellte der Papst somit alle Parteien zufrieden ${ }^{431}$.

In Oberitalien war nun zwar ein erster Etappensieg in Form des durch Kar-

429 An anderer Stelle hatte er die Gier nach Geld als eines der größten gravamina innerhalb des Klerikerstandes benannt, vgl. Collatio Benedicam, in: MS 240, fol.192vb: Nunquam sic sumus misericordes hodie nos clerici et religiosi, nunc ad sensum apparet, quam magis avari et cupidi et magis immisericordes quam layci, de quo conqueritur.

430 Vgl. das Vorgehen des Papstes im Falle des Kardinallegaten Aimeric de Châtelus 1345, Kap. 5.2.2.3.

431 Lettres Clément VI autres que la France, n. 286 (nur Regest); vgl. RV 137, fol. 88: Intellectu pleno collectis omnibus, que continentur in litteris a tua prudentia ultimo nobis missis, et matura deliberatione cum aliquibus ex fratribus nostris Sancte Romane Ecclesie cardinalibus habita super eis cum statu negociorum et patrie partium Lombardie per easdem litteras recitato licentiam petas cum instantia et ferventi desiderio de nostram presentiam et sedem apostolicam redeundi, sinceritati tue breviter super hoc respondemus, quod cum in eisdem partibus Lombardie pro reformatione status partium earundem pacifici ac morum in clero et populo, alias iaciendis doctrine salutaris seminibus et extirpandis viciis tibi legationis officium sit commissum, tu in scola experiencie constitutus, quod super remanendo adhuc in ip- 
dinal Court vermittelten Waffenstillstands erzielt worden $n^{432}$, doch war man vom Ideal eines vollständig befriedeten Territoriums noch weit entfernt. Die zweite im Entsendungsschreiben genannte Aufgabe der Legation, Verhandlungen mit Venedig zwecks wirksamer Bekämpfung der Türkengefahr, war von Guillaume Court erst gar nicht verwirklicht worden. So durfte man auf etwaige offizielle Stellungnahmen und Bewertungen der Legation gespannt sein.

\subsubsection{Sicut frigus nivis: die Collatio Clemens' VI. anläßlich der Rückkehr von Kardinal Guillaume Court an die Kurie}

Mit der Collatio Sicut frigus nivis ist die Begrüßungsansprache erhalten, die Clemens' VI. anläßlich der Rückkehr von Kardinal Guillaume Court in Avignon hielt ${ }^{433}$. Textimmanente Hinweise zum genauen Predigtzeitpunkt sucht man vergeblich. Der Tenor der Predigt macht aber ebenso wie die im Pariser Manuskript enthaltene Überschrift eine enge zeitliche Nähe zur Rückkehr wahrscheinlich ${ }^{434}$. Die Erlaubnis Clemens' VI. zur Rückkehr ist - wie oben erwähnt - auf den 21. September 1343 datiert. Der Kardinal kann also frühestens Anfang Dezember wieder in Avignon eingetroffen sein. Diese Vermutung wird durch einen Eintrag in den Protokollbüchern der päpstlichen Kammerkleriker gestützt, wo die Teilnahme des Kardinals an einem am 1.Dezember tagenden Konsistorium belegt ist ${ }^{435}$. Offensichtlich hatte es der Kardinal also eilig, seine Zelte in Oberitalien abzubrechen und den sicheren Hafen Avignon anzusteuern.

Als Thema seiner Ansprache wählte Clemens VI. einen dem Buch der Sprüche entnommenen Vers: »Wie die Kälte des Schnees zur Zeit der Ernte, so ist ein getreuer Bote dem, der ihn gesandt hat, und erquickt seines Herren Seele ${ }^{436}$. Zu Beginn - auf ein Prothema wird verzichtet - steht die Entschlüs-

sis partibus vel ad nos et sedem redeundo predictam expediat scire potes. Quamobrem magis negociis et utilitati rei publice circa que mereri poteris apud Deum multipliciter, quam tuis privatis affectibus, quos ad reditum habere videris consulendo, quod in hac parte melius expediencius et salubrius cognoveris secundum Deum eligas, quia te super hiis tue discretionis arbitrio providimus relinquendum.

432 Auf diesen Waffenstillstand, der sich als außerordentlich fragil erweisen sollte, wird in anderen Briefen des öfteren Bezug genommen, vgl. Lettres Clément VI autres que la France, nn. 1432/1433 (13.07.1347); Lettres Clément VI, nn.739, 740, 776, 1827, 2142, $2516,2906,3189,3219,3275,3317,3653$. Als Hauptstörenfriede erwiesen sich insbesondere Mailand und Asti.

433 Den folgenden Ausführungen liegt der Text der Handschrift Paris, Bibliothèque SainteGeneviève, MS 240, fol.247v-251r zugrunde. Zur Parallelüberlieferung vgl. SCHNEYER, Repertorium, Bd. 4, S.766, n. 82 ; Mollat, Euvre oratoire, S. 258f., n.76; Schmitz, Sermons, S. 31, n. 69; WooD, Sermon literature, S. 163-172.

434 MS 240, fol. 247vb: Collatio facta per Dominum Clementem quando venit dominus cardinalis albus de Ytalia.

435 Vgl. SCHRöDER, Protokollbücher, n. 82 (betrifft die Absolution des Franziskaners Franciscus de Esculo). 
selung des dem Thema innewohnenden Litteralsinns. Hitze (ardor), Arbeit (labor) und Schweiß (sudor) beschreiben als Nomina die Mühen, denen jeder Erntearbeiter bei der Ernte ausgesetzt ist ${ }^{437}$. Der hereinbrechende Schnee nebst der damit verbundenen Kälte hat Dinge in seinem Gefolge, die dazu angetan sind, den Erntemühen entgegenzuwirken: Abkühlung (refrigerium), Trost/Freude (solacium/gaudium) und Arznei (remedium) werden in reichem Maße gespendet ${ }^{438}$.

In der unmittelbar folgenden allegorischen Deutung wird zunächst der Papst zum messor in die messis, zum Pontifex, dem die Sorge um den gesamten Erdkreis obliegt ${ }^{439}$. Eingeschlossen in diese Sorge sind neben der Herde, der Masse der Gläubigen, auch die pastores, die Geistlichen, deren klare Unterordnung unter den Haupthirten in Gestalt des Papstes bereits an dieser Stelle betont wird. So wie sich ein Erntearbeiter mühe, sich freue und leide, so habe auch der Pontifex drei Dinge beständig zu bewältigen. Er mühe sich für die Anliegen einzelner ab, er leide an den Fehlern der Untergebenen, freue sich jedoch an den Fortschritten seiner geistigen Söhne ${ }^{440}$.

Insbesondere der zweite Punkt läßt aufhorchen. Nachdem der Papst kurz zuvor auf die Unterordnung der Prälaten unter ihren geistlichen Oberhirten verwiesen hatte, nun aber auf Fehler dieser Untergebenen verweist und dazu kompositorisch geschickt eine Stelle innerhalb der Collatio wählt, die die Einführung der Gestalt des Kardinallegaten nahelegt, trägt er zu einer gedank-

436 Prov 25,13: Sicut frigus nivis in die messis, ita legatus fidelis ei qui misit eum. In Verbindung mit seiner zweiten Italien-Collatio anläßlich der Rückkehr von Kardinal Bertrand de Deux 1348 sollte der Papst auf eine Parallelstelle im Buch der Sprüche zurückgreifen. Als Thema dient dort der Vers Legatus fidelis sanitas (Prov 13,17).

${ }^{437}$ MS 240, fol. 247vb: Videtur nobis, quod merens in diebus messis consuevit estuare ardoris incendio, suspirare laboris exercitio, habundare sudoris profluvio. Et ista patent ad sensum [...]. Patet ergo, quod metens in die messis et patitur ardorem, et sustinet laborem, et emittit sudorem. Verwiesen sei auf die dreifache Struktur einer concordantia in voce: Sowohl die Endungen der Verben (estuare, suspirare, habundare), als auch diejenigen der Genitive (ardoris, laboris, sudoris) und der Nominative (incendio, exercitio, profluvio) korrespondieren jeweils miteinander und zeugen von dem Bemühen des Papstes, seine rhetorische Kunstfertigkeit unter Beweis zu stellen.

438 Ibid., fol. 248ra: Videtur autem nobis, quod frigus illo tempore superveniens dat sibi tria contra ista tria. Dat enim sibi primo refrigerium contra ardoris incendium, dat sibi secundo solacium vel gaudium contra laboris exercitium, dat sibi tercio remedium contra sudoris profluvium. Dat frigus enim illo tempore temperamentum refrigerando ardorem, oblectamentum confortando et alleviando laborem, medicamentum desiccando sudorem, sicut patet manifeste ad sensum.

439 Ibid., fol. 248rb: Modo videtur michi, quod prelatus quilibet, sed maxime Romanus Pontifex, cui oportet non solum istius determinati gregis aut populi, sed totius universalis ecclesie non solum ovium, sed etiam pastorum ovium curam et sollicitudinem gerere, utpote cui dictum est [...] [es folgen die beiden Zitate Joh 21,17 und Lc 22,32], est recte positus sicut messor in die messis.

440 Ibid., fol. 248vb: Et ideo sicut messor in die messis ardet, languet et gaudet, sic Romanus Pontifex singulariter et principaliter et continue habet ista tria: ardet pro sollicitudinibus singulorum, languet pro defectibus subditorum, gaudet de profectibus filiorum. 
lichen Verbindung der beiden Elemente Fehler/Kardinallegat bei, die der Verifizierung oder Falsifizierung harrt.

Clemens VI. verweilt jedoch zunächst bei der Person des Papstes, dessen Aufgabe gemäß Rom 12,15 darin bestehen müsse gaudere cum gaudentibus, flere cum flentibus. Die Entfaltung dieses Gedankens wird jedoch einer Autorität überlassen, die immer dann herangezogen wird, wenn auf Fragen der Über- und Unterordnung und damit einhergehend auf die Problematik der päpstlichen plenitudo potestatis verwiesen wird: Bernhard von Clairvaux. Eine ganze Seite der Pariser Handschrift wird für die wörtliche Wiedergabe eines Abschnitts aus Bernhards zehnter Predigt zum Hohelied verwendet - immerhin rund ein Sechstel des überlieferten Gesamttextes ${ }^{441}$. Darin werden den beiden Brüsten der Braut die beiden Herzensregungen der Freude (gaudere cum gaudentibus) und des Mitleids (flere cum flentibus) zugewiesen und davon ausgehend Gedanken artikuliert, die sich auf die zweifache Milch der Brüste beziehen, ohne die jeder Seelsorger zu einem unwürdigen Vertreter der Kirche wird: die Milch der Ermunterung und die Milch der Tröstung. Der Papst nimmt für sich in Anspruch, über beide Arten von Milch zu verfügen, sich somit als Schützer und Verteidiger derjenigen Bedrängten erweisen zu können, die der Ermunterung und Tröstung bedürfen. Wer anders als Kardinal Guillaume Court könnte sich hier angesprochen fühlen? Wer anders als der nach Italien entsandte Zisterzienserlegat, der sich während seiner Legation mit Vorwürfen der Bestechlichkeit und Vorteilsnahme im Amt konfrontiert sah, könnte mit einem Zitat der Art »Wenn sie [die Braut] zum Beispiel merkt, daß jemand von denen, die sie im Evangelium geboren hat, von heftiger Versuchung erschüttert wird, daß er deshalb verwirrt, traurig und kleinmütig geworden ist, daß er die Macht der Versuchung schon nicht mehr ertragen kann, wie leidet sie da mit, wie besänftigt sie, wie klagt, wie tröstet sie, wie viele Beweise der Liebe findet sie, durch die sie den Einsamen aufrichtet! «42 sonst gemeint sein?

Die Vorgehensweise Clemens' VI. liegt auf der Hand. In seiner BegrüBungscollatio wird auf direkte Kritik an der Arbeit des Legaten verzichtet, werden mögliche explizit formulierte Anschuldigungen durch ein sehr viel raffinierteres rhetorisches Verfahren substituiert. Weder der Papst noch die angeführte Autorität Bernhard von Clairvaux fokussieren ihre Kritik auf eine spezielle Person. Und dennoch wird ungeachtet der Allgemeingültigkeit der

441 Ibid., fol. 248va-249ra. Der Text findet sich in BERnHARD von Clairvaux, Sermones super Cantica Canticorum, hg. v. Jean LEClerCo und Henri Rochals, in: Sancti Bernardi Opera, Bd.1, Rom 1957, S. 49f.; zur deutschen Übersetzung vgl. Bernhard von Clairvaux. Sämtliche Werke, Bd. 5, S. 147-149.

442 Vgl. ibid., S.147. Der lateinische Text lautet: Verbi gratia, si quem forte ex his quos genuit in Evangelio, deprehenderit forti aliqua tentatione concussum, et inde turbatum et tristem pusillanimemque factum, non posse iam ferre vim tentationis, quomodo condolet, quomodo mulcet, quomodo plangit, quomodo consolatur, quot argumenta pietatis mox reperit, quibus erigat desolatum. 
Aussagen eine Verortung im hic et nunc angestrebt. Verbale Leerstellen müssen dazu lediglich mit offiziellen Verlautbarungen über die Legation gefüllt werden. Verborgene Kritik bedarf eines wenig komplexen Entschlüsselungsmechanismus, als dessen Hauptbestandteil die Kenntnis um die im Vorfeld der Collatio an der Kurie diskutierten diplomatischen Demarchen des Legaten gelten muß. Nicht nur die ins politische Tagesgeschäft der Kurie unmittelbar involvierten Kardinäle sind es also, die zur interpretatorischen Weitung des Bernhard-Zitats in der Lage sind, sondern ganz allgemein all diejenigen, die die Politik der Kurie mit Interesse verfolgen.

Noch unproblematischer erweist sich diese Art des Vorgehens in Hinblick auf den zweiten, von Bernhard entfalteten Gedankengang: die Klage um die unwürdigen Seelenlenker. Als Grund der Unwürdigkeit wird das Verlangen, alles »im Ofen der Habgier« einzuschmelzen, alles »zum Erwerb schmählichen Gewinns « zu erniedrigen, benannt ${ }^{443}$. Bemüht wird also der alte Topos der insbesondere den Klerikern zu eigenen avaritia, der Liebe zum Geld ${ }^{444}$. Daß Guillaume Court Geld und Besitz alles andere als indifferent gegenüberstand, davon zeugen nicht nur die gegen ihn gerichteten Anklagen der Bestechlichkeit und Parteilichkeit, sondern auch sein Bemühen um Besitzstandswahrung, wie es sich in der Sorge um seine Livrée in Avignon artikuliert ${ }^{445}$. Nachdem der Papst mit Hilfe Bernhards von Clairvaux seiner Klage um die defectibus subditorum breiten Raum gegeben hatte, gerät auch das dritte zu behandelnde Element, die Freude nämlich um die profectibus filiorum nicht ganz so optimistisch, wie eigentlich zu erwarten wäre. Wohl wahr sei es - so der Papst - daß mit der Freude stets auch Angst verbunden sei, Angst davor, daß der Erfolg (profectus) durch widrige Umstände verhindert werden könne ${ }^{446}$.

$\mathrm{DaB}$ vom gezeichneten Negativbild unmittelbar zur Gestalt des Legaten selbst übergeleitet wird, dürfte kein Zufall sein. Zunächst werden diejenigen Fähigkeiten abgehandelt, über die ganz allgemein jeder vom Papst entsandte Legat verfügen muß. Verwiesen wird auf Schlüsselqualifikationen wie das Bemühen um Ausgleich, Gerechtigkeit und Frieden ${ }^{447}$. Vor diesem Hintergrund richtet sich dann der Blick zum ersten Mal explizit auf die Gestalt von Kardinal Guillaume Court, dem immerhin eingangs bescheinigt wird, er habe alle ihm

443 Vgl. ibid. Der lateinische Text lautet: [...] haec omnia in fornace avaritiae conflant et profligant in acquisitione turpis quaestus [...].

444 Helga SCHÜPPERT, Kirchenkritik in der lateinischen Lyrik des 12. und 13. Jahrhunderts, München 1972, bes. S.75-79.

$445 \mathrm{Vgl}$. Lettres Clément VI autres que la France, n. 55.

446 MS 240, fol.249ra: Verum est, quod isti gaudio de profectu semper est quidam timor anexus, ne scilicet profectus iste perdatur per tempestatem, incendium, inimicum aut aliter.

447 Ibid.: Modo videtur michi, quod legatus fidelis per Romanum Pontificem missus et eius ardorem mitigat, et eius languorem sanat et eius timorem assecurat. Mitigat quidem ardorem dando temperamentum refrigerii comissa sibi cum omni sollicitudine prosequendo, sanat languorem dando medicamentum suspirii vicia cum omni rectitudine et mansuetudine corrigendo, assecurat timorem dando oblectamentum gaudii seu desiderii pacis, virtutis et unitatis federa cum omni plenitudine afferendo. 
übertragenen Aufgaben getreulich ausgeführt, gegen unterschiedlichste Laster gekämpft und tragfähige Bündnisse vermittelt ${ }^{448}$. Die erste grobe Ergebnisbilanz fällt also durchaus zugunsten des Kardinals aus, dem zusätzlich durch eine Reihung positiv konnotierter Adjektive gehuldigt wird ${ }^{449}$. Welche Aufgaben waren es genau, die vom Legaten zu bewältigen waren? Der Papst benennt drei Dinge: die Vermittlung eines Friedensvertrags oder Waffenstillstands in der Lombardei, das Schmieden eines Bündnisses der oberitalienischen Städte, um den Durchzug Ludwigs des Bayern zu verhindern, und das Überzeugen insbesondere der Venezianer, an einem Kreuzzug gegen die Türken teilzunehmen ${ }^{450}$.

Eine politische Wertung der von Guillaume Court vollbrachten Leistungen bleibt Clemens VI. jedoch schuldig. Nur in allgemeinsten und deshalb wenig aussagekräftigen Wendungen erfährt man von der tatsächlichen Durchführung der ihm übertragenen Aufgaben ${ }^{451}$. Noch kürzer fällt die Behandlung der Reformbemühungen des Legaten aus ${ }^{452}$. Als wichtigstes Ergebnis der Legation werden Waffenstillstandsabkommen angeführt, an denen neben den Visconti von Mailand, den Scaligeri von Verona und dem Markgrafen von Montferrat auch Johanna I. von Sizilien beteiligt war ${ }^{453}$. Zusätzlich gibt der Papst seiner Hoffnung Ausdruck, die auf drei Jahre befristeten Abkommen mögen zu veritablen Friedensschlüssen führen. Nach der Erwähnung einiger

448 Ibid., fol.249rb: Modo videtur Nobis, quod legatus noster de partibus Italie rediens commissa sibi opera feliciter consummavit, repertaque in sua legatione vitia, quantum in eo fuit, virilter resecavit, magna et inter magnos federa utiliter copulavit. Der zweite Punkt, in dem die Sprache auf nicht näher spezifizierte vitia gebracht wird, die der Legat bekämpft habe, wird durch Beifügung des Zusatzes quantum in eo fuit doppeldeutig, ergeben sich doch zwei Übersetzungsvarianten. Zum einen könnte der Legat die erwähnten Laster »soweit es ihm möglich war « bekämpft haben, zum anderen sich gegen eigene Laster, "so weit es ihn betraf«, gewendet haben. Auch das französische quant à lui, das sich aus dem lateinischen quantum in eo fuit entwickelte, hat sich diese Doppeldeutigkeit bewahrt.

449 Ibid.: Unde videtur michi, quod hodie ad Nos rediens venit gloriosus et desiderabilis ex comissi operis consummatione, venit virtuosus et commendabilis ex morum in clero et populo reformatione, venit fructuosus et utilis ex tanti federis copulatione.

450 Ibid.: Ad litteram enim ipsum preter negocia, que ad officium legati incumbunt, misimus ad tria opera specialiter exercenda. Primo ad faciendum pacem seu treugas in Lombardia, que erat variis bellis et multiplicibus afflicta mirabiliter et concussa; secundo ad uniendum omnes de illis partibus ad resistendum Bavaro si vellet Lombardiam intrare; tertio ad inducendum Venetos et alios ad succurrendum $X$ annis in Romanie partibus contra Turcos.

451 Wenn Clemens VI. in Hinblick auf den gegen Ludwig den Bayern gerichteten lombardischen Städtebund von einem sicut nobis scripsit spricht und als Reaktion der Venezianer auf die Kreuzzugspläne lediglich deren responsionem gratam et utilem erwähnt, sind Zweifel an der Dauerhaftigkeit und politischen Durchsetzbarkeit der vom Legaten erzielten Verhandlungsergebnisse erlaubt.

452 Ibid., fol.249va: Ipse enim ad modum boni legati mores in clero et populo reformavit. Mit 2 Cor 5,19f. wird zur Bekräftigung des Gesagten auch nur eine einzige biblische Autorität angeführt.

453 Ibid.: Ad litteram enim ipse inter illos de Mediolano et de Scala, inter principem et marchionem Montisferrati, inter gentes regine Sicilie et breviter inter omnes sue legationes treugas ad trienium, que pacis gerunt ymaginem, copulavit. 
biblischer Autoritäten ${ }^{454}$ und der Würdigung der Legation durch ein weiteres Bernhard-Zitat ${ }^{455}$ wird der bisherige Gedankengang nochmals umständlich zusammengefa $\mathrm{t}^{456}$.

Die in direktem Zusammenhang mit der Legation geäußerten Gedanken werden von allgemeinen Ausführungen zum Thema »Was zeichnet einen guten Legaten aus? « eingerahmt. Der Papst verweist auf vier Charakterzüge, über die ein Legat unbedingt verfügen müsse, den Schmuck der Reinheit und Unbestechlichkeit (puritatis et incorruptionis decor), die sich aus Heiligkeit, Predigt und heiliger Ermahnung ergebende Außenwirkung (sanctitatis, predicationis et sancte exhortationis clamor), das Handeln in Treue und Demut (fidelitatis et humiliationis tenor) und schließlich die Glut der Aufrichtigkeit und Hingabe (sinceritatis et devotionis fervor) ${ }^{457}$. Damit wird ein idealtypisches Modell geliefert, das zu einem Vergleich mit der Person des Kardinallegaten herausfordert. Doch auch hier hütet sich der Papst davor, etwaige Kritik explizit auf ihn zu beziehen. Mögliche Erwartungshaltungen werden durch ein non prosequor enttäuscht, mittels eines sich anschließenden sed more solito moveo questionem jedoch aufgefangen und in eine andere Richtung gelenkt. Auf ein weiteres Eingehen auf Charakteristika guter Legaten will der Papst zugunsten der üblichen (more solito) Behandlung einer Frage verzichten. Nur: Welche Frage ist gemeint? Unter Rückgriff auf das Thema Sicut frigus nivis, das mit zwei weiteren Bibelstellen kontrastiert wird, in denen die Begriffe nix bzw. frigus eine zentrale und ausgesprochen negative Rolle spielen ${ }^{458}$, wird die Gelegenheit genutzt, auf die scheinbare Unvereinbarkeit der drei biblischen Aussagen hinzuweisen und daraus die Frage abzuleiten, wie ein Legat, der mit der Kälte des Schnees zur Zeit der Ernte verglichen wird, für denjenigen, der ihn aussendet, zum Segen werden könne ${ }^{459}$. Angesprochen ist damit zum einen der für den theologisch geschulten Papst interessante Komplex der Bibelexe-

454 Lc 14,32; 1 Mkk 9,70; Jer 49,14. Das dem 1. Buch der Makkabäer entnommene Zitat Jonathas misit legatos componere pacem - liefert das einzige Beispiel einer Bezugnahme auf eine zeitgleich laufende Legation: Istum in Lombardiam, alium in Tusciam. Mit ersterem ist Guillaume Court, mit letzterem Aimeric de Châtelus gemeint. Der Papst reiht sich so in die Phalanx alttestamentarischer Referenzpersönlichkeiten ein.

455 Das Zitat wird Bernhards Schrift De consideratione entnommen, in: San Bernardo, Opere, I, S.878.

456 Dafür wird immerhin eine Spalte in der Pariser Handschrift verwandt, vgl. MS 240, fol. $249 \mathrm{vb}$.

457 Ibid., fol. 250ra: In quibus verbis - sed non prosequor - tanguntur quattuor, que debet habere bonus legatus. Primo puritatis et incorruptionis decorem, qui refrigeret omnis concupiscentie incendium [...]. Secundo sanctitatis, predicationis et sancte exhortationis clamorem, qui germinet preconium omnis sanctimonie [...]. Tercio fidelitatis et humiliationis tenorem, qui dat fastigium omnis excellentie [...]. Quarto sinceritatis et devotionis fervorem, qui reportet preconium glorie non quidem sibi, sed ei, qui misit eum.

458 Vgl. Prov 26,1 - Quomodo nix in estate et pluvia in messe sic indecens est stulto gloria und Prov 31,21 - Non timebit domui sue a frigoribus nivis.

459 MS 240, fol.250tb: Quomodo fit ista comparatio, ut noster legatus comparetur frigori nivis in die messis? 
gese unter besonderer Berücksichtigung der concordantia oppositorum, zum anderen das Verhältnis zwischen ausgesandtem Legaten und der aussendenden Instanz, genauer: zwischen Kardinal und Papst.

In seiner vielschichtigen Antwort läßt der Papst mit der Glossa ordinaria nicht nur eines der wichtigsten exegetischen Instrumente des Mittelalters zu Wort kommen, sondern stellt durch den Verweis auf Aristoteles auch seine Kenntnisse paganer Philosophie unter Beweis ${ }^{460}$. Untermauert wird dadurch folgendes Ergebnis: Im speziellen Fall der thematisch vorgegebenen Similitudo könne keinesfalls von Allgemeingültigkeit ausgegangen werden. Auch wenn sich Schnee zur Zeit der Ernte als desaströs erweisen könne, so sei im speziellen Fall des Legaten doch von einer segensreichen Wirkung auszugehen $^{461}$. Diese positive Wirkung wird eng an das dem Begriff nix innewohnende Bedeutungsspektrum gekoppelt. Schnee, der seinen Ursprung in himmlischen Regionen habe, verweise auf Erhöhung und hervorragende Talente (eminentia), besteche durch Klarheit (evidentia), durch ein Übermaß an Feuchtigkeit (in humore abundantia), sei frisch, energiegeladen und deshalb in hohem Maße wirksam (in vigore efficacia) ${ }^{462}$.

Was heißt dies nun für den Legaten? Clemens VI. läßt keinen Zweifel daran, daß auch der Legat aufgrund des von ihm übernommenen Amtes dem Himmel sehr viel näher stehe als andere Personen. Grund dafür sei die von ihm ausgeübte potestas göttlichen, nicht menschlichen Ursprungs. Die dem Kardinallegaten vom Papst übertragene Gewalt zeitigt aber noch andere, im Bereich der Präzendenz vor anderen legatorischen Klassen zu verortende Vorteile. Als Legat stehe er aufgrund der herausgehobenen Stellung klar über den Nuntien, zumal wenn die Entsendung wie im Falle des Guillaume Court als legatus a latere erfolge ${ }^{463}$. Festgehalten werden sollte jedoch, daß dem Legaten diese herausgehobene Position nicht aufgrund eigener Qualitäten zuteil

460 Vgl. ibid., fol. 250ra-250vb; vgl. Marie-Henriette JulliEn DE POMMEROL, Textes politiques dans la bibliothèque des papes d'Avignon, in: L'État moderne. Genèse, bilans et perspectives, hg. v. Jean-Philippe GENET, Paris 1990, S. 207-216.

461 MS 240, fol. 250va: Et videtur michi, quod sicut legatus fidelis comparatur huic frigori nivis in die messis propter refrigerium, propter remedium, proper gaudium, ita legatus negligens aliam recipit comparationem.

462 Ibid.: Et videtur michi, quod non sine misterio non solum positum est sicut frigus in die messis, sed additum est sicut frigus nivis. Ego enim considero, quod nix habet quatuor conditiones, quas habet ad litteram noster legatus. Nix enim habet in origine quandam eminentiam. Nix enim non in terra sumit originem, sed in celo [...]. Secundo nix habet in candore magnam evidentiam, est enim albissima. Unde qui negat, quod nix sit alba, indiget sensu et pena [...]. Tertio nix habet in humore abundantiam, unde statim resolvitur in aqua [...]. Quarto habet in vigore quandam efficaciam.

463 Ibid., fol. 250vb: Modo legatus noster habet istas quatuor conditiones. Habuit enim primo in origine et in situ celsitudinem. Potestas enim sue legationis non de terra, sed de celo duxit originem. Unde omnis potestas terrena de terra originatur, sed potestas ecclesiastica de celo a Christo immediate derivatur [...]. Et ideo iste tantam habuit celsitudinem, quod legatus, qui habet magnam preeminentiam supra nuntium et non quicumque legatus, sed legatus a latere. 
wird. Göttliche Potestas verwirklicht sich im Amt, nicht in der Person. Als vermittelnder Zwischeninstanz obliegt dem Papst die Übertragung dieser potestas, was - auf eine griffige Kurzformel gebracht - heißt: ohne Papst kein Legat.

In Kardinal Guillaume Court sieht Clemens VI. das Ideal der »goldenen Mitte « verwirklicht. So wie der Schnee in einem Zwischenraum der Luft entstehe (in medio interstitio aeris), so bewege sich der Kardinal in der Mitte des aus 25 Personen bestehenden Kardinalskollegs ${ }^{464}$. Als Charakteristikum von virtus wird deren Stellung in der Mitte benannt. Gerade die Mittelstellung ist es also, die Exzellenz und Entfaltung aller Tugenden gewährleistet: Mitte ist nicht Mittelmaß, sondern Voraussetzung für Exzellenz. Clemens VI. neigt dazu, seinen Predigten im Schlußteil durch ironisch gefärbte Verweise auf die Hauptperson einen persönlicheren Anstrich zu geben. So dient ihm der Verweis auf die Schönheit und Weiße des Schnees dazu, zum einen die Zugehörigkeit des Kardinals zum Zisterzienserorden, zum anderen seine weiße Haarpracht zu erwähnen ${ }^{465}$. Vergessen wird auch nicht der Hinweis auf die "Weiße« des Geistes (albus in mente), womit auf das Übermaß der den Geist des Kardinals zierenden Tugenden verwiesen wäre. Das Übermaß an Frische und Energie, das Guillaume Court des weiteren auszeichnet, wird anhand einer Adjektivreihung verdeutlicht ${ }^{466}$.

Treu, wahrhaftig, freundlich, liebenswert, bescheiden und stark ist der Kardinal, dessen Legation als Erfolgsgeschichte gelten müßte, stünde nur der letzte, sich in lobenden Worten verbreitende Teil der päpstlichen Collatio zur Verfügung ${ }^{467}$. Die Analyse sowohl der Einträge in den päpstlichen Registern als auch des einleitenden Teils der Collatio dürfte jedoch verdeutlicht haben, $\mathrm{da} B$ den im offiziellen Rahmen als notwendig empfundenen ostentativen Lobeshymnen nicht allzu viel Glauben geschenkt werden sollte. Die Legation des Guillaume Court nach Oberitalien konnte deshalb kein Erfolg werden,

464 Ibid.: Et videte, quod nix ad rei veritatem in medio interstitio aeris generatur. Medium autem magnam virtutem habet. Unde sol in medio planetarum, rector in medio populi, Christus natus in medio duorum animalium, conversatus in medio apostolorum, passus in medio latronum [...]. Virtus etiam omnis in medio. Iste ergo istum situm tam virtuosum in numero cardinalium ad litteram tenet. Habet enim XII supra et XII post et ipse recte medius. Als Kandidat in der einzigen Promotion Benedikts XII. nimmt Guillaume Court im durch zehn Neuzugänge erweiterten Kolleg tatsächlich hinsichtlich der Ancienneté eine Mittelstellung ein.

465 Ibid., fol.251ra: Ad litteram enim ipse monachus albus est [...]. Et non solum albus in veste, ymmo albus in capite.

466 Ibid.: Habet vigoris magnitudinem. Fuit enim ad modum boni legati fidelis in commissis, verax in promissis, affabilis in verbis, amabilis in factis, humilis in prosperis, fortis in adversis.

467 Die Collatio endet wie folgt: Patet ergo, quod merito non solum facta est comparatio frigoris in die messis ad legatum nostrum, sed etiam frigoris nivis, ut sit de numero illius frigoris et illius nivis, de quibus dicitur Dan III. Benedicite gelu et frigus, domino laudate et superexaltate eum in secula. Ipse enim laudabilis et gloriosus et superexaltatus in secula. Amen. 
weil dem Kardinal einige entscheidende, vom Papst explizit benannte Charakteristika fehlten oder im Laufe der Legation abhanden gekommen waren. Clemens VI. war geneigt, seinen alten Studienkollegen aus Pariser Zeiten vor allen Angriffen in Schutz zu nehmen, ließ aber zwischen den Zeilen erkennen, daß die Vorgehensweise des Kardinals mitnichten seinen Vorstellungen entsprach. Die Zurschaustellung mediokrer politischer Fähigkeiten in legationibus verzögerte den Aufstieg des Kardinals allerdings wenn überhaupt, dann nur kurz. Bereits 1348 wurde er zum Kämmerer des Kardinalskollegs ernannt, 1350 erfolgte die Kreation zum Kardinalbischof von Tusculum. Interessante Vergleichsmöglichkeiten ergeben sich in Hinblick auf die anläßlich dieses Ereignisses von Clemens VI. gehaltene Collatio ${ }^{468}$.

\subsubsection{Die Legation von Kardinal Aimeric de Châtelus nach Tuszien und Neapel}

\subsubsection{Clemens VI., Johanna I. und das Königreich Neapel}

Nach dem Zusammenbruch der staufischen Herrschaft in Süditalien wurde mit Karl von Anjou, dem Bruder Ludwigs des Heiligen, 1264 ein Franzose von Papst Clemens IV. mit dem Königreich Sizilien belehnt. Bereits 1282 mußte die neue Dynastie infolge der "Sizilianischen Vesper « einen bedeutenden Gebietsverlust hinnehmen: Die Insel Sizilien fiel an die Krone von Aragon, den Anjou verblieb mit dem Königreich Neapel lediglich der Festlandsbesitz. Im offiziellen Sprachgebrauch hielt man zwar daran fest, die Bezeichnung regnum Sicilie weiterhin für das Königreich Neapel zu verwenden, die Insel Sizilien hingegen als regnum Trinacrie zu bezeichnen, die Namensgebung konnte jedoch nicht darüber hinwegtäuschen, daß sich Herrschaftsbildung und -konsolidierung für die Anjou schwieriger als erwartet erwiesen. Trotz hervorragender Herrscherpersönlichkeiten wie Karl I. ${ }^{469}$ oder Karl II. ${ }^{470}$ verging rund ein halbes Jahrhundert, bis mit Robert von Neapel, dessen Namen schon bald das ehrende Epitheton »der Weise « hinzugefügt wurde, 1309 ein Herrscher den Thron Neapels bestieg, der zwar an der Aufgabe der Rückgewinnung der Insel Sizilien scheiterte, dessen Herrschaft aber als die eines weisen, ungemein gebildeten und selbst literarisch tätigen Königs in die Geschichte einging ${ }^{471}$.

468 Collatio Super montem excelsum ascende, in: Bibliothèque Sainte-Geneviève, MS 240, fol.454rf, s. Kap. 4.7. Der Papst beschwört darin geradezu die alte Freundschaft, die ihn seit seiner Studienzeit in Paris mit Guillaume Court verbindet.

469 Peter Herde, Karl von Anjou, Stuttgart 1979.

470 Andreas KIESEWETTER, Die Anfänge der Regierung König Karls II. von Anjou (1278-1295). Das Königreich Neapel, die Grafschaft Provence und der Mittelmeerraum zum Ausgang des 13. Jahrhunderts, Husum 1999. Zu Johanna I. bemerkt Kiesewetter (ibid., S.9) treffend: »Obwohl während ihrer Regierungszeit das Königtum Neapel einen Tiefpunkt seiner Geschichte erlebte, zog die tragische Gestalt der >regina dolorosa< immer wieder die Forscher in ihren Bann, da sich in der zweiten Hälfte des 14. Jahrhunderts die königliche Familie gleich den Atriden der griechischen Tragödie gegenseitig auslöschte.« 471 Walter GoETZ, König Robert von Neapel (1309-1343). Seine Persönlichkeit und sein Verhältnis zum Humanismus, Tübingen 1910; Samantha KELLY, The new Solomon. Ro- 
Als Förderer der Künste und Mäzen wirkte Robert der Weise richtunggebend für die weitere kulturelle Entwicklung Europas ${ }^{472}$. Nach dem frühen Tod seines Sohnes regelte Robert die Nachfolgefrage bereits zu Lebzeiten und bestimmte mit Johanna die älteste seiner Enkeltöchter zu seiner Nachfolge$\mathrm{rin}^{473}$. Tatsächlich folgte sie ihm $1343 \mathrm{im}$ Alter von $18 \mathrm{Jahren}$ auf dem Thron nach. Bereits im Alter von sieben Jahren hatte sie Andreas, den zweiten Sohn des Königs von Ungarn, geehelicht, der selbst dem Hause Anjou angehörte.

Die kurialerseits vorgenommenen Bewertungen Neapels und des dort herrschenden politischen Systems wechselten nach Maßgabe der Problemlage, verliefen zumindest während des Pontifikats Clemens' VI. jedoch keinesfalls stringent. Anders bei den zeitgenössischen Autoren, insbesondere Petrarca, für den Neapel untrennbar mit der eigenen Dichterkrönung verbunden war und als Hort der Musen zum Gegenbild des verderbten Avignon mutierte ${ }^{474}$. Tatsächlich erinnerte die Herrschaft Johannas I. allerdings nur noch entfernt an diejenige König Roberts, unter dem das kulturelle und intellektuelle Leben am Hof zur Entfaltung gebracht worden war ${ }^{475}$.

Beunruhigt über die in der Anfangsphase alles andere als stabile Herrschaft, die er durch interne Rivalitäten der aus den Häusern Tarent und

bert of Naples (1309-1343) and fourteenth-century kingship, Leiden 2003 (The medieval Mediterranean, 48); Jean-Paul BoYER, Prédication et état napolitain dans la première moitié du XIVe siècle, in: L'État angevin. Pouvoir, culture et société entre XIII'e et XIVe siècle. Actes du Colloque international organisé par l'American Academy in Rome, l'École française de Rome, l'Istituto storico italiano per il Medio Evo, l'U.M.R. Telemme et l'université de Provence, l'università degli studi di Napoli Federico II (Rome-Naples, 7-11 novembre 1995), Rom 1998, S. 127-157.

$472 \mathrm{Vgl}$. Isabelle Heullant-Donat, Quelques réflexions autour de la cour angevine comme milieu culturel au XIVe siècle, in: L'État angevin. Pouvoir, culture et société entre $\mathrm{XIII}^{e}$ et XIVe siècle. Actes du Colloque international organisé par l'American Academy in Rome, l'École française de Rome, l'Istituto storico italiano per il Medio Evo, l'U.M.R. Telemme et l'université de Provence, l'università degli studi di Napoli Federico II (RomeNaples, 7-11 novembre 1995), Rom 1998, S. 173-191.

473 Die Literatur zu Johanna I. ist uferlos. Die maßgebliche Darstellung findet sich bei Émile LÉonarD, Histoire de Jeanne Ire, reine de Naples, comtesse de Provence (1343-1382), 3 Bde., Monaco, Paris 1932-1937; immer noch nützlich ist Matteo CAMERA, Elicubrazioni storico-diplomatiche su Giovanna I Regina di Napoli e Carlo III di Durazzo, Salerno 1889; Giuseppe Galasso, Il regno di Napoli. Il mezzogiorno angioino e aragonese (1266-1494), Turin 1992; Felice Froio, Giovanna I d'Angiò, Mailand 1992 (Storia e documenti, 112). Äußerst instruktiv Andreas KIESEwETrER, Art. Giovanna I, in: DBI 55 (2001) S.455-477, zur weiteren Bibliographie vgl. ibid., S. 474-477.

474 Vgl. Roberto Mercuri, Avignone e Napoli in Dante, Petrarca e Boccaccio, in: Avignon \& Naples. Italy in France - France in Italy in the fourteenth century, hg. v. Marianne Pade, Hannemarie Ragn Jensen, Lene WaAge Petersen, Rom 1997, S.117-129; vgl. auch Charmaine LEE, Avignon and Naples: an Italian court in France, a French court in Italy, in: Avignon \& Naples. Italy in France - France in Italy in the fourteenth century, Rom 1997, S. 141-149.

475 Vgl. GoETz, König Robert von Neapel; KELLY, The new Solomon. 
Durazzo stammenden Cousins väterlicherseits massiv gefährdet sah ${ }^{476}$, entsandte Clemens VI. in Wahrnehmung seiner Pflichten als oberster Lehnsherr Kardinal Aimeric de Châtelus als Legat ins regnum Sicilie. Dort oblag ihm insbesondere die Annulierung all derjenigen Belehnungen und Schenkungen, mit denen Johanna I. leichtsinniger- und großzügigerweise ihre Herrschaft eröffnet hatte. Trotz fortgesetzter Spannungen zwischen Johanna und Andreas, dem lediglich der Titel eines Prinzgemahls zuerkannt wurde, ordnete der Papst dessen Krönung an. Allein seine Ermordung in der Nacht vom 18. auf den 19. September 1345 verhinderte die Realisierung dieser Anordnung. Die Schuldfrage stellte sich unmittelbar. Trotz überstürzt vorgenommener Exekutionen vermochte es Johanna I. nicht, den ihr gemachten Vorwurf einer Mitwisser-, ja sogar Mittäterschaft zu entkräften ${ }^{477}$. Insbesondere der Bruder des Ermordeten, König Ludwig von Ungarn, drängte auf baldige Überführung der Schuldigen, zu denen er Johanna selbst zählte, die er offiziell als viricida, als Gattenmörderin, bezeichnete. Als die von der Kurie forcierten, von Johanna fortgesetzt behinderten Untersuchungen zu keinem befriedigenden Ergebnis führten, als auch über das Schicksal Karl Martells, des gemeinsamen Sohnes von Johanna und Andreas, keine Übereinkunft erzielt werden konnte, rüstete Ludwig von Ungarn zu einer Invasion des Königreichs ${ }^{478}$.

Um die gespannte politische Situation zu entkrampfen, entsandte der Papst mit Kardinal Bertrand de Deux einen weiteren Legaten nach Neapel. Seine Mission scheiterte. Johanna, inzwischen unter dem Einfluß Roberts von Tarent stehend, den sie am 9. September 1347 ohne päpstlichen Dispens geheiratet hatte, verließ Neapel am 15. Januar 1348, schiffte sich in die Provence ein und erreichte schließlich Avignon, das wie die Provence im Besitz der Anjou war. Eine an der Kurie initiierte Untersuchung, die die am Tode des Andreas Schuldigen überführen sollte, verlief im Sande ${ }^{479}$. Johanna verließ Avignon am 22. Juli, nachdem sie die Stadt knapp einen Monat zuvor für die Summe von 80000 Florin an den Heiligen Stuhl verkauft hatte ${ }^{480}$. Am 17. August er-

476 In weiser Voraussicht hatte König Robert seiner Enkelin einen Regentschaftsrat an die Seite gestellt, in dem die Linien Anjou-Durazzo und Anjou-Tarent ebensowenig wie die Kirche vertreten waren. Ohne Zustimmung dieses Rates sollte es für Johanna unmöglich sein, vor ihrem 25. Lebensjahr autonome politische Entscheidungen zu treffen. Die Entscheidung Clemens' VI., den Regentschaftsrat mittels der Bulle Ex ore sedentis vom 28. November 1343 für abgesetzt zu erklären, erwies sich in der Folge als klare politische Fehlentscheidung mit katastrophalen Auswirkungen.

477 Vgl. zur Ermordung des Andreas v.a. LÉonARD, Jeanne, I, S. 456-513; ZACour, Talleyrand, S. 31-43.

478 Vgl. zur Geschichte Ungarns im Mittelalter Pál EngeL, The Realm of St. Stephen. A History of Medieval Hungary (895-1526), London, New York 2001.

479 Mit den Untersuchungen wurde eine aus drei Mitgliedern - Bertrand du Pouget, Guillaume d'Aure und Galhard de la Mothe - bestehende Kardinalskommission betraut, vgl. Lettres Clément VI, n. 3852 (07.05.1348).

$480 \mathrm{Ob}$ der Papst die Möglichkeit zum Rückkauf gewährt hatte, war strittig. Johanna bat jedenfalls nach dem Tode Clemens' VI. einen anonymen Kardinal um Unterstützung bei 
folgte ihre Rückkehr nach Neapel, das der ungarische König wegen der Pest und der feindseligen Haltung des neapolitanischen Adels verlassen hatte. Noch einmal fand von April bis September 1350 unter seiner Führung ein Feldzug gegen Neapel statt, ehe im April 1352 unter maßgeblicher Vermittlung des Papstes Frieden geschlossen werden konnte. Johanna I. gilt nach wie vor als eine der schillerndsten Frauengestalten der Geschichte, wobei die Spannbreite in der Bewertung ihrer Persönlichkeit außerordentlich groß ist und bereits bei den Zeitgenossen von den Lobeshymnen eines Boccaccio ${ }^{481}$ über die Anklagen bezüglich einer disordinata lussuria durch Giovanni Villa$\mathrm{ni}^{482}$ bis hin zur offenen Schmähung in den Istorie Pisane reicht ${ }^{483}$.

\subsubsection{Die Legation des Aimeric de Châtelus im Spiegel kurialer Register- überlieferung}

Lediglich drei Monate nach Entsendung von Kardinal Guillaume Court als Legat nach Oberitalien erfolgte am 14. Oktober 1342 mit der Ernennung von Aimeric de Châtelus als legatus a latere die Konstituierung einer neuen diplomatischen Mission, deren Ziel abermals Italien war ${ }^{484}$. Die Wahl fiel auf einen der besten Kenner der verworrenen Verhältnisse in Italien, der als ehemaliger Rektor des Heiligen Stuhls in der Romagna und Erzbischof von Ravenna (1322-1332) ausreichend Gelegenheit gehabt hatte, sich mit der politischen Situation vertraut zu machen. Die Ernennung stand in unmittelbarem $\mathrm{Zu}-$ sammenhang mit einer von den Gesandten der Königin von Neapel im Konsistorium vom 13. Oktober vorgebrachten Bitte, der Papst möge die rechtlich beanstandete Regierung Johannas I. legitimieren. Aimeric de Châtelus sucht man zwar vergeblich unter den in den Protokollbüchern der Kammerkleriker namentlich aufgeführten Teilnehmern des Konsistoriums, doch mußte es sich

ihrer Absicht, Avignon vom Heiligen Stuhl zurückzuerwerben, vgl. LÉONARD, Jeanne, II, S. 490 (pièces justificatives: Brief von Ende Dezember 1352); vgl. auch Anne-Marie HAYEZ, Le conseil de ville supplie la reine Jeanne de ne pas vendre Avignon, in: Avignon au Moyen Âge, Avignon 1987, S.97-102.

481 Giovanni Boccaccio, De mulieribus claris, hg.v. Vittorio ZACCARIA, Mailand 1967, c. 106 (De Iohanna Ierusalem et Sycilie regina), S. 442-449.

482 Giovanni Villani, Nuova Cronica, ed. PORTA, S. 148; vgl. auch PorTA, Giuseppe, Giovanni Villani storico e scrittore, in: I racconti di Clio. Techniche narrative della storiografia. Atti del convegno di studi (Arezzo 6-8 novembre 1986), Pisa 1989, S. 147-156; Franca RAGONE, Le scritture parlate. Qualche ipotesi sulla redazione delle cronache volgari nel Trecento dopo l'edizione critica della Nuova Cronica di Giovanni Villani, in: Archivio storico italiano 149 (1991) S. 783-810; DiEs., Giovanni Villani e i suoi continuatori. La scrittura delle cronache a Firenze nel Trecento, Rom 1998 (Nuovi Studi Storici, 43).

483 Istorie Pisane, in: Archivio storico italiano 6 (1890) S. 810. Johanna soll ihren Gatten schlichtweg deshalb umgebracht haben, weil sie ihn poco atto alle cose veneree fand.

484 Vgl. Baluze/Mollat, Vitae I, S. 264f., 282; LÉONARD, Jeanne, I, S.291-418 mit der ausführlichen Darstellung der administrativen Maßnahmen, die Aimeric im Regno ergriff. Unschätzbar sind die Analysen Léonards, denen die Bestände des im Zweiten Weltkrieg zerstörten Staatsarchivs von Neapel zugrunde liegen. 
bei dem zu diesem Anlaß angekündigten Legaten um ihn handeln ${ }^{485}$. Im Ernennungsschreiben wurde das Legationsgebiet durch Nennung folgender Gebiete umrissen: neben Tuszien, Sardinien, Korsika, der Romagna, Mark Ancona, Kampania und Marittima, dem Dukat von Spoleto und dem Patrimonium Petri in Tuszien wurden explizit die Städte und Diözesen Ferrara, Bologna, Perugia, Todi, Narni, Rieti und Terni angeführt ${ }^{486}$. In dem Schreiben zeichnete Clemens VI. ein recht düsteres Gemälde der aktuellen politischen Situation. Festverwurzelte Zwietracht scheine im Legationsgebiet alle Hand-

485 In einem zweiten, am 21. Oktober tagenden Konsistorium wird in Gegenwart von 21 Kardinälen das Verhalten der Königin für rechtlich unmöglich erklärt. Auch hier taucht Aimeric unter den Teilnehmern nicht auf, vgl. SCHRÖDER, Protokollbücher, n. 75. Ein detaillierter Bericht über dieses Konsistorium - betitelt als Protestatio facta per procuratores regine Sicilie coram domino papa - ist erhalten, vgl. LÉONARD, Jeanne, II, S.400-406 (pièces justificatives).

486 Lettres Clément VI autres que la France, n. 56 (nur Regest); vgl. RV 152, fol. 37, n.1: [...] dum status Tuscie et circumpositarum et aliarum vicinarum partium, quas inveterata dissensio longis prodolor recto continuate temporibus plurimum lacessivit, et quas guerrarum turbines exposuerunt animarum periculis et personarum et rerum dispendiis infinitis, quodque propter hec neglectus cultus dominicus ecclesiarum et locorum ecclesiasticorum iura violenta direptione in predam posita, libertas ecclesiastica conculcata fuerunt, et, quod deflendum est potius et dolendum, pulularunt scismata et insurrexerunt hereses contra catholice fidei puritatem et, quod quamvis status huius fuerit in nonullis locis dictarum partium aliqualiter tranquillitatem, nichilominus tamen inter multos magnates et nobiles, universitates civitatum, castrorum, villarum et aliorum locorum partium eorumdem solite dissensionis fomes et rancorum seminaria remanserunt, ex quibus noscuntur premissa et alia non facile numeranda pericula animarum et corporum facultatum lapsus et multa dispendia provenire nostris presentantur obtutibus, dum etiam in mente revolvimus obstinatas nequicias et rebellionem protervam Ludovici de Bavaria, hostis Dei et Ecclesie manifesti et de heresi condempnati, et quod ipse sub pretextu contubernii de filio suo cum Comitissa Tirolis contra Deum et bonum publicum suarum, que animarum periculum per sui facti potentiam publice attemptati Comitatum Tirolis, partibus Lombardie contiguum seu vicinum, sua temeritate dampnabili occupavit, ut per illum sibi ad predictas et alias partes, quas, sicut multi fidedigni referunt, se velle intrare asserit, liberior pateat transitus et accessus ac fideles et devotos partium earumdem sub vestra et Sanctae Romanae Ecclesie obedientia ac devotione manentes in suum devium dampnabiliter trahere et ab eorum devotione et obedientia revocare, necnon dissidentes turbare gravius et earumdem partium pervertere gravius et turbare anxiamur immense, cogitationibus profundis immergimur et zelus noster et ignis caritatis paterne in nostris meditationibus exardescit pro dictarum partium, quas plenitudine dilectionis paterne prosequimur statu dirigendo salubriter ac pace, concordia et unione in eis perfecte actore domino reformandis, ut incole partium earumdem effecti unanimes et concordes et bono pacis, quod omnia alia bona superat, et perfruentes tam contra ipsius Ludovici obstinatam propter viam et rebellionem protervam quam contra sequaces et fautores ac auxiliatores ipsius pro statu eorum / dirigendo salubriter ac honore ipsius sacrosancte Romane Ecclesie defensando insurgant tam zelo fidei quam devotionis fervore viriliter et potenter. Nos vero diligentius attendentes, quod propter magna et ardua, que nobis in partibus citramontanis incumbunt ad partes illas, ubi mente sumus, accedere pro huius nostro exequendo desiderio non valemus et quod personam tuam gratiarum dator altissimus scientiarum magnitudine, industrie claritate ac aliis multis virtutibus insignivit, ad te, in cuius affectibus geritur pacifice discordes ac virtutum semina serere nostrum intuitum, ut fortem opere et sermone mittamus ad fortia et tuis robustis humeris onera grandia imponamur duximus dirigendum, 
lungen zu bestimmen und Ursache für fortgesetzte kriegerische Handlungen zu sein. Daraus resultierten nicht nur Gefahren für die Seelen, sondern auch Leib und Leben, Hab und Gut seien ständigen Bedrohungen ausgesetzt. Ebenso seien kirchliche Rechte und Freiheiten nicht mehr gewährleistet. Besondere Erwähnung fand das Anwachsen von Häresien und anderen, nicht mehr der Kontrolle durch die Kirche unterliegenden Bewegungen. Diese alles andere als ermutigende Zustandsbeschreibung erfuhr mit der Nennung Ludwigs des Bayern eine nochmalige Steigerung ins Negative. Das abstrakte Prinzip des Bösen wurde damit in einer einzigen Person greifbar.

Spätestens jetzt stand die eigentliche Absicht, die Clemens VI. mit der Legation verband, klar vor Augen. Verhindert werden sollte der Durchmarsch Luwigs des Bayern nach Rom ${ }^{487}$. Päpstlicher und kaiserlicher Machtanspruch trafen auf dem Gebiet Mittelitaliens aufeinander. Päpstliche Prärogativen sollten durch das energische Auftreten des Legaten durchgesetzt werden. Fortis opere et sermone, stark in Tat und Wort: Diese Aufforderung zu energischem Handeln wurde an einen Kardinal gerichtet, dem vom Papst in stereotyper Aufreihung vielerlei Eigenschaften bescheinigt wurden - neben nicht weiter ausgeführten Tugenden waren dies vor allem die Größe seiner Bildung (scientiarum magnitudo) und sein allseits bekannter Fleiß (industrie claritas). Clemens VI. betonte, daß alles getan werden müsse, um Ludwig den Bayern

ideoque gerentes de tuis claris meritis fiduciam in domino specialem, quamvis nos et fratres nostri tanti viri presentia nobis et Ecclesie Romane necessaria et perutili careamus inviti, tamen propter urgentem et evidentem necessitatem Tuscie et aliarum partium predictarum, quibus spectamus per tuam providentiam circumspectam illo tibi auxiliante, qui potest omnia, in premissis salubriter consuli et utiliter subveniri te tanquam pacis angelum ad partes illas Tuscie, Sardinie et Corsice, Romandiole, Marchie Anconitane, Campanie et Maritime, ducatus Spoletani et Patrimonii Beati Petri in Tuscia partes necnon Ferrarien., Bononien., Perusin., Tudertin., Narmen., Reatin. et Interannen. civitates et dioceses tibi in eisdem partibus, civitatibus et diocesis vices nostras ac plene legationis officium committendo[...] de dictorum fratrum nostrorum consilio destinamus tibi, ut in proxime nominatis partibus, civitatibus et diocesis inter ecclesiasticas mundanasve personas, duces, principes, marchiones, barones et nobiles, comitates, universitates ac populos et alios universos et singulos discordes bonum pacis studeas reformare ac concordes in fraterne dilectionis glutino conservare ac etiam confirmare ac nichilominus agere et tractare, quecumque ad cultum Dei exaltationem, catholice fidei apostolice sedis honorem, observantiam ecclesiastice sanctionis et reintegrationem ecclesiastice libertatis, honestatis et morum cultum, relevationem ecclesiarum, locorum ecclesiasticorum et pauperum salutem animarum, tranquillitatem corporum ac robur status prosperi partium ac civitatum et diocesum predictarum quomodolibet pertinebunt et nichilominus universos et singulos partium civitatum et diocesium eorumdem ex parte nostra salubribus persuasionibus inducas pariter et horteris, ipsosque unias, confederes et coniungas, ut eidem Ludovico, qui sanctam Romanam ecclesiam et eius honorem ex indurata sibi pertinacia offendere ac afficere nititur iniuriis, sismatibus et scissuris statumque ipsorum et aliorum fidelium partium Italie perturbare, fideles ipsos subvertere ac eos in profundum in quo ipse demersus est demergere malignorum, ne illas vel alias Italie partes ingredi aut aliquid contra honorem eiusdem sancte Romane Ecclesie atque nostrum in partibus illis quoquomodo attemptare valeat [...].

${ }^{487}$ Dies war auch ein Ziel der Legation des Guillaume Court, vgl. Kap. 5.2.1.2. 
in seine Schranken zu weisen. Die dem Legaten zu diesem Zweck übertragenen Fakultäten waren nahezu deckungsgleich mit den bereits Kardinal Guillaume Court bewilligten ${ }^{488}$. Zusätzlich wurde Aimeric de Châtelus jedoch devotionis causa der Besuch der Stadt Rom gestattet - ein Wunsch, der vom Kardinal allem Anschein nach bereits im Vorfeld der Legation geäußert worden war ${ }^{489}$. Außerdem sah er sich in der vorteilhaften Lage, bereits nach einem Jahr ohne besondere päpstliche Erlaubnis an die Kurie zurückkehren zu können ${ }^{490}$.

Rund einen Monat später erfolgte in einem Schreiben vom 18. November 1342 die Erweiterung der Kompetenzen. Namens des Heiligen Stuhls sollte der Legat das Homagium und den Treueschwur König Roberts von Sizilien entgegennehmen ${ }^{491}$. Der Wortlaut des Schreibens läßt vermuten, die Abreise des Kardinallegaten sei in zeitlicher Nähe zur Abfassung des Sendschreibens erfolgt ${ }^{492}$. Die Fülle der Fakultäten wurde am 1. Januar 1343 um drei Verleihprivilegien ergänzt, die die Stellung des Legaten als Spender kirchlicher Wohltaten stärkten ${ }^{493}$. In der an den Kardinallegaten gerichteten päpstlichen

488 Lettres Clément VI autres que la France, nn. 57-72.

489 Ibid., n. 61 (nur Regest); vgl. RV 152, fol. 39v, n. 10: Cum tu quem ad Tuscie provinciam aliasque certas partes Italie commisso in eis tibi plene legationis officio destinemus cupias, sicut asseris, civitatem Romanam ingredi et devotionis causa beatorum apostolorum limina aliaque Urbis sanctuaria visitare, nos tuum in hac parte laudabile propositum commendantes ac volentes satisfacere votis tuis ingrediendi civitatem ipsam causa visitationis huius quando et quociens devotio tua suggesserit seu aliter tibi videbitur expedire ibique, quantum tibi videbitur, inmorandi necnon et ea, que ad executionem tue legationis pertinent, si causa rationabilis id exposcat, inibi exercendi plenam et liberam tibi concedimus auctoritate presentium facultatem. Volumus autem, quod propter huius tuum in dictam Civitatem / ingressum et moram dicte tue legationis officium non expiret, sed ad provincias et partes easdem regredi licite valeas officii tui debitum prout illud tibi commisimus exequendo libere sicut prius quacumque constitutione contraria non obstante.

490 Lettres Clément VI autres que la France, n. 68.

491 Ibid., n. 73 (nur Regest); vgl. RV 147, fol.1r-4v: Der Papst berichtet, König Robert, der stets ein guter Untertan der Kirche gewesen sei, habe Botschafter an die Kurie entsandt, die coram nobis et fratribus nostris eiusdem Sancte Romane Ecclesie Cardinalibus in consistorio constituti pro parte ipsius Regis reverenter exponere, weshalb es ihm persönlich nicht möglich sei, nach Avignon zu kommen, um dort dem Papst den Treueid zu leisten. Da sich Aimeric in Tuscien befindet, wird er dazu auserkoren, ad recipiendium homagium, vassalagium et iuramentum huiusmodi hac vice ab eodem Rege iuxta conventiones et pacta predicta. In diesem Zusammenhang wird auch der umfangreiche Text des Treueids überliefert; vgl. auch SCHÄFER, Ausgaben Klemens VI., S. 217. Dort sind unter dem 21. Dezember 1342 Zahlungen belegt für Petro Rigaldi pergamenario pro 1 magna pelle pro scribendo formam homagii faciendi per dominum regem Roberti, quod factum est domino cardinali Carnotensi, in illis partibus legato Ecclesie Romane, 2 fl. $12 \mathrm{~s}$. parve monete.

492 In den Eintragungen der päpstlichen Kammerkleriker über die Präsenz der Kardinäle in den Konsistorien wird Aimeric de Châtelus zum ersten Mal am 5. Dezember 1345 anläßlich der Erneuerung des Lehnseides durch Albertus und Mastinus della Scala erwähnt, vgl. SCHRÖDER, Protokollbücher, S. 121-286, n. 103.

493 Lettres Clément VI autres que la France, nn. 102-105. 
Korrespondenz nahmen die auf die Befriedung des Gebietes der Romagna hin abzielenden Betreffe breiten Raum ein. Aufforderungen zur Rehabilitierung des Johannes de Manfredis oder zur Zuweisung befestigter Ortschaften an Bartholachio de Magnardo dürften dabei der Absicht entsprungen sein, den Legaten bei der Einleitung einer päpstlichen Rekuperationspolitik insbesondere in der Romagna zu unterstützen ${ }^{494}$. Zu diesem Zwecke wurden Vertreter des lokalen Adels, die in der Vergangenheit nicht immer im Sinne der Kirche gehandelt hatten, massiv umworben. $\mathrm{Da} \beta$ von der Kurie die eigenständig getroffenen Personalentscheidungen des Legaten aufmerksam verfolgt und registriert wurden, belegt eine an den Rektor der Romagna, Philippus de Antilla, abgehende Verfügung vom 13. Februar 1344, in der dieser aufgefordert wurde, sich im Falle einer Absetzung durch den Legaten unverzüglich zum Rapport nach Avignon zu begeben ${ }^{495}$. Offensichtlich verspürte man kurialerseits das Bedürfnis, sich unterschiedlicher Informationsquellen zur Bewertung der politischen Situation insbesondere in der Romagna zu bedienen.

Einige der päpstlichen Briefe stellen direkte Antworten auf Fragen des Legaten dar. $\mathrm{Ob}$ jedoch angesichts des mangelhaften und zeitaufwendigen Informationsaustauschs nachgeschobene Fakultäten wie diejenige, mit Franciscus de Ordelaffis in Unterhandlungen treten zu dürfen ${ }^{496}$, tatsächlich noch ihren Zweck erfüllten, vielleicht doch eher als Absicherung des Legaten post festum zu verstehen sind, mag dahingestellt bleiben. Man war jedenfalls um gegenseitige Rückkoppelung bemüht.

Von den Versuchen des Papstes, die Position seines Legaten im Königreich Neapel zu stärken, zeugen Briefe, in denen zum ersten Mal am 13. Oktober 1343 alle weltlichen und geistlichen Würdenträger des Königreichs zum Gehorsam gegenüber Aimeric aufgefordert wurden ${ }^{497}$. Unter demselben Datum erfolgte die offizielle Übertragung der legatorischen Gewalt auch auf das Königreich Neapel - ausdrücklich verwiesen wurde dabei auf die Beibehaltung des Legatenamtes in Tuszien ${ }^{498}$. Des weiteren erging die Aufforderung an Jo-

494 Ibid., nn. 389, 391, 393.

495 Ibid., n. 388 (nur Regest); vgl. RV 137, fol. 192v, n. 696: Si dilectus filius noster Aymericus tit. Sancti Martini in Montibus presbyter cardinalis $A$. S. legatus de alio Rectore in provincia Romandiole provideat, super quo sibi concedimus per alias litteras potestatem, volumus quod tu ad nostram te conferas presentiam nos informaturus de statu et negociis Provincie prelibate.

496 Lettres Clément VI autres que la France, n. 419 (nur Regest); vgl. RV 137, fol. 202v, n.740: Si tue circumspectioni expediens videatur, quod cum Francisco de Ordalafis sicut cum aliis componatur, tu qui docente magistra rerum experientia quid pro bono statu et pacifico provincie Romandiole magis expediat noticiam habere nosceris pleniorem, quod in hac parte tibi videbitur exequaris. Am 5. Januar 1344 ergeht die Aufforderung an den Legaten, Franciscus de Ordelaffis, der sich an die Kurie begeben wollte, freies Geleit zu gewähren, vgl. Lettres Clément VI, n.597.

497 Lettres Clément VI autres que la France, nn. 302f.

498 Lettres Clément VI, n. 442 (nur Regest); vgl. RV 157, n. 38, fol. 8v: [...] evocavit nos 
hanna I., den Kardinallegaten gebührend zu empfangen und ehrenvoll zu behandeln - immerhin werde im Legaten nicht die Person Aimeric de Châtelus, sondern er selbst, der Papst, geehrt ${ }^{499}$. Daß sich Clemens VI. bemüßigt fühlte, diesen Sachverhalt zu erwähnen, mag der Absicht entsprungen sein, für den in Neapel unerwünschten Legaten zu werben und ihm günstigere Startbedingungen zu verschaffen ${ }^{500}$. In einem nur wenig später verfaßten Schreiben wurde noch einmal darauf hingewiesen, daß Aimeric ungeachtet seiner hervorragenden Qualitäten weniger in seiner Eigenschaft als Kardinal der Heiligen Römischen Kirche als vielmehr von der Kurie beauftragter Legat handle. Der Blick wurde bereits zu diesem Zeitpunkt - es sollten noch einige Monate vergehen, bis Aimeric tatsächlich in Neapel eintraf ${ }^{501}$ - weg von der Person hin auf das

regni et terre predictorum ac ecclesiarum et incolarum ipsorum statum prosperum, pacificum et tranquillum per apostolice sedis ministerium et providentiam salubriter dirigi et augeri totis desideriis affectantes, sperantes quoque per te, cui, sicut experiencie probatione didicimus, dedit dominus sapientiam et linguam etiam eruditam, ut scias quando et qualiter debeas proferre sermonem et in quo viget rectitudo iudicii, consilii providencia regiditasque censure, cum expedit in prosperitate devotio, in zelo sobrietas, in agendis circumspectio singularis et in arduis experiencia multipliciter comprobata regni, terre, ecclesiarum et incolarum predictorum status tranquillus et bonus non solum solidari et conservari debeat, sed etiam multipliciter augmentari dispositione Regni et terre predictorum necnon paterno affectu, quem ad illa et personas eorum bonumque statum ecclesiarum eorumdem gerimus et aliis certis rationabilibus causis suadentibus tibi, de cuius claris meritis singularem in domino fiduciam obtinemus, in regno et terra predictis plene legationis officium de fratrum nostrorum consilio auctoritate apostolica tenore presentium duximus comittendum, ut in illis evellas [...] ac statuas salubriter auctoritate nostra quecumque ad bonum statum regni, terre et incolarum predictorum, cultum Dei, exaltationem catholice fidei, apostolice sedis honorem, observantiam ecclesiastice sanctionis, reintegrationem et conservationem ecclesiastice libertatis, honestatis et morum, decus ecclesiarum et aliorum ecclesiasticorum locorum et personarum reformationem, animarum salutem et tranquillitatem corporum quomodolibet noveris pertinere aliaque circa ista tractes, ordines et disponas sicut temporis et negotiorum ipsorum qualitas eorumque circumstantie suadebunt tibi [...]. Per hec autem te ab officio legationis in Tuscie et certis aliis Italie partibus per nos tibi commisso nequaquam revocare intendimus, quinimo volumus, ut ipsum legationis officium sicut prius usque ad nostrum beneplacitum exequaris.

499 Lettres Clément VI, n. 443 (nur Regest); vgl. RV 157, n. 41, fol. 9v: [...] Ideoque serenitatem tuam rogamus et hortamur attente, quatinus prudenter considerans paterne dilectionis zelum et caritatis affectum, qui nos ad mittendum legatum ipsum pro bono et prospero statu tuo regni, terre et incolarum predictorum rationabiliter induxerunt, eundem legatum cum illuc Deo duce pervenerit, immo potius personam nostram in ipso, benigne recipiens et honorificentia digna pertractans, sibi tanquam apostolice sedis legato devote intendas et ea, que in hiis, que ad sue legationis spectant officium, celsitudini tue ex nostra parte suaserit, efficaciter studeas adimplere, ita quod ipse tuo fultus auxilio possit huiusmodi legationis officium salubriter exercere ac ex fructuosis eiusdem laboribus tuus regni, terre et incolarum predictorum status tranquillus et bonus de bono in melius adaugeri et preter hec tua propterea possit sublimitas dignis in domino laudibus commendari.

500 Wie ungünstig die Situation für Aimeric de Châtelus tatsächlich war, verdeutlicht Émile LÉONARD auf den wenigen, dieser Legation gewidmeten Seiten, vgl. DERS., Les Angevins de Naples, Paris 1954, S.342-344.

501 Ende März 1344 ist Aimeric noch nicht vor Ort, vgl. Lettres Clément VI, n. 747 
Amt gelenkt, um dadurch Vorbehalte der Königin und ihrer Ratgeber gegenüber der Person des Legaten zu entkräften ${ }^{502}$.

Der Papst verschwieg, daß die Entsendung auch innerhalb des Kollegiums nicht auf ungeteilte Zustimmung gestoßen war. Insbesondere Kardinal Talleyrand wird dabei als Haupt einer innerkardinalizischen Opposition faßbar, der wohl auch der eigene Bruder des Papstes angehört haben dürfte, hatte er doch im November 1343 üppige finanzielle Zuwendungen aus Neapel erhalten ${ }^{503}$. Johanna vertraute auf den Einfluß Talleyrands und hoffte vergeblich, durch ihn die weitgespannten Befugnisse des Legaten beschneiden zu können ${ }^{504}$. In Neapel fürchtete man sich offensichtlich vor Einmischungen der Kurie in die

(31.03.1344). Der Papst mahnt Aimeric, sich endlich zur Entgegennahme des Lehnseides nach Neapel zu begeben. Von einer Präsenz desselben vor Ort ist erst ab Juni auszugehen. 502 Ibid., n. 454 (17.10.1343; nur Regest); vgl. RV 137, n.387, fol.115v: [...] Serenitatem regiam volumus non latere, quod licet super mittendo ad partes regni tui sedis apostolice legato de latere tam cum fratribus nostris Sancte Romane Ecclesie cardinalibus quam viris sapientibus aliis prehabita prolixa deliberatione provida et matura et adductis in deliberatione ipsa omnibus, que circa materiam huiusmodi occurrere poterant pro et contra, tandem tamen in hoc deliberatio ipsa resedit, quod tam ecclesie Romane iuribus et honoribus quam tuis, filia carissima, et regni predicti expediebat utilitatibus, legati missio supradicta, quam obrem habentes necessario procedere ad eandem et attendentes provide, quod per dilectum/ filium nostrum Aymericum tit. S. Martini in Montibus presbyterum cardinalem in partibus Tuscie dicte sedis legatum, virum utique profunde sciencie, alti consilii ac discretionis et probitatis experte ac tui et regni predicti honoris, utilitatis et status pacifici fervidum zelatorem cum minoribus eiusdem regni gravaminibus poterat legationis officium huiusmodi adimpleri eidem illud de dictorum fratrum consilio providimus committendum, in eo, qui celum terramque regit, sperantes, quod per ipsius Cardinalis providentiam et diligentiam studiosam tam tibi quam statui dicti Regni pacifico tot provenient utilitates et bona, quod ad onus vel gravamen missionem ipsius reputare minime poterit dictum Regnum. Quocirca tuam regiam rogamus excellentiam et in domino attentius exhortamur, quatinus de missione ipsa nec mireris quomodolibet nec turberis, sed de illa potius velut tibi et eidem Regno perutili leteris et etiam consoleris, scitura pro certo, filia dilectissima, quod nos super hiis et aliis ad illa, que tui et eiusdem Regni augmentum honoris comodi et pacifici status respiciunt, paternis et benivolis intendimus affectibus et intendere quantum cum de honestate possumus non cessamus.

503 LÉonARd, Jeanne, II, S. 406f. (pièces justificatives: Brief Johannas und Sancias an die Gesandten in Avignon, Ende November): [...] Post hec subjungimus quod fratri domini nostri Summi Pontificis et suis heredibus inperpetuum de annuis untiis ducentis supra bonis feudalibus in regno primitus excissuris duximus noviter providendum, et quod interim mille libras currentis usualis monete [...] debeat ipse annuatim percipere et habere [...].

504 Ibid., S. 408f. (pièces justificatives: Brief Johannas an Talleyrand vom 03. 12.1343): Reverende pater et affinis carissime. In arduis incumbentibus nobis assistentie et favoris vestri presidium fiducialiter implorantes, affectuose precamur ut prosecutionem in antea missionis legati per oportuna exquisita remedia atque consilia, que melius perspicax vestrum judicium noverit, impedire ipsa Paternitas Vestra velit. Nos enim instanter quemdam fidum nuntium paramus ad pedes Sanctitatis dominice et presentiam vestram indilate venturum et talia deferentem de quibus ipsa dominica Sanctitas Vestraque Paternitas poterunt contentari [...]. Nur zwei Monate später tritt der Papst in einem Brief an Johanna Gerüchten entgegen, er habe die Kompetenzen des Legaten beschnitten, vgl. Lettres Clément VI, n. 648 (04. 02. 1344). 
inneren Angelegenheiten des Königreichs. $\mathrm{Da} ß$ diese Furcht alles andere als unbegründet war, verdeutlicht die Einsetzung des Aimeric de Châtelus zum bajulus, vicarius, administrator und gubernator generalis des Königreichs ${ }^{505}$ und die ihm in diesem Zusammenhang gewährte Vollmacht ${ }^{506}$, gegen all diejenigen mit Kirchenstrafen vorzugehen, die ihn an der Ausübung seines Amtes hindern sollten. Diese Einsetzung erfolgte zeitgleich mit der Absetzung des von König Robert testamentarisch eingesetzten Regentschaftsrates, der die Regierungstätigkeit der jungen Königin überwachen sollte. Der Papst reservierte sich mit diesem Schritt weitgehende Verfügungsrechte politisch-administrativer Natur im regnum Sicilie, erkannte Johanna aber als legitime Erbin Roberts an ${ }^{507}$. Trotz fortgesetzter Interventionen Johannas an der Kurie gegen diese Entscheidung blieb der Papst hart ${ }^{508}$ und versuchte, Aimeric bereits in absentia an seiner Neapel betreffenden Politik teilhaben zu lassen ${ }^{509}$.

Die Situation des Legaten stellte sich in der Tat alles andere als günstig dar. Spätestens seit der am 19. Januar 1344 im Konsistorium getroffenen Entscheidung, mit Andreas von Ungarn den ungeliebten Ehemann Johannas I. zum König von Neapel zu krönen ${ }^{510}$, war der Legat im Umfeld der Königin von Neapel zur persona non grata geworden. Bereits Ende November mußte er sich den Zorn Johannas durch die Publikation einer päpstlichen Verfügung zugezogen haben, in der die testamentarischen Bestimmungen König Roberts aufgehoben und alle noch von diesem eingesetzten Administratoren abgesetzt worden waren ${ }^{511}$. Der Erwartungsdruck, der auf Aimeric lastete, war immens. Ohne das Territorium des Königreichs überhaupt betreten zu haben, hatte er einen schriftlichen Schlagabtausch mit dem Papst zu führen. Clemens VI. warf ihm vor, mit Personen im Umfeld Johannas I. in Separatverhandlungen zum Schaden der Kirche eingetreten zu sein, Vorwürfe, die vom Legaten erst einen

505 RV 157, fol. 10v, n. 42 (28.11.1343): [...] Ideoque de fratrum eorundem consilio et apostolice plenitudine potestatis te vicarium et baiulum, administratorem et gubernatorem Regni et Terrarum predictorum ordinamus et constituimus generalem, curam, bailiam, administrationem, gubernationem, potestatem et regimen ac omnem plenamque iurisdictionem in Regno et Terris predictis tibi tenore presentium committentes [...]. Vgl. auch Lettres Clément VI, n. 631 (23.01.1344).

506 Ibid., n.632 (23.01.1344).

507 Dies schlug sich nicht zuletzt in der am 28. August 1344 erfolgten Krönung Johannas zur Königin von Sizilien und ihrer von Aimeric de Châtelus vorgenommenen Investitur mit dem Regno nieder.

508 Ibid., n. 648 (04. 02.1344). In die Unterhandlungen an der Kurie miteinbezogen sind die Kardinäle Talleyrand de Périgord und Étienne Aubert.

509 Ibid., n. 694 (26.02.1344).

510 Darüber informiert ein an den König von Ungarn gerichteter Brief des Papstes vom 22. Februar 1344, vgl. Lettres Clément VI autres que la France, n. 407; vgl. auch Lettres Clément VI, nn.643-645 (02.02.1344). Aimeric befindet sich zu diesem Zeitpunkt auf dem Weg ins Königreich.

511 Lettres Clément VI autres que la France, n. 331. 
knappen Monat später entkräftet werden konnten ${ }^{512}$. Selbst zu diesem Zeitpunkt - das Betreten neapolitanischen Territoriums stand unmittelbar bevor schien es noch nicht sicher, ob den Befehlen des Legaten und damit der Autorität des Papstes Folge geleistet werden würde.

Letzterer setzte jedenfalls alles daran, dieser Autorität zum Durchbruch zu verhelfen: Am 6. April 1344 erging ein weiteres Schreiben um Unterstützung des Legaten an alle Bischöfe im Königreich ${ }^{513}$. Ein Mittel, sich Verbündete zu verschaffen, wurde Aimeric durch eine weitere Fakultät an die Hand gegeben: sie versetzte ihn in die Lage, diejenigen, die zuvor gegen ihn und seine Legation intrigiert und deshalb kirchliche Strafen auf sich gezogen hatten, von diesen processus zu lösen ${ }^{514}$. Von großer Wichtigkeit während dieser ersten Legationsphase war die Frage der dem Legaten zu leistenden Treu- und

512 Lettres Clément VI, n. 767 (11.04. 1344; nur Regest); vgl. RV 137, n. 971, fol. 235v: [...] Sane postmodum relatu personarum fidedignarum alti status et auctoritatis non infime percepimus disciplenter, quod tu cum gentibus regine predicte tractatus aliquos preiudiciales Ecclesie Romane non modicum, quos nos et fratres nostri nequaquam audire voluimus, habuisti vel habes, quod quidem nobis est difficile credere, dum virtutum tuarum excellentiam, quibus hactenus clarere studuisti, attendimus et discredendum difficilius redditur auctoritate personarum predictarum id solide et ex certo asserentium diligenter attenta. Ideoque discretioni tue districtiori, qua possumus hortatione mandamus, quatenus precavendo prudenter ne ponas maculam in gloriam fame tue si forte ad tractatus aliquos tales processeris quantotius ab illis resilire procures et ad tales vel similes ulterius non prorumpas, sed cum super administratione predicta merus executor esse noscaris ad gerendam et exercendam administrationem eandem iuxta tenorem et continentiam litterarum tibi super hoc directarum procedere cum omni diligentia et celeritate, quibus tute ac comode poteris, non postponas, nos redditurus de predictis quantotius nichilominus certiores. Ceterum scire te volumus, quod ad tui exonerationem et excusationem processus adversus illos, qui tibi non obedirent super administratione predicta et revocatione administratorum deputatorum per inclite memorie Robertum Regem Sicilie ac gestorum per ipsos seu per eandem reginam de ipsorum consilio et assensu et aliis contentis dudum per nos factos die Jovis in Cena Domini proximo preterita fecimus in vestra et eorumdem fratrum nostrorum presentia sollempniter, astante fidelium copiosa multitudine, publicari litteras autem nostras clausas prelatis, baronibus et comitatibus principalioribus regni et terrarum predictorum super assistentia et obedientia tibi circa premissa prestandis mittimus, quarum seriem notificabit tibi cedula presentibus interclusa. Porro, licet in predictis litteris nostris ultimo tibi missis fecerimus inter cetera mentionem, quod virum aliquem fidelem, circumspectum et providum super predictis de intentione nostra sufficienter instructum intendebamus ad te breviter destinare, quia tamen adhuc talis nobis non occurrit nec plene deliberavimus an mittamus eundem eo non expectato ad exequendum et complendum sollicitudini tue commissum in hac parte ministerium intendere sublata quavis dilatione morosa, que dispendiosa proculdubio secum portaret sicut sepe refricavimus pericula studeas solerter, fideliter et prudenter. Zur Entkräftung der an keiner Stelle ausführlicher beschriebenen Vorwürfe vgl. ibid., n. 837 (19.05.1344). Das Bild der von der Kurie bisher propagierten legatorischen Ausnahmegestalt ging aus dieser Auseinandersetzung beschädigt hervor. Von der temporären Verstimmung zeugen ebenfalls die Gratialentscheidungen des Papstes: zumindest eine Entscheidung in beneficiis wurde klar zuungunsten Aimerics gefällt, vgl. ibid., n. 850 (21.05.1344).

513 Lettres Clément VI autres que la France, n. 445.

514 Lettres Clément VI, n. 912 (19.06.1344); vgl. n.632. 
Lehnseide. Insgesamt dreimal erging die an Aimeric gerichtete Forderung, den von Johanna I. zu leistenden Lehnseid entgegenzunehmen ${ }^{515}$. Gleichzeitig wurde ihm eingeschärft, das Königreich Neapel gut, d.h. frei von Partikularinteressen, zu regieren. Kaum ein päpstlicher Brief kam zu diesem Zeitpunkt ohne die dringende Bitte aus, die Kurie durch regen Briefverkehr an den Entwicklungen in Neapel teilhaben zu lassen ${ }^{516}$.

Neben Fragen der großen Politik wurde jedoch auch dem Problemkomplex der dem Legaten zu leistenden Prokurationen gebührende Beachtung geschenkt. Die üblichen Prokurationszahlungen (procurationes consuete) wurden vom Papst am 5. Juli 1344 konzediert ${ }^{517}$, dabei gleichzeitig dem Legaten die Erlaubnis erteilt, mittels Kirchenstrafen seinen berechtigten Forderungen Nachdruck zu verleihen ${ }^{518}$. Insbesondere dem Klerus Siziliens wurde die Leistung dieser Zahlungen eingeschärft ${ }^{519}$. Rund zwei Wochen später fand dieselbe Problematik wiederum Erwähnung. Notwendige Ausgaben sollten zwar aus den Einkünften des Königreichs bestritten werden, den Legaten jedoch nicht davon abhalten, das ihm persönlich Zustehende einzutreiben ${ }^{520}$. Auch die Kurie hatte Interesse an der geordneten Erhebung der finanziellen Leistungen. Selbst in seinem ursprünglichen Legationsgebiet Tuszien sollten in absentia weiterhin Prokurationsleistungen entgegengenommen werden, die freilich nicht mehr der freien Verfügungsgewalt des Legaten unterstanden. Die Verwendung dieser Summen behielt sich Clemens VI. selbst vor ${ }^{521}$.

515 Vgl. ibid., nn. 747 (31.03.1344), 937 (02.07.1344), 968 (18.07.1344).

516 Ibid., n. 967 (18.07.1344; nur Regest); vgl. RV 138, n. 141, fol. 46v: Gratum et acceptum est nobis et fratribus nostris admodum, quod super negotio Baiulie ac gubernationis Regni Sicilie et Terrarum citra Farum per nos tibi commisso diligenter, constanter et strenue spretis minis, terroribus et aliis verbalibus et realibus reiectis rationabiliter obstaculis, sicut exigebat iusticia et honori Dei et ecclesie ac commodis et utilitatibus Carissime in Christo filie nostre Johanne Regine Sicilie Illustris ac Regni et Terrarum predictorum expediebat et expedit, processisti. Super quibus tuam prudentiam multipliciter in domino commendantes eam exhortamus et solicitamus attente, quatinus, que in hac parte laudabiliter et utiliter incepisti, continuatione virtuosa et solida prosequi divina tibi assistente gratia non postponas. Rescripturus nobis sepius solito, que tibi occurrerint super hiis et aliis intimanda.

517 Lettres Clément VI, n. 945.

518 Ibid., n. 946 (05.07.1344).

519 Ibid., n. 947 (05.07.1344).

520 Ibid., nn. 969, 970 (18.07.1344; nur Regest); vgl. RV 138, n. 144, fol. 47r: Licet per alias tibi scribamus litteras nostre ac fratrum nostrorum intentionis sicut rationi et iusticie convenire credimus existere, quod quamdiu exercebis gubernationem et baiuliam regni Sicilie ac terrarum citra Farum pernos tibi commissas, tibi super tuis necessariis de redditibus et proventibus regni et terrarum predictorum rationbiliter et moderate debeas facere provideri, quia tamen legationis officium in regno et terris eisdem tibi, ut gubernationem et baiuliam predictas melius et utilius exercere valeres committendum providimus sicut nosti tam de predictis, que pro tuis necessariis predictis de redditibus et proventibus eisdem percipies, quam de procurationibus ratione officii eiusdem legationis debitis commodius et decentius poteris tibi super eisdem necessariis sicut tue circumspectioni expedire videbitur providere.

521 Ibid., n. 971 (18. 07.1344; nur Regest); vgl. RV 138, n. 145, fol. 47v: Quamvis in regno Sicilie ac terris citra Farum plene legationis fungens officio, procurationes ibidem tibi ratione 
Die Bedeutung des Aimeric de Châtelus als oberster Vertreter der päpstlichen Politik im Königreich Neapel - am 22. Mai wurde er von Johanna feierlich willkommengeheißen ${ }^{522}$ - erschöpfte sich nicht nur im Versuch, den zahlreich bei ihm eintreffenden Schreiben des Papstes und der darin enthaltenen Aufforderungen gerecht zu werden. Clemens bat nicht nur - sämtliche Empfehlungsschreiben wurden als Bitte formuliert ${ }^{523}$-, sondern ordnete auch an ${ }^{524}$. Offensichtlich vertraute man an der Kurie nicht nur auf Worte allein. Vor diesem Hintergrund darf die Anweisung, die von Johanna beim Papst erbetene Bestätigung der wichtigsten Hofämter von einer vom Legaten durchzuführenden Untersuchung abhängig zu machen, in der festgestellt werden sollte, ob tatsächlich alle in Frage kommenden Personen einen offiziellen Treueid geleistet hatten, getrost als massiver Eingriff in die inneren Angelegenheiten Neapels gewertet werden 525 .

Solche Aktionen machten Aimeric de Châtelus nicht beliebter. Auch im Falle der von der Kurie vehement befürworteten Verhandlungen Johannas mit Ludwig von Aragon um den Besitz der Insel Sizilien agierte der Legat zum Leidwesen der Königin an exponierter Stelle. Als Sprachrohr des Papstes hatte er dessen Ansicht zu vertreten, daß es nach einer langen Zeit des über Sizilien lastenden Interdikts zum Wohle der dort lebenden Menschen zu einem Verständigungsfrieden kommen müsse. Nichts lag Königin Johanna I. ferner, die krampfhaft am seit Jahrzehnten mehr oder minder erfolgreich verfochtenen Konzept der - wenn auch kaum mehr durchsetzbaren - territorialen Integrität des Königreichs Neapel festgehalten hatte. Die Erwartungen, die Clemens' VI. mit dem Wirken seines Legaten verband, gingen weit. Im Gegensatz zu der vom Papst verfochtenen Ausgleichspolitik war der Königin die Taube auf dem Dach jedoch wichtiger als der Spatz in der Hand. Dem Legaten wurde freie Hand gegeben, im Falle eines Scheiterns der Unterredungen um Unterstützung der päpstlichen Absichten bei den Prälaten und Adli-

officii legationis eiusdem debitas recipias pro tuis sumptibus et necessariis oportunis, volumus tamen, quod in partibus Tuscie, in quibus tibi etiam legationis officium est commissum, procurationes ac si resideres ibidem exigi et levari easque fideliter facias conservari, ut nos de illis disponere sicut nobis expedire videbitur valeamus. Vgl. auch ibid., n. 2041 (12.10.1345).

522 LÉONARD, Jeanne, II, S. 414f. (pièces justificatives: Brief Johannas an Ludwig von Durazzo vom 3. Juni 1344). Die Königin beklagt sich darin über das unkonziliante Vorgehen des Legaten: [...] Postmodum habita est pro parte nostra cum ipso frequens collacio de modo obediendi, sed ipse difficulter conferre volebat, nec modum assumere aliquem voluit, qui intendebatur secundum mentem et seriem commissionum suarum, sed, sicut sibi placuit, in sua duricie persistit et processus et commissiones suas quamtocius publicavit.

523 Vgl. Lettres Clément VI, nn. 549, 710, 1096, 1135, 1236, 1320.

524 Die Spannbreite dieser Verfügungen war ausgesprochen weit und konnte so unterschiedliche Dinge wie das Verfolgen häretischer Gruppen, die Befreiung Oppositioneller aus neapolitanischer Kerkerhaft oder die Durchsetzung unterschiedlichster Restitutionsmandate betreffen, vgl. ibid., nn. 525, $1010 f ., 1040$.

525 Ibid., n. 972. 
gen des Königreichs nachzusuchen. Damit wurde die Königin zu einer zwar repräsentativen, letztendlich jedoch völlig sekundären Figur auf dem Schachbrett kurialer Politik degradiert ${ }^{526}$.

Die Spannungen zwischen ihr und der Kurie hatten zu diesem Zeitpunkt ihren ersten Höhepunkt erreicht, was nicht zuletzt in der beharrlichen Weigerung Johannas begründet lag, ihren Zahlungsverpflichtungen nachzukommen - immerhin war ein jährlicher Census von 8000 Goldunzen zu entrichten ${ }^{527}$. Der Zorn des Papstes richtete sich in dieser Angelegenheit jedoch nicht nur auf die Person der Königin, sondern bezog auch den Legaten mit ein. In scharfen Worten gab er seinem Erstaunen über die laxe Behandlung dieser Angelegenheit durch den Legaten vor Ort Ausdruck und verga $\beta$ dabei auch nicht zu erwähnen, $\mathrm{da} ß$ es insbesondere die von den Census-Zahlungen profitierenden Kardinäle seien, die ihrem Unmut im Konsistorium Luft gemacht hätten ${ }^{528}$. Die Situation stellte sich für Aimeric als recht delikat dar: Auf der einen Seite hatte er gegen eine unwillige und ausgesprochen inkonziliante Königin vorzugehen, wollte er den Vorgaben päpstlicher Politik auch nur annähernd gerecht werden, auf der anderen Seite mußte er sich gegen Verdächtigungen und Unterstellungen zur Wehr setzen, die von der Kurie selbst ausgingen. Niemand konnte Aimeric de Châtelus um sein Amt beneiden, war er doch zwischen die Mühlsteine der politischen Realität in Neapel und den in Avignon formulierten Zielsetzungen geraten. Was fehlte, war der Rückhalt an der Kurie, wo die das Königreich Neapel betreffenden Direktiven steten Wandlungen unterzogen waren. Eine Neuorganisation der Verwaltungsstrukturen, ein personales revirement des innersten Führungszirkels, wurde vom Legaten nicht in Angriff genommen. Gleichwohl legt eine von ihm für seinen persönlichen Gebrauch angefertigte Briefsammlung Zeugnis von seinem Bemühen um eine Stabilisierung insbesondere der innenpolitischen Lage $a b^{529}$.

526 Ibid., n. 1131 (25.09.1344): [...] duximus injungendum, quatinus nostris litteris per te regine presentatis eidem, sibi predicta et alia, que tibi in scola experientie constituto expedire pro utilitate negotii videbuntur exponas, ac ipsi viis et modis, quibus poteris persuadere procures, quod in treugis ad biennium vel triennium duraturis consentiat, et quod interim interdictum in predicta insula Sicilie appositum non solum pro animarum salute, sed etiam pro validandis in favorem partis sue factis processibus suspendatur. Ubi vero regina predicta tuis exhortationibus salubribus acquiescere recusaret, tu prelatis et nobilibus dicti regni honorem et commodum ipsius regine ac bonum statum patrie zelantibus ad tuam presentiam evocatis]. 527 Ibid., n. 1132 (25.09.1344); vgl. zum Census des regnum Sicilie BAUMGARTEN, Untersuchungen, S. CXXVI-CXXXVIII.

528 Lettres Clément VI, n. 1133 (25.09.1344).

529 Der Band - aufbewahrt im Vatikanischen Archiv im Bestand der Collectoriae 279 umfaßt 203 Seiten und deckt - chronologisch ungeordnet - die Zeit der gesamten Legation mit einem klaren Schwerpunkt auf den beiden letzten Monaten des Jahres $1344 \mathrm{ab}$. Aimeric legte die Sammlung, die größtenteils Privilegienverleihungen und -bestätigungen, daneben aber auch Berichte über finanzielle Transaktionen enthält, höchstwahrscheinlich auch in Hinblick auf eine mögliche Rechtfertigung seiner Handlungen vor der Kurie an. Der letzte Eintrag datiert vom 20. Mai 1345; vgl. LEONARD, Jeanne, I, S. 366-377. 
Die am 19.November 1344 erfolgte Entbindung Aimerics von seinen Pflichten als Legat, die Aufforderung, sich ohne Verzug nach Avignon zu begeben, und die Rückübertragung der Regierungsgewalt in die Hände Johannas belegen eindrucksvoll das Widersprüchliche und Sprunghafte der päpstlichen Politik ${ }^{530}$. In zwei Monaten hatte sich weder das Verhältnis zur Königin grundlegend gebessert, noch war Aimeric durch diplomatische Fehlleistungen untragbar geworden. Weshalb dann aber diese Abberufung und Wiedereinsetzung, die der Papst wenig später bitter bereuen sollte? Im Brief selbst spricht der Papst vom schon lange zuvor geäußerten Wunsch des Legaten, an die Kurie zurückkehren zu wollen. Die Abberufung erfuhr somit eine Deutung als einfacher Gnadenakt des Papstes. Negatives wurde positiv verbrämt. Der - vor dem Hintergrund der aktuellen politischen Situation in Neapel vielleicht tatsächlich artikulierte - Wunsch des Legaten in Ehren: hinter der Abberufung dürfte jedoch noch mehr stecken. Licht ins Dunkel bringt ein Brief des Papstes an König Philipp von Frankreich vom 11. Mai 1345, abgefaßt zu einem Zeitpunkt, an dem die immer wieder verschobene Abreise des Legaten aus Neapel unmittelbar bevorstand ${ }^{531}$. Darin gibt er seinem Bedauern darüber Ausdruck, die Herrschaft über das Königreich Neapel an Königin Johanna zurückgegeben zu haben, eine Rückgabe, die auch auf massives Drängen des französischen Königs hin erfolgt sei. Diesem wird denn auch nicht die Auflistung der von Johanna seither begangenen Verfehlungen samt der Aufforderung erspart, zur Entkrampfung der mitverschuldeten Situation in Neapel beizutragen ${ }^{532}$.

530 Lettres Clément VI, n. 1262 (19.11. 1344; nur Regest); vgl. RV 138, n. 463, fol. 131r: [...] Demum tuis nobis sepe oblatis petitionibus super tuo regressu ad nostram presentiam, attentis tuis fructuosis et fidelibus laboribus, quos pro negociis tibi commisse legationis et aliis arduis prudenter et fideliter portasti, diutius favorabiliter annuentes, volumus et nobis placet, quatinus gubernatione ac administratione regni et terrarum predictorum iuxta huiusmodi concessionem nostram dummodo prius tu nomine nostro et eiusdem Romane Ecclesie baiuliam, gubernationem et administrationem regni et ducatus Calabrie ut prefertur habueris, tenueris et exercueris plene, libere et quiete absque contradictione quacumque prefate regine dimissis et eam commoneas et inducas, ut nostris predictis exhortationibus utique salubribus et de fonte paterne caritatis prodeuntibus effectualiter acquiescat ac deinde quamcitius commode poteris ad nostram et eiusdem sedis presentiam cum nostre benedictionis gratia revertaris. Wiederholt wird die Aufforderung in einem am 17.Dezember 1344 abgefaßten Schreiben, ibid., n. 1338.

531 Vgl. LÉonARD, Angevins de Naples, S. 344. Aimeric verläßt Neapel am 24. Mai 1345.

532 Lettres Clément VI, n. 1705 (11.05.1345): Dudum tuis, fili carissime, receptis litteris, per quas celsitudo regia nos rogabat, ut administrationem regni Sicilie et terrarum citra Farum ad nos et Ecclesiam Romanam pro certo spectantem tempore, carissime in Christo filie nostre Johanne regine Sicilie illustri remittere dignaremur, nos, hujusmodi precibus inclinati, eandem administrationem dicte regine remisimus de gratia speciali, et per dilectum filium nostrum Aymericum tit. Sancti Martini in Montibus presbiterum cardinalem, Apostolice Sedis legatum, cui erat per nos administratio ipsa commissa, mandavimus remittendam, et forsan fuisset expediens, quod facta hujusmodi remissio non fuisset. 
Aimeric de Châtelus hatte zu diesem Zeitpunkt das Schlimmste bereits hinter sich ${ }^{533}$ und befand sich auf dem Weg nach Rom. Vom Papst waren ihm noch zusätzliche Mittel in Höhe von 15000 Florin zugesagt worden, die von der Königin und den Prälaten des Königreichs zu zahlen waren ${ }^{534}$. Da die Zahlungsmoral sich jedoch als denkbar schlecht erwies, sollte der Mittelzufluß in Raten erfolgen ${ }^{535}$. Auch der Seneschall der Provence wurde aufgefordert, so schnell als möglich 2000 Florin zur Deckung der dem Legaten zwischen der Abberufung und der tatsächlichen Rückkehr an die Kurie entstandenen Kosten aufzutreiben ${ }^{536}$. Teile der von Aimeric während seiner Legation verhängten Kirchenstrafen wurden rückgängig gemacht ${ }^{537}$.

Der Aufenthalt des Legaten in Rom hatte einen eminent politischen Charakter, sollte er dort doch zur Verwirklichung eines innerrömischen Friedens und insbesondere zur Versöhnung der Orsini mit den Colonna beitragen ${ }^{538}$. Das Gegenteil geschah: Aimeric wirkte alles andere als ausgleichend und schaffte es, sich in kürzester Zeit den Großteil des römischen Adels zum Feind zu machen ${ }^{539}$. Deshalb war sein Aufenthalt in Rom auch nur von sehr

533 Noch im Januar 1345 oblag ihm die Aufgabe, alle Verleihungen und Schenkungen, die von Johanna nach dem Tode König Roberts vorgenommen worden waren, zu widerrufen, vgl. ibid., nn. 1441f. (30.01.1345), 2824 (22.09.1346).

534 Ibid., nn. 1334-1336 (15.12.1344).

535 Ibid., nn. 1579, 1580 (18.03.1345).

536 Ibid., n. 1538 (20.03.1345).

537 Ibid., n. 2220 (19.12.1345).

538 Ibid., n. 1830 (16.07.1345).

539 Ibid., n. 1877 (07.08.1345; Brief gerichtet an Raymundus Orsini; nur Regest); vgl. RV 139, n. 241, fol.69v-70r: Quia status Urbis pacificus et quietus, in quo utique quiescimus, multipliciter / nos delectat eius cultores gratos habemus admodum et turbatores displicibiles et infestos, sane rumores infesti hiis diebus perduxerunt ad nostri apostolatus auditum, quod pridem dilecto filio nostro Aymerico tit. $S$. Martini in Montibus presbitero cardinali apostolice sedis legato volente ingredi urbem ipsam inter nonnullos familiares seu adherentes quorumdam magnatum Urbis eiusdem occasione honoris exhibendi legato predicto, verbis emulatoriis habitis, magnates predicti ad iracundiam dissentiones et suspiciones, ex quibus status predictus turbari timetur verisimiliter concitati, hoste procurante humani generis, non modicum extiterunt tuque fili propterea commissum per nos tibi senatus in Urbe predicta officium assumere distulisti. Nos igitur obviari periculis, que possent ex premissis contingere, cupientes nobilitatem tuam requirimus attentius et hortamur, quatinus a noxiis novitatibus, que statum turbarent predictum, abstineas penitus et illos de parte tua procurans abstinere una cum dilecto filio nobili viro Nicolao de Anibaldis, domino Castri Sancti Petri in Formis, collega tuo in eodem officio, ascendere capitolium et exercere diligenter et fideliter predictum officium non postponas, sciturus, fili, quod quanto maiorem de persona tua fiduciam gerimus tanto, si huiusmodi nostris requisitionibus et exhortationibus non obtemperares, effectualiter contra te gravius turbaremur. Postquam autem legatus predictus, quem expectamus improximo, venerit de premissis et illis turribus proximis Capitolio per eum plenius informati taliter ordinare intendimus, quod suspicionis sinistre materia subducetur. Vgl. auch Lettres Clément VI autres que la France, n. 738 (08.08. 1345; Brief gerichtet an den Bischof von Rieti, vicarius in spiritualibus des Papstes in Rom). Vor diesem Hintergrund muß die von MOLLAT, Contribution, S.578, vorgenommene Charakterisierung des Aimeric als »homme loyal, intègre et froidement psychologue« mit der gebotenen Skepsis betrachtet werden. 
kurzer Dauer. Spätestens Anfang September erfolgte seine Rückkehr nach Avignon $^{540}$, wo er zwar ehrenvoll empfangen wurde, bis zu seinem Tod 1349 jedoch keine Rolle mehr spielte. Bewertungen der legatorischen Leistungen des Kardinals durch den Papst sucht man - abgesehen von der Collatio anlässlich seiner Rückkehr - vergeblich. Daß Clemens VI. die Verschleppungs- und Hinhaltetaktik des Aimeric jedoch nicht nur in Zusammenhang mit den ausstehenden Census-Zahlungen beklagte, wird zumindest aus einem nach $\mathrm{Ab}$ schluß der Legation abgefaßten Schreiben ersichtlich ${ }^{541}$. Aimeric de Châtelus trat ins zweite Glied zurück, ist als einer der Testamentsvollstrecker des verstorbenen Kardinals de Farges ${ }^{542}$ nachweisbar und machte nur noch einmal in $\mathrm{Zu}$ sammenhang mit einem um seine Livrée geführten Rechtsstreit von sich reden: Nach seiner Rückkehr war ihm die eigentlich Dauphin Humbert gehörende Livrée zugewiesen worden, die aufgrund einer längeren Abwesenheit des Besitzers leer stand. Als Humbert 1347 nach Avignon zurückkehrte und von seinem angestammten Palast Besitz ergreifen wollte, stie $B$ er auf heftigsten Widerstand des Kardinals, der sich - Alter, Gebrechlichkeit und bereits vorgenommene Umbaumaßnahmen vorschützend - beharrlich weigerte, die Livrée zu verlassen, und an den Papst appellierte. Dies geschah mit Erfolg ${ }^{543}$. Bis zu seinem Tod, der vor dem 16. November 1349 erfolgte $^{544}$, bewohnte er die Livrée.

\subsubsection{Egrediebatur et intrabat: die Collatio Clemens' VI. anläßlich der} Rückkehr des Kardinallegaten Aimeric de Châtelus an die Kurie

Was könnte einen Papst dazu bewegen, einen Kardinal der Heiligen Römischen Kirche und einen Hecht im selben Atemzug zu nennen? Was hat ein Fisch mit Seufzern zu tun? Clemens VI. gelingt es, Zusammenhänge herzu-

540 Die päpstliche Collatio ist auf den 5. September datiert; als in Avignon anwesend taucht Aimeric in den Registern zum ersten Mal am 4.Oktober auf, vgl. Lettres Clément VI, n. 2004; ein auf Anfang September datierter Rechnungsbeleg über ein zu Ehren des Kardinals abgehaltenes Festmahl stützt die Datierung, vgl. SCHÄFER, Ausgaben Klemens VI, S.285c: Comederunt cum papa omnes cardinales propter adventum cardinalis Carnotensis et princeps Insularum Perditarum et fuit nativ. B. Marie (Sept. 8).

541 Lettres Clément VI, n. 2557 (10.06.1346; nur Regest); vgl. RV 140, fol.25v, n. 74: [...] Et licet nos dudum dilecto filio nostro Aymerico tit. S. Martini in Montibus presbitero cardinali tunc in partibus illis officio legationis fungenti litteras nostras duximus super hiis speciales, ipse tamen cardinalis aliis occupatus arduis negociis et demum ad sedem apostolicam rediens super eodem negocio sicut intelleximus non processit, volentes igitur super premissis et ea tangentibus iusticiam exhiberi, fraternitati tue per apostolica scripta committimus et mandamus, quatinus vocatis, qui fuerint, evocandi facias simpliciter et de plano sine strepitu et figura iudicii super predictis auctoritate apostolica iusticie complementum [...].

542 Lettres Clément VI, nn. 2940 (18.11.1346), 2943 (21.11.1346).

543 Vgl. ibid., n. 3456 (16.09. 1347), 3465 (20.09.1347). Allgemein wird davon gesprochen, $\mathrm{da} \beta$ der Kardinal senectutis incommodis que, ut nosti, multa sunt, graviter premeretur ac nonnulla edificia etati sue fragili necesaria in dicto hospitio construxisset [...].

544 Unter diesem Datum geht ein Trostbrief des Papstes an den Bruder des verstorbenen Kardinals. Darin betont Clemens VI., er sei ex caritatis affectione mit Aimeric verbunden gewesen und habe dessen virtutes geschätzt, vgl. ibid., n. 4306. 
stellen, die - vorsichtig ausgedrückt - Anlaß zum Staunen geben. Die am 5. September 1345 in Avignon gehaltene Collatio anläßlich der Rückkehr des Kardinallegaten Aimeric de Châtelus aus Italien sticht, was die Extravaganz der Vergleiche betrifft, sicherlich aus dem Predigtwerk Clemens' VI. hervor $^{545}$. Das Bindeglied zwischen Hecht, Seufzern und Kardinallegat liefert einmal mehr die Wunderwelt mittelalterlicher Etymologie, genauer: die vom Papst bemühte Etymologie des Namens Aimeric de Châtelus. Der lateinische Vorname Aymericus wird dabei in zwei Glieder aufgespalten: Ayme-(r)-icus. Tatsächlich gemahnt der lautliche Befund des ersten Bestandteils an die im italienischen weitverbreitete Exklamation des Schmerzes »Ahimè». Damit gelingt es Clemens, die im Laufe der Collatio des öfteren bemühte Feststellung, die Entsendung des Legaten sei mit Angst und Pein verbunden gewesen, etymologisch ad personam zuzuschneiden ${ }^{546}$. Damit nicht genug: auch der zweite Namensbestandteil »-ycus« wird näher erläutert, dieses Mal sogar unter $\mathrm{Zu}$ hilfenahme der Etymologie des Griechischen. Ycus wird, wenn auch auf linguistisch bedenkliche Weise, so doch virtuos, auf ein nicht näher benanntes griechisches Etymon in der Bedeutung von custos, also Wächter, zurückgeführt ${ }^{547}$. Freilich ist es im erwähnten Falle nicht Aimeric, der wacht, sondern Gott, der seine schützende Hand über den Kardinal hält ${ }^{548}$.

Im Umgang mit dem Familiennamen "Châtelus «, lat. Castrolucii, oder de castro lucu, entwickelt Clemens VI. ein noch höheres Maß an Phantasie. Der Bezug auf das castrum, die Burg, liegt nahe ${ }^{549}$. Die Charakteristika, die eine Burg auszeichnen, werden auf das Wirken des Kardinals übertragen. Eine Burg sei nämlich nicht nur hochgelegen, gut befestigt, durch ihre Lage ins Auge springend, sondern auch sorgsam bewacht - so der Papst ${ }^{550}$. Was evo-

545 Den folgenden Ausführungen liegt der Text der Handschrift Paris, Bibliothèque SainteGeneviève, MS 240, fol.420v-424r zugrunde. Dort findet sich die Überschrift: Collatio quam fecit in reditu Aymerici cardinalis legati in Italia et in regno Sicilie. Zur Parallelüberlieferung vgl. SCHNEYER, Repertorium, Bd.4, S.761, n.31; Mollat, Euvre oratoire, S. 254f., n. 59; SCHMITZ, Sermons, S. 23, n. 26; Wood, Sermon literature, S. 163-172.

546 MS 240, fol. 423vb: [...] quia vocatur Aymericus. Quia enim egressus eius fuit laboriosus et plenus tedio, idcirco frequenter, ut credimus, prorumpit in vocem dolentis, in vocem gementis more italico dicens principium sui nominis: ayme.

547 Ein solches griechisches Etymon sucht man allerdings vergeblich. Am wahrscheinlichsten ist der Bezug auf oíkos.

548 Ibid.: [...] Sed quia regressus gaudiosus et dignus iubilo et eius progressus virtuosus clarus preconio eiusque fructus copiosus datus Dei auxilio, idcirco ycus, quod est custos, quia domino et in eundo et morando et in redeundo salubriter custoditus. Dominus enim custodivit introitum suum et exitum suum ex hoc nunc etc.

549 Erwähnt sei auch, daß in I Chr 11,7 die Burg mit der Stadt Davids gleichgesetzt wird. Explizit findet dieser Zusammenhang - erinnert sei daran, daß Aimeric von Anfang an mit David verglichen wird - zwar keine Erwähnung, dürfte jedoch als Allgemeinwissen verbreitet gewesen sein.

550 Ibid.: Cognominatur enim de castro lucu. Est enim castrum emminenter situm, affluenter munitum, precellenter insignitum, diligenter custoditum. Es folgt die Angabe einiger Bibelstellen, darunter auch diejenige Jer 20,11: Dominus mecum est tamquam bellator fortis. 
ziert werden soll, ist das Bild eines machtvollen Streiters im Namen des Herrn, wobei die Frage, wer sich hinter dem Begriff des Herrn verbirgt, Gott oder der Papst, von Clemens zu diesem Zeitpunkt bereits zugunsten seiner selbst beantwortet worden war. Für den zweiten Bestandteil des Nachnamens werden zwei Herkunftsmöglichkeiten benannt: lux, das Licht, oder eben lucius, der Hecht. Den Geboten der concordantia in voce folgend, wird das Licht - jeweils durch einen Superlativ ergänzt - auf die ganz zu Beginn der Collatio bereits genannten und in der Folge weiter entfalteten Charaktereigenschaften des Legaten bezogen: Stärke, Sanftmut, Klarheit und Heiligkeit gelten als Eigenschaften des Kardinals, die während der Legation zur freien Entfaltung gebracht worden seien. Dies kann spätestens jetzt nicht mehr erstaunen, wo der Zusammenhang zwischen dem Träger des Namens und die diesem Namen inhärenten Eigenschaften so wunderbar offengelegt worden ist ${ }^{551}$. Vom Licht zum Hecht, von der ätherisch strahlenden Lichtgestalt zum Fisch, dessen kulinarische Qualitäten am Papsthof geschätzt worden sind ${ }^{552}$. Die dem Hecht zugewiesenen Eigenschaften, nämlich honigbestrichen, schmackhaft; fest und sanft zu sein, werden jeweils wieder an kardinalizische Charakteristika gekoppelt. Was allerdings ein honigbestrichener Fisch mit Charakterstärke oder ein schmackhafter Fisch mit Milde zu schaffen haben, wird wohl ewig das Geheimnis Clemens' VI. bleiben. Lediglich der Verbindung »fest-Klugheit « (solidus-prudentia) und "sanft-Gnade« (placidus-gratia) eignet eine gewisse gedankliche Nachvollziehbarkeit ${ }^{553}$. Daß den Papst die Bezugnahme auf sprichwörtliche Redensarten dazu bewegt haben könnte, das Element des Hechts in seiner Collatio zu verwenden, ist unwahrscheinlich ${ }^{554}$. Um so wahrschein-

551 Ibid.: A luce quidem, quia lux certissima propter fortitudinem, quia lux suavissima propter mansuetudinem, quia lux splendissima propter limpitudinem. Quia lux purissima propter sanctitudinem, ut de eo dicamus illud primo Jo. primo: Lux est et tenebre in eo non sunt ulle; vgl. 1 Joh 1,5 .

552 Dies legen zumindest die überlieferten Rechnungsbelege nahe, vgl. SCHÄFER, Ausgaben Klemens VI., S. 209, 240, 271, 296, 332f., 368f., 399, 424, 444, 465f., 495. Die Variationsbreite ist erstaunlich: unter dem Begriff lucius werden einige Unterarten subsumiert. Am 24. April 1348 erfolgt so z. B. eine Zahlung pro 40 luciis magnis de clareta [...], pro 70 luciis stolardos de clareta [...], pro 214 luciis vocatis alausar [...], pro 149 luciis vocatis regeyrols [...], pro 43 luciis vocatis cavilhos [...], ibid., S. 369. Daneben schätzt man an der Kurie besonders Aale und Stockfische, vgl. WeIss, Versorgung, S. 397-399.

553 MS 240, fol. 423vb: Est enim lucius piscis melitus propter constantiam, piscis sapidus propter clementiam, piscis solidus propter prudentiam, piscis placidus propter gratiam.

554 vgl. Hans WalTHER, Lateinische Sprichwörter und Sentenzen des Mittelalters, II/2, Göttingen 1964, S. 763; DERs., Lateinische Sprichwörter und Sentenzen des Mittelalters, II/8, S. 322, mit jeweils demselben, für obige Predigt nicht relevanten Beispiel; Thesaurus proverbiorum medii aevi, Bd.3, Berlin 1996, S.263f., 272, mit Beispielen des 15./16. Jahrhunderts, die die Rolle des Hechts als großer Fisch, der die kleinen verspeist, betonen. Die Literatur über die theologische Bedeutung des Fischsymbols ist uferlos, genannt sei hier der für das Mittelalter nach wie vor einschlägigste Titel von Cyrill VoGEL, Symboles cultuels chrétiens. Les aliments sacrés: poisson et refrigeria, in: Simboli e simbologia nell'Alto Medioevo, Bd. 1, Spoleto 1976, S. 197-265. 
licher jedoch ist die Hypothese, daß der Hecht-Vergleich nur deshalb bemüht wurde, um die Zuhörer mit einem Schmunzeln - gleichsam positiv gestimmt zu entlassen ${ }^{555}$.

Welche Bewertung läßt nun Clemens VI. der Legation insgesamt angedeihen? Als programmatisch darf bereits die Wahl des Themas gelten: »Und David zog aus und ein vor dem Kriegsvolk und richtete all sein Tun recht aus, und der Herr war mit ihm « ${ }^{556}$. Mit König David wird die Vergleichsebene von Anfang an bewußt hoch angesetzt. Er erscheint als Musterbeispiel eines guten Königs - eines Königs, »mit dem der Herr war «557. Auch die in der Folge angeführten Bibelzitate belegen, daß sich der Papst im Fahrwasser allgemein üblicher und weit verbreiteter Bewertungsmuster bewegt. Nicht nur die militärischen Erfolge Davids gegen Philipper, Ammoniter, Moabiter und Edomiter finden Erwähnung. Durch den Verweis auf den Sieg über Goliath wird der Blick bereits auf die Tatsache gelenkt, daB militärische Unterlegenheit sich durch Gottes Beistand und Hilfe in ihr Gegenteil verwandeln und zum Sieg führen kann. Worauf der Papst allerdings nicht verweist, sind die negativen Seiten Davids: kein Wort über den Konflikt mit Absalom, über den Ehebruch mit Batseba und die anschließende Ermordung Urijas. Clemens' Wahrnehmung ist bewußt selektiv. Ihm geht es nicht um eine Darstellung der Vielschichtigkeit der Person Davids, sondern um die Evokation einer beispielhaften Gestalt, an deren positiven Seiten sich der Legat zu messen hat, an denen er sich aber auch messen lassen kann. Und - die Analyse der Collatio Sicut frigus nivis zeigte es bereits - tatsächlich sind es nur Positiva, die in der päpstlichen Collatio explizit benannt werden.

All das, so der Papst, was im Thema bereits angeklungen sei, könne auch auf die Person des Legaten Anwendung finden, der in Tuszien und Sizilien klug gehandelt habe, weil Gott mit ihm gewesen sei. Und Clemens VI. vergißt nicht hinzuzufügen, da $B$ die Aussendung auf seinen ausdrücklichen Befehl hin erfolgt sei558. Diese Grundüberlegung dient als Basis für alle weiteren Aus-

555 Erinnert sei hier an die humoristische Schlußwendung der Collatio Hii sunt viri, vgl. Kap. 5.1.9.

5561 Sam 18,13. Egrediebatur et intrabat in conspectu populi, in omnibus quoque viis suis David prudenter agebat et dominus erat cum eo.

557 Vgl. I Sam 16,18; 18,12; 14,28; II Sam 5,10; vgl. zur Person Davids die kunstgeschichtlich orientierte Arbeit von Hugo STEGER, David rex et propheta, Nürnberg 1961 und die Biographie von Steven L. McKenzIE, König David, Berlin 2001, in der von der sagenumwobenen Gestalt nach kritischer Durchsicht der biblischen Erzählungen, althistorischen Texte und neuen archäologischen Funde nicht viel mehr als das Bild eines Thronräubers, Ehebrechers und Mörders übrigbleibt, der seinen Aufstieg zum König geschickter Machtpolitik und Terror verdankte; vgl. zur Namensetymologie Isidor v. Sevilla, Etymologiae, V, 39,19 ; VIII, 6,64 .

558 MS 240, fol.420va : Et videtur michi, quod proprie possunt dici de nostro legato, qui ad mandatum nostrum, qui hodie licet immeriti regimus et presidemus, egressus ad partes Tuscie et postea ad partes Sicilie et hodie regressus in cunctis prudenter se gessit et dominus fuit cum eo. 
führungen. Was allerdings erst geschaffen werden mußte, war das Sprachmaterial, mittels dessen sich das Predigtgebäude rhetorisch weiter aufrichten ließ. Ein Blick auf die David zugeschriebenen Charakterzüge schuf Abhilfe. Festigkeit und Stärke (constantia/fortitudo), Milde und Sanftmut (clementia/mansuetudo), Klarheit, Hellsichtigkeit und Sicherheit (prudentialimpitudo/certitudo) und schließlich Gnade und Heiligkeit (gratia/sanctitudo) zeichnen David aus und lassen ihn zur Ausnahmegestalt werden. Was folgt, ist die biblische Unterfütterung dieser vier Wortpaare anhand von überwiegend den beiden Büchern Samuel entnommenen Zitaten ${ }^{559}$.

Aus der angeführten Zitatenfülle meint Clemens VI., auf die Person des Legaten rückschließen zu können. Ihm, der schmeichelhaft als noster David misticus erscheint, werden mit Hilfe einer Analogiebildung ebenfalls vier Eigenschaften zuerkannt, die ihrerseits den vier Bestandteilen des Themas zugeordnet werden. Festigkeit und Stärke erweist der Legat im Umgang mit seinen Gegnern (egrediebatur), Milde und Sanftmut im Zusammentreffen mit der Bevölkerung seines Legationsgebiets (intrabat in conspectu populi), Klarheit, Hellsichtigkeit und Sicherheit in der Bewertung und Ausführung seiner Handlungen (in omnibus viis suis prudenter agebat) und nicht zuletzt in der Gnade und Heiligkeit, die ihm aus dem Beistand Gottes erwuchsen (Dominus erat cum eo $)^{560}$. Die vier Bestandteile dieses Divisionsschemas werden in der Folge näher ausgeführt, wobei ein klarer inhaltlicher Schwerpunkt auf der Behandlung des ersten Punktes liegt. Der Papst stellt darin unmißverständlich klar, daß es einem legatus a latere nicht um die Befriedigung eigener Bedürfnisse oder Eitelkeiten gehen dürfe, er in seiner Arbeit vielmehr darauf abzielen müsse, als Reformer zu wirken, korrigierend einzugreifen und Mißstände zu beseitigen ${ }^{561}$. Die eigene Person müsse hinter der Sache zurücktreten. Als Gewährsmann wird Bernhard von Clairvaux mit seiner Schrift De considera-

559 constantialfortitudo: I Sam 17,23; I Sam 21,11; II Sam. 23,1; II Sam 23,8; I Sam 17,34-36; I Sam 16,18; clementia/mansuetudo: Ps 131,1; I Sam 24,18; I Makk 2,57; generell I Sam 24; I Sam 26; prudentia/limpitudo/certitudo: I Sam 16,18; I Sam 18,12; II Sam 23,8; gratia/sanctitudo: Ps 88,21; Act 13,22; generell die beiden Chronikbücher.

560 MS 240, fol. 421ra: Modo videtur michi, quod noster David misticus, sicut dicunt verba thematis preassumpta, potest de istis quatuor conditionibus merito commendari: primo, quia mire constantie et fortitudinis in agressu et tollerantia adversorum egrediebatur; secundo grate clementie et mansuetudinis in amplexu et benevolentia universorum vel subditorum, quia intrabat in conspectu populi; tertio, quia clare prudentie et limpitudinis vel certitudinis in conspectu et intelligentia agendorum, quia in omnibus viis suis prudenter agebat; quarto, quia magne gratie et sanctitudinis ex influxu, ex comitatu et assistentia divinorum, quia dominus erat cum eo.

561 Ibid., fol. 421rb: Egressus enim legati a latere non debet esse ad voluptates et delitias prosequendas, non ad cupiditates et divitias assequendas, non ad vanitates et inanes glorias consequendas; sed potius ad laborum tollerantia, ad vigilantiam, ad morum reformationem, ad peccatorum increpationem et reductionem, ad tirannorum malleationem et ad bonorum remunerationem. 
tione ad Eugenium papam herangezogen ${ }^{562}$. Ein Teil des wörtlich aus dem vierten Buch entnommenen vierten Kapitels wird zitiert und nimmt so rund ein Fünftel der in der Pariser Handschrift überlieferten schriftlichen Predigtfassung ein ${ }^{563}$. Im angeführten Zitat unterstreicht Bernhard die Bedeutung der charakterlichen Eignung des kurialen Personals und verdammt Karrieristen, denen man die Erledigung von Amtsgeschäften niemals anvertrauen sollte. Das Idealbeispiel eines Kurialen wird entworfen und sein mustergültiges Verhalten auf Legationsreisen geschildert.

Die hier getroffenen Aussagen bezüglich des selbstlosen, nicht auf persönlichen Gewinn ausgerichteten Einsatzes des Legaten liegen den Ausführungen des Papstes zugrunde. $\mathrm{Da} \beta$ das von Bernhard geschilderte Ideal nur bedingt mit der Wirklichkeit zu tun hatte, belegt jede noch so oberflächliche Durchsicht der kurialen Korrespondenz. In den an die Legaten abgehenden Briefen erscheint die Welt nicht so heil wie in der Schrift Bernhards geschildert. Nuntien und Legaten, zumal solche im Kardinalsrang, taten sich offensichtlich schwer damit, ihre Würde und damit sich selbst als Person hinter die zu erledigende Mission zurücktreten zu lassen. Klagen über selbstherrliches und allzu prunkhaftes Auftreten sind keine Einzelfälle und belegen die Schwierigkeit, Norm und Praxis miteinander in Einklang zu bringen. Was Clemens VI. allerdings in der konkreten Redesituation interessiert, ist der durch Bernhard aufgestellte Katalog der Positiva, die auf die Person des Legaten übertragen werden können. Die von Aimeric de Châtelus erzielten Ergebnisse, seine aufgewandten Mühen sprechen für sich: er, der in der Romagna die Städte Imola und Faenza für die Kirche zurückgewann, der sich auch durch massive Drohungen nicht von der Verwaltung des Königreichs Sizilien abhalten ließ, wird zum bonus miles Christi ${ }^{564}$, zum fortis athleta ${ }^{565}$. War der Beginn der Legation von Furcht geprägt - Furcht auf seiten des Legaten, den kurialen Vorgaben nicht gerecht zu werden, Furcht auf seiten der Souveräne vor den Maßnahmen des Legaten -, so geht das Ende gleichwohl in anderer Atmosphäre vonstatten. Der Auszug des Legaten geschieht nicht verzagt und furchtsam, sondern mit Macht ${ }^{566}$. Angedeutet sei bereits an dieser Stelle, daß

562 Zur Bedeutung des Zisterziensers für das Denken Clemens' VI vgl. Kap. 3.2., 4.2.

563 De consideratione, IV, iv, 12, in: San Bernardo, Opera, I, S. 874-878.

564 II Tim 2,3.

565 MS 240, fol.422ra: Sic autem per Dei gratiam fecit noster legatus, qui fuit in laboribus plurimis, in vigiliis, in sollicitudinibus, in temptationibus variis tam in Romandiola, ubi statim obtinuit Imolam et Faventiam, et multa alia loca, quam etiam in regno, ubi et antquam ingrederetur et postquam ingressus est, nimis territus, promissionibus allectus, ne administrationem regni, quam sibi commiseramus, gereret ipse sicut fortis athleta et constans; nec timore concutitur, nec blandimentis seducitur, nec promissis corrumpitur [...].

566 Ibid.: Et certe bene egressus est sicut fortis, qui etsi flumina irruerint, pluvie descenderint et multi venti flaverint, tamen non concidit: fundatus enim erat super firmam petram. Klar erkennbar ist hier der Bezug auf das petrinische Amt, Mt 16,18, damit auf die Person des Papstes selbst. Ein Scheitern des legatus a latere wäre immer zugleich auch ein Scheitern des Paptes - quod absit! 
die Sprache der kurialen Registereinträge eine andere ist, daß das Ende der Legation dort nicht derart glanzvoll überzeichnet erscheint. Die Collatio in der überlieferten Form verzichtet auf die Erwähnung der mit der Legation verbundenen Mühen und Schwierigkeiten. Aimeric ist der vir preliator ${ }^{567}$, der über die Feinde der Kirche obsiegt, der allen Widerständen zum Trotz Herausragendes leistet.

Die Begründung dieser erstaunlichen Erfolgsgeschichte - und als solche erscheint sie in vorliegender Collatio - folgt unmittelbar. Der Kardinal ist auf festem Fels gegründet (fundatus enim erat supra firmam petram) ${ }^{568}$. Diese Feststellung impliziert zweierlei. Zum einen wird sprachlich variiert auf den letzten Bestandteil des Themas verwiesen: et Dominus erat cum eo. Zum anderen läßt sich die Bemerkung aber auch in Hinblick auf das Petrus von Christus übertragene Amt, das Papstamt, deuten. Ist Aimeric also auf festem Fels gegründet, zeigt er sich nicht nur als irgendein Bestandteil der auf diesem Fels ruhenden Christenheit, sondern in seiner direkten Zuordnung zum Papst. Clemens VI. ist der Fels, ist die eigentliche Basis, von der jedwede legatorische Gewalt innerhalb der Kirche auszugehen hat. Deshalb geht man wohl nicht fehl in der Annahme, daß Clemens hier nicht nur ein Verhältnis der $\mathrm{Zu}$-, sondern vielmehr der Unterordnung insinuiert. Worauf in der Folge besonders hingewiesen wird, ist das unbestechliche Verhalten des Legaten, der sich frei von Habsucht gezeigt habe. Auf ein langes Jesaja-Zitat ${ }^{569}$, das mit der Aussage schließt, nur der könne auf die Hilfe Gottes zählen, »der schändlichen Gewinn haßt und seine Hände bewahrt, daß er nicht Geschenke nehme; wer seine Ohren zustopft, daß er nichts von Blutschuld höre, und seine Augen zuhält, daß er nichts Arges sehe ${ }^{570}$, folgt in der Pariser Handschrift ein kurzes Expo$n e$ und verweist damit auf eine Leerstelle innerhalb der Überlieferung. Was anderes sollte mit diesem Imperativ gemeint sein als das spontane Eingehen des Papstes auf dieses Bibelzitat? Allein: Die Collatio überliefert lediglich die Schlußfolgerung des in der aktuellen Redesituation sicherlich weiter ausgeführten Gedankengangs. Der Papst faßt seine in der Collatio nicht überlieferten Ausführungen zu Jesaja 33,15 in einem Lob der Unbestechlichkeit des Legaten zusammen ${ }^{571}$. Aimeric de Châtelus kann so mit dem bei Bernhard von Clairvaux als legatorische Ausnahmegestalt gepriesenen Kardinallegaten Martin, der sich auf einer Legation nach Dacien zwar seine moralische Inte-

\footnotetext{
567 Vgl. Jes $42,13$.

568 MS 240, fol. 422ra.

569 Vgl. Jes 33,13-16.

570 Jes 33,15. Kardinal Guillaume Court dürfte an dieser Stelle unwohl geworden sein, war seine Legation doch genau von diesen Vorwürfen der Bestechlichkeit überschattet gewesen.

571 MS 240, fol. 422rb: Unde iste - quod est satis commendabile et gloriosum - ita manus suas nudas habuit ab omni munere, ut nichil in utraque legatione recepisse dicatur. Mit Sir 31,8 und 1 Sam 12,3f. werden zwei weitere Bibelstellen auf das Wirken des Legaten bezogen.
} 
grität bewahrt hatte, dafür jedoch bettelarm an die Kurie zurückgekehrt war, verglichen werden ${ }^{572}$.

Milde und Sanftmut sind Charakteristika, die im zweiten Abschnitt Behandlung finden ${ }^{573}$. Die Notwendigkeit, sich insbesondere den Armen und Unterdrückten zuzuwenden, um eine Legation zum Erfolg zu führen, wird nicht nur anhand einiger Bibelzitate, sondern auch anhand einer Stelle aus Senecas Abhandlung De clementia weiter ausgeführt ${ }^{574}$.

Damit war ein Problem angesprochen, vor das sich alle weiteren ins Königreich Neapel entsandten Legationen gestellt sahen, bestand die Hauptschwierigkeit doch nicht nur in einer gezielten Obstruktionspolitik durch Königin Johanna I. und ihre Entourage, sondern auch im fehlenden Rückhalt innerhalb einer Bevölkerung, der die Ziele päpstlicher Politik in keinem Fall nähergebracht werden konnten. Der Papst entdeckt hier also nicht sein Herz für die Schwachen und Entrechteten dieser Erde, sondern formuliert ein Gebot, das realpolitisches Handeln fördert, wenn nicht überhaupt erst möglich macht. Als sanftmütig und milde hat sich Aimeric in der Tat erwiesen. Ob Sanftmut, wenn sie sich wie in seinem Fall in fehlender Durchsetzungsfähigkeit konkretisiert, tatsächlich als Vorzug eines kurialen Spitzendiplomaten zu gelten hat, bleibt an dieser Stelle unbeantwortet. Clemens VI. bleibt seinem Vorsatz, ausschließlich positive Dinge zu benennen, treu. Arbeit müsse zwar vorausgehen - so der Papst -, dann dürfe jedoch getrost die Ehre folgen ${ }^{575}$. Der Empfang des Legaten an der Kurie gestaltet sich deshalb entsprechend ehrenvoll ${ }^{576}$.

Die rhetorische Untermauerung der im dritten Abschnitt behandelten Charakteristika Klugheit, Hellsichtigkeit und Sicherheit ${ }^{577}$ fällt insofern aus dem üblichen Rahmen, als eine ansonsten unübliche Vielzahl antiker Autoritäten angeführt wird. Neben Aristoteles, aus dessen sechstem Buch der Ethik zitiert wird, ist es erneut Seneca, der als Fachmann für in Zusammenhang mit prudentia stehende Fragen herangezogen wird. Der Papst hebt insbesondere auf die Verbindung $z$ wischen Tugenden und Klugheit ab: Nur ein tugendhafter Mensch handelt klug und weise. Neben den bereits genannten antiken Autoren wird eine Reihe biblischer Autoritäten zur Bestätigung dieser Tatsache

572 Vgl. De consideratione, in: San Bernardo, Opere, I, S. 878.

573 MS 240, fol. 422va: Dico II, quod iste commendatur, quia grate clementie et mansuetudinis in amplexu et benivolentia universorum et subditorum, quia intrabat in conspectu populi.

574 Vgl. II Tim 2,24; Sir 32,1-3; Sir 4,7; II Sam 15,23f.; Sir 10,24.

575 MS 240, fol. 422vb: Debet enim precedere labor, postea sequi honor.

576 Vgl. II Sam 5,2; I Mkk 13,41; Mt 25,23; Sap 8,16; Lc 24,26. An den Vorgaben des Zeremoniells scheint man sich - folgt man den Aussagen des Papstes - ausgerichtet zu haben, vgl. MS 240, fol. 422vb: Non solum ibi intravit in conspectu populi, sed etiam hodie intravit civitatem istam in conspectu totius populi et aliorum obviantium sibi. Die Collatio scheint also am Tag der Rückkehr selbst gehalten worden zu sein.

577 MS 240, fol. 422vb: Dico III, quod iste commendatur, quia clare prudentie et limpitudinis vel certitudinis in prospectu et intelligentia agendorum, quia in omnibus viis suis prudenter agebat. 
herangezogen ${ }^{578}$. Über die geistigen Grundlagen der Legation, über ihre Verwurzelung im antiken und biblischen Schrifttum, erfährt man somit viel, über die konkrete Handlungsweise des Legaten jedoch wenig ${ }^{579}$. Über die allgemeine Bemerkung hinaus, Aimeric habe die Stärke der Kirche (vis ecclesiae) verteidigt, finden sich keine weiteren Hinweise auf das Wirken des Legaten in situ.

Gnade und Heiligung werden im vierten Abschnitt abgehandelt ${ }^{580}$. Stärker noch als in den vorhergehenden Passagen verschwinden die wenigen "originalen« Aussagen des Papstes im Wust der Bibelzitate. Einzig der Vergleich mit Joseph zeugt von einiger Originalität ${ }^{581}$. So wie sich dieser von geringen Ursprüngen hin zu einer hochgeschätzten Autorität entwickelt habe, so vollziehe sich auch in der Person des Aimeric eine Entwicklung, die ihn von bescheidenen Ämtern - Erwähnung finden die Funktionen des Bischofs, Erzbischofs und Kardinals - auf die höchste Sprosse der Karriereleiter, gemeint ist das Amt des Legaten, geführt habe ${ }^{582}$. Diese Zuordnung mag verdeutlichen, daß in den Augen Clemens' VI. die dem Kardinalat inhärente Würde durch die Übernahme einer Legation erst zur endgültigen Entfaltung gebracht wurde. In einer gewaltigen, auf den Prinzipien der Viergliedrigkeit beruhenden Reihung werden die erzielten Ergebnisse schließlich noch einmal zusammengefaßt, die Verbindung von thematischen Vorgaben, Charaktereigenschaften und Fähigkeiten des Legaten zum letzten Mal beschworen ${ }^{583}$. Danach versucht sich der Papst darin, Namensetymologie und legatorische Eigenschaften aneinanderzukoppeln.

Wie aussagekräftig ist die vorliegende Collatio? Was transportiert sie außer etymologischen Kuriosa an konkreten Feststellungen, die Rückschlüsse auf das Verhältnis von Papst und Kardinälen gestatten würden? Die Ergebnisbilanz ist im Vergleich zu den anderen hier behandelten Collationes gering. Da ist zunächst die Feststellung, daß sich das Legationsamt nur auf der Basis des

578 Prov 3,13f.; Prov 28,26; Prov 10,19; I Chr 22,15; Job 26,13; I Sam 18,5; Lc 16,8.

579 MS 240, fol. 423ra: Noster autem legatus hanc prudentiam tenuit et in omnibus viis suis habuit.

580 Ibid., fol. 423rb: Dico IIII, quod iste commendatur, quia magne gratie et sanctitudinis ex influxu, ex comitatu et assistentia divinorum, quia dominus erat cum eo.

581 Vgl. Gen 49,22-25.

582 MS 240, fol. 423rb: Sic iste de archiepiscopo factus episcopus, postmodum in cardinalem et legatum Sedis Apostolicae est assumptus. Das inkonsequente Erklimmen der Karriereleiter ist wohl auf ein Versehen des Schreibers zurückzuführen.

583 Ibid., fol. 423va: Et videte, quod in istis verbis, sed non prosequor, possumus considerare quattuor. Primo eius egressum laboriosum et plenum tedio, secundo eius ingressum gaudiosum et dignum jubilo, tertio eius progressum virtuosum, clarum preconio, quarto fructum copiosum datum Dei auxilio. Iste ergo egreditur cum sollicitudine, vigilantia et labore, recipitur cum dulcedine, complacentia et amore, progreditur cum fortitudine, efficacia et vigore, regreditur cum plenitudine, gloria et honore. Ut hodie attendamus vigilem infatigabilem, humilem et accessibilem atque tractabilem, pugilem, inexpugnabilem, utilem et desiderabilem. 
Felsen, auf dem die Kirche gegründet ist, entfalten kann, die Legation ihre Daseinsberechtigung also aus dem Papstamt selbst bezieht. Angesprochen ist damit die klare Unterordnung des Befehlsempfängers unter den Befehlsgeber, des Legaten unter den im Bild des Felsen beschriebenen Papst. Da ist zum anderen die Wertschätzung, die der Papst dem Legatenamt entgegenbringt, ein Amt, dessen enge Zuordnung zum Kardinalat und damit zur höchsten innerhalb der Kirche zu vergebenden Würde diese erst zur vollen Entfaltung bringt. Diese Feststellung impliziert freilich auch, daß die volle Entfaltung der Kardinalswürde letztlich im Ermessen des Papstes begründet liegt, ist er es doch allein, der Legaten ernennt und gegebenenfalls abberuft. Eine sehr viel stärkere Bewertung als die bloße Faktenebene erfährt die Vorstellungsebene, die sich in Reflexionen darüber verliert, wie ein idealer Legat $\mathrm{zu}$ sein hat. Leicht könnte man der Versuchung erliegen, die Aussagen des Papstes dahingehend zu interpretieren, als würde dem Legaten insbesondere unter Bezugnahme auf die Autorität Bernhards von Clairvaux ein Spiegel vorgehalten und damit ein leuchtendes Vorbild vor Augen gestellt. Konsequent weiterinterpretiert hieße dies dann, in Aimeric de Châtelus einen Legaten zu erblicken, der den von Bernhard bzw. dem Papst unter Bezugnahme auf Bernhard formulierten idealen Vorgaben nur bedingt gerecht geworden ist - angesichts des Verlaufs, den die Legation genommen hat, ein durchaus legitimer SchluB.

\subsubsection{Die Legation von Kardinal Bertrand de Deux nach Neapel und Rom}

(1346-1348)

\subsubsection{Die Legation im Spiegel der kurialen Registerüberlieferung}

Nur knapp zwei Monate nach der Rückkehr des Kardinallegaten Aimeric de Châtelus dachte man an der Kurie bereits wieder an die Entsendung einer Legation nach Neapel. Inzwischen hatte sich dort die Situation dramatisch verschärft, war doch der junge Prinzgemahl, Andreas von Ungarn, Opfer eines grausamen Mordanschlags geworden ${ }^{584}$. An der Kurie erfuhr man um den 6.-7. Oktober von der Tat. Immerhin mußte nach Bekanntwerden der Nachricht aufgrund der Aufregung, die sich unter den Kardinälen verbreitete, ein gerade tagendes Konsistorium vertagt werden ${ }^{585}$. Die Rekonstruktion des Tathergangs gestaltete sich - auch vor dem Hintergrund der reichlich fließenden historiographischen Quellen - recht einfach, ja Clemens VI. selbst zeigte

584 LÉONARd, Les Angevins de Naples, S. 344-347; LÉonARD, I, S. 471-473.

585 Vgl. Lettres Clément VI, n. 2027 (07.10.1345): [...] Porro cum super hiis, que nobis antea scripseras, cepissemus cum fratribus nostris in consistorio deliberationem habere, supervenerunt rumores infesti hujusmodi turbationem afferentes nobis et eisdem fratribus non indigne; quamobrem deliberare plene nequivimus super eis. 
sich in einer Collatio erstaunlich gut informiert ${ }^{586}$. Schwieriger war jedoch die Suche nach den wahren Schuldigen. Königin Johanna gehörte zu den Hauptverdächtigen - immerhin war mit dem Tod des Gatten ihr Wunsch in Erfüllung gegangen, weiterhin als alleinige Regentin schalten und walten zu können. Tragischerweise war der Befehl des Papstes, Andreas von Ungarn zum König von Sizilien zu krönen, erst am 20./21. September, mithin zwei Tage nach dem Mordanschlag, ergangen ${ }^{587}$. Ludwig, König von Ungarn und Bruder des Ermordeten, intervenierte beim Papst, um die Bestrafung der Schuldigen zu forcieren. Seine Briefe zeugen von seiner Bestürzung und inneren Anteilnahme am Tod seines Bruders, machen jedoch auch deutlich, daß ihm daran gelegen war, aus diesem Tod den größtmöglichen machtpolitischen Profit zu schlagen. ${ }^{588}$ Mit Kardinal Élie Talleyrand de Périgord, dem Ludwig unterstellte, Anführer einer insbesondere den Interessen Johannas I. wohlgesonnenen Partei an der Kurie zu sein, wurde zudem eine der einflußreichsten kardinalizischen Persönlichkeiten ins Visier genommen ${ }^{589}$.

Tatsächlich war Talleyrand durch verwandtschaftliche Bande in die Geschehnisse in Neapel involviert. Seine Schwester Agnes, die mit Johannes de Gravina, Herzog von Durazzo, den Großonkel Johannas geehelicht hatte, intrigierte nach dem Tode Roberts bis zu ihrem eigenen Ableben 1345, um einem ihrer Söhne die Hand der Maria, einer Schwester Johannas, zu verschaffen $^{590}$. Im April 1343 fand die Vermählung Marias mit Karl von Durazzo statt. Da Maria im Falle eines frühen Ablebens Johannas erbberechtigt gewesen wäre, hätte dies bedeutet, daß gleichzeitig auch ein Neffe Talleyrands König von Sizilien geworden wäre. Für die Vermittlung der für die Verbindung

586 Die Collatio Vox sanguinis fratris ist breit überliefert (in der Leithandschrift MS 240 auf fol.361r-367r) und besticht durch die Gewagtheit der Vergleiche. Obgleich sowohl Christus als auch Andreas von ihrem eigenen Volk umgebracht worden seien, habe doch letzterer größeres Unrecht als Christus erlitten, den die Juden als König schließlich nicht anerkannt hätten, vgl. MS 240, fol.363vb: Sed videtur michi, quod licet multi legantur in scriptura prodicionaliter interfecti, tamen nullius mors, nullius occisio fuit ita similis morti Christi sicut mors nostri Andree [...]. Primo quidem ratione patientis passus est enim Christus, passus est noster Andreas, qui habent similitudinem quo ad tria. Primo quo ad teneritudinem complexionis. Uterque enim in etate tenera, sed Andreas in magis tenera [...]. Tercio quantum ad celsitudinem dominationis. Uterque enim Rex, et uterque a suo populo interfectus. Sed videtur prima facie, quod etiam in hoc homicide Regis Andree gravius peccaverunt. Iudei enim licet Christus esset Rex verus, eorum tamen eum non cognoscebant in regem.

587 Lettres Clément VI, nn. 1975 (20.09.1345), 1977-1981 (21.09.1345). Die Nachricht vom Tode Andreas' gelangte erst am 6./7. Oktober nach Avignon. Am 13. Oktober - nach Erhalt eines Briefes aus Neapel - schrieb der Papst litterae consolatoriae an den König von Ungarn und dessen Mutter, vgl. Lettres Clément VI autres que la France, n. $790 f$.

588 Émile LÉonARD, Lettres écrites par Elisabeth et Louis de Hongrie au pape Clément VI après l'assassinat du roi de Sicile André (1346-1347), in: Studi di storia napoletana in onore di Michelangelo Schipa, Neapel 1926, S.201-219.

$589 \mathrm{Vgl}$. hierzu ZACOUR, Talleyrand, S. 31-43.

590 Genealogie des Grafenhauses von Périgord - Verbindung zum Hause Durazzo, in: Vones, Urban V., Tafel I, S. 538. 
notwendigen Dispense wurde der Kardinal angemessen vergütet: Agnes überschrieb ihrem Bruder die 22000 Florin, die aus ihrer Mitgift noch ausstanden $^{591}$. Für die weitere Zukunft des Königreichs sollte sich diese Eheverbindung als katastrophal erweisen, geriet damit doch das prekäre Gleichgewicht zwischen den Häusern Tarent und Durazzo aus dem Lot ${ }^{592}$. An der Kurie zählte Talleyrand zu den erbitterten Gegnern einer Krönung Andreas'. Nach dessen Ermordung wurde er von Kardinal Jean de Comminges in einem turbulent verlaufenden Konsistorium der Mitwisserschaft angeklagt ${ }^{593}$. Ludwig von Ungarn ging noch weiter: Er war der festen Überzeugung, Talleyrand habe den Mord von Avignon aus geplant ${ }^{594}$.

591 Vgl. Zacour, Talleyrand, S. 32-37; Der Ehekontrakt zwischen Agnes und Johannes findet sich in BaLuZE/MolLAT, Vitae III, S. 344-353. Die Höhe der gesamten Mitgift belief sich auf 35000 Florin.

592 In weiser Voraussicht hatte Robert für seine Enkelin eine Verbindung mit Ludwig von Ungarn vorgesehen. Im Falle eines Scheiterns dieses Projekts sollte Karl, der Sohn des zukünftigen französischen Königs Jean II., an die Stelle Ludwigs treten.

593 Vgl. Matthias von NeuEnburg, in: MGH SS, n.s. 4, S.164f.; Giovanni Villani, ed. PORTA, III, lib. XIII, c. 60, S. 437f.: A tale stato venne il collegio dell'apostolica nostra santa Eclesia per le disensioni di suoi cardinali. Di ciò è gran cagione e colpa di papi ch'hanno eletti a cardinali i detti due grandi e possenti Galli e simiglianti, e questo è l'esempio ci danno a.nnoi laici, e seguono bene a contrario l'umilità di santi apostoli di Cristo, il cui ordine rapresentano [...]; vgl. auch lib. XIII, c. 52, S.419. Mit ihrem offen ausgetragenen Streit verstießen die Kardinäle gegen das Friedensgebot, das von ihnen anläßlich ihrer Kreation nicht weniger als dreimal beschworen worden war, vgl. DYKMANS, Céremonial, II, S. 480f.: Et tunc dicit eis qualiter debent cum reverentia loqui in consistorio cum loquentur aliis cardinalibus et etiam cum loquentur tam in viam consilii, quam in viam collationis, non contraicendo seu impugnando dicta aliorum cardinalium, sed alias dicendo prudenter cum reverentia quod eis Dominus ministrabit, et qualiter etiam alios cardinales debeant honorare [...]; vgl. auch S. $482 \mathrm{f}$.

594 LÉonard, Lettres écrites, S. 206; GiovanNi Villani, ed. PORTA, III, lib. XIII, c. 59, S. 433f. Nach der Invasion ins Königreich zählte Karl von Durazzo zu den ersten Opfern des ungarischen Königs. Auf Giovanni Villani geht die Feststellung zurück, Ludwig habe sich durch die grausame Exekution Karls an Kardinal Talleyrand rächen wollen, vgl. GrovanNI VILLANI, ed. PoRTA, III, lib. XIII, c. 112, S. 544. Clemens VI. nimmt Talleyrand in Schutz, vgl. Lettres Clément VI, n. 3852 (07.05.1348; Brief an Bertrand): [...] Item super hiis, que nomine dicti regis Ungarie proposuerunt contra dilectum filium nostrum Talayrandum, tituli S. Petri ad Vincula presbiterum cardinalem, dicendo, quod per eum mors Andree regis predicti machinata fuerat et tractata, respondeatur eidem, quod valde miramur, si circumspectio regia aures prebeat credulas tante et tam patentis assertoribus falsitatis, nam cum dictus cardinalis persona sit nobilis et generose insignisque prosapie, profunde scientie, providentie circumspecte, magne reputationis ac opinionis et fame ac sincere devotionis, et conscientie pure ac multis virtutibus insignitus, et una ex columpnis Ecclesie Sancte Dei, et que frequenter celebrat divina ministeria, quomodo potuit vel potest in cor alicuius prudentis ascendere, quod talis et tanta tamque devota persona, tanto facinori prestitisset assensum et irregularitatis nota, super qua secum nunquam dispensaremus, perpetuo se fedasset. Clemens VI. geht noch weiter und verwahrt sich gegen jede Anschuldigung, die sich gegen das Kardinalskolleg richtet: Revera non videtur magnum honorem eidem conferre Ecclesie et sacro eorumdem fratrum nostrorum collegio, qui hoc asserit taliaque seminare presumit, nam nos etiam experimento cognovimus, quod idem cardinalis, audita morte dicti Andree regis, multa signa displicentie grandis ostendit et vehementis indicia doloris expressit. 
Der Papst reagierte schnell und designierte am 27. Oktober zwei Kardinäle, die als Legaten vor Ort Licht in das neapolitanische Verschwörungsdunkel bringen sollten ${ }^{595}$. Dem Rektor der Mark Ancona, Johannes de Ripparia, wurde am 5. November 1345 deren Kommen angekündigt. Für diese Funktion vorgesehen waren die beiden Kardinalpresbyter Pierre Bertrand d. Ä. und Bertrand de Deux ${ }^{596}$. Mit der Person des Pierre Bertrand sollte auf kardinalizisches Urgestein zurückgegriffen werden - immerhin war er 1346 bereits 15 Jahre lang Mitglied des illustren Kollegs. Weshalb man an der Kurie schließlich von einer Entsendung dieses Purpurträgers absah, ist nicht bekannt. Anzunehmen ist jedoch, daß das vorgerückte Alter und eine schwache Gesundheit mit dafür verantwortlich waren ${ }^{597}$. Anders im Falle des Bertrand de Deux: Seine Ernennung zum Kardinal durch Papst Benedikt XII. 1338 war bereits als Anerkennung für erbrachte legatorische Leistungen erfolgt, hatte er, zu dieser Zeit Erzbischof von Embrun, doch von 1333 bis 1337 als päpstlicher Legat in Neapel, Sizilien und den Territorien des Kirchenstaates durchaus erfolgreich amtiert. Mit den verworrenen Verhältnissen in der Region war er also bestens vertraut ${ }^{598}$.

Bis zur endgültigen Entsendung sollte jedoch noch fast ein Jahr vergehen. Immerhin waren die Planungen im März 1346 bereits so weit fortgeschritten, daß Bertrand zum legatus et reformator in Tuscia et aliis terris, civitatibus et provinciis Italiae, E.R. subjectis ernannt werden konnte. Zeitgleich erfolgte

595 Ibid., n. 2073.

596 Lettres Clément VI autres que la France, n. 817 (05.11. 1345; nur Regest); vgl. RV 139, n. 585, fol.149r: Laboriosas sollicitudines, quas circa tui regimen officii ac honores et iura Ecclesie Romane in Anconitan. Marchia, cuius Rector existis, conservanda et manutenenda sicut ad nos pervenit sepius relatibus fidedignis adhibuisti hactenus et adhibere fideliter et constanter non cessas, multipliciter in Domino commendantes discretionem tuam solicitantes circa hoc exhortamur attente, quatinus diligenter attendens, quod perseverantibus coronam glorie veritas repromittit in huiusmodi tuis laudandis operibus assendendo ad cor altum virtuosius perseveres. Nos equidem tibi oportunis assistemus favoribus et assisti per dilectos filios nostros Petrum Sancti Clementis et Bertrandum Sancti Marchi tit. presbiteros cardinales apostolice sedis legatos profecturos in proximo ad partes Italie faciemus. Das Kommen von Bertrand de Deux allein wird in Briefen vom 2. Mai 1346 angekündigt, vgl. ibid., nn. $974 f$.

597 Pierre Bertrand stirbt denn auch bereits im Juni 1348 wohl an den Folgen der Pest, vgl. Biogramm, Kap. 9.2.36. Das bei der Ernennung von Legaten zu beachtende Zeremoniell sah solche Fälle vor, vgl. DYKMANs, Cérémonial II, S. 497.

598 Vgl. Kap. 9.2.9. mit dem Biogramm des Kardinals. Die päpstlichen Register überliefern die Fakultäten für eine Bertrand de Deux im Mai 1344 übertragene Legation nach Mallorca und Aragon vgl. Lettres Clément VI autres que la France, n. 500-529 (12.05.1344), des weiteren Lettres Clément VI, nn. 820 (12.05.1344), 892 (09.06.1344), 896 (12.06.1344), 897 (12.06.1344), 926 (28.06.1344), 928 (28.06.1344). Vor der Übertragung der Legation nach Neapel wurde Bertrand de Deux zusammen mit Kardinal Guillaume d'Aure Ende 1344 mit der Untersuchung häretischer Gruppierungen in der Lombardei betraut, vgl. ibid., n. 1290 (29.11.1344). Noch im Februar 1346 untersuchen die Kardinäle Bertrand de Deux und Gui de Boulogne Vorkommnisse im Bistum Lüttich, vgl. ibid., n. $2330(24.02 .1346)$. 
die Ernennung zum legatus et reformator im Königreich Sizilien ${ }^{599}$. Deutlich wird aus dem Ernennungsschreiben, daß man sich an der Kurie der problematischen Situation in Neapel wohl bewußt war, daß vom Legaten ungleich mehr als die Überführung der Mörder des Andreas von Ungarn erwartet wurde ${ }^{600}$. Alle Bewohner des Königreichs wurden dazu aufgefordert, Bertrand ehrenvoll zu empfangen und ihm jedwede Unterstützung zuteil werden zu lassen ${ }^{601}$. Weshalb sich die Abreise des Bertrand bis in den August hinein verzögerte, wird aus dem kurialen Quellenmaterial nicht recht ersichtlich. In ihm werden zur Begründung der Verzögerung pauschalierend die unbeständige Witterung und andere nicht näher spezifizierte Hindernisse angeführt. Die Entsendung des Ildebrandinus Conti, Bischof von Padua, Mitte Juni nach Neapel muß vor diesem Hintergrund als Verlegenheitslösung gewertet werden ${ }^{602}$. Die offiziel-

599 Ibid., nn. 2364, 2369 (nur Regest); vgl. RV 169, n. 6, fol. 20v: [...] Sane dum consideramus statum et dispositionem regni Sicilie et terrarum ipsius regni citra Farum ad nos et Romanam Ecclesiam directo et alto dominio pertinentium variis et procellosis commotionibus et turbinibus fluctuare, dum inter nobiles et potentes ac universitates eiusdem regni odia, dissensiones et partialitates admodum periculosas fore sentimus, dum continuatis querelis audimus ibidem crassari, latronum, predonum et publicorum itinerum aggressorum multitudinem cotidie prodolor excrescentem, qui non solum libere et impune committunt rapinas et homicidia publice, verum etiam ad sacras edes et res ecclesiasticas invadendas et occupandas manus sacrilegas et raptrices extendunt, non parcentes etiam statui, sexui vel etati, et quod deterius est, hii, qui eos prosequi studiis indeffessis pro bono rei publice et totius Regni predicti statu pacifico poterant et debebant in offensionem Dei animarumque ipsorum periculum illos protegunt et deffendunt, dum clerum regni predicti in prelibet ad inordinata prolapsum reformatione et ecclesias, monasteria aliaque loca ecclesiastica secularia et regularia potentum oppressione in suis bonis et iuribus multipliciter deformata et lea relevatione et defensione conspicimus indignere, dum precipue attendimus propter horribilem et inauditam Deo, nobis et hominibus detestabilem mortem clare memorie Andree Regis Sicilie multorum corda non immerito zelus noster et ignis in nostre meditationis anxietatibus exardescit moventur nostra in commotione filiorum precordia et in eorum turbatione paterna viscera colliduntur ac dolentes de commissis preteritis nec minus de futuris discriminibus ac periculis probabiliter dubitantes, cogitationibus profundis immergimur et laboriosis anxietatibus vigilamus, querentes opportunum per nos et alios in tantis necessitatibus et periculis remedium adhibere demumque interna meditatione pensantes, quod in rebus subiectis occulis clarius agitur, consultius proceditur et salubrius providetur, quodque quocumque potentia nostra protenditur ibi corporali presentia esse nequimus cogimur illius exemplo, qui et si ubique stabilis manens dat cuncta moveri et facit spiritus suos angelos et ministros per alios, qui vocati sunt in partem sollicitudinis, quod nobis incumbere noscitur adimplere, qui supplentes laudabiliter vices nostras indirecta dirigant et aspera in plana convertant [...]. Bertrands Legation behandeit ausführlich LEONARD, Jeanne, I, S. 592-656; II, S. 90-195; vgl. auch BaLUZE/MOLlat, Vitae I, S. 267.

600 Seine Vollmachten erstreckten sich bezeichnenderweise weder auf die Königin selbst, noch auf Catherine de Courtenay, die Mutter Ludwigs und Roberts von Tarent.

601 Lettres Clément VI autres que la France, n. 930 (15.03.1346); ibid., nn.2364-2368, 2370 (15.03.1346).

602 Lettres Clément VI, n. 2572 (15.06.1346; nur Regest); vgl. RV 140, n. 101, fol.31r: [...] Et licet nos pro reformatione regni et terrarum predictorum ac huiusmodi odiis, dissensionibus, emulationibus et discordiis extirpandis aliisque arduis negociis dilectum filium nostrum Bertrandum tit. Sancti Martini presbiterum cardinalem commissi sibi per nos in illis partibus 
le Beauftragung und Verleihung der Fakultäten erfolgte am 31. Juli $1346^{603}$. Der Bestand an Vollmachten orientierte sich dabei klar an den bereits Guillaume Court und Aimeric de Châtelus gewährten Fakultäten - mit einer Ausnahme. In Zusammenhang mit den Bertrand de Deux zustehenden Prokurationen verzichtete man darauf, von procurationes consuete zu sprechen, und zog die Nennung einer konkreten Summe vor. Der Kardinal hatte Anrecht auf 40 Florin täglich. Gesorgt wurde ebenfalls für die entsprechenden Zensurfakultäten, mit denen er seine Ansprüche im Ernstfall durchsetzen konnte ${ }^{604}$.

Die Abreise aus Avignon erfolgte unmittelbar nach der Beauftragung ${ }^{605}$. Im Vordergrund stand zunächst die Beruhigung der nicht zuletzt wegen des Mordes an Andreas von Ungarn gespannten Lage in Neapel ${ }^{606}$. Dies hinderte die Kurie jedoch nicht daran, dem Kardinallegaten bereits auf seinem Weg Aufträge zur Friedensvermittlung zu erteilen. Die Stadt Genua sollte von einem Angriff auf das Gebiet um Ventimiglia, das nominell der Herrschaft Neapels unterstand, abgehalten werden. Dieses Ziel glaubte man an der Kurie durch die Präsenz eines hochrangigen Vertreters vor Ort besser erreichen zu können. Das Kommen des Kardinals wurde für Mitte August angekündigt,

plene legationis officio ad partes providerimus destinandum, quia tamen propter intemperiem aeris et alias causas rationabiles nequit sic celeriter eundi ad partes predictas arripere iter suum [...]. Vgl. zum Bischof Bernd-G. KoHL, Art. Ildebrandinus Conti, in: DBI 28 (1983), Sp. 438-441.

603 Lettres Clément VI autres que la France, nn.1082-1145. Nur einen Tag zuvor war Bertrand zusätzlich zum Generalvikar in partibus Italiae und reformator in temporalibus für das Königreich Sizilien ernannt worden, vgl. Lettres Clément VI, nn.2399, 2406 (30.03.1346), Alain de BoüARD, Le régime politique et les institutions de Rome au Moyen Âge (1252-1347), Paris 1920, S. 335, n. 40; Guillaume Mollat, Origine de la fonction de vicaire général au temporel dans les états de l'Église (1346-1348), in: Comptes rendus de l'Académie des inscriptions et belles-lettres 27 (1964), S. 164-168. Nachgeschoben werden in Neapel noch weitere Fakultäten, vgl. Lettres Clément VI autres que la France, nn. 3087-3089 (31.01. 1347).

604 Ibid., nn. 1083, 1099, 1127, 1129. Nachgeschoben werden noch weitere Fakultäten, ibid., nn. 2689 (31.08.1346), 2716-2719 (10.08.1346), 2740 (18.08.1346).

605 Bei der am 6. November 1346 in Avignon stattfindenden Approbation Karls IV. zum römischen König taucht Bertrand nicht mehr als Teilnehmer auf, vgl. ScHRöDER, Protokollbücher, n. 109. Tatsächlich muß die Abreise Anfang August erfolgt sein, vgl. Lettres Clément VI, nn. 2699 (05.08.1346), 2705 (06.08.1346).

606 Lettres Clément VI autres que la France, n. 1246 (18. 10.1346). Processus generales gegen die Mörder Andreas' waren vom Papst in Anwesenheit der Kardinäle in einem öffentlichen Konsistorium bereits im Februar beschlossen worden. Interessanterweise unterschied sich die von den Kardinälen zu diesem Anlaß getragene offizielle Gewandung von der überlicherweise zu solchen Gelegenheiten verwendeten, vgl. BALUZE/MOLLAT, Vitae II, S. 369: Notandum tamen quod cardinalibus non erant parati, sed cum cappis laneis tantum pro eo quia fiebant processus generales contra incertos et non nominatos, vgl. zur liturgischen Gewandung (mit wertvollen Hinweisen zu dem von Kardinälen außerhalb des rein liturgischen Geschehens getragenen Ornat) Joseph BRAUN, Die liturgische Gewandung im Occident und Orient nach Ursprung und Entwicklung, Freiburg 1907; Karin STOLLEIS, Messgewänder aus deutschen Kirchenschätzen vom Mittelalter bis zur Gegenwart, Regensburg 2001. 
doch erst Ende des Monats traf Bertrand in Genua ein ${ }^{607}$. In der Zwischenzeit hatten ihn noch andere Aufträge erreicht. Auch in Siena sollte er als pacis angelus wirken und damit einen substantiellen Beitrag zur Versöhnung der miteinander verfeindeten Stadtgeschlechter, insbesondere der Salimbene und der Tolomei, leisten ${ }^{608}$. In Benevent sollte er eine Definierung der strittigen Stadtgrenzen herbeiführen, gleichsam als oberster Landvermesser agieren - eine Aufgabe, der er nicht nachkam ${ }^{609}$. In der Mark Ancona wurde von ihm erwartet, zusammen mit dem unglücklich agierenden Rektor Johannes de Ripparia gegen die Umtriebe lokaler Tyrannen vorzugehen ${ }^{610}$. Offensichtlich setzte man in Avignon großes Vertrauen in die Fähigkeiten des neuen Legaten. Die Last des Amtes wurde ihm durch die Verleihung eines hospitium in Orvieto auf Lebenszeit versüßt ${ }^{611}$.

Ab Mitte August ist eine Fülle von Briefen nachweisbar, die von der Kurie nach Neapel abgingen. In ihnen wurde insbesondere die Königin dazu aufgefordert, Bertrand de Deux nach Kräften zu unterstützen ${ }^{612}$. Im politischen oder eher privaten - Kalkül Johannas I. war in der Zwischenzeit das Interesse an einer lückenlosen Aufdeckung des Mordes an ihrem Gatten erlahmt. Im Vordergrund stand jetzt die Absicht, vom Papst die notwendigen Dispense zu erhalten, um eine zweite Ehe eingehen zu können ${ }^{613}$. An der Kurie war man

607 Lettres Clément VI, nn. 2705 (06.08.1346), 2712 (09.08.1346), 2758 (26.08.1346). Die Streitigkeiten Johannas mit Genua um die Herrschaft über Ventimiglia wurden erst 1350 beigelegt, vgl. ABULAFIA, The western mediterranean kingdoms, S.163; grundsätzlich Steven A. EPSTEIN, Genoa and the Genoese 958-1528, Chapel Hill, London 1996, S. 155-179. 608 Lettres Clément VI, nn. 2738, 2739 (18.08.1346).

609 Ibid., n. 2772 (01.09. 1346). Noch im November des folgenden Jahres mahnt ihn Clemens VI. zur Erfüllung seiner Pflichten, vgl. ibid., n. 3592 (12.11.1347). Wahrscheinlich erinnerte sich Bertrand de Deux noch an die Bemerkung des Papstes vom Mai 1347, daB negocium inquisitionis predicte [gemeint ist die Untersuchung über den Tod des Andreas] preferendum est, et cum diligentia oportuna et celeri, prout premisimus, exequendum, vgl. ibid., n. 3267 (03.05. 1347; nur Regest); THEINER, Monumenta Hungariae, I, n. 1111, S. 740 f. 610 Lettres Clément VI, n. 2819 (20.09.1346).

611 Ibid., n. 2754 (23.08.1346; nur Regest); vgl. RV 140, n. 435, fol. 101v: Grandia virtutum tuarum merita, quibus ecclesiam Romanam tamquam honorabile membrum ipsius honorare continue non desistis exposcunt, ut te prerogativa specialis favoris et gratie prosequamur, cum itaque quoddam hospitium nostrum et Ecclesie Romane situm in civitate Urbevetana per aliquos romanos pontifices predecessores nostros quibusdam eisdem ecclesie Romane cardinalibus concedi sicut intelleximus consueverit tenendum, regendum et inhabitandum ad vitam pro ipsorum libito voluntatis illudque ultimo bone memorie Johannes Sancti Theodori diaconus cardinalis ex concessione felicis recordationis Johannis pape XXII predicte nostri tenuisse dicatur, nos ob tuorum exigentiam meritorum huiusmodi personam tuam honorare volentes, dictum hospitium per te tenendum, regendum et habendum cum omnibus iuribus et pertinentiis suis quamdiu vitam egeris in humanis liberaliter duximus concedendum. 612 Lettres Clément VI, nn. 2720 (10.08.1346), 2721 (10.08.1346).

613 Ibid., n. 2699 (05.08.1346): [...] Preterea consideramus et attendimus super hiis precipue honorem et decentiam status tui esse, quidem infra tempus vidualis luctus adhuc dinosceris constituta, infra quod decentia suadet honestis et honorabilibus viduatis mulieribus a secundis nuptiis abstinere [...] ; vgl. auch ibid., n. 2848 (08. 10. 1346), wo der Papst die gewünsch- 
weder von dem einen noch von dem anderen begeistert ${ }^{614}$. Dem Legaten wurde eingeschärft, die Umstände, die zum Tod des Andreas geführt hatten, gegen alle Widerstände gewissenhaft zu untersuchen und dabei auch vor der Person der Königin selbst nicht haltzumachen ${ }^{615}$. Für Beunruhigung sorgte in Avignon nicht nur das deutlich spürbare Desinteresse Johannas an einer Aufklärung, sondern auch das allzu lebhafte Interesse des Königs von Ungarn an einer Überführung der Schuldigen. Ganz offenbar mißtraute man in Ungarn dem vom Papst zur Klärung der Vorwürfe eingesetzten Bertrand de Baux mit der Begründung, dieser sei als Vasall Johannas nicht unabhängig616. In Neapel selbst waren es zu dieser Zeit die als Nuntien vor Ort entsandten Bischöfe von Padua und Chartres, die quasi in Vertretung des Kardinallegaten agierten. Von ihnen wurde erwartet, den Zugang zur Königin zu kontrollieren und sie am Verlassen des Palastes zu hindern ${ }^{617}$ - Maßnahmen, die nicht dazu angetan waren, die ohnehin gespannte Situation zu entkrampfen.

Bertrand de Deux erreichte Neapel am 20. November 1346. Mit Recht konnte er als Grund für sein langes Ausbleiben die bereits vom Papst bemühte unbeständige Witterung anführen. Damit untertrieb er, war das Schiff, dem er sein Geld und andere wertvolle Besitztümer anvertraut hatte, doch vor Rom in Seenot geraten und anschließend ausgeplündert worden ${ }^{618}$. Seine

ten Dispense erneut verweigerte und außerdem verfügte, Robert von Tarent den Zutritt zum Palast so lange zu verweigern, bis Bertrand de Deux in Neapel eingetroffen sei. Letzterem wurde denn auch zeitgleich mitgeteilt, er möge im Königspalast Quartier nehmen, ibid., n. 2854 (08.10.1346). In der Zwischenzeit hatte Johanna jedoch selbst die Initiative ergriffen, Robert von Tarent am Betreten des Palastes gehindert, einen Brief an Bertrand de Deux in Siena gerichtet und ihn darum gebeten, sich so schnell wie möglich nach Neapel zu begeben, vgl. LEONARD, Jeanne, I, S. 614.

614 Vor ihrem Bruch mit Robert von Tarent hatte sich Johanna in Briefen nicht nur an den Papst, sondern auch an die Kardinäle Jean de Comminges, Hugues Roger und Gui de Boulogne mit der Bitte um Beförderung des Heiratsprojektes gewandt, vgl. LEONARD, Jeanne, II, S. 437 (pièces justificatives).

615 Lettres Clément VI, n. 2769 (31.08.1346). Ein Duplikat dieses Briefes wurde erneut fünf Tage später abgesandt, ibid., n. 2784 (04.09.1346). Dies war kein Einzelfall, wollte man an der Kurie doch sicher gehen, daß wichtige Informationen den Empfänger tatsächlich auch erreichten.

616 Ibid., n. 2770 (31.08.1346). Bertrand de Baux wurde in der Folge Verschleppung der Untersuchungen zugunsten der Königin unterstellt, ibid., nn. 294-2946 (25.11. 1346); vgl. zur Person Gustave Noblemaire, Histoire de la maison des Baux, Paris 1913, bes. S. 58-65; generell Florian MAZEL, La noblesse et l'Église en Provence (fin Xe-début XIVe siècle). L'exemple des familles d'Agoult-Simiane, de Baux et de Marseille, Paris 2002.

617 Lettres Clément VI, n. 2919 (29.10.1346); dazu auch ibid., n. 3086 (31.01.1347). Bertrand wurde damit beauftragt, Johanna dazu zu bewegen, suspekte Personen aus ihrer Umgebung zu entfernen, ibid., n. 3090 (31.01.1347).

618 Ibid., n. 3081 (27.01.1347; nur Regest); vgl. RV 140, n. 943, fol. 213v (gerichtet an Raimundus, den vicarius in spiritualibus in Rom): Pertulit ad nostri apostolatus auditum relatio fidedigna, quod cum dilectus filius noster Bertrandus tit. S. Marchi presbiter cardinalis, apostolice sedis legatus, certa bona sua tam in pecuniis quam rebus aliis consistentia in quadam Galea deferri faceret ad partes regni Sicilie, ad quas se pro exercendo commisso sibi per nos 
Versuche, wieder in den Besitz seines Eigentums zu gelangen, waren bisher erfolglos geblieben. In Neapel machte er den Königspalast zu seiner offiziellen Residenz und entsprach damit den Wünschen sowohl des Papstes als auch der Königin. Seinen Machtanspruch führte er allen sogleich deutlich vor Augen, wurde auf sein Betreiben hin doch eine der engsten Vertrauten der Königin, Sancia de' Cabanni, die der Mitwisserschaft am Tode des Andreas beschuldigt worden war, Ende Dezember hingerichtet. Der an der Kurie schon seit längerem gehegte Wunsch eines von allen Untertanen zu leistenden Treueids gegenüber Karl Martell, dem Sohn der Johanna und des Andreas, wurde ebenso realisiert wie die Revindikation der von Johanna seit dem Tode König Roberts ausgegebenen Güter und Schenkungen ins königliche Domanialgut. Für den Kardinallegaten fiel die Bilanz zum Jahresende also durchaus positiv aus.

Von schnellen Erfolgen verwöhnt, ließ es Bertrand in der Folge jedoch an der notwendigen Energie mangeln, die nötig gewesen wäre, um den Mord an Andreas den Vorstellungen der Kurie und Ungarns entsprechend lückenlos aufzuklären. Bereits im Februar 1347 mahnte der Papst, daß es von allergrößter Wichtigkeit sei, die Untersuchungen auch auf die Königin und die Prinzen auszudehnen. Er, der Papst, wolle zwar nicht, daß Bertrand sein Leben aufs Spiel setze, wenn aber eine ordentliche Untersuchung im Palast oder auf dem Gebiet Neapels nicht möglich sei, dann rate er diesem, sich an einen sichereren Ort zu begeben ${ }^{619}$. Nicht nur in dieser Angelegenheit sollte Bertrand entschlossener agieren. Die Erwartungshaltung der Kurie trat am eindrücklichsten in denjenigen Briefen in Erscheinung, in denen der Papst zu zahlreichen Fragen seines Legaten Stellung bezog ${ }^{620}$. Neben der erwähnten Untersuchung übertrug er ihm die Sorge um die Zukunft des jungen Karl Martell, die Lösung der sich aus dem Heiratswunsch Johannas ergebenden Probleme und

ibidem legationis officio conferebat, eademque Galea passa casu fortuito naufragium ad plagam Romanarum partium cum bonis et rebus huiusmodi applicaret, dilectus filius nobilis vir Martinus Francisci, quondam Stephani Gaetani de Urbe bona cepit et occupavit predicta eaque dicto legato restituere indebite contradicit. Quacirca Fraternitati Vestre per apostolica scripta committimus et mandamus, quatinus vos vel alter vestrum per nos vel alium seu alios simpliciter et de plano sine strepitu et figura iudicii super predictis informare solerti et fideli adhibita diligentia procurantes, si per informationem huiusmodi vobis constiterit de premissis eundem nobilem et quosvis alios clericos et laicos cuiuscumque status, ordinis, dignitatis vel conditionis existant, etiam si pontificali vel quavis alia prefulgeant dignitate, qui bona predicta ceperunt, habuerunt vel ad quorum manus pervenerint ad ea dicto legato vel eius certo procuratori restituenda et assignanda previa monitione auctoritate nostra per censuram ecclesiasticam appellatione postposita compellatis [...]; dazu auch Lettres Clément VI, n. 3251 (27.04.1347).

619 Ibid., n.3121 (17.02.1347): [...] Rursum multum expedit, quod inquisitio diligens et fidelis super nece dicti Andree regis juxta tenorem litterarum nostrarum inde tibi directarum contra prefatam reginam et regales solerti adhibita diligentia per te fiat, nostre tamen intentionis existit, quod personam tuam non exponas propterea periculis quovis modo, sed, si forsan in castro vel civitate Neapolitana aut dominio dicte regine secure vel comode super hiis procedi non possit, necessarium est alibi fieri, ubi tua prudentia viderit expedire [...]. 620 Ibid., nn. 3090 (31.01.1347), 3121 (17.02.1347), 3330 (21.06.1347), 3448 (15.09.1347), $3786(23.03 .1348)$. 
schließlich das Hinarbeiten auf eine Versöhnung Neapels mit Ungarn. Daneben oblag dem Legaten die Sorge um das verwaltungspolitische Tagesgeschäft, darunter so sensible Punkte wie die Verwaltung der Einkünfte und die Personalpolitik ${ }^{621}$. Wird von der fehlenden Energie des Kardinals gesprochen, sollte keinesfalls vergessen werden, daß es sich bei ihm, dem ranghöchsten päpstlichen Vertreter vor Ort, um einen kranken Mann handelte. Fortgesetzte Gichtanfälle dürften ihm die Erfüllung seiner Aufgaben nicht leichter gemacht haben ${ }^{622}$. Was seine Arbeit jedoch in jedem Fall behinderte, war die Konkurrenz zu anderen päpstlichen Beauftragten vor Ort: zu Bertrand de Baux, der wie er selbst mit der Untersuchung des Prinzenmordes betraut war, und zu den beiden anderen Nuntien, den Bischöfen von Chartres und Padua. Aus den päpstlichen Schreiben wird deutlich, daß ein Informationsaustausch zwischen ihnen nur sporadisch stattfand. Ganz offensichtlich favorisierte man an der Kurie eine Art Doppeldiplomatie, an deren Spitze zwar nominell unangefochten der Kardinallegat stand, die gegenseitiges Abstimmen über das jeweilige Vorgehen jedoch vermissen lie ${ }^{623}$. Immerhin wurde die Kurie dadurch in die vorteilhafte Lage versetzt, Informationen aus erster Hand in unterschiedlicher "Färbung « geliefert zu bekommen.

Im Mai verdichteten sich die Gerüchte über eine bevorstehende Invasion Neapels durch Ludwig von Ungarn. Selbst Karl IV. wurde jetzt als Schwager des ungarischen Königs vor den Karren der päpstlichen Diplomatie gespannt, um das Schlimmste zu verhindern ${ }^{624}$. Gleichzeitig ergingen dringende Mahnungen an Königin Johanna, Untersuchungen bezüglich des Todes ihres Gatten zu gestatten, um Ludwig von Ungarn nicht unnötig herauszufordern ${ }^{625}$. Schnelligkeit war vonnöten. Ungünstig wirkte sich in dieser Situation jedoch die Beschäftigung unterschiedlicher Personen mit ein- und demselben Sachverhalt aus. Bertrand de Baux - zu diesem Zeitpunkt bereits im Besitz eines Untersuchungsberichts - hatte es nämlich bisher versäumt, diesen Bericht dem Kardinallegaten zukommen zu lassen ${ }^{626}$.

621 Vgl. ibid., nn. 2975, 2997, 3019, 3021, 3030, 3035, 3119, 3138, 3560.

622 Ibid., n. 3090 (31.01.1347): [...] Tu vero circa predicta et alia incumbentia tibi negocia laborare, prout cepisti laudabiliter et utiliter, assistente tibi divina gratia, non omittas de persona tamen tua et eam non exponas ultra quam pati possis laboribus nichilominus curam gerens. Nos quidem tibi paterno more compatimur super passione podagrica, qua te gravatum fuisse displicenter audivimus hiis diebus. Et audito nichilominus, quod laborare non desinebas propter gravamen hujusmodi tuam circumspectam et providam diligentiam ducimus non indigne commendationum titulis attollendam [...].

623 Ibid., nn. 3122 (17.02. 1347), 3124 (17.02. 1347), 3238 (21.04.1347), 3270 (03.05.1347).

624 Ibid., n. 3267 (03.05.1347); dazu auch KLICMAN, Acta Clementis VI, S. 511, n. 876.

625 Lettres Clément VI, n. 3268 (03.05.1347).

626 Ibid., n. 3270 (03.05.1347); dazu auch ibid., n. 3267 (03.05.1347)(nur Regest), Text bei August Theiner (Hg.), Vetera monumenta historica Hungariam sacram illustrantia, Bd.1, Rom 1859, n.1111, S.740f.: Der Papst bedauert darin, Bertrand de Baux non satis invective dazu aufgefordert zu haben, ut processus per eum habitos contra patratores et conscios mortis clare memorie Andree Regis Sicilie tibi communicet integraliter et faciat copiam de eisdem. 
An der Kurie war man mit dem Vorgehen des Legaten höchst unzufrieden. Diese Unzufriedenheit, ja Empörung über das abwartende und durchweg reaktive Verhalten zeigt sich am eindrücklichsten in einem Brief, den der Papst am 3. Mai 1347 nach Neapel schickte. Er verzichtete darin auf die im Briefverkehr mit Legaten sonst üblichen Wendungen und Höflichkeitsformeln und bediente sich statt dessen eines Tons, der an Schärfe seinesgleichen sucht. Insbesondere mit zwei Kritikpunkten wurde Bertrand de Deux konfrontiert. Der Papst gab seinem Erstaunen darüber Ausdruck (rursus miramur admodum), daß seiner ausdrücklichen Anweisung bisher noch nicht Folge geleistet worden sei, mit den geistlichen und weltlichen Entscheidungsträgern des Königreichs über eine mögliche Abwehr des Königs von Ungarn zu beraten. Kritisiert wurde die vom Legaten übernommene Rolle eines schwachen und zur Handlungsunfähigkeit verdammten Dulders. Des weiteren stieß bei Papst und Kardinälen der offensichtliche Unwille des Legaten auf Kritik (preterea nostre ac fratrum eorundem admirationi adicit), die Untersuchung der Umstände des Todes von Andreas von Ungarn wirkungsvoll voranzutreiben. Beiden Anklagen zugrunde lag die Untätigkeit des Legaten, die ihn nicht nur daran hinderte, die politische Initiative zu ergreifen, sondern den Briefverkehr mit der Kurie auf ein nicht mehr tolerierbares Minimum beschränkte. Vor diesem Hintergrund wird das Bemühen der Kurie verständlich, sich anderer Informationskanäle, sprich weiterer diplomatischer Vertreter vor Ort, zu bedienen. Im letzten Satz des Briefs wurde die Bedeutung eines regen Informationsaustauschs noch einmal auf rüde Weise unterstrichen. Wenn er, der Papst, sich schon nicht scheue, eigenhändig Brief auf Brief zu verfassen, könne man doch wohl auch erwarten, daß der stilus scribendi des Legaten sich etwas lebhafter gestalte - non sit piger. Clemens VI. ersetzte hier das $t u$ des Legaten durch ein stilus scribendi und vermied so vordergründig die Verbindung von Person und pejorativem Adjektiv. Doch genau dies dürfte beabsichtigt gewesen sein. Die Untätigkeit des Legaten war an der Kurie zum Ärgernis geworden, inertia war zur Faulheit, pigritia, mutiert ${ }^{627}$.

Man scheute sich nun auch nicht mehr, bereits ergangene Maßnahmen des Legaten zu kritisieren. So mußte er die von ihm im Patrimonium Beati Petri in Tuscia und im Dukat von Spoleto vorgenommenen Personalentscheidungen widerrufen, weil er damit - so der Vorwurf aus Avignon - seine Kompetenzen

${ }^{627}$ Lettres Clément VI, n. 3267 (03.05.1347; nur Regest); Text bei ThEINER, Monumenta Hungariae, I, n.1111, S.740f.: Demum cum sepe per litteras diversas etiam manu nostra sub occultis nominibus quandoque confectas tibi super diversis scripserimus, veremur, an ad manus tuas littere pervenerint supradicte: quapropter tam super premissis et eorum singulis, quam aliis, que tibi occurrerint nuncianda, stilus scribendi, quando et quociens oportunum cognoveris, non sit piger. Léonard bemerkt zu diesem Brief: »La lettre que Clément VI envoya au légat est un véritable coup de fouet. L'expression est dure, mais la prose pontificale l'est encore plus. Le dernier mot en est un reproche: piger, paresseux, et s'il ne s'adresse, en apparence, qu'au zèle épistolaire du cardinal, c'est bien, en fait, toute sa conduite qu'il

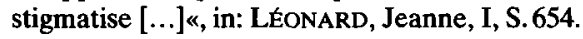


weit überschritten habe ${ }^{628}$. Die von der Kurie ausgehenden, immer ausführlicher werdenden Anweisungen an den Legaten verdeutlichen, daß das Vertrauen in sein Verhandlungsgeschick massiv erschüttert war. Doch auch hier ergab sich das Problem, da $ß$ aufgrund der langen Übertragungswege nicht unmittelbar reagiert werden konnte - rund zwei Wochen benötigte ein Brief, um die Entfernung zwischen Neapel und Avignon zu überbrücken.

Dissens zwischen Papst und Legat bestand insbesondere in Hinblick auf die Heiratspolitik. Während Bertrand de Deux eine neue Heirat Johannas rundweg verwarf, war die Position des Papstes keineswegs eindeutig. Ursprünglich hatte auch er die Königin beschworen, auf eine neue Ehe zu verzichten und sich zunächst auf die Rolle als Witwe einzustellen ${ }^{629}$. Nach massiver Intervention des französischen Königs zugunsten Johannas war er jedoch dabei, seine Position zu überdenken. In diese Überlegungen wurde der Legat vor Ort einbezogen. Entspreche es denn wirklich der Realität, so der Papst, daß sich Neapel deshalb mit einer wirksamen Verteidigung gegen eine ungarische Invasion so schwer tue, weil Johanna eines Mannes an ihrer Seite entbehre ${ }^{630}$ ? In diesem Brief wird der Eindruck vermittelt, als zähle man in Avignon zur Lösung des Problems auf die Weitsicht und Erfahrung des Legaten, dem denn auch eingeschärft wurde, von seinen Vollmachten Gebrauch zu machen. Daß Bertrand de Deux an der Kurie jedoch nur eine Stimme unter vielen - und sicherlich nicht die bedeutendste - war, liegt auf der Hand. In die Angelegenheit der Stundung des von Neapel jährlich an die Kurie abzuführenden Cen-

628 Lettres Clément VI, n. 3320 (17.06.1347; nur Regest); vgl. RV 141, n. 45, fol.13v: der Vorwurf lautete: Tam de patrimonio beati Petri in Tuscia quam ducatu Spoletano et quasi omnibus aliis terris et provinciis Ecclesie Romane immediate subiectis in partibus Italie consistentibus ad nos insinuatio querulosa perduxit, quod ad importunitates multorum, per quas non concedenda sepius extorquentur quedam nova in Terris eisdem constituisti officia cum stipendiis de nostra camera persolvendis et pro antiquis officiis ab antiquo deputata stipendia nonparum auxisti et diversas personas tam in antiquis quam novis officiis huiusmodi cum eisdem stipendiis deputasti, rectoribus et thesaurariis terrarum et provinciarum ipsarum sub penis mandando formidabilibus, ut personis per te, ut premittitur, in predictis officiis constitutis de stipendiis satisfaciant supradictis [...]. Die Amtsanmaßung selbst wurde wie folgt charakterisiert: Nec nos audivimus, quod alii legati vel nuncii ad terras et provincias predictas per sedem apostolicam hactenus destinati de hiis, que tangunt Cameram predictam, absque mandato speciali se intromiserint nec ad deputationem officialium nisi causa subesset necessaria processerint quovismodo.

629 Dem Papst war klar, daß eine zweite Ehe Johannas wohl nicht zu verhindern sei, vgl. Lettres Clément VI, n. 3267 (03.05.1347; nur Regest), Text bei THEINER, Monumenta Hungariae, I, n. 1111, S. 740f.: der Legat wird aufgefordert, die Königin dazu zu bewegen [...] ut libenter et gratanter inquisitioni consentiat faciende, seque decenter, pacienter et honeste in sua viduitate teneat, quousque sedato vel mitigato huiusmodi negocio aliud possit pro statu suo, sicut decet, honorabiliter et utiliter ordinari.

630 Lettres Clément VI, n. 3330 (21.06.1347): [...] Et insuper, quid tibi super licentia et dispensatione pro parte dicte regine sepius postulatis, ut matrimonium contraheret, concedendis expediens videretur, presertim cum tam per carissimum in Christo filium nostrum Philippum, regem Francie illustrem quam quosdam alios nobis imputari dicatur ex eo quod indefensio dicti regni, quod regina ipsa viro caret, qui defensionis hujusmodi caput esset [...]. 
sus scheint der Kardinal lediglich als Erfüllungsgehilfe der in Avignon nach Separatverhandlungen mit Königin Johanna erreichten Ergebnisse involviert gewesen zu sein ${ }^{631}$. Er war genausowenig wie der Papst in der Lage, die Entscheidungen der auf ihre Unabhängigkeit bedachten Königin zu beeinflussen oder gar zu steuern. In Avignon selbst war man dazu gezwungen, sich weiterer flankierender diplomatischer Maßnahmen zu bedienen. Nach der Ablehnung einer neuen Ehe durch die Johanna ansonsten treu ergebenen Provenzalen rief man eine unter Vorsitz des Erzbischofs von Bordeaux tagende Versammlung ein, an der neben Adligen und Funktionsträgern mit Philip de Sanguineto auch der Seneschall der Provence teilnahm. Auf dieser Versammlung wurde insbesondere gegen die Übergriffe Ludwigs von Tarent in Neapel beredt Klage geführt. Die Reaktion erfolgte unmittelbar: Bertrand solle seinen Einfluß sowohl bei der Königin als auch bei Ludwig von Tarent efficaciter geltend machen ${ }^{632}$. Mitte September war die Bedrohung aus Ungarn noch stärker geworden. Anstelle eines überstürzten Aktionismus setzte man an der Kurie jedoch auf Konsultationen, die der Legat cum peritioribus dicti Regni, quos illius maxime status prosperi cognoveris amatores aufnehmen solle ${ }^{633}$. Damit wurde der Forderung, Bertrand solle wegen der eklatanten politischen Unfähigkeit Johannas die Zügel in die Hand nehmen, etwas von ihrer Schärfe genommen. Eine unmittelbare Einflußnahme des Legaten war schon zu diesem Zeitpunkt illusorisch, hatte er doch bereits Vorbereitungen zur Abreise aus der von ihm als unsicher und bedrohlich wahrgenommenen Stadt getroffen. Bereits Anfang Oktober datierte er Briefe in S. Gimignano, Anfang November in Montefiascone ${ }^{634}$.

Nicht erst als sich das Scheitern des Legaten in Neapel deutlich abzeichnete, richtete sich das Augenmerk des Papstes auf einen weiteren Brennpunkt seines Interesses, nämlich Rom, wo dem Treiben des Volkstribunen Cola di Rienzo Einhalt geboten werden sollte ${ }^{635}$. Dieser hatte in einem Handstreich

631 Ibid., nn. 3346, 3347 (06.07.1347).

632 Ibid., n. 3427 (03.09.1347).

633 Ibid., n. 3448 (15.09. 1347); vgl. auch ColA DI RIENZo, Briefwechsel, 5 Teile, hg.v. Karl BuRdaCH, Paul PIUR, Berlin 1913-1929, hier IV, n. 21, S. 55-57.

634 Lettres Clément VI, nn. 3592 (12.11.1347), 3625 (03.12.1347).

635 Ibid., n. 1480 (12.09.1347), n. 1503 (04.10.1346) mit der Aufforderung an den Legaten, die von Cola di Rienzo gefangengesetzten römischen Adligen zu befreien. Die Literatur zu Leben und Wirken Rienzos ist sehr umfangreich, maßgeblich ist nach wie vor Paul PIUR, Cola di Rienzo. Darstellung seines Lebens und seines Geistes, Berlin 1931; vgl. des weiteren Walther ReHM, Der Untergang Roms im abendländischen Denken. Ein Beitrag zur Geschichte der Geschichtsschreibung und zum Dekadenzproblem, Leipzig 1930 (ND Darmstadt 1969); Eugenio DUPRÉ-THESEIDER, Roma dal comune di popolo alla signoria pontificia (1252-1377), Bologna 1952, S. 517-649; Ludovico GaTTo, Storia di Roma nel Medioevo. Politica, religione, società, cultura, economia e urbanistica della Città Eterna tra l'avvento di Costantino e il saccheggio di Carlo V, Rom 1999, S. 453-471; Amanda CoLLINS, Greater than emperor. Cola di Rienzo (ca. 1313-1354) and the world of $14^{\text {th }}$ century Rome, Ann Arbor 2002; Ronald G. Musto, Apocalypse in Rome. Cola di Rienzo and the politics of the New Age, Berkeley 2003. 
am 20. Mai 1347 das Kapitol in seine Gewalt gebracht. Ziel der neuen Herrschaft war der von Ordnung und Gerechtigkeit geleitete »gute Staat«, den Rienzo durch legislative und judikative Maßnahmen zu verwirklichen suchte. Insbesondere der römische Adel hatte unter dieser Politik zu leiden. Sein $\mathrm{Au}$ genmerk richtete sich jedoch nicht nur auf Rom. Rienzo betrieb eine aktive Italienpolitik. Zahlreiche Sendschreiben wurden an die Stadtregimenter und Souveräne mit der Absicht gerichtet, diese zu einem gemeinsamen Vorgehen, zu einer Art nationaler Politik zu bewegen. Die Kurie in Avignon zeigte sich spätestens nach der am 1 . August im Lateran vorgenommenen und propagandistisch inszenierten Ritterweihe Rienzos in hohem Maße beunruhigt ${ }^{636}$. Auch der römische Adel konspirierte weiterhin, schloß sich zu einem Bündnis zusammen und versuchte vergeblich, Rienzo am 20 . November 1347 in der Schlacht an der Porta S. Lorenzo zu besiegen. Gestürzt wurde er erst Mitte Dezember von den eigenen Gefolgsleuten. Einer Verurteilung entzog er sich durch Flucht, die ihn zunächst in die Abruzzen, anschließend nach Prag zu Kaiser Karl IV. und Erzbischof Ernst von Pardubitz führte. Von Karl IV. wurde er an den Papst ausgeliefert. Den gegen ihn eröffneten Häresieprozeß überstand er unversehrt. Bereits Innozenz VI. griff 1354 auf die Fähigkeiten Rienzos zurück, stellte ihn dem Kardinallegaten Albornoz zur Seite und machte ihn zum Senator von Rom. Dort errichtete er ein auf Gewalt und Rachsucht basierendes Regiment, das nach nur zwei Monaten im Oktober 1354 mit seiner Ermordung ein Ende fand.

Auf Bertrand de Deux wartete also kein leichter Gegner: In der öffentlichen Meinung galt Rienzo als Initiator einer auf Restauration der antiken Größe Roms ausgerichteten Politik, dem man seine Exzesse nachsah ${ }^{637}$. Des Instruments der politischen Propaganda bediente er sich meisterhaft. In einem Brief vom 21. August 1347 wurde Bertrand vom Papst zum ersten Mal aufgefordert, sich persönlich nach Rom zu begeben - freilich nur, wenn dies die Situation in Neapel gestatte ${ }^{638}$. Mittels einer wahren Briefflut wurde von

636 Vgl. zum Verhältnis zwischen Clemens VI. und Cola di Rienzo Dupré-THESEIDER, I Papi di Avignone, S. 85-107. Rienzo war an der Kurie seit 1342 bekannt. Als Mitglied der römischen Gesandtschaft hatte er an den Verhandlungen teilgenommen, die zwar nicht zur Rückkehr des Papstes nach Rom, aber zur Verkündigung des Heiligen Jahres 1350 führten. In diesen Zeitraum fiel auch die Bekanntschaft mit Petrarca, der in Rienzo den geeigneten Mann sah, um Rom die alte Freiheit und republikanische Verfasssung wiederzugeben, vgl. hierzu Mario Emilio CosenZA, Francesco Petrarca and the revolution of Cola di Rienzo, Chicago 1913; Jaroslav MACEK, Petrarque et Cola di Rienzo, in: Historica 11 (1965) S. 5-51.

637 Serena Romano, Regio dissimilitudinis. Immagine e parola nella Roma di Cola di Rienzo, in: Bilan et perspectives des études médiévales en Europe, hg.v. Jacqueline HAMESSE, Louvain-la-Neuve 1995, S. 329-356.

638 Lettres Clément VI, n.3412 (21.08. 1347); vgl. auch BURDACH, Briefwechsel des Cola di Rienzo, IV, n. 15, S.38-41: [...] mandamus, quatenus ad dictam Urbem seu vicinas partes eidem, si tamen absque grave preiuditio commissorum tibi negociorum Regni Sicilie fieri possit, sine delatione qualibet studeas ad tempus aliquod te conferre [...]. An der Kurie hat- 
Avignon aus versucht, dem Legaten den Boden zu bereiten. Nicht weniger als 73 Empfänger - zumeist aus dem römischen Adel - sahen sich mit der Ankündigung des baldigen Eintreffens Bertrands und der Aufforderung konfrontiert, diesen in seinem Wirken zu unterstuitzen ${ }^{639}$. Bereits in Neapel war der Kardinallegat mit der Untersuchung der von Giovanni de Vico in und um Rom begangenen Greueltaten betraut worden ${ }^{640}$. Über die Situation in der Ewigen Stadt wurde er auf dem laufenden gehalten, ja dazu aufgefordert, sich der von Cola gefangengesetzten römischen Adeligen anzunehmen und einer Einverleibung der Städte des Patrimoniums und der Sabina entgegenzutreten ${ }^{641}$. Frucht dieser päpstlichen Einflußnahme aus der Ferne war eine Verleumdungskampagne, deren Opfer Bertrand wurde. Da sich der Papst demonstrativ vor den Legaten stellte, resultierte aus den aliqua nobis contra te relata et scripta kein weiterer Schaden ${ }^{642}$. Den ihm bereits in einer Fakultät vom 31. Juli 1346 zugestandenen Aufenthalt in der Ewigen Stadt hatte sich der Legat sicherlich anders vorgestellt ${ }^{643}$. Um Geld brauchte er sich zwar keine Sorgen zu machen, erging doch eine ergänzende Fakultät, die ihn in die Lage versetzte, finanzielle Mittel bei Bankhäusern aus Florenz, Lucca und Pistoia $\mathrm{zu}$ beanspruchen ${ }^{644}$, doch waren damit die politischen Probleme noch nicht gelöst. Immerhin gelang es Bertrand nicht zuletzt aufgrund der ihm zur Verfügung stehenden Mittel, zum Sturz Rienzos beizutragen und mit Bertold Orsini und Luca Savelli zwei dem Papst ergebene Senatoren einzusetzen.

Mit dem Sturz Rienzos entledigte er sich eines Widersachers, der - schenkt man dem Bericht des Anonimo Romano Glauben - ihm die größte Demütigung seiner bisherigen Laufbahn zugefügt hatte. Die kurz vor 1360 in Rom ge-

te man auch die Entsendung eines weiteren Kardinallegaten ins Auge gefaßt. Wiederholt wurde die Aufforderung rund drei Wochen später; Lettres Clément VI, n. 3450 (15.09.1347): Bertrand möge sich zur Überwachung Rienzos nach Rom begeben, oder, falls die Situation in Sizilien ihn an der Wahrnehmung dieses Auftrags hindern sollte, dies mitteilen, damit ein anderer Legat entsandt werden könne, zumal der für dieses Amt vorgesehene Matthäus von Verona in Folge einer Erkrankung seine Reise noch nicht habe antreten können.

639 Lettres Clément VI autres que la France, n. 1504 (04.10.1347).

${ }^{640}$ Lettres Clément VI, nn. $3295-3296$ (18.05.1347), 3632 (04.12.1347). Der Konflikt war auch im Mai des nächsten Jahres noch nicht gelöst, vgl. ibid., n. 3850 (07.05.1348), was freilich auch darin begründet lag, daß im Kardinalskolleg selbst Uneinigkeit hinsichtlich des weiteren Vorgehens herrschte. Auch die Einsetzung einer Kardinalskommission brachte zunächst keine Ergebnisse, vgl. ibid., n. 3853 (07.05.1348); vgl. zum Geschlecht der de Vico und ihrer Funktion als wichtigste Gegenspieler der weltlichen Ansprüche der Kirche Jean-Claude MAIRE VIGUEUR, Comuni e signorie in Umbria, Marche e Lazio (Storia d'Italia, hg. v. Giuseppe GaLasso, VII/2), Rom 1987, S. 321-606.

${ }^{641}$ Lettres Clément VI, nn. 3404 (02.08. 1347), 3412 (21.08. 1347), 3462 (19.09.1347), 3503

(07.10. 1347); vgl. auch BuRDACH, Briefwechsel des Cola di Rienzo, III, n. 37, S. 134.

${ }^{642}$ Lettres Clément VI, n. 3451 (15.09.1347).

${ }^{643}$ Lettres Clément VI autres que la France, n. 1137.

644 Ibid., n. 1515 (07. 10.1347); vgl. zur Geldproblematik auch ibid., nn. 3592, 3619, 3621, 3634-3638, 4762f. 
schriebene, volkssprachliche Chronik ${ }^{645}$, deren Autor trotz intensiver Bemühungen noch immer nicht identifiziert werden konnte ${ }^{646}$, entwirft - durchaus romzentriert - ein farbiges, ja poetisches Bild einer Epoche, die von der Ausnahmegestalt des Cola di Rienzo geprägt war. Bertrand de Deux als Legat des Papstes wurde als Eindringling empfunden, was Rienzo ihn offensichtlich spüren ließ. Folgt man der Chronik, ereignete sich folgendes: Rienzo erschien vom Legaten herbeizitiert - in dessen Residenz bei St. Peter und verwies dabei allein durch seine äußere Gestalt auf seinen Machtanspruch. Gewandet wie ein römischer Kaiser, trat er, Herrschaftsstab in der Hand und Krone auf dem Haupt, vor den Legaten. Bezeichnenderweise war er es auch, der die Unterredung mit der herausfordernden Frage eröffnete: $» D u$ hast nach uns geschickt. Was hast Du mir aufzutragen? « Der Legat antwortete knapp: "Wir haben einige Nachrichten von unserem Herrn, dem Papst «. Hochmütig erwiderte Rienzo: »Welche Nachrichten können das schon sein?« Der Anonimo bricht an dieser Stelle mit der Erzählung des ersten und einzigen Zusammentreffens der beiden politischen Kontrahenten ab, kann jedoch nicht umhin, zu bemerken, der Legat sei sprachlos gewesen und habe in Schweigen verharrt ${ }^{647}$. Zwei Welten prallten aufeinander. Die Gestalt des sich an antiker

645 Die kritische Ausgabe legte Giuseppe Porta 1979 vor, vgl. Anonimo romano, Cronica, ed. Giuseppe PorTA, Mailand 1979. Mit großem Gewinn zu konsultieren ist die vergleichend angelegte Studie von Gustav SEIBT, Anonimo Romano. Geschichtsschreibung in Rom an der Schwelle zur Renaissance, Stuttgart 1992 (it. Übersetzung: Anonimo romano. Scrivere la storia alle soglie del Rinascimento, ed. it. a cura di Roberto DeLle DonNE, Rom 2000); vgl. des weiteren Gian Mario ANSELMI, Il tempo della storia e quello della vita nella Cronica dell'Anonimo romano, in: Studi e problemi di critica testuale 21 (1980) S. 181-194; Giuliano TANTURLI, La Cronica di Anonimo romano, in: Paragone 31 (1980) S. 84-93; Massimo MIGLIO, Anonimo romano, in: Il senso della storia nella cultura medievale italiana (1100-1350). Atti del XIV Convegno internazionale di studio (Pistoia, 14-17 maggio 1993), Pistoia 1995, S.175-187. Die Vita des Cola di Rienzo machte Gabriele d'Annunzio zum Gegenstand einer auf hohem literarischem Niveau stehenden »Nacherzählung«, die nicht nur durch ihren Inhalt, sondern auch durch linguistische Innovationen besticht, vgl. Gabriele D'Annunzio, La vita di Cola di Rienzo, ed. Pietro Gibellini, Mailand 1999. 646 Der letzte Identifizierungsversuch wurde vom Doyen der italienischen Petrarca-Forschung, Giuseppe Billanovich, unternommen. Laut Billanovich soll sich hinter dem Anonimo Romano der Arzt und Geistliche Bartolomeo di Jacopo da Valmontone verbergen, ein entfernter Freund Petrarcas aus dem Umkreis des Ildebrandino Conti. Zu dieser Erkenntnis gelangt Billanovich jedoch lediglich aufgrund von Analogieschlüssen. Einen tragfähigen Indizienbeweis bleibt er schuldig, vgl. Giuseppe Billanovich, Come nacque un capolavoro: la Cronica del non più Anonimo Romano. Il vescovo Ildebrandino Conti, Francesco Petrarca e Iacovo da Valmontone, Rom 1995 (Atti dell'Accademia Nazionale dei Lincei. Rendiconti, IX. Folge, VI/1). Kritisch äußert sich Roberto DELle DONNE, Storiografia ed "esperienza storica « nel Medioevo: l'Anonimo romano, in: Storica 2/6 (1996) S.97-117.

647 Anonimo Romano, ed. Porta, S.144: Con cutale veste sopra l'arme a muodo de Cesari sallio lo palazzo dello papa con tromme sonanti e fu denanti allo legato, soa bacchetta in mano, soa corona in capo. Terribile, fantastico pareva. Quanno fu pervenuto allo legato, parlao lo tribuno e disse: "Mannastivo per noa. Que vi piace de commannare? "Respuse lo legato: "Noa avemo alcune informazioni de nuostro signore lo papa«. Quanno lo tribuno ciò odio, iettao una voce assai aita e disse: "Que informazioni so' queste? "Quanno lo legato odio si rampognosa resposta, tenne a si e stette queto. 
Größe orientierenden Volkstribunen, der durch die Adjektive terribile und fantastico charakterisiert wird, erscheint vor dem Hintergrund einer indifferentneutral dargestellten Persönlichkeit wie der des Legaten in grellem Licht. Er allein konnte alle Aufmerksamkeit auf sich und die mit seiner Politik verbundenen Zielsetzungen lenken. Neben dem Projekt einer Restauration der antiken Größe Roms mußte die päpstliche Politik, mußte der Vertreter eben dieser Politik vor Ort als unbedeutend erscheinen. Bertrand de Deux, der es versäumte, Rienzo in seine Schranken zu weisen, war für diesen kein ebenbürtiger Partner, was sich denn auch in der Demütigung durch den Volkstribunen manifestierte. Tatsächlich sollten sich die Qualitäten des Legaten nicht im unmittelbaren Kräftemessen mit Rienzo zeigen. Bertrand wirkte im Hintergrund, mied jede direkte Konfrontation und setzte sich für das Zustandekommen eines Bündnisses ein, das schließlich zum Sturz des Volkstribunen führen sollte.

So gelang es ihm zwar, sich Rienzos zu entledigen: den neapolitanischen Wirren entkam er jedoch auch in Rom nicht. Wiederholt erkundigte sich Clemens VI. durchaus mahnend nach dem Stand der Verhandlungen mit Ludwig von Ungarn. Wenig Begeisterung dürfte bei Bertrand die Nachricht ausgelöst haben, man verzichte auf die Entsendung eines weiteren Kardinallegaten nach Italien. Auch die Nachricht vom Ehedispens für Johanna war wohl nicht dazu angetan, die diplomatische Energie des Legaten gleichermaßen auf römische wie auf neapolitanische Belange zu lenken ${ }^{648}$. Seine Weigerung, der päpstlichen Bitte zu entsprechen und sich persönlich zum König von Ungarn, der als Invasor in Neapel weilte, zu begeben, wurde an der Kurie ohne Widerspruch zur Kenntnis genommen ${ }^{649}$ - die Furcht vor der grassierenden Pest dürfte das ihrige dazu beigetragen haben, die Entscheidung des Legaten anzuerkennen. An der Kurie hatte man zudem von dem Überfall erfahren, durch den Bertrand aus Cesano (Sabina) mit dem Ruf »Tod dem Legaten!« vertrieben worden war. Dabei waren einige Familiaren getötet und das Gepäck vernichtet worden ${ }^{650}$. Natürlich war man darum bemüht, die Weigerung nicht als solche erscheinen zu lassen. So sprach denn auch der Papst in einem Schreiben vornehm-zurückhaltend von Gründen, die es Bertrand unmöglich machen könnten, sich persönlich zum König von Ungarn zu begeben ${ }^{651}$. Über

648 Lettres Clément VI, n. 3786 (23.03.1348); vgl. BURDACH, Briefwechsel des Cola di Rienzo, IV, n. 43, S. 116-119. Anstelle eines Kardinals wurde Francesco Orsini nach Rom entsandt, um damit der Praxis einer Doppeldiplomatie ein Fortleben zu garantieren; vgl. auch Lettres Clément VI, n. 3851 (07.05.1348); zu Ehedispensen vgl. ScHORMANN, Beiträge zur Ehepolitik, S. 93-138.

649 Lettres Clément VI, n. 3800 (01.04.1348).

650 Ibid., n. 3791 (24.03.1348).

651 Lettres Clément VI autres que la France, n. 1640 (11.05.1348; nur Regest); vgl. RV 141, n. 1405, fol.277v: Carissimo in Christo filio nostro Ludovico regi Ungarie illustri per alias nostras litteras scribimus iuxta formam cedule presentibus intercluse. Tu igitur sicut per alias tibi nostras litteras scribimus, si commode poteris, conferas personaliter te ad ipsum. Alioquin venerabili fratri nostro Petro episcopo Viterbensi, quem ad eundem regem in casu, in quo tu illuc accedere nequeas, destinamus aliquem de familiaritate ac societate tua virum 
den Stand der Verhandlungen hielt man Bertrand jedoch auf dem laufenden $^{652}$. Das in Kollationsangelegenheiten selbstherrliche Verhalten des Kardinals rief bei seinen Mitbrüdern im Kollegium großes Mißfallen hervor. Der Papst fühlte sich immerhin dazu gedrängt, Bertrand dazu aufzufordern, von seinen Kollationsrechten sparsamer Gebrauch zu machen und alles zu vermeiden, was zu finanziellen Einbußen der Kardinäle führen könnte ${ }^{653}$. Nach seiner im November 1348 erfolgten Rückkehr an die Kurie - die römischen Verhältnisse blieben ungeordnet - galt Bertrand zwar als Spezialist für die Belange Italiens, war jedoch augenscheinlich körperlich derart geschwächt, daß man in Zukunft von seiner weiteren Verwendung als Legat absah. Bezeichnend ist ein vom Papst an die Königin von Ungarn gerichtetes Schreiben, in dem ihr bedeutet wird, Bertrand sehe sich languore corporis fatigatus et legationis sue negociis impeditus zu einer Reise nach Ungarn außer Stande ${ }^{654}$. Der Rat des in der Zwischenzeit in den ordo der Kardinalbischöfe Aufgenommenen wurde weiterhin geschätzt ${ }^{655}$. Dem Erzbischof von Mailand wurde so im Dezember 1349 mitgeteilt, seine Nuntien hätten deshalb noch nicht angehört werden können, weil Kardinal Bertrand aufgrund körperlicher Unpäßlichkeiten nicht in der Lage gewesen sei, an den Konsistorien teilzunehmen ${ }^{656}$. Die letzte Erwähnung während des Pontifikates Clemens' VI. zeigt ihn als Mitglied einer Kardinalskommission, die mit den Friedensverhandlungen zwischen Aragon, Venedig und Genua betraut war ${ }^{657}$.

honorabilem adiungere studeas et dirigas cum eodem. An die Stelle von Bertrand trat $\mathrm{Pe}$ trus, der Bischof von Verona, vgl. ibid., n. 3914 (15/7/1348).

652 Lettres Clément VI, nn.3852 (07.05.1348), 3858 (10.05.1348); vgl. BuRDACH, Briefwechsel des Cola di Rienzo, IV, n. 44, S. 119f., n.47, S.124f.

653 Lettres Clément VI, n. 3854 (07.05.1348).

654 Ibid., n. 4005 (04.12.1348).

655 Seine Translation erfolgte um den 4 . November 1348, dem Tag, an dem der Papst seine Collatio Fecit in domo hielt. Bertrand de Deux war zu diesem Zeitpunkt noch nicht an der Kurie eingetroffen.

656 Lettres Clément VI autres que la France, n. 2114 (15.12.1349; nur Regest); vgl. RV 143, fol. 121r: Speravimus negotium, pro quo dilectum filium magistrum Guillelmum de Arimondis legum doctorem, civem Parmensem et Johannem de Silva laicum Lucan. dioc., nuncios tuos, qui illud solicite prosecuti sunt et prosecuntur assidue ad sedem apostolicam destinati ante festum nativitatis dominice futurum proximo expedire, sed quia emergentibus negociis variis impediti vota fratrum omnium nondum audire potuimus nec voluimus etiam propter supervenientem discrasiam venerabilis fratris nostri Bertrandi episcopi Sabinensis, qui consistoriis pluribus interesse non potuit et quem velut de negocii meritis plenius informatum pro ipsius utiliori expeditione negocii voluimus audientie interesse, expeditio predicti negocii necessarie est dilata. Sed prestante Deo cum idem episcopus recuperata salute poterit consistoriis interesse ad accelerandam expeditionem dicti negocii quantum cum Deo poterimus favorabiliter intendemus sicut iidem nuncii tui, quos hic proinde remanere volumus, plenius sicut credimus tibi scribunt. Vgl. auch Lettres Clément VI, n. 4342 (15.12.1349). In den einschlägigen Lexika wird dyscrasia entweder unmittelbar als Magenkrankheit oder als eine aus dem Ungleichgewicht der Körpersäfte resultierende Disposition zum Kranksein definiert, vgl. Albert BLAISE (Hg.), Lexicon latinitatis medii aevi, Turnholt 1975, S. 311.

657 Lettres Clément VI, n. 5465 (23.11.1352). 
5.2.3.2. Legatus fidelis sanitas: die Collatio Clemens' VI. anläßlich der Rückkehr des Kardinallegaten Bertrand de Deux aus Italien

Die Collatio Clemens' VI., mit der Bertrand de Deux am 17. November 1348 an der Kurie willkommengeheißen wurde, scheint sich auf den ersten Blick in bekannten rhetorischen Bahnen zu bewegen ${ }^{658}$. Die vom Legaten in Neapel entfaltete Wirksamkeit wird nur bedingt einer kritischen Wertung unterzogen und verschwindet hinter der Aneinanderreihung positiv konnotierter Charakterzüge. Immerhin zeugt vorliegende Collatio - und dies im Gegensatz zu bereits untersuchten Vertretern dieser Gattung - von einer gewissen Spannung, die sich aus dem fortwährenden Kampf der beiden Prinzipien Gut-Böse ergibt. Zum besseren Verständnis sei hier zunächst die Gliederung der Collatio angeführt:

\section{LEGATUS FIDELIS SANITAS}

Collatio facta per dominum Clementem papam VI. in reditu Cardinalis Ebredunensis legati die XVII novembris pontificatus sui anno septimo

I. Abhandlung über die Pest 1348

II. Allgemeine einleitende Gedanken zum Komplex: Legatus/Medicus/Pacificator Missus fuit ad triplicem infirmitatem sanandam

- omnem regionem legationis sibi commissae

- specialiter Siciliam

- Romam Urbem inclitam

III. Bedeutung der Stadt Rom

Roma/Urbs inclita/domina gentium et princeps provinciarum

Bertrand als princeps militie

Ipse [Bertrand de Deux] erat vir

- magne scientie, sapientie et cognitionis

- magne prudentie et discretionis

- magne experientie et probationis

- magne eloquentie et persuasionis

- magne efficacie et operationis

- plene sufficientie et perfectionis

Habemus ergo duo:

1. primum, quod egrotanti desideratissimum est sanitas

2. secundum, quod noster legatus et regioni, ad quam missus est, et regno et urbi quantum in se fuit attulit sanitatem

Thema: Legatus fidelis sanitas, ubi tria tanguntur:

1. auctoritas humiliter acceptata. legatus

2. fidelitas irrefrigabilis observata. fidelis

3. utilitas multipliciter reportata. sanitas

Posset aliquis quaerere:

- Quis fuit istius status?

-Quis actus vel cultus?

658 Den folgenden Ausführungen liegt der Text der Handschrift Paris, Bibliothèque SainteGeneviève, MS 240, fol.434v-440r zugrunde. Dort findet sich die Überschrift: Collatio facta per dominum Clementem papam VI. in reditu cardinalis Ebredunensis legati die XVII novembris pontificatus sui anno septimo. Zur Parallelüberlieferung vgl. SCHNEYER, Repertorium, Bd. 4, S. 763, n. 57; Mollat, Euvre oratoire, S. 256, n. 69; SchMiTZ, Sermons, S.27, n. 49; WoOD, Sermon literature, S.163-172. 
- Quis finis vel fructus?

Responsiones:

- status fuit magne excellentie et honoris

- actus vel cultus fuit probate sanctimonie, iusticie et vigoris

- finis vel fructus fuit mire complacentie et dulcoris, efficacie et valoris

Iste ergo:

- aliquid acceptavit in egressu

- aliquid observabit in progressu

- aliquid reportavit in regressu

Acceptavit alte dignitatis fastigium multum honorabile sed laboriosum

Observabit debite fidelitatis obsequium valde commendabile et virtuosum

Reportavit optate sanitatis solacium summe delectabile et gaudiosum

Ad 1. Auctoritas humiliter acceptata:

Iste fuit valde bonus legatus et optime habent conditiones boni legati $[. . .]^{659}$.

1. claritas intelligentie

7. Equitas iusticie

2. puritas conscientie

8. Firmitas constancie

3. humilitas obedientie

4. sedulitas diligentie

9. Severitas discipline

5. maturitas patientie

10. Veritas doctrine

6. suavitas clementie

11. Gravitas continentie

12. Immensitas gratie

Possumus dicere quod noster legatus fuit bonus legatus qui habuit [...].

- in commissis fidelitatem

- in promissis veritatem

- in verbis affabilitatem

- in factis mutabilitatem

- in prosperis humilitatem

Prestat enim bonus legatus

- refrigerium contra ardorem

- solacium vel gaudium contra laborem

- remedium contra sudorem vel languorem

Ad 2. Fidelitas irrefragabiliter observata:

[...] recte fuit fidelis legatus habendo $X$ condiciones, quas debet habere fidelis legatus.

- mittentis beneplacitum et voluntatem prudenter recolligendo

- iussum iuxta suam possibilitatem viriliter exequendo

- mandatum observando nec praeteriendo nec excedendo

- omnem contrarietatem fortiter repellendo

- omnem adversitatem equanimiter sustinendo

- acceptam auctoritatem irreprehensibiliter prosequendo

- datam potestatem non secundum personarum acceptionem, sed secundum merita salubriter distribuendo

- fructus iocunditatem multipliciter reportando

- assecutam prosperitatem mittendi principaliter attribuendo

- gestorum veritatem fideliter referendo

659 Hier wird auf einen Bestand an Eigenschaften zurückgegriffen, der bereits in der 1343 gehaltenen Collatio Et iste bonus est nuntius Gegenstand der Betrachtungen war, vgl. MS 240, fol. 68va: Modo videtur michi, quod iste nuncius, quem miseramus pro pace tractanda inter illustres Aragonum et Maioricarum reges vel saltem pro treugis et abstinentiis faciendis, habuit istas quatuor conditiones: primo claritatem intelligentie in mandatorum recollectione sagaci; secundo sedulitatem diligentie in comissorum prosecutione vivaci; tercio potestatem efficacie in iniunctorum consumatione efficaci; quarto veritatem iusticie in gestorum relatione veraci. 
Ad personam zugeschnitten, fällt die Wahl des Papstes auf einen Vers, den er dem alttestamentarischen Buch der Sprüche entnimmt: „Ein gottloser Bote bringt ins Unglück, aber ein getreuer Bote bringt Hilfe «660. Zwar wird der erste Teil des Verses explizit nicht erwähnt, dürfte aber dennoch der Zuhörerschaft bekannt gewesen sein, erfolgte doch die Kontextualisierung biblischer Inhalte - davon ist zumindest bei einem aus Kanonisten und Theologen zusammengesetzten Publikum auszugehen - nicht nur bruchstückhaft, sondern vor dem Hintergrund größerer Zusammenhänge. Auch wenn der Papst den ersten Versteil zugunsten des zweiten unterdrückt, eröffnet er also doch die Möglichkeit, zumindest gedanklich die Vor- und Nachteile guter und schlechter Boten gegeneinander abzuwägen.

Nicht zufällig wird zunächst der Begriff der sanitas einer näheren Betrachtung unterzogen. In ihm wird nicht nur auf unspezifische Hilfsleistungen verwiesen. Was mitschwingt, ist die Unterstützung bei der Gesundung eines mental oder körperlich Kranken. Die Collatio wird im November 1348 gehalten, zu einem Zeipunkt, an dem die in Avignon wütende Pest ihren Höhepunkt bereits überschritten hatte. Die bis dato verzeichnete Sterblichkeit apokalyptischen Ausmaßes - man geht wohl nicht fehl in der Annahme, daß rund die Hälfte der Bevölkerung Opfer der Pest wurde - hatte auch an der Kurie zu einem völlig neuen Verständnis des Begriffs sanitas geführt. So kann es nicht erstaunen, wenn der Papst zunächst mit einer geschichtlichen Betrachtung anhebt und sich dabei nicht nur auf biblische Autoritäten, sondern auch auf Werke der antiqui und moderni stützt. Auch wenn er einräumt, gelesen zu haben, daß andere Pestepidemien ebenso unheilbringend wie die jetzige gewesen seien, so könne man doch nicht verschweigen, daß die ganze Welt Opfer dieser Epidemie geworden sei661. Seine Ausführungen zeugen zum einen von Belesenheit, zum anderen vom Umfang der päpstlichen Bibliothek. In dichter Folge werden Passagen zitiert, die unter anderem aus der Historia scolastica des Petrus Comestor ${ }^{662}$, den Antiquitates des Josephus, aus dem Buch des

660 Prv 13,17: Nuntius impii cadet in malum legatus fidelis sanitas; vgl. allgemein zur Bedeutung der aus der Bibel entnommenen Zitate Ceslas SPICQ, Esquisse d'une histoire de l'exégèse latine au Moyen Âge, Paris 1944, S.159-164; Beryll SMALLEY, The Study of the Bible in the Middle Ages, Oxford 1952; Henri de LuBAC, Exégèse médiévale. Les quatre sens de l'écriture, 4 Bde., Paris 1959-1964; Willem Lourdaux, Daniel Verhelst (Hg.), The Bible and Medieval Culture, Löwen 1979. Auffällig ist immerhin, daß der Begriff sanitas mit 43 Belegen vor allem im AT zu finden und seine Präsenz im NT mit nur 7 Nennungen eher sekundär ist.

661 MS 240, fol. 435ra: Modo videtur michi, quod licet videatur tota mundi machina egrotare quadam pestilentia vel epidemia, que a domino vel propter peccata mea et aliorum prepositorum, vel propter peccata subditorum videtur esse inflicta et tam universaliter, quam fere alias inaudita, quamvis enim legerim alias fuisse eque magnam vel maiorem intensive. Hingewiesen sei darauf, daß der Papst die Möglichkeit nicht ausschließt, er selbst könne zum Kreis der an der Pest Schuldigen gehören. Das Interesse des Papstes am Pestphänomen schlägt sich in der Widmung zweier anonymer Pesttraktate an ihn nieder, vgl. CRISCIANI, PEREIRA, Black Death and golden remedies.

662 Petrus COMESTOR, Historia scolastica, in: PL 198, Sp. 1053-1722. 
Hieronymus De hebraicis questionibus super II libro Regum, der Historia Langobardorum des Paulus Diaconus ${ }^{663}$ und dem Speculum historiale des Vinzenz von Beauvais ${ }^{664}$ stammen. Clemens VI. geht recht in der Annahme, wenn er unterstellt, alle vorangehenden Pestausbrüche seien zwar verheerend, in ihren Auswirkungen jedoch nicht so weitgehend und derart nationenübergreifend wie die jetzige gewesen ${ }^{665}$. Welche Rolle spielt vor diesem Hintergrund der Legat, der zwar nicht ausgesandt wird, um der Pestplage Herr zu werden, dem jedoch die Sorge für Leib und Leben der Bewohner seines Legationsbezirks anvertraut wird? Ihm obliegt die Bekämpfung von drei Krankheitsherden auf unterschiedlichen Gebieten seines Legationsbezirkes. Hervorgehoben werden dabei insbesondere das Königreich Neapel und Rom ${ }^{666}$. In Hinblick auf die Gesamtheit des Legationsgebietes dienen ihm

663 Vgl. MGH SS rer. Langob. I, S. 74. Allerdings schreibt Clemens VI. die korrekt zitierte Historia Langobardorum nicht Paulus Diaconus (720-800), sondern Cornelius Nepos (geb. 110 v. Chr.) zu, einem Zeitgenossen von Cicero, Catull und Lukrez, bekannt durch sein Werk De viris illustribus, den nur bruchstückhaft überlieferten Biographien berühmter Männer. Als erster hatte sich Cornelius Nepos an einem heute verlorenen Abriß der Weltgeschichte versucht, einer Chronica in drei Bänden, vgl. Abraham B. BREEBAART, Weltgeschichte als Thema der antiken Geschichtsschreibung, in: Acta Historiae Neerlandica 1 (1966) S.1-21. Über die Tatsache hinaus, daß beide Autoren als Verfasser historischer Schriften gelten dürfen, besteht zwischen ihnen jedoch keinerlei Gemeinsamkeit. Clemens VI. muß auf eine Handschrift der päpstlichen Bibliothek zurückgegriffen haben, die bereits eine falsche Autorenzuweisung trug.

$664 \mathrm{Vgl}$. Vincentius Bellovacensis (Vinzenz von Beauvais), Speculum historiale (sive Speculum maius), Douai 1624 (ND Graz 1965), lib. 24, c. 126, S. 943. In der päpstlichen Bibliothek wurden Exemplare dieses Werks aufbewahrt, vgl. EHRLE, Historia, S. 326f.

665 MS 240, fol.436rb: Omnes autem iste pestilentie non fuerunt adeo generales sicut ista, que incipiens ab oriente per meridiem giravit usque ad occidentem et tam incipit flecti ad aquilonem. Als einzige Epidemie mit ähnlich gravierenden demographischen Einbrüchen gilt die sogenannte Justinianische Pest des 6. Jahrhunderts, vgl. hierzu Andries WeLKENHUYSEN, La peste en Avignon (1348) décrite par un témoin oculaire, Louis Sanctus de Beringen, in: Pascua mediaevalia. Studies voor Prof. Dr. J. M. de Smet, Löwen 1983, S. 452-492; Klaus Bergdolt, Der Schwarze Tod in Europa. Die Große Pest und das Ende des Mittelalters, München ${ }^{31995}$, S. 14-17; Karl-Heinz LEVEN, Die Justinianische Pest, in: Jahrbuch des Instituts für Geschichte der Medizin der Robert-Bosch-Stiftung 6 (1987) S. 137-161; Gundolf KEIL, Seuchenzüge des Mittelalters, in: Mensch und Umwelt im Mittelalter, hg.v. Bernd Herrmann, Stuttgart 1989, S.109-128; grundsätzlich Yves RenOUARD, L'événement mondial le plus important du XIVe siècle. La peste noire de 1348-1350, in: DeRS., Études d'histoire médiévale, Bd.1, Paris 1968, S.143-155 ; Jean Noël BIRABEN, Les hommes et la peste en France et dans les pays européens et méditerrannéens, 2 Bde., Paris, Den Haag 1976; Neithard BulsT, Der Schwarze Tod. Demographische, wirtschafts- und kulturgeschichtliche Aspekte der Pestkatastrophe von 1347-1352. Bilanz der neueren Forschung, in: Saeculum 30 (1979) S. 45-67; Dormeier, Heinrich, Die Flucht vor der Pest als religiöses Problem, in: Laienfrömmigkeit im späten Mittelalter, hg. v. Klaus SCHREINER, München 1992, S.331-397.

666 MS 240, fol. 436va: Videtur michi, quod missus fuit ad triplicem infirmitatem sanandam, primo quidem ad sanandam omnem regionem legationis sibi commisse, que egrotabat quasi morbo reumatico et inficiente; secundo ad curandum specialiter Siciliam seu terram citra Farum, que egrotabat morbo quasi erratico et deficiente; tertio ad sanandum Romam Urbem inclitam, que egrotabat morbo quasi frenetico et inpingente. 
zwei Adjektive zur Bezeichnung der Krankheitssituation: reumaticus und inficiens. Da ersteres - ut dicunt medici - vor allem Menschen fortgeschrittenen Alters befalle, gleichsam den körperlichen Verfall einer Person flankiere, ist für den Papst die Assoziation hin zum Verfall der christianitas nicht mehr weit ${ }^{667}$.

Die Begründung bleibt der Papst nicht schuldig: zum einen fehle es an innerem Feuer (ex defectu vigoris seu caloris intrinseci), zum anderen müsse den Angriffen des äußeren Feindes standgehalten werden (ex conatu et impulsu hostis extrinseci). Bereits an dieser Stelle richtet sich der Blick nicht nur auf das Legationsgebiet, sondern auch auf den Legaten selbst. Die Untersuchung der kurialen Registerüberlieferung sollte deutlich gemacht haben, daß die Vorwürfe, die sich ad personam gegen Bertrand de Deux richteten, dessen Untätigkeit, also gleichsam einen defectus vigoris, zum Gegenstand hatten. Während der ganzen Zeit seiner Abwesenheit von der Kurie hatte er beständig gegen äußere Feinde in Gestalt Ludwigs von Ungarn oder Rienzos zu kämpfen. Vergessen werden sollte auch nicht, daß Bertrand de Deux ein kranker Mann war, der unter Gichtanfällen litt. Er wird zum Musterbeispiel für die Auswirkungen des morbus reumaticus et inficiens, leidet wie die Gesamtheit der Bewohner seines Legationsgebietes an einer gleichermaßen nach innen wie nach außen gerichteten Krankheit. Was macht nun aber diesen Arzt, der, obgleich krank, dazu ausersehen ist, Heilung zu bringen, zu etwas Besonderem? Der Papst läßt keinen Zweifel daran, daß Bertrand die gestellte Aufgabe nur deshalb habe bewältigen können, weil er die Kurie nicht mit leeren Händen verlassen, sondern in seinem Gepäck vielerlei Arten an Arznei verwahrt habe: Wundpflaster, Salböle, Unterweisungen, Arzneien, Kräuter und Worte, also ein Reservoir, das dem Legaten nicht im wörtlichen, sondern im übertragenen Sinne zur Verfügung stand ${ }^{668}$.

Vom Allgemeinen richtet sich der Blick dann auf das Besondere. Deutlich wird, daß dem Papst das Königreich Neapel - nostre recreationis pomarium am Herzen liegt, daß er den $\mathrm{Ha}$ und die allgemeine Zwietracht, die die Situation kennzeichnen, nur schwer verstehen $\mathrm{Kann}^{669}$. Er unterstreicht, daß der

${ }^{667}$ Nach einem langen, der Schrift Innozenz' III. De miseria humane conditionis entnommenen Zitat gelangt Clemens VI. zu der Feststellung: Etas autem, in qua nunc sumus, comparatur senectuti [...]. Et videtur michi, quod istam etatem sicut senectutem multa circumveniunt incommoda tam corporaliter quam spiritualiter ex duobus. Primo quidem ex defectu vigoris seu caloris intrinseci, secundo ex conatu et impulsu hostis extrinseci, ibid., fol. $436 \mathrm{vb}$.

${ }^{668}$ Ibid., fol.437rb: Ad hanc ergo plagam curandam magnus noster missus est medicus, quia magnus ubique iacebat egrotus. Missus quidem cum emplastris sanitatis, cum unguentis suavitatis, cum documentis veritatis, cum medicamentis honestatis, cum herbis virtuositatis, cum verbis felicitatis.

669 Ibid., fol.437va: Dico II, quod languebat Sicilia sive Terra citra Farum. Terra, inquam, nostra peculiaris hereditas, spiritualis nostre recreationis pomarium, nostre consolationis solacium, equidem egrotabat morbo quasi erratico et deficienti [...]. In der Folge zitiert Cle- 
Legat alles unternommen habe (nichil de contingentibus omittendo), um der Situation Herr zu werden. Der Papst verliert sich nicht in Details, sondern wendet sich nach Nennung einiger Bibelstellen, die das Wirken des guten Arztes thematisieren ${ }^{670}$, unmittelbar dem dritten Punkt, der Stadt Rom, zu, in der sich die politische Lage ähnlich verworren präsentiere wie in Neapel ${ }^{671}$. Zitate von Apollinaris Sidonius, Hieronymus und Ambrosius dienen dazu, zunächst die Einzigartigkeit Roms und seiner Bewohner herauszustellen. Dem durch die spätantike Literatur tradierten Idealbild folgt der Verweis auf die ernüchternde Realität. Der beklagenswerte Zustand Roms wird auf das Wirken einer einzigen Person zurückgeführt. In Cola di Rienzo meint der Papst, den Schuldigen ausfindig gemacht zu haben ${ }^{672}$. Er wird mit dem bösen Geist verglichen, von dem König Saul einst heimgesucht wurde (1 Sam 16,5), nimmt die Gestalt des Belial an ${ }^{673}$ (2 Sam 20,1) und wird schließlich mit Seba, dem Empörer aus dem Stamm Benjamin, gleichgesetzt. Dessen Aufstand gegen König David, die Verfolgung durch den Heerführer Joab samt seinem von Gott gewollten Untergang, wird vom Papst nach 2 Sam 20, 18-21 geschildert. Am Ende der Erzählung steht der Vergleich der dramatis personae mit den Hauptexponenten der kurialen Politik Ende 1348. Seba, der sich in Abel Beth Maacha verschanzt, wird zum in Rom wütenden Cola di Rienzo. In David, dem die Revolte einiger Stämme Israels unterdrückenden König, erblickt der Papst sich selbst, während Joab, der von seinem Bruder Abisai den Oberbefehl über die gegen Seba ziehende Armee übernimmt, von niemand anders als Bertrand de Deux verkörpert wird ${ }^{674}$. Ein für das Verhältnis zwischen David und seinem Neffen Joab wesentliches Detail wird dabei freilich unterschlagen: Joab,

mens VI. Ps 37,4 (Non est sanitas in carne mea a facie ire tue, non est pax ossibus meis a facie peccatorum meorum) und bemerkt dazu: Et nota, quod dicit non esse sanitatem nec in carne nec in ossibus, quia nec in mulieribus nec in viris, quia nec in fragilibus nec in fortibus, quia nec in popularibus nec in magnatibus. Ad istam ergo infirmitatem sanandam missus est noster medicus, qui ad hoc omnem sollicitudinem adhibuit, nichil de contingentibus ommittendo [...].

$670 \mathrm{Vgl}$. Sir 38,1f., 7; Jes 58,8.

671 MS 240, fol. 437vb: Dico IIl, quod laborabat Roma Urbs inclita singulariter morbo quasi frenetico et inpingente, Urbs quidem inclita.

672 Ibid., fol.438ra: Ista ergo Urbs sic inclita morbo frenetico et inpingenti egrotabat, quando illum Nicolaum Laurentii insanum et freneticum, de scismate et heresi vehementer suspectum et utinam non infectum sequebatur, et eius motus freneticus et inpingens nunc contra ecclesiam, nunc contra imperium, nunc contra nobiles, nunc contra non nobiles plures fatuitates attemptantem, quid unquam in aliqua hystoria de aliquo insano legatur.

$673 \mathrm{Vgl}$. Dictionary of deities and demons in the Bible, hg.v. Karel VAN DER TOORN, Bob BECKING, Pieter VAN DER HORST, Darmstadt 21999, S. 45-50.

674 MS 240, fol. 438rb: Applica, ut per Abela intelligatur Roma, domina gentium et princeps provinciarum, per Siba virum Belial, filium Botri, Nicolaus Laurentii filius molendarii, per David ego immeritus presidens isti sedi urbi et orbi, per Joab principem milicie. Legatus noster, qui presentialiter venit ad Abelam, id est ad Urbem, et illum super multis fatuitatibus revocandis monuit et contra eum precessit et tandem eius ministerio de Urbe et ab omni officio expulsus fuit. 
der mehr als einmal David die Herrschaft sicherte, wurde von ihm nicht geliebt, weil er als eigenständig denkender, auf Unabhängigkeit bedachter Kopf Widerspruch erhob. Seine Opposition ging schließlich so weit, daß er sich gegen David auflehnte und dabei den Tod fand. Nichts davon verlautet in der Collatio, und dennoch dürften die Zuhörer die negativen Untertöne vernommen haben.

Die Vorgehensweise des Papstes ist bekannt: Positives wird in oftmals topischer Reihung betont, während Negatives kaum einmal explizit ausgesprochen, in einem subtilen Spiel bibelgestützter Andeutung und Verschleierung jedoch dem Haupttext unterlegt wird. Der unbestreitbare Erfolg, zur Vertreibung Rienzos aus der Stadt Rom beigetragen zu haben, wird gebührend gewürdigt. Die Eigenschaften des Bertrand de Deux werden mittels einer umfangreichen Auflistung - fast unnötig zu betonen, daß die Wahl der Nomina dabei auch durch die Vorgaben der concordantia in voce motiviert ist - lobend hervorgehoben. Ihm wird nicht nur großes Wissen, Weisheit und Einsicht bescheinigt, er verfüge - so der Papst - des weiteren über Klugheit und Unterscheidungsfähigkeit, Erfahrung und Erprobung, Beredsamkeit und Überzeugungskraft, Wirksamkeit und Einsatzbereitschaft, vermittle das Bild von Perfektion und Vollkommenheit ${ }^{675}$. Doch damit nicht genug: Obgleich im Kriegshandwerk nicht ausgebildet, vollbringe er auch auf diesem Gebiet Erstaunliches. Er habe nicht nur dafür gesorgt, daß der Präfekt von Rom, Giovanni de Vico, zu Unrecht besetzte Burgen wieder ausliefern mußte, daß Cola di Rienzo aus den von ihm unterworfenen Städten der Sabina vertrieben wurde ${ }^{676}$, sondern sich auch in der Vertreibung des Söldnerführers Werner erfolgreich gezeigt.

675 Ibid., fol. 438va: Ad litteram enim, licet constaret nobis omnibus, quod ipse erat vir magne scientie, sapientie et cognitionis, magne prudentie et discretionis, magne experientie et probationis, magne eloquentie et persuasionis, magne efficacie et operationis, plene sufficientie et perfectionis, tamen non ita constabat, quod esset tam bonus rei bellice et congressionis, et tamen ita bene scivit rem bellicam ducere et etiam ordinare, quod castrum occupatum per comitem Guidonem, comitatum etiam Sabinie occupatum per illum virum Belial et etiam terras occupatas in comitatu Campanie per ducem Guarnerium cum auxilio fidelium Ecclesie recuperavit.

676 Bei mindestens einem Kardinal in Avignon konnte Rienzo für eben dieses Projekt auf Verständnis und Sympathie hoffen, informierte er den Purpurträger doch über die freiwillige Unterwerfung der Städte der Sabina und des Patrimoniums, vgl. hierzu BURDACH, Briefwechsel Cola di Rienzo, III, n. 37, S. 134 (01.09.1347). Rienzo beklagt darin die fortgesetzten Übergriffe der kirchlichen Amtsträger in dem Gebiet und legitimiert sein Einschreiten: Noverit etiam paternitatis vestre benignitas, quod hodie primo Sepembris quasi omnes Terre de Sabinia et Patrimonio propter iniusta gravamina, que ab officialibus ecclesie, quod cum pudore referimus Deo teste, inferuntur eisdem, et ut liberentur a rabie tirampnorum et possint vitam ducere in iusticia et pace securam, per Sindicos eorum ad hoc legitime ordinatos nobis eorum regimen cum lacrimis supplices commiserunt [...]. Rienzo wird zum Künder von Frieden und Gerechtigkeit und füllt damit genau die Rolle aus, die der Kardinallegat Bertrand de Deux als sein Widersacher ebenfalls für sich in Anspruch nimmt. 
Singulär im untersuchten Predigtwerk Clemens' VI. ist der nun folgende Einwurf. Einem Zuhörer wird die Entgegnung in den Mund gelegt, wie man denn davon sprechen könne, der Legat habe seinen Auftrag erfüllt, wo doch das Legationsgebiet noch nicht befriedet sei. Der Papst selbst artikuliert damit Zweifel an dem von ihm mit rhetorischem Aufwand erstatteten Bericht, exkulpiert sich durch den Verweis auf den Einwurf eines Zuhörers, um u.a. Bertrand de Deux das Gefühl zu vermitteln, keinerlei Zweifel an seinen Gaben und Fähigkeiten zu hegen. Die Antwort auf die angesichts der alles andere als befriedeten Situation in Italien durchaus berechtigte Frage fällt erstaunlich wortkarg aus. Nur mit einem Bibelvers wird geantwortet - Curavimus Babilonem et non est sanata derelinquamus eam (Jer 51,9) - und auf den entsprechenden Kommentar des Hrabanus Maurus verwiesen. Schuld an der nach wie vor unübersichtlichen Lage trage nicht der Legat. Allein verantwortlich seien die Bewohner des Gebietes, die sich, so der Papst, im Angesicht legatorischer sanitas aufgrund freier Willensentscheidung dem Bösen zugewandt hätten. Die Antwort schließt mit einem relinquamus ergo eam etc. und läßt den Leser in Zweifel darüber zurück, ob die Handschrift die Redesituation tatsächlich vollständig wiedergibt. Gleichsam nachgeschoben wird eine Ehrenrettung des Legaten: Unwilligkeit und Mißachtung der anderen seien der Grund dafür, daß die vom Legaten vermittelte sanitas nicht angenommen worden sei677. Damit wird zwar ein Scheitern der Legation eingeräumt, das inhaltlich jedoch klar von einem persönlichen Scheitern des Legaten abgegrenzt wird. Schuld trifft allein die anderen. Das Paradoxe der Situation, das darin besteht, daß dem Kranken zwar nichts willkommener als Gesundung sein müßte, das Legationsgebiet unzweifelhaft als krank gelten muß, der dorthin entsandte Arzt-Legat auch eine segensreiche Wirkung - quantum in se - entfaltete, es ihm aber dennoch nicht gelang, Gesundung herbeizuführen, wird in einer Art Zwischenergebnis festgehalten, von dem aus auf die bisher noch nicht behandelten Grundvoraussetzungen für die erfolgreiche Ausführung einer Legation übergeleitet wird ${ }^{678}$.

Auf drei Dinge wird in diesem Zusammenhang verwiesen: die in Demut angenommene Autorität (primo auctoritas humiliter acceptata) muß sich mit der Beachtung unverbrüchlicher Treue (secundo fidelitas irrefrigabilis observata) und einer sich auf vielfache Weise erweisenden Nützlichkeit (tertio utilitas multipliciter reportata) verbinden, um ein erfolgreiches legatorisches Wirken zu garantieren. Andere, der vorgegebenen ternären Struktur folgende Elemente werden ergänzend herangezogen und liefern zusätzliche Aspekte bei

677 M 240, fol. 438vb: Iste ergo noster legatus, quantum in se fuit, sanitatem attulit, sed si non est secuta, ex indispositione et contemptu aliorum fuit.

678 Ibid., fol. 439ra: Habemus ergo duo: primum quod egrotanti desideratissimum est sanitas, secundo, quod noster legatus et regioni, ad quam missus est, et regno et Urbi, quantum in se fuit, attulit sanitatem, ut merito dicam de eo verba thematis preassumpta. 
der sich anschließenden Behandlung der einzelnen Punkte ${ }^{679}$. Besondere Bedeutung kommt dabei dem Element der in Demut angenommenen Autorität $\mathrm{zu}$, wird damit doch auf Quelle und Ursprung der legatorischen Autorität verwiesen: die Schlüsselgewalt des Papstes. Als sehr guter Legat habe sich Bertrand erwiesen (fuit valde bonus legatus) und dabei durch zwölf Eigenschaften auf sich aufmerksam gemacht: 1 . hervorragende geistige Gaben (claritas intelligentie), 2. Reinheit des Gewissens (puritas conscientie), 3. demütigen Gehorsam (humilitas obedientie), 4. gewissenhaftes Vorgehen (sedulitas diligentie), 5. unerschütterliche Geduld (maturitas patientie), 6. wohltuende Milde (suavitas clementie), 7. Gerechtigkeitssinn (equitas iustitie), 8. Standfestigkeit und Prinzipientreue (firmitas constantie), 9. Sittenstrenge (severitas discipline), 10. der Wahrheit verpflichtete Lehre (veritas doctrine), 11. erhabene Mäßigung (gravitas continentie) und 12. Fülle der Gnade (immensitas gratie). Deutlich tritt die Verschränkung von geistigen und moralischen Qualitäten in der Person des Legaten zu Tage. Bertrand beeindruckt gleichermaßen durch Intellekt wie durch Affekt. Dieser Befund wird durch eine weitere Reihung bestätigt, in der ihm Treue gegenüber den ihm übertragenen Aufgaben, Wahrhaftigkeit in seinen Versprechungen, Leutseligkeit in seinen Worten, Anpassungsfähigkeit in seinen Taten, Demut auch im Erfolg und Standhaftigkeit im Unglück bescheinigt werden 680 .

Was folgt, ist eine gedankliche, in großen Teilen auch wörtliche Übernahme von Gesichtspunkten, die der Papst bereits im Dezember 1343 anläßlich der Rückkehr von Kardinal Guillaume Court an die Kurie geäußert hatte. Neben dem Thema Sicut frigus nivis wird das umfangreiche Zitat aus Bernhards Schrift De consideratione wiederbemüht, in dem die Eigenschaften eines guten Legaten lobend herausgestellt werden ${ }^{681}$. Dies verdeutlicht, wie hoch die Aussagekraft solch topischer Reihungen zu veranschlagen ist. Wo Aussagen zur intellektuellen und charakterlichen Eignung für das Legatenamt aus-

679 Ibid.: Legatus fidelis sanitas, ubi tria tanguntur: primo auctoritas humilier acceptata (legatus), secundo fidelitas irrefrigabilis observata (fidelis), tertio utilitas multipliciter reportata (sanitas). Vel possumus sic distinguere: posset aliquis querere, quis fuit istius status, quis actus vel cultus, quis finis vel fructus. Modo respondeo in verbis thematis preassumpti et dico primo, quod status fuit magne excellentie et honoris, secundo actus vel cultus fuit probate sanctimonie, iusticie et vigoris, tertio finis vel fructus fuit mire complacentie et dulcoris, efficacie et valoris. Describitur ergo dignitas assecuta, ut videatis eius principium gloriosum, puritas prosecuta, ut videatis eius medium virtuosum, sanitas consecuta, ut videatis eius terminum fructuosum. Iste ergo aliquid acceptavit in egressu, aliquid observabit in progressu, aliquid reportavit in regressu. Acceptavit alte dignitatis fastigium multum honorabile, sed laboriosum, observabit debite fidelitatis obsequium valde commendabile et virtuosum, reportavit optate sanitatis solacium summe delectabile et gaudiosum.

680 Ibid., fol.439va: Possum dicere, quod noster legatus fuit bonus legatus, qui habuit in comissis fidelitatem, in promissis veritatem, in verbis affabilitatem, in factis mutabilitatem, in prosperis humilitatem, in adversis securitatem.

681 Zum direkten Vergleich heranzuziehen sind MS 240, fol.439va und fol.248ra. Das Bernhard-Zitat findet sich in San Bernardo, Opere, I, S. 874-878. 
tauschbar werden, wo das Reservoir zur Beschreibung positiver Eigenschaften aus beliebig miteinander kombinierbaren Einzelbestandteilen besteht, tut man gut daran, sich von der Vorstellung zu lösen, der Papst konzipiere seine Collationes, um damit - ad personam zugeschnitten - eine unverwechselbare, weil persönliche Würdigung des jeweiligen Legaten vorzunehmen. Der Gehalt der angeführten Wertungen bleibt im Topischen verhaftet. Selbstverständlich bemüht man sich an der Kurie, erfahrene, intelligente, moralisch gefestigte Persönlichkeiten auf den Weg zu schicken. Angesichts dieser Tatsache kann festgehalten werden, daß Aussagekraft lediglich dort vorhanden ist, wo topische Lobeshymnen unterbleiben bzw. implizit oder explizit Kritik am Verhalten des Legaten geübt wird. Nur dort wird die rhetorische Routine unterbrochen, tauchen Brüche innerhalb der glatten Sprachhülle auf. Das erste Element - auctoritas humiliter acceptata - ist damit abgehandelt, ohne daß noch einmal explizit auf die überragende Position des Papstes als Quelle jedweder Autorität eingegangen worden wäre. Das zweite Element in Gestalt der unverbrüchlichen Treue des Legaten (fidelitas irrefragabiliter observata) verweist ebenfalls auf eine inferiore Position im Verhältnis zum Papst, dem Treue geschuldet wird ${ }^{682}$.

Die dem Papst bewiesene Treue sollte sich für Bertrand auszahlen. Gleichsam beiläufig verkündet der Papst die Absicht, ihn für geleistete Dienste in den Rang eines Kardinalbischofs zu erheben ${ }^{683}$. Hatten kurz zuvor die Eigenschaften eines bonus legatus Erwähnung gefunden, sind es nun diejenigen eines fidelis legatus, die zwar benannt, jedoch nicht weiter ausgeführt werden ${ }^{684}$. Die Ansprache schließt mit einem der Apokalypse entnommenen Zitat - Esto fidelis usque ad mortem et dabo tibi coronam vite [Apc 2,10] -, dem eine knappe Segensformel beigefügt wird. Offensichtlich war die Collatio zu umfangreich geraten, mußte der Papst doch auf die Behandlung des noch ausstehenden dritten Elements, der sich auf vielfache Weise ausdrückenden Nützlichkeit (utilitas multipliciter reportata), verzichten.

682 Freilich bemerkt Clemens VI., daß sich Bertrand de Deux nicht nur ihm gegenüber als treu erwiesen, sondern in diese Treue auch alle Bewohner seines Legationsgebietes miteingeschlossen habe, MS 240, fol. 440ra: Invenisti cor eius fidele coram te [Neh 9,8]. Et certe non solum coram me, ymmo etiam coram illis, ad quo missus est.

683 Ibid., fol.440ra: Ut de eo dicam illud I ad Corinthios IIII: Misi ad vos Thimotheum, qui est filius meus carissimus et fidelis in Domino [I Cor 4,17]. Et bene dicit carissimus filius, quia cum misi eum filius erat dilectus inter ceteros valde. Erat enim tunc presbyter cardinalis, quibus papa scribit ut dilectis filiis suis. Sed in regressu factus est frater, quia episcopus cardinalis. 684 Zehn Eigenschaften werden angeführt, ibid., fol. 440rb: [...] Primo quidem mittentis beneplacitum et voluntatem prudenter recolligendo; secundo iussum iuxta suam possibilitatem viriliter exequendo; tertio mandatum et eius qualitatem diligenter observando, nec preteriendo, nec excedendo; quarto omnem contrarietatem fortiter repellendo; quinto omnem adversitatem equanimiter sustinendo; sexto acceptam auctoritatem irreprehensibiliter prosequendo; septimo datam potestatem non secundum personarum acceptionem sed secundum merita salubriter distribuendo; octavo fructus iocunditatem multipliciter reportando; nono assecutam prosperitatem mittendi principaliter attribuendo; decimo gestorum veritatem fideliter referendo. 


\subsubsection{Die Legationen der Kardinäle Annibaldo Ceccano und Gui de Boulogne nach Rom, Neapel und Ungarn (1348-1351)}

\subsubsection{Die Legation von Kardinal Annibaldo Ceccano im Spiegel der kurialen Registerüberlieferung}

Mit der Bulle vom 30. November 1348 hatte der Papst den legationserprobten Purpurträger Annibaldo Ceccano zum Legaten in Tuszien, der Romagna, Mark Ancona, dem Dukat von Spoleto, der Campagna und Marittima, den Bistümern Perugia, Todi, Narni, Rieti, Terni und weiteren Gebieten ernannt. In einer zweiten, zeitgleich ausgestellten Bulle wurde ihm die Legation im Königreich Sizilien übertragen ${ }^{685}$. Die Kurie handelte also ungewohnt

685 Lettres Clément VI autres que la France, nn.1758-1759 (30.11.1348) (nur Regest); vgl. RV 187, fol. 1r-v, n.1: [...] Nos vero diligentius attendentes, quod propter magna et ardua, que nobis in partibus citramontanis incumbunt et ad partes illas, ubi mente sumus, accedere personaliter pro huiusmodi nostro exequendo desiderio non valemus, et quod personam tuam gratiarum dator altissimus scientie magnitudine, industrie claritate et aliis multis virtutibus insignivit, ad te, in cuius affectibus geritur pacificare discordes et virtutum seminaria serere nostrum intuitum, ut fortem opere et sermone mittamus ad fortia et tuis robustis humeris onera grandia imponamus duximus dirigendum. Ideoque gerentes de tuis claris meritis et virtuosis operibus fiduciam in domino specialem, quamvis nos et fratres nostri tanti viri presentia nobis et Ecclesie Romane necessaria et perutili careamus inviti, tamen propter urgentem et evidentem necessitatem Tuscie et aliarum partium predictarum, quibus speramus per tuam providentiam circumspectam illo tibi auxiliante, qui potest omnia in promissis salubriter consuli et utiliter subveniri, te tanquam pacis angelum ad dictas partes videlicet Tuscie, Romandiole, Marchie Anconitane, ducatus Spoletani et Patrimonii beati Petri in Tuscia, Campanie Maritimeque provincias necnon Perusine, Tudertine, Reatinensis, Narniensis, Interampnensis civitates et dioceses et alias terras et provincias Romane ecclesie subiectas in partibus Italie, ut predicitur constitutas, Ferrariensis et Bononiensis civitatibus et diocesibus dumtaxat exceptis, committendo tibi in eisdem partibus, civitatibus et diocesibus vices nostras ac plene legationis officiu [...] de dictorum fratrum consilio destinamus tibi, ut in proximo nominatis partibus, provinciis, civitatibus et diocesibus inter ecclesiasticas mundana sue personas duces, principes, marchiones, comites, barones, milites et nobiles, communitates, universitates ac populos et alios universos et singulos discordes bonum pacis studeas reformare ac concordes in fraterne dilectionis glutino conservare et etiam confirmare et nichilominus agere et tractare, quecumque ad cultum Dei, exaltationem catholice fidei, Apostolice Sedis honorem, observantiam ecclesiastice sanctionis et reintegrationem ecclesiastice libertatis honestate et morum cultum relevationem ecclesiarum et locorum ecclesiasticorum et pauperum salutem animarum et tranquillitatem corporum et robur status prosperi patrum provinciarum ac civitatum et diocesium predictarum quomodolibet pertinebunt, et huiusmodi commissum tibi legationis officium ad nostrum et Apostolice Sedis honorem ac commodum et tranquillitatem et pacem incolarum partium earundem et presertim terrarum et locorum nobis et eidem ecclesie Romane subiectarum in eisdem partibus consistentium et utilius et efficacius iuxta cor nostrum gerere valeas, quo maiora prerogativa favoris et gratie fueris communitas te zelatorem pacis, amatorem iusticie ac veritatis amicum et in arduis negociis clara fidelitate probatum reformatorem dictarum provinciarum terrarumque immediate nobis eidem ecclesie Romane subiectas in spiritualibus et temporalibus auctoritate nostra, quecumque reformationis et correctionis auxilio videris et cogitaveris indigere, pro honore ipsius ecclesie atque nostro ac utilitate, pace et tranquillitate terrarum huiusmodi ecclesie eidem Romane, ut premittitur, subiectarum nec- 
schnell: Nur knapp zwei Wochen waren seit der Rückkehr des Bertrand de Deux nach Avignon vergangen. Mit dem neuen Legaten wurde ein Diplomat reaktiviert, der mehrere Vorteile in seiner Person vereinigte. Annibaldo war 1347 während einer Gesandtschaft, die ihn zusammen mit Étienne Aubert zum englischen und französischen König geführt hatte, mit der Vermittlung des Waffenstillstands von Calais ein diplomatischer Achtungserfolg gelungen, der ihn für eine weitere Verwendung im diplomatischen Dienst der Kurie prädestinierte. Nach Guillaume Court, Aimeric de Châtelus und Bertrand de Deux handelte es sich bei ihm um den ersten, in das genannte Gebiet entsandten Legaten, der als Italiener mit der Situation im Gebiet von Rom vertraut war ${ }^{686}$. Leider ist in Hinblick auf seine Legation nicht annähernd so viel Quellenmaterial erhalten wie im Falle der zeitgleich verlaufenden $\mathrm{Ge}$ sandtschaft des Gui de Boulogne nach Ungarn. Wegen des in legationibus erfolgten Todes von Annibaldo fehlt außerdem eine Begrüßungscollatio Clemens' VI.687

Der Bestand der bewilligten Fakultäten ist mit rund 80 Eintragungen außerordentlich umfangreich ${ }^{688}$. Die ihm zustehenden Prokurationszahlungen innerhalb des eigentlichen Legationsgebietes waren Gegenstand einer eigenen Bulle, darüber hinaus wurde jedoch auch seine finanzielle Versorgung außerhalb dieses Gebiets mit 40 Florin täglich festgesetzt ${ }^{689}$. Der Aufenthalt in der Heiligen Stadt wurde durch eine Fülle romspezifischer Vollmachten flankiert ${ }^{690}$. Die Abreise des Kardinals aus Avignon muß unmittelbar vor dem 16. Januar 1349 erfolgt sein ${ }^{691}$, doch noch am 18. d. M. ist er in seiner Sommerresidenz in Gentilly nachweisbar ${ }^{692}$. Sein Gefolge umfaßte 30 Kapläne und Familiaren, wie aus einem dem Papst unterbreiteten Supplikenrotulus

non contradictores et rebelles quoslibet per excommunicationis, suspensionis et interdicti, ammonitionis, privationis et depositionis sententias et alias per censuram ecclesiasticam ap. pelatione postposita compescendi [...] plenam et liberam facultatem [...]. Quocirca fraternitati tue per apostolica scripta mandamus, quatinus iniunctum tibi eiusdem legationis ministerium et reformationis officum pro divina et dicte sedis ac nostra reverentia devote suscipiens sic illa viriliter, diligenter et solicite iuxta datam tibi a Deo prudencia exequaris, quod de tuis studiosis laboribus celesti favente clementia optati fructus adveniant [...]. Am 13. Januar 1349 ergehen zusätzlich Empfehlungsschreiben an 67 Empfänger im regnum Siciliae, vgl. Lettres Clément VI, n. 4031.

686 Diese verwandtschaftlichen Beziehungen lassen Annibaldo freilich auch stärker als angemessen in die römischen Fraktionskämpfe involviert sein, vgl. Lettres Clément VI autres que la France, nn. 1998 (28.05.1349), 2025 (01.07.1349).

687 Die Legation behandelt DYkMANS, Annibal de Ceccano, S. 247-279.

688 Lettres Clément VI autres que la France, nn.1760-1838; nachgeschoben werden die nn. 1883 (24.12.1348), 1892-1896 (13.01.1349).

689 Ibid., nn. 1762f. Auf eine Angabe der genauen Höhe der im Legationsgebiet zu leistenden Prokurationen wurde mittels Verweis auf procurationes in partibus legationis sue debitas legato a latere verzichtet.

690 Ibid., nn. 1767, 1816, 1827, 1883, 1892.

691 Ibid., n. 1899 (16.01.1349).

692 Dykmans, Annibal de Ceccano, S. 254. 
vom 13. Januar ersichtlich ist ${ }^{693}$. Die eigentliche Reiseroute des Kardinals ist nur schwer rekonstruierbar, da abgesehen von einigen chronikalen Belegen keinerlei administrative Akte überliefert sind. Der Anonimo Romano berichtet von einem Zusammentreffen Annibaldos mit Giovanni Visconti, dem Erzbischof von Mailand, vor den Toren der Stadt. Der Anblick des Erzbischofs, dem fünf prächtig geschmückte Pferde vorangingen, soll ihn zu der Frage veranlaßt haben: "Erzbischof, weshalb dieser Pomp, diese eitle Zurschaustellung von Reichtum«? Visconti blieb die Antwort nicht schuldig und bemerkte maliziös: »Legat, hier handelt es sich nicht um Pomp, sondern um meinen Wunsch, dem Heiligen Vater vor Augen zu führen, daß es unter ihm noch einen kleinen Kleriker gibt, der über gewisse Machtmittel verfügt «. Eine Antwort des Legaten auf diese anmaßende Äußerung ist nicht überliefert ${ }^{694}$. Der Einfluß des Giovanni Visconti sollte rund 18 Monate später noch einmal deutlich werden: Auf seinem Gebiet wurde die Korrespondenz des Kardinals mit der Kurie abgefangen und geöffnet ${ }^{695}$. Das Chronicon Mutinense berichtet vom Durchzug des Legaten durch Modena am 22. Februar 1349 mit einem beeindruckenden Gefolge, das allein 600 Pferde umfaßt haben soll ${ }^{696}$. In der Romagna kam es zum Konflikt mit Astorge Dufort, dem Rektor und Neffen des Papstes ${ }^{697}$.

Die Ankunft in Rom muß im Frühjahr 1349 während der Fastenzeit erfolgt sein. Dort harrten zwei Aufgaben der Erledigung. Alles sollte unternommen werden, um eine Rückkehr des vertriebenen Cola di Rienzo nach Rom zu verhindern ${ }^{698}$. Des weiteren sollten die Bullen, mit denen das in Rom $1350 \mathrm{zu}$ begehende Heilige Jahr offiziell proklamiert worden war, bekanntgemacht werden. Damit verbunden war die Organisation des Heiligen Jahres. Zumindest bis Juni blieb Annibaldo in Rom. In einem umfangreichen, auf den 6. Juni datierten Schreiben beglückwünschte ihn der Papst zu den bisher vorgenommenen Reformen, zur Bestrafung der mit Rienzo sympathisierenden Aufrührer und zu den Maßnahmen, die den zu erwartenden Pilgerstrom in ruhige Bahnen lenken sollten. Außerdem wurde ihm die sorgfältige Auswahl neuer Senato-

$693 \mathrm{Vgl}$. RS 18, fol.99-102v. Dykmans unterzieht diese Eintragungen einer eingehenden Analyse, vgl. Dykmans, Annibal de Ceccano, S. 247-251.

694 Anonimo Romano, ed. PORTA, S. 157: Questo cardinale legato, scritta che abbe soa famiglia, muosso de Avignone, descenneva in Lommardia. Missore Ianni Visconte arcivescovo de Milana, tiranno de Lommardia, li iessio innanti per farli onore. Cinque destrieri copierti de scarlatto, menati a mano, ivano denanti allo arcivescovo. Quanno lo legato vidde questo, stordio, favellao e disse: Arcivescovo, que pompa, que vanagloria è questa? Respuse lo arcivescovo e disse: Legato, questo non ène pompa, ma ène ca voglio che saccia lo patre santo ca esso hao sotto de si uno chierichetto lo quale pò qualche cosa.

695 Lettres Clément VI autres que la France, n. 2261 (24.07.1350).

696 JohanNes de BAZANo, Chronicon Mutinense, Mailand 1729 (RIS, 15), S. $146 f$.

697 Lettres Clément VI autres que la France, n. 2011 (06.06.1349).

698 Der Kardinallegat hatte daran wohl auch ein ureigenstes Interesse, waren während der kurzen Herrschaft Rienzos in Rom doch einige Verwandte zu Opfern im Kampf gegen den Tyrannen geworden, vgl. DykMaNs, Annibal de Ceccano, S. 255. 
ren ans Herz gelegt ${ }^{699}$. In dieser Sache überließ der Papst nichts dem Zufall. Im September stellte er den Legaten vor vollendete Tatsachen und teilte ihm die Ernennung des Gérard de Ventadour zum Senator mit ${ }^{700}$.

$\mathrm{Zu}$ diesem Zeitpunkt befand sich Annibaldo bereits in Neapel ${ }^{701}$, wo er hauptsächlich damit beschäftigt war, die nach nur wenigen Monaten am Rande des Scheiterns stehende Ehe Johannas I. mit Ludwig von Tarent zu retten, um damit die nach wie vor instabile Situation vor Ort zu festigen ${ }^{702}$. Angesichts des neapolitanischen Ränke- und Intrigenspiels hatte die an den Legaten gerichtete Warnung, die eigene virtus nicht zu verlieren, ihren Sinn ${ }^{703}$. Da man eine erneute Invasion des ungarischen Königs in das Königreich Neapel befürchtete, wurde enger Kontakt zwischen der Kurie und den beiden in Neapel und Ungarn positionierten Legaten, die auch ohne den Umweg über Avignon miteinander Austausch pflegten, gehalten. Annibaldo gelang es immerhin, mit den das Gebiet des Königreichs verwüstenden Söldnertruppen - Werner von Ürslingen an der Spitze - einen Waffenstillstand zu schließen, dem Johanna I. und Ludwig von Tarent zustimmen mußten ${ }^{704}$. Trotz oder gerade wegen dieses Erfolgs wurde die Position des Annibaldo in Neapel durch massive Verleumdungskampagnen geschwächt. In Avignon schenkte man diesen Anschuldigungen freilich keinen Glauben: Nach zwei Legationen in dasselbe Gebiet war man an der Kurie mit dem Instrumentarium personaler Diskreditierung vertraut ${ }^{705}$. Als sich die Gerüchte über eine unmittelbar bevorstehen-

${ }^{699}$ Lettres Clément VI autres que la France, n. 2011 (06.06.1349).

700 Lettres Clément VI, n. 4257 (18.09.1349). Bereits im November sollte der neue Senator auf sein Amt verzichten, vgl. I8ID., n. 4330 (06.12.1349).

701 Am 2. Juli 1349 landete er in der Bucht von Neapel, vgl. Chronicon Siculum, hg.v. Giuseppe de BLASIIS, Neapel 1887, S. 14; LEONARD, Jeanne, I, S. 223.

702 Vgl. zur "Eheproblematik « Lettres Clément VI, nn. 4036 (20.01.1349), 4056-4057 (10.02.1349), 4226 (17.08.1349), 4238 (27.08.1349), 4245 (10.09.1349), 4250 (13.09.1349), 4260 (19.09.1349), $4555(09.06 .1350)$.

703 Lettres Clément VI autres que la France, nn. 2011 (06.06.1349), 2013 (12.06.1349). Angekündigt wurde des weiteren die Übersendung der von Kardinal de Deux gegen Cola di Rienzo vorbereiteten processus.

704 Vgl. Dykmans, Annibal de Ceccano, S. 266f. Der Waffenstillstand trat am 23. Juli 1349 in Kraft und sollte bis Weihnachten dauern. Am 10. August gelang es Annibaldo außerdem, die in der Terra di Lavoro umherziehenden Söldnerheere gegen Zahlung der hohen Summe von 250000 Goldflorin zum Verlassen des Territoriums zu bewegen. Gleichzeitig war es Gui de Boulogne gelungen, dem ungarischen König die Zustimmung zu einem Waffenstillstand abzutrotzen, der von Weihnachten 1349 bis Weihnachten 1350 dauern sollte; vgl. zu den Söldnern die Überblicksdarstellung von Stephan SELZER, Deutsche Söldner im Italien des Trecento, Tübingen 2001 (Bibliothek des DHI Rom, 98).

705 Lettres Clément VI, n. 4245 (10.09.1349). Clemens VI. unterstellt in diesem Schreiben Ludwig von Tarent, quod tu adversus venerabilem fratrem nostrum Anibaldum, episcopum Tusculanum, A.S. legatum, suggerentibus aliquibus tibi mendaciter, ut probabiliter credimus, quod ipse tractatus aliquos prejudiciales tibi cum hostibus prefatis habebat, et quod inter te dictamque reginam scandalum seminabat, tuo detrahebat honori, fideles tuos a devotione tua et obedientia advertebat, et statum supprimebat tuum, occasionem concepisti suspicionis et causam. 
de Invasion weiter verdichteten, erging die Aufforderung, Johanna I. und Ludwig von Tarent dazu zu bewegen, die administratio regni in die Hände des Papstes zu legen. Damit oblag dem Legaten die undankbare Aufgabe, Neapel zur Akzeptanz eines von außen verfügten Ausnahmezustands zu bewegen und eine temporäre Entmachtung der legitimen Souveräne vorzubereiten ${ }^{706}$. Johanna stand dem Ansinnen des Legaten keineswegs ablehnend gegenüber, hätte es ihr doch die Möglichkeit eröffnet, sich dem Einfluß des tyrannischen Ludwig von Tarent zu entziehen. Ihre Absicht blieb nicht verborgen. Auf demütigende Weise zwang man sie dazu, ihre Einwilligung, das Königreich der direkten Verwaltung durch den Papst zu unterstellen, zu widerrufen.

Annibaldo dachte zu diesem Zeitpunkt bereits wieder an eine Rückkehr nach Rom, wo die in Zusammenhang mit Cola di Rienzo und dem Heiligen Jahr stehenden Probleme noch nicht vollständig gelöst waren ${ }^{707}$. Bereits im November 1342 war einer 18 Mitglieder umfassenden römischen Gesandtschaft die Verkündigung eines Heiligen Jahres für 1350 zugesagt worden ${ }^{708}$, gefolgt von der feierlichen Proklamation der Jubiläumsbulle Unigenitus Dei

706 Ibid., n. 4263 (22.09.1349) (nur Regest), vgl. RV 143, fol. 84v: Compacientes ex paterne caritatis affectu carissime in Christo filie nostre Johanne Regine Sicilie Illustri et dilecto filio nobili viro Ludovico de Tarento viro suo super periculis et tribulacionibus, quibus involuti multipliciter fore noscuntur et que ipsi minus prudenter non cogitant ac miserabili Regno Sicilie, quod multiplicatis in eo scissuris innumeris discerpitur, undique et non solum ab hostibus impugnatur et premitur, sed ab ipsis eius incolis et habitatoribus more vipereo ab omni latere corroditur, prodolor condolentes eisdem Regine ac Ludovico per alias nostras scribimus hortantes et rogantes eosdem, ut consentiant, quod administratio dicti Regni eorum, videlicet que ipsi possident et eorum, que ab hostibus detinentur, in manibus nostris vel alicuius alterius persone ipsis Regine ac Ludovico non suspecte, sed de qua possint plene confidere, ponatur gerenda nomine nostro et ipsius ecclesie, donec negocia, que imminent finem aliquem prosperum fuerint auctore domino consecuta cum sicut ex hiis, que tibi scripsimus pridie perpendere potuisti, carissimus in Christo filius noster Ludovicus Rex Ungarie illustris in hoc voluntati nostre conformare se videatur. Tu ergo frater ex paucis, que premisimus, multa considerans et attendens, quam utile ac expediens foret, quod procellis et fluctibus, quibus idem Regnum exestuat tranquillitas, serenitas alicuius finem imponeret, aliqualem da operam favorabiliter et solicite, prudenter et provide, sicut nosti apud Reginam, quam in hoc voluntariam testimonio litterarum tuarum invenire confidimus et Ludovicum predictos, quod nostris in hac parte exhortationibus et consiliis acquiescant rescripturus nobis celeriter eorum super hiis voluntatem et quicquid egeris in eisdem. Nos enim a dilecto filio nostro Guidone tit. S. Cecilie presbyteri cardinale, A.S. legato, cui super hoc scripsimus, responsionem expectamus habere celeriter, per quam nobis intentio circa hoc dicti Regis Ungarie clarius innotescet. Vgl. zum weiteren Vorgehen des Königs von Ungarn Lettres Clément VI, nn. 4384 (25.01.1350), 4471 (14.04.1350). Trotz der noch immer schwebenden Untersuchung über den Tod Andreas' von Ungarn galt Johanna I. an der Kurie weiterhin als legitime Herrscherin, ibid., n. 3852 (07.05.1348).

707 Die facultas adeundi ad Urbem war bereits am 3. September 1349 ergangen, ibid., n. 2055. Die Entscheidung für eine Rückkehr nach Rom wurde dem Legaten durch die Bewilligung einer wichtigen Personalie versüßt: Auf Empfehlung Annibaldos war einer seiner Kämmerer zum neuen Erzbischof von Genua ernannt worden.

708 Dupré-Theseider, Roma, S.524-526; SChMidinger, Antwort Clemens' VI., S. 323-365. 
filius am 27. Januar $1343^{709}$. Clemens VI. hatte darin zwar die enge Verbindung zum ersten, von Bonifaz VIII. im Jahre 1300 gefeierten Heiligen Jahr unterstrichen, aber dennoch substantielle Änderungen bzw. Erweiterungen vorgenommen. Seine Ausführungen bezüglich der Lehre vom Kirchenschatz (thesaurus Ecclesie) wurden Grundlage der kirchlichen Ablaßlehre ${ }^{710}$. War im Jahr 1300 der Besuch zweier Basiliken, St. Peter und St. Paul vor den Mauern, für die Erlangung des vollständigen Ablasses nötig gewesen, fügte Clemens VI. als drittes Etappenziel nun zusätzlich die Basilika S. Giovanni in Laterano hinzu. Das von Bonifaz VIII. festgelegte Intervall zwischen den Heiligen Jahren wurde des weiteren von hundert auf fünfzig Jahre verkürzt ${ }^{711}$. Die Publikation der Bulle wurde vom Papst freilich über Jahre hinweg immer wieder hinausgeschoben und als Druckmittel verwandt, um die eigensinnigen Römer zum Widerstand gegen Cola di Rienzo zu bewegen. Tatsächlich erfolgte die Publikation erst am 18. August $1349^{712}$. Als höchste Vertreter der Kurie in Rom fungierten 1350 papa absente die beiden Kardinäle Annibaldo Ceccano und Gui de Boulogne, letzterer jedoch nur für wenige Tage. Nicht alle Anordnungen des Legaten fanden Zustimmung. Insbesondere seine Verfügung, die für die Gewinnung des Plenarablasses nötigen Bedingungen dahingehend abzuschwächen, daß der Besuch der drei Patriarchalbasiliken nicht mehr an

709 Die kardinalizischen Teilnehmer an diesem öffentlichen Konsistorium verzeichnen die Protokollbücher der päpstlichen Kammerkleriker, vgl. SCHRÖDER, Protokollbücher, n. 74. Unter den anwesenden 13 Kardinälen sucht man Annibaldo Ceccano vergeblich, vermittelte er in seiner Eigenschaft als Nuntius im Januar 1343 doch fernab von Avignon den Waffenstillstand von Malestroit. Die Bulle fand Eingang ins Kirchenrecht, vgl. Extr. comm. 5,9,2; Acta Clementis PP. VI (1342-1352), hg. v. Aloysius L. Tautu, Città del Vaticano 1960 , n. 155, S.246-250. Die in der Ansprache Desidero enim videre vos artikulierte Antwort Clemens' VI. an die Gesandtschaft der Stadt Rom wurde ediert von SCHMIDINGER, Antwort, S.143-167. Eine Predigt Clemens' VI. zum Heiligen Jahr Clemens et pius omnipotens Deus misericordiarum pater ist nach wie vor unediert, vgl. WooD, Clement VI, S. 212. Die kritische Edition des Textes nach Ms. Barth. 71 der Stadt- und Universitätsbibliothek Frankfurt a. M., fol.207ra-209ra erfolgt in Kürze vom Vf.

710 Die maßgebliche Darstellung zur Entwicklung der kirchlichen Lehre vom Ablaß findet sich noch immer bei PAULus, Geschichte des Ablasses, Bd.2, S. 102-123; vgl. auch Iacobus STEFANESCHI, De centesimo seu iubileo anno, hg. v. Paul G. Schmidt, Florenz 2001, S. 81-84. 711 Agostino Paravicini Bagliani, Clemente VI e il giubileo del 1350, in: La Storia dei Giubilei, Bd. 1 (1300-1423), Prato 1997, S.270-278; Jacques Verger, Annus centesimus vel quinquagesimus. Le pape Clément VI et la bulle d'indiction du Second Jubilé (27 janvier 1343), in: I Giubilei nella storia della Chiesa. Atti del Congresso internazionale (Rom, 23.-26. Juni 1999), Città del Vaticano 2001, S. 281-289; in den Vitae Clementis VI wird̀ zwar die Tatsache der Verkürzung des Intervalls zwischen zwei Heiligen Jahren, die Rolle des Kardinallegaten jedoch mit keinem Wort erwähnt, vgl. BaLUZE/Mollat, Vitae I, S.253f., 270, 278f., 290, 299, 304f.

712 Lettres Clément VI autres que la France, n. 2047; Lettres Clément VI, nn. 4227f.; Paul VIAN, Papi, popolo e giubilei, in: Roma Sancta. La città delle basiliche, Rom 1985, S.18-27; SCHMidinger, Antwort, S. 138f. Vier Jubiläumsbullen, bestimmt für die drei Patriarchalbasiliken und das Legationsgebiet, waren Annibaldo bereits am 10. April 1349 zugegangen, vgl. Lettres Clément VI, n. 1976 (10.04.1349). 
fünfzehn, sondern nur noch an sieben Tagen erforderlich war, rief den Zorn der Römer hervor, da sie aufgrund dieser Maßnahme substantielle Verluste im Geschäft mit den Pilgern befürchteten ${ }^{713}$. Der unbestreitbare Vorteil dieser Anordnung, die Lenkung und Kanalisierung der Pilgerströme, wurde nicht gesehen $^{714}$.

Die mit Abstand lebendigste Erzählung von der Unbill, die Annibaldo Ceccano durch die Römer erlitt, findet sich einmal mehr beim Anonimo Romano, der die Persönlichkeit des Legaten scharfer Kritik unterzog ${ }^{715}$. Er beklagte nicht nur die Herkunft des Legaten aus der Campagna, einem Rom seit jeher feindlich gesonnenen Gebiet, seine Spielernatur und seine überbordende Pracht- und Luxusliebe ${ }^{716}$, sondern verwies auf ein besonderes Laster, das er nicht konkret benannte, sondern mit der Wendung la quarta voglio tacere lediglich andeutete. Das Laster, das man besser verschweigt, galt als die »stumme Sünde«. Im Gegensatz zu der von F. X. Kraus vertretenen Meinung, es handle sich hierbei wohl um aus der Verwaltungstätigkeit resultierende Spannungen mit den Römern, sollte festgehalten werden, daß der Terminus »stumme Sünde« die gängige Bezeichnung für das Laster »wider die Natur«, nämlich die Homosexualität, war ${ }^{717}$. Obwohl die Geißelung sexueller Vergehen zum Grundbestand fast jeder mittelalterlichen Klerikerschelte zählte, ist doch aufällig, daß für das Avignonesische Papsttum solche Belege rar sind. Zwar

713 Lettres Clément VI autres que la France, n. 2142 (20.02.1350).

714 Die prekäre Infrastruktur zur Zeit des Heiligen Jahrs 1350 beschreibt Matteo Villani in seiner Chronik, lib. I, c. 58. Auf die Erwartungshaltung der Römer hinsichtlich der ökonomischen Vorteile des Heiligen Jahres verweist Giovanni Villani, in: Cronaca, ed. PorTA, lib. XIII, c. XI, S. 321. Im letzten Satz berichtet der Chronist davon, Clemens sei ob der Bewilligung des Heiligen Jahres von der gesamten Christenheit hochgelobt worden, $e$ maggiormente da' Romani, che nn'aspettavano la grascia. Das, was die Römer vom Heiligen Jahr erwarteten, wird also recht unverblümt auf den Punkt gebracht: la grascia verweist dabei weniger auf die sprituellen Gnadengaben, sondern die handfesten materiellen Vorteile, die von den Römern wohl auch als Teilkompensation der ihnen aus der fortwährenden Abwesenheit des Papsthofes entstandenen materiellen Schäden begriffen wurden.

715 Ibid., S. 157-160; eine Teilübersetzung findet sich bei Franz Xaver KRAUs, Essays, Bd. 2, Berlin 1901, S.288-291.

716 Die Feststellungen des Anonimo sind nicht aus der Luft gegriffen. Erinnert sei an das Gastmahl, das Annibaldo Ceccano 1343 mit ungeheurem Kostenaufwand in seiner Residenz in Gentilly für Clemens VI. veranstaltete, vgl. dazu CaSANOVA, Visita di un papa; französische Übersetzung bei de LOYE, Réceptions, S. 81-92; vgl. zum kulinarischen Luxus der Kardinäle auch den bei Muratori, RIS 12, c. 1046 getätigten Vergleich mit dem königlichen Luxus eines Giovanni Visconti: Nec sunt hodie quatuor cardinales simul, qui tantas expensas faciant.

717 Vgl. zur Problematik des peccatum mutum v.a. Bernd-Ulrich HeRgemöLLER, Sodomiter - Erscheinungsformen und Kausalfaktoren des spätmittelalterlichen Kampfes gegen Homosexuelle, in: Randgruppen der spätmittelalterlichen Gesellschaft, Warendorf ${ }^{2} 1994$, S. 361-405; Ders., Sodom und Gomorrha. Zur Alltagswirklichkeit und Verfolgung Homosexueller im Mittelalter, Hamburg 1998, bes. S.21f.; John Boswell, Christianity, social tolerance and homosexuality, Chicago, London 1981, bes. S. 41-61 (definitions); Mark D. JORDAN, The invention of Sodomy in christian theology, Chicago, London 1997. 
wurde dem Papst selbst mit ermüdender Regelmäßigkeit ein Verhältnis mit der Vicomtesse de Turenne unterstellt ${ }^{718}$, die Gesamtheit der Kardinäle blieb von solcherart Unterstellungen jedoch verschont. Lediglich Petrarca machte eine Ausnahme und verwies auf »unnatürliche Laster «, die das Leben in Avignon begleiteten - doch auch hier wurden Kardinäle nicht explizit genannt ${ }^{719}$.

Die Aussage des Anonimo Romano ist also genausowenig verifizierbar wie der sich anschließende Bericht über einen Volksaufstand, der sich an nichts geringerem als dem Kamel des Kardinals entzündet haben soll - offensichtlich führte Annibaldo Ceccano eine Art Menagerie mit sich, ein weiterer Beleg für seine Prachtliebe ${ }^{720}$. Das exotische, den Römern weitgehend unbekannte Tier habe, so der Anonimo, für einen solchen Menschenauflauf gesorgt, daß die Familiaren des Kardinals, um das Leben des Tieres fürchtend, wahllos auf die Menge eingeschlagen hätten. Die Situation geriet in der Folge außer Kontrolle: Eine Schlacht entbrannte, der Apostolische Palast wurde belagert, von den Männern des Kardinals jedoch gehalten. Der Legat verfolgte den Aufstand denn auch erstaunt und voller Furcht von einem Balkon aus. Die Intention des Berichts ist eindeutig. Dargestellt werden sollte das wenig souveräne Verhalten des Kardinals, seine völlige Hilf- und Ahnungslosigkeit. Mit einem Pfund konnte er offensichtlich nicht wuchern, mit dem der Autorität. So scheint es auch nicht weiter verwunderlich, daß niemand seine Bemühungen, durch Gestikulieren für Ruhe zu sorgen, beachtete. Wenig staatsmännisch präsentiert sich denn auch der Ausruf: »Was habe ich den Römern getan?»

Annibaldo zeigte sich persönlich verletzt und hieß die Entscheidung des Papstes, Rom fernzubleiben, mit beredten Worten gut: Was solle das Oberhaupt der Christenheit auch an einem Ort, wo er Schwierigkeiten hätte, für sich den Rang eines Erzpriesters zu behaupten? Stolz seien sie, die Römer, und arm - so das abschließende Verdikt des Kardinals ${ }^{721}$. Die Situation beruhigte sich erst nach dem Eingreifen des Vorstehers des Hospitals S. Spirito in Sassia, Giovanni di Lucca.

Die Kompositionsgabe des Chronisten erweist sich in den folgenden Sätzen, wo auf die Feststellung, der Legat habe große Angst gehabt und habe es vorgezogen, nach Avignon zurückzukehren, die lakonische Bemerkung folgt:

718 Vgl. Mollat, Clément VI et la vicomtesse de Turenne.

719 Vgl. Sine nomine 8; Ep. Metr. 3,14.

720 Als Vorbild dürfte hier der Papst selbst gedient haben, der sich in Avignon nicht nur ein Hirschgehege, sondern auch eine Löwin hielt, vgl. SCHÄFER, Ausgaben Klemens VI., S. 239f., 257, 269, 297, 384; zur Bedeutung auch exotischer Tiere im Mittelalter vgl. Enrico ANNosCIA, Gli animali e l'uomo nel Medioevo, in: Quaderni medievali 38 (1994) S. 86-105. 721 Anonimo Romano, ed. PORTA, S. 158: [...] Ben pare che per forza vogliano tollere la fortezza. Quanno lo legato sentio ciò, maravigliaose e abbe paura. Staieva su alli balconi de sopre. Spre tutto vedeva. Non sapeva per che cascione questo fussi. Davase della mano per lo visaio e diceva: Questo che vole dicere? Que aio io fatto? Per que tanto detoperio me se fao? Vedi como date cascione voi Romani che.llo patre santo venga a Roma! In questa terra lo papa non fora signore, non fora iusto arciprete. Non me cresi venire a badaluccare. Haco li Romani somma povertate e granne regoglio. 
Questo legato fece preclare cose. Worin bestanden die vom Chronisten gerühmten bewundernswerten Taten? Die an erster Stelle angeführten schönen Teppiche, die der Legat den Jubiläumsbasiliken verehrte, dürften damit wohl genausowenig gemeint gewesen sein wie der Besuch der Schatzkammer von St. Peter. Die Nennung gerade dieser Elemente zu Beginn einer umfangreicheren Auflistung dürfte mit Absicht erfolgt sein, bot sie doch die Gewähr für eine weitere Diskreditierung des Legaten, der offensichtlich nicht zwischen Wichtigem und Unwichtigem zu unterscheiden verstand. Denn die Auflistung enthielt auch Bedeutenderes: So gewährte er vielen Städten, Provinzen und Fürsten Ablässe, machte von seinem Korrektionsrecht Gebrauch, indem er Pönitentiare und andere Verwaltungsbeamte bestrafte, ernannte Beamte und verkürzte die Anwesenheitspflicht der Pilger in der Stadt, eine Maßnahme, die der Anonimo nicht kritisierte, eröffne sie Rom doch die Möglichkeit, noch mehr Pilger aufzunehmen. Auf die persönliche Frömmigkeit des Kardinals wurde mittels der Bemerkung verwiesen, auch er habe den Plenarablaß gewinnen und - der alten Praxis folgend - während 15 Tagen die drei vorgeschriebenen Basiliken besuchen wollen. Alle Heimsuchungen hatte der Legat zu diesem Zeitpunkt jedoch noch nicht überstanden. Einem Attentat, das gegen ihn auf dem Weg von St. Peter nach St. Paul, genauer: zwischen S. Lorenzo degli Pesci und S. Agnolo delle Scale, ausgeübt wurde, entkam er nur knapp $^{722}$. Zwei Pfeile seien auf ihn abgeschossen worden, so der Chronist, von denen einer den Kardinalshut glatt durchbohrt habe. Annibaldo Ceccano kam mit dem Schrecken davon. Als arme, ja fast schon tragisch zu nennende Gestalt, als Häuflein Elend kehrte er in den Palast zurück und äußerte, daß in Rom auch ein hoher Rang vor persönlichen Anfeindungen nicht schütze ${ }^{723}$. Als Quintessenz durfte dabei die Erkenntnis gelten: »Besser wäre es für mich, ein kleiner Kleriker in Avignon als ein großer Prälat in Rom zu sein «724.

Vor diesem Hintergrund kann es nicht verwundern, daß er energisch seine Abberufung betrieb und dem Papst unmißverständlich zu verstehen gab, er habe das Mitleid der Kurie verdient. Sinn für dramatische Effekte konnte man ihm dabei nicht absprechen, legte er dem Brief an den Papst doch die ungewöhnliche Form einer cedula bei: den Pfeil, der ihn fast getötet hätte. Seit dem Attentat bewegte sich der Legat nur noch gepanzert durch eine Stadt, deren Feindseligkeit ihm von Tag zu Tag stärker zu Bewußtsein kam. Der Chronist verweist auf die Trostworte des Kardinals von S. Crysogone ${ }^{725}$, Rom sei

722 Vgl. zur Topographie der Kirchen Christian HülSEN, Le Chiese di Roma nel Medioevo, Florenz 1927, S. 294, n. 28, S.388, n. 118.

723 Anonimo Romano, ed. PORTA, S. 160: Allora se torna a casa lo legato. Omo pomposo che cercava gloria vedeva che era non reputato. Crepava da dolore. Staieva infiammato. Non trovava posa.

724 Ibid.: Meglio me fora essere in Avignone piccolo pievano che in Roma granne prelato.

725 Hierbei handelte es sich um Gui de Boulogne, der die Titelkirche Santa Cecilia innehatte, jedoch zusätzlich am 5.September 1351 die Basilika S. Chrysogone in commenda erhielt, vgl. Reg. Vat. 206, fol. 166v. Gui hielt sich im März 1350 für einige Tage in der Stadt auf. 
derart verderbt, daß alle Reformversuche bereits im Vorfeld zum Scheitern verurteilt seien. Wer Rom wirklich reformieren wolle, sei dazu gezwungen, es erst ganz zu zerstören, um auf den Trümmern neu anfangen zu können ${ }^{726}$. Der Anonimo beabsichtigte sicherlich keine ausgewogene Würdigung des Kardinallegaten. Als Römer bezog er klar Position und verzichtete nur dort auf seinen ironischen Unterton, wo ihn das Vorgehen des Kardinals entrüstete. Dessen Rachsucht, die sich in der Verhaftung und Verurteilung vermeintlich Schuldiger äußerte, wurde von ihm als verzweifelter Versuch gewertet, seine verletzte Würde wiederherzustellen. Freilich verzichtete er aber auf Schmähungen im Stile einer Birgitta von Schweden, für die Annibaldo einem Affen glich und zur Unperson wurde ${ }^{727}$.

Welche Absicht war mit der chronikalen Demontage des Legaten verbunden? Sicherlich ging es dem Anonimo nicht darum, Rom als Ort der Verdammnis darzustellen. Die Stadt zeichnete sich ihm zufolge durch einen stark ausgeprägten Willen zu Eigenständigkeit und Unabhängigkeit aus, Errungenschaften, die man sich auch von päpstlichen Kardinallegaten nicht nehmen lassen wollte. Wer in Avignon groß ist, muß vor der Größe Roms klein werden. Dies galt auch für Annibaldo Ceccano. Welchen Niederschlag fand die Verzweiflung und Verzagtheit des Legaten innerhalb der kurialen Korrespondenz? Clemens VI. erfuhr im Juni von dem Attentat auf Annibaldo, versicherte ihn augenblicklich seines Mitgefühls, forderte ihn jedoch zu noch größeren Anstrengungen auf, um ein Wiedererstarken der Sache Rienzos in Rom zu verhindern $^{728}$. Als eigentlich Schuldiger galt der Kurie also der Volkstribun, der sich ab Juli 1350 in Prag aufhielt, vom dortigen Erzbischof gefangengesetzt und anschließend nach Avignon ausgeliefert wurde. In Zusammenhang mit dem Heiligen Jahr hatte sich Annibaldos Organisationstalent bewährt. Nachrichten über ernsthafte Zwischenfälle liegen nicht vor. Wenn sich die vom Anonimo in dunkelsten Farben geschilderte Verzagtheit des Legaten irgendwo erwies, dann sicherlich bei der Behandlung aller Neapel betreffenden Angelegenheiten. Wie schon Bertrand de Deux vor ihm suchte er sich dem päpstlichen Mandat zu entziehen, das ihn dazu aufforderte, sich persönlich zum König von Ungarn zu begeben, indem er eine Klausel nutzte, die Clemens VI. seinem Schreiben beigefügt hatte: Die Reise solle selbstverständlich

726 Anonimo Romano, ed. PORTA, S. 160: Trovaose a Roma a queste cose lo cardinale de Santo Grisogano, omo dee Francia, granne prelato, granne barone. Gio denanti a missore Aniballo. Per consolarelo queste parole disse: Chi volessi rettificare Roma convénnera che tutta la guastassi, puoi la edficassi de nuovo.

727 Revelationes, 3, 11 (quasi simia) und 6, 70, Edition Rom 1606, S.185, 583 und Sancta Birgitta, Revelaciones, lib. VI, ed. Birger BERGH, Stockholm 1991, S. $230 f$.

728 Lettres Clément VI, n. 4555 (09.06.1350; nur Regest); vgl. RV 144, fol.26v: [...] Et ideo studii tui sit propositum dictorum populi circa hoc modis omnibus impedire, ne fiant novissima hominis illius, per quem venerunt non solum scandalum, sed scandala plurima peiora prioribus, si, quod advertat dominus, reascendat. Scimus enim argumentum ex preteritis suis actibus colligentes, quod quanquam ipse, ut reintegrationem eius multa promitteret, tandem sibi irridente fortuna pauca vel nulla servaret sicut est homo rare fidei et constantie rarioris. 
nur dann erfolgen, wenn eine Gefahr für Leib und Leben ausgeschlossen werden könne ${ }^{729}$. Nur wenig später wurde ihm jede Eigeninitiative in der ungarisch-neapolitanischen Angelegenheit untersagt. Der Papst wiederholte zwar seinen Wunsch, Annibaldo möge sich zum König von Ungarn begeben, versagte ihm jedoch die Vollmacht, eigenständig (nobis inconsultis) bindende Vertragsabschlüsse zu tätigen ${ }^{730}$.

Dazu sollte es auch nicht mehr kommen. Auf dem Weg von Rom nach Neapel starb der Kardinal am 17. Juli bei S. Giorgio in Liri ebenso unerwartet wie plötzlich, was zu gewissen Zweifeln an einem natürlichen Ableben führte. An der Kurie wußte man mit Gewißheit seit dem 13. August 1350 vom Tod des Legaten ${ }^{731}$. Und wieder ist es die Chronik des Anonimo romano, die eine farbenreiche Schilderung seiner letzten Stunden bietet. Ausgeschlossen wird die Vermutung, der Legat sei durch den Genuß vergifteten Weins ums Leben gekommen. Der Anonimo kommt jedoch nicht umhin zu bemerken, daß Annibaldo zu den guten Trinkern in der Kirche Gottes gehört habe ${ }^{732}$. In der Chronik wird die These vom Tod durch Unverdaulichkeit frischer Früchte in Verbindung mit Milch favorisiert. Selbst die beiden Leibärzte des Kardinals, Guido von Parma und Matthäus von Verona, konnten sein Ableben nicht verhindern. $\mathrm{Zu}$ großer Verwunderung führte die Tatsache, daß es nicht nur der Kardinal selbst war, der das Zeitliche segnete, sondern mit ihm noch weitere Familiaren starben. Sein Leichnam wurde nach Rom transportiert und dort in aller Eile in der Kapelle SS. Lorenzo e Giorgio in St. Peter, als deren Erzpriester Annibaldo fungiert hatte, bestattet.

Damit endete eine Legation, als deren positive Ergebnisse die Organisation des Heiligen Jahres und der Abschluß des Waffenstillstands mit den marodierenden Söldnertruppen im Königreich Neapel herausgestellt werden können. Trotzdem bleibt eine beträchtliche Negativbilanz bestehen: Dem Legaten gelang es weder, die gegen Johanna von Neapel gerichteten Vorwürfe, schuld am Tode ihres ersten Gatten Andreas gewesen zu sein, zu entkräften, noch sah er sich dazu in der Lage, das Verhältnis zu ihrem zweiten Gatten Ludwig von Tarent zu verbessern. Dies wäre jedoch conditio sine qua non für die Wiederher-

729 Lettres Clément VI, n. 4519 (24.05.1350); vgl. TheINER, Monumenta Hungariae, I, S.787, n. 1194. Immerhin ersuchte Annibaldo um die facultas redeundi ad curiam, die ihm am 23. Juli 1350 unter der Bedingung si tamen negociorum tibi commissorum dispositio patiatur auch zugestanden wurde, Lettres Clément VI, n.4611. Der ungarische König war Anfang Mai 1350 in Manfredonia gelandet.

730 IBID., n. 4559 (13.06.1350).

731 IBID., n 4647 (13.08.1350). Gerüchte waren bereits vor dem 10. August nach Avignon gedrungen, vgl. IBID., n. 4644.

732 Anonimo romano, ed. PORTA, S. 161: Venne a un castiello non moito da longa. In quello castiello posao. Como usanza ène, li presienti li currevano da onne parte. Fra le aitre cose li fuoro presentati moiti buoni vini in fiaschi. Dice omo ca questi vini fuoro venenati, ca li votti tutti erano venenati per la Gran Compagnia che curreva lo paiese. Questo non è verisimile. Pazzo fora chi volessi venenare sio vino. De questi divierzi vini lo cardinale, callo per lo cavalcare, bebbe e bene, perché aveva sete. Era delli buoni vevitori che avessi la Chiesia de Dio. 
stellung der vollen Reaktionskraft Neapels vor dem Hintergrund einer erneuten Invasion durch den König von Ungarn gewesen ${ }^{733}$. Aufgrund der schmalen Überlieferung ist Vorsicht bei dem Bemühen angebracht, das Verhältnis zwischen Papst und Legat zu beurteilen ${ }^{734}$. Deutlich wird, daß der Papst ebenso wie in allen anderen vorangegangenen Legationen bemüht war, seine Entscheidungskompetenz zu wahren und damit den Kardinallegaten von allzu eigenmächtigem Handeln abzuhalten. Wie in anderen Fällen zuvor stellte sich Clemens VI. schützend vor den Purpurträger und nahm ihn vor Verleumdungen in Schutz. Eine Mitschuld an der zumindest in einem Falle eskalierenden Situation in Rom wurde ihm nicht unterstellt. Im Gegenteil: Nach dem Mordanschlag auf Annibaldo fand er tröstende Worte. Abgesehen von der stereotypen Aufforderung, durch umfangreiche Korrespondenz Kontakt zur Kurie zu halten, sind jedoch keine weiteren Mahnungen oder Verbesserungsvorschläge von seiten des Papstes überliefert ${ }^{735}$.

\subsubsection{Die Legation von Kardinal Gui de Boulogne im Spiegel der kurialen} Registerüberlieferung

Kardinal Gui de Boulogne wurde gleichzeitig mit Annibaldo Ceccano mit der Legation nach Italien betraut ${ }^{736}$. Allerdings hatte seine Ernennung einen sehr viel längeren Vorlauf als diejenige Annibaldos. Bereits im Konsistorium vom

733 Dem Urteil Pierre Jugies, der die im Vergleich zu Gui de Boulogne sehr viel positivere Ergebnisbilanz Annibaldos unterstreicht, sollte mit Vorsicht begegnet werden, vgl. Pierre JuGIE, La légation en Hongrie et en Italie du cardinal Gui de Boulogne (1348-1350), in: Il Santo 31 (1989) S.29-69, bes. S.61: "S'il était un cardinal qui eût dô recevoir des louanges pour son action politique, c'était bien Anibaldo Caetani di Ceccano, et non Gui de Boulogne«.

734 Dies bemerkt auch Dykmans, Annibal de Ceccano, S. 280: »Tel qu'il nous est apparu à travers des documents trop souvent incomplets, il ne nous semble mériter ni trop d'éloges ni trop d'indignité. Par bien des côtés il méritait un moment d'attention [...]. Ses entreprises diplomatiques ont suivi les consignes de son ancien collègue de Paris, Clément VI, devenu un maître aussi impérieux que courtois«.

735 In Rom bezog Annibaldo neben dem 25. Teil der kirchlichen Einkünfte einen Teil der Opfergaben, die von den Pilgern auf dem Altar von St. Peter niedergelegt wurden. Die Rückstände aus diesen Zahlungen reklamierte Clemens VI. nach dem Tod des Kardinals für sich, vgl. BAUMGARTEN, Untersuchungen, S. XL.

736 Die Legation des Kardinals von Sancta Cecilia war Gegenstand einer profunden Detailanalyse durch JUGIE, La légation en Hongrie. Der Persönlichkeit des Kardinals widmete Pierre Jugie auch seine Dissertation, die bedauerlicherweise noch immer der Publikation harrt, vgl. Ders., Le cardinal Gui de Boulogne (1316-1373). Der Vf. dankt Dr. Jugie für die Erlaubnis zur Einsicht in die in den Archives nationales zu Paris unter der Signatur AB XXVIII 331 aufbewahrte Dissertation, vgl. außerdem DERS., L'activité diplomatique du cardinal Gui de Boulogne en France au milieu du XIVe siècle, in: BEC 145 (1987) S. 99-127; DERS., Les cardinaux issus de l'administration royale française: typologie des carrières antérieures à l'accession au cardinalat (1305-1378), in: Crises et réformes dans l'Église de la réforme grégorienne à la préréforme. Actes du $115^{\mathrm{e}}$ congrès national des Sociétés savantes (Avignon 1990), Paris 1991, S.157-181; Ders., Un discours inédit. Aufgrund der bereits vorliegenden Forschungsergebnisse wird an dieser Stelle nur auf die wichtigsten Ereignisse der Legation eingegangen, der Akzent jedoch auf die Analyse der päpstlichen Collatio gesetzt. 
27. Oktober 1345 waren Pierre Bertrand senior und Bertrand de Deux, Kardinalpresbyter tit. S. Clementis und S. Marci, als Legaten designiert worden. Pierre Bertrand wurde schon im Dezember auf ausdrücklichen Wunsch der französischen Königin durch Gui de Boulogne ersetzt ${ }^{737}$. Die Abreise ließ trotz mehrmaliger Ankündigung, ein Verlassen Avignons stünde unmittelbar bevor - auf sich warten. Diese Zeit wurde vom ungarischen König zum Ausbau einer Allianz genutzt, in die er nicht nur Ludwig den Bayern und Edward III., sondern auch den Signore von Turin, die Stadt Genua und nicht zuletzt Karl von Durazzo als erbitterte Gegner Johannas einzubeziehen versuchte. Die Frage, ob Gui de Boulogne angesichts dieser Perspektiven verzagte oder andere Gründe für seinen Verzicht ausschlaggebend waren, kann anhand der Registerüberlieferung nicht geklärt werden; fest steht jedoch, daß er im Februar/März 1346 von seiner Beauftragung entbunden wurde und Bertrand de Deux sich allein auf den Weg nach Italien machte ${ }^{738}$. Noch an der Kurie bezog er im Konflikt um Neapel dezidiert für die Partei der Tarent Stellung, ja er versuchte sogar zusammen mit den Kardinälen Jean de Comminges und $\mathrm{Hu}$ gues Roger, den Papst zu einer Ehedispens zugunsten Roberts von Tarent zu bewegen, der sich noch vor seinem Bruder Ludwig um die Hand Johannas bemüht hatte ${ }^{739}$. Dieses Engagement dürfte mit ausschlaggebend für die Feindschaft gewesen sein, die Élie Talleyrand de Périgord, ein Verteidiger der Interessen der Durazzo, zeitlebens mit Gui de Boulogne verband.

Die Beweggründe, die Clemens VI. zur Ernennung des Kardinals von S. Cecilia veranlaßt hatten, wurden nirgendwo so deutlich dargelegt wie in einem an den König von Ungarn gerichteten Schreiben vom 18 . November $1346^{740}$. Besonders hervorgehoben wurden darin die verwandtschaftlichen Bande, die zwischen dem Legaten und der Königin von Ungarn, Margarete von Luxemburg,

737 Lettres Clément VI, n. 2213 (15/12/1345).

738 Teil des Entsendungszeremoniells waren topische Entschuldigungen, mittels derer die zu Legaten ernannten Kardinäle darzulegen versuchten, weshalb sie unwürdig seien, dieses Amt anzunehmen. Normalerweise ließ der Papst diese dem Zeremoniell geschuldete Selbsterniedrigung gänzlich unbeachtet. Das Zeremoniale des Kardinals Stefaneschi überliefert jedoch die Akzeptanz der von Gui de Boulogne vorgebrachten Gründe durch den Papst, vgl. Dykmans, Cérémonial, II, S.497: Et ita fuit observatum tempore domini Clementis pape VI, pontificatus sui anno quarto, quando dictus dominus papa excusavit dominum cardinalem de Bolonia, qui fuerat electus legatus unacum domino cardinali Ebredunensi Bertrando de Deucio pro eundo ad partes Italie et regni Sicilie.

739 LÉONARD, Jeanne, II, S. 437-439, 606.

740 Lettres Clément VI, n. 3999 (nur Regest), vgl. RV 142, n. 372, fol. 94r-v: [...] innotuit nobis fidedigna relatione ac informatione multorum, quod tu de predictis Ytalie partibus ad regnum tuum Ungarie te duxeras referendum, et licet extunc cogitaverimus et cogitaremus semper ad te aliquos propterea destinare tamen propter mortalitatis pestem, que istas sicut et nonnullas alias partes orbis inaudita et incredibili quodammodo clade vastavit, nonnullis ex fratribus nostris permittente Deo ab hac luce subductis, aliis a Curia Romana vitande mortis gratia secedentibus et paucis admodum ex eis remanentibus apud illam, quos ad te mitteremus, non potuimus reperire. Nunc autem peste huiusmodi divine mansuetudinis gratia mitigata decrevimus dilectum filium nostrum Guidonem tit. S. Cecilie presbiterum cardinalem 
bestanden. Die Verleihung der Fakultäten erfolgte am 30. November 1348. Das Legationsgebiet umfaßte Ungarn, die Lombardei, die Kirchenprovinzen Salzburg, Aquileia und Grado, Mailand, Genua, Zara, Split, Ragusa und Antivari sowie die Diözesen Bologna, Ferrara, Modena, Reggio Emilia, Parma und Pavia $^{741}$. Der Kardinal verließ die Kurie am 15. Januar $1349^{742}$ und erreichte Ungarn im Mai oder Anfang Juni ${ }^{743}$. Auf dem Weg hatte er ausreichend Gelegenheit, sich mit der politischen Situation in Oberitalien vertraut zu machen. Stationen seiner Reise waren Mailand, Treviso - dort gelang es ihm, einen Waffenstillstand zwischen Giovanni Visconti, den della Scala, den Este, Pepoli und Gonzaga zu vermitteln - Brescia, Verona, Padua und Venedig, wo der Legat auf dem Gebiet von Mestre Opfer eines Überfalls wurde ${ }^{744}$. In Ungarn erzielte er einen ersten diplomatischen Erfolg mit einem Waffenstillstand, dessen Bedingungen vom König in Bratislava zwar Mitte Juni akzeptiert wurden, der jedoch erst am 25. Dezember in Kraft treten sollte ${ }^{745}$. Annibaldo Ceccano hatte es immerhin vermocht, am 23. Juli einen sofort gültigen Waffenstillstand zwischen den Vertretern Ludwigs in Neapel und Johanna zu vermitteln ${ }^{746}$.

Ludwig spielte ein doppeltes Spiel und nutzte den Umstand, daß er über seine Botschafter in Avignon und über den Legaten vor Ort eine Art Doppeldiplomatie betreiben konnte, die es ihm ermöglichte, einerseits sowohl den Papst als auch den Legaten von seinem Friedenswillen zu überzeugen, andererseits jedoch seine Rüstungsanstrengungen in Hinblick auf eine neue Invasion Neapels voranzutreiben. Für die päpstliche Diplomatie gab es ein böses Erwachen, als im April 1350 die zweite Invasion Neapels begann. Der Zorn des Papstes richtete sich auf den gutgläubigen Gui de Boulogne, der Empfän-

A.S. legatum ad te ac partes ipsas commisso in eis sibi plene legationis officio destinandum, de quo cum sit vir generositate sublimis, scientia clarus ac insignis multis virtutibus et carissime in Christo filie nostre regine Ungarie Illustri consorti tue proxima consanguinitate coniunctus et tui sincerus et fervidus zelator honoris, potes et debes merito contentari, qui cum ad te propicio Deo pervenerit et exposuerit excellentie tue, que exponenda tibi per eum imposuimus, nos eidem nostram et Romanam ecclesiam matris tue sinceram affectionem erga te tuaque negocia et utrum tibi an parti alteri in negocio Regni Sicilie faverimus pocius clarius apercius, quod cognosces. Tu ergo, fili carissime, nostram et ipsius ecclesie ad honorem profectusque tuos / plenitudinem caritatis attendens sic nostris et eiusdem ecclesie beneplacitis progenitorum tuorum vestigia prosequens in devotionis et reverentie promptitudine sicut de te pollicetur nobis certa fiducia te conformes, quod ad tui honoris augmentum tuaque vota favorabilius prosequendum iugiter delectemur.

741 Acta Salzburgo-Aquilejensia. Quellen zur Geschichte der ehemaligen Kirchenprovinzen Salzburg und Aquileja, hg. v. Alois LANG, Bd.1, Graz 1903, n. 393, n. 1; vgl. zu den Fakultäten Lettres Clément VI autres que la France, nn. 1839-1872, nachgeschoben werden nn.1890f. (11.01.1349), 1990f. (01.05.1349), 2074 (24.09.1349); LENZENWEGER, Acta Pataviensia Austriaca, I, nn. 290-295.

742 EUBEL, I, S. 17, n. 3.

743 Leonard, Jeanne, II, S. 204, n. 8; vgl. Baluze/Mollat, Vitae I, S. 269, 293-295.

$744 \mathrm{Vgl}$. zu den einzelnen Stationen JUGIE, Légation, S. 40-45.

745 LEONARD, Jeanne, II, S. 204.

746 Ibid., S. 208. 
ger eines wenig schmeichelhaften Schreibens war $^{747}$. Darin wurde er angeklagt, nicht nur verantwortlich für den Ansehensverlust der Kirche, sondern auch für die Schutzlosigkeit Neapels zu sein, wo man es im guten Glauben auf die Zusagen des Königs versäumt hätte, Verteidigungsanstrengungen zu unternehmen. Gui de Boulogne wurde zum Sündenbock, dem der Papst ein Gutteil seines eigenen schlechten Gewissens aufbürdete.

Dieses Schreiben erreichte den Legaten nicht mehr in Ungarn. Bereits am 27. September 1349 hatte er Esztergom mit dem Ziel Italien verlassen. Im Dezember verkündete er in Treviso, wo er noch Ende Januar 1350 nachweisbar war, den Jubiläumsablaß ${ }^{748}$. Danach steuerte er Padua an, wo er am 15. Februar an der Translation der Reliquien des heiligen Antonius teilnahm und damit seiner Legation einen eminent religiösen Anstrich gab $^{749}$. Dieses religiöse Moment sollte in der Folge weiter verstärkt werden. Mitte März erreichte er Rom, wo er als Pilger der Segnungen des Heiligen Jahres teilhaftig werden wollte. Nach kurzem, quellenmäßig nur ungenügend belegtem Aufenthalt 750 kehrte er nach Padua zurück, wo er für den 8. Mai ein Provinzialkonzil einberufen hatte, das unter seinem Vorsitz zahlreiche neue Statuten verabschiedete $^{751}$. Bereits zu diesem Zeitpunkt war er im Besitz der päpstlichen Erlaubnis, an die Kurie zurückzukehren ${ }^{752}$. Am 7. Juni traf er in Avignon ein und wurde von Clemens VI. mit einer Collatio willkommen geheißen, die in nichts den Ärger des Papstes über das Scheitern seines Legaten widerspiegelt.

\subsubsection{Homo quidam nobilis: die Collatio Clemens' VI. anläßlich der Rück- kehr von Kardinal Gui de Boulogne}

Als Clemens VI. den Legaten durch die Begrüßungsansprache ehrte ${ }^{753}$, war dessen Position innerhalb des Kollegiums kurz zuvor wesentlich gestärkt wor-

747 Lettres Clément VI, n. 4501 (14.05.1350); abgedruckt in THEINER, Monumenta Hungariae, I, n. 1190, S. 784; vgl. dazu LÉONARD, Jeanne, II, S. 249f., wo das Schreiben folgendermaßen charakterisiert wird: "Le pape lui adressa une des plus dures lettres que mandataire maladroit ait pu recevoir. Le roi de Hongrie avait trompé sa candeur et celle de l'Église par des promesses mensongères; la reine de Naples et son mari se plaignaient d'avoir été empêchés de se préparer et de s'armer pour avoir eu trop confiance dans les promesses que le légat avait obtenues. C'était par sa faute qu'ils avaient été dupés, et le Saint-Siège avec eux. Aussi, c'était maintenant à lui d'essayer d'arranger les affaires [...] «; JuGIE, Légation, S. 46f., mit der treffenden Bemerkung: »Il est certain que Gui de Boulogne eut affaire à plus fort que lui $\ll$.

$748 \mathrm{Vgl}$ ibid., S. $50 \mathrm{f}$.

749 Vgl. ibid., S. 52-55.

750 Über eine mögliche Zusammenarbeit mit Annibaldo Ceccano verlautet nichts.

751 Vgl. Domenico MANSI, Sacrorum conciliorum nova et amplissima collectio, Bd.26, Florenz, Paris 1784 (ND Paris 1904), Sp. 221-236; JUGIE, Légation, S. 56-59.

$752 \mathrm{Zu}$ welchem Zeitpunkt genau diese Autorisierung erfolgte, ist unklar, ein Schreiben des Papstes vom 1. Mai nimmt jedoch zum ersten Mal darauf Bezug, vgl. Lettres Clément VI, n. 4483.

${ }^{753}$ Den folgenden Ausführungen liegt der Text der Handschrift Paris, Bibliothèque Sainte-Geneviève, MS 240, fol.440v-444v zugrunde. Die Ansprache ist dort überschrieben mit 
den. Am 9. Februar 1350 hatte die Nichte des Kardinals, Jeanne de Boulogne, Gräfin von Boulogne und der Auvergne und Witwe Philipps von Burgund, den Ehebund mit Jean, Herzog der Normandie und Thronerbe Frankreichs, geschlossen. Das im Thema bemühte Adjektiv nobilis hatte also seine volle Berechtigung: Gui de Boulogne zählte neben Talleyrand de Périgord zu den hochadligen Purpurträgern. Für das Thema fiel die Wahl auf ein Zitat aus dem Lukas-Evangelium: Homo quidam nobilis abiit in regionem longinquam accipere sibi regnum et reverti ${ }^{754}$. Bei dieser dem Gleichnis von den zehn Pfunden entnommenen Passage handelte es sich um ein beliebtes und oft verwendetes Thema, das häufig für das Schicksal der Seele eines Verstorbenen stand $^{755}$. Anders beim Papst, der bereits in der Einleitung keinen Zweifel daran ließ, welcher zentrale Begriff Hauptgegenstand seiner Ausführungen werden sollte.

Das Bedeutungsspektrum des Substantivs regnum als Emanation einer guten und gerechten, nach Aristoteles der besten Herrschaftsform, wurde zunächst gegen sein negatives Pendant, die Tyrannis, abgegrenzt. Der Papst stützte sich hierbei auf das dritte Buch der Politik des Aristoteles, dessen Inhalt ihm durch den Kommentar bekannt gewesen sein dürfte, den Walter Burley ${ }^{756} \mathrm{ihm} 1342$ gewidmet hatte ${ }^{757}$. Drei condiciones fanden Erwähnung, die den Unterschied zwischen regnum und tyrannidis verdeutlichen sollten: sanctimonia (Heiligkeit), iustitia (Gerechtigkeit) und habundantia (Überfluß) eig-

Collatio facta per sanctissimum patrem et dominum dominum C. papam VI in regressu cardinalis Bononiensis de legatione Ungarie et Lumbardie, pontificatus sui anno IX' ${ }^{\circ}$ Zur $\mathrm{Pa}-$ rallelüberlieferung vgl. SCHNEYER, Repertorium, Bd.4, S.762, n.47; MOLLAT, Euvre oratoire, S.256, n.67; SCHMITZ, Sermons, S.26, n. 40; Wood, Sermon literature, S. 163-172. Teilübersetzungen liefern LÉoNARd, Jeanne, I, S. 198 und MOLLAT, Contribution, S. 585. 754 Lc 19,12; vgl. auch Mt 9,13, 10,6, 18,11; I Tim 1,15.

755 Vgl. die Totenpredigt des Giovanni Regina für Hugues de Baux, in: Jean-Paul BoyER, Les Baux et le modèle royal. Une oraison funèbre de Jean Regina de Naples (1334), in: Provence historique 181 (1995) S. 427-452, hier S. 448.

756 Vgl. zu Burley den biographischen Abriß in Walter Burley, Quaestiones super librum Posteriarum, hg. v. Mary Catherine Sommers, Toronto 2000, S. 1-5; Richard WoOD, Studies on Walter Burley 1968-1988, in: Bulletin de philosophie médiévale 30 (1988) S. 233-250.

757 Anneliese MAIER, Zu Walter Burleys Politik-Komentar, in: Ausgehendes Mittelalter. Gesammelte Aufsätze zur Geistesgeschichte des 14. Jahrhunderts, I, Rom 1964, S.93-99; Charles H. LoHR, Medieval latin Aristotle commentaries, in: Traditio 26 (1968) S. 171-187; WoOD, Clement VI, S. 208; James M. BLYTH, Ideal government and the mixed constitution in the Middle Ages, Princeton 1992, S. 184. Das Widmungsschreiben ist in Vat. Borgh. 129 überliefert und auf den 23. November 1343 datiert; zur Bedeutung der Politica des Aristoteles für das lateinische Mittelalter vgl. Marie Luise BULST, Aristoteles im Mittelalter, Göttingen 1932; Christoph FlüELER, Rezeption und Interpretation der Aristotelischen Politica im späten Mittelalter, 2 Bde., Amsterdam, Philadelphia 1992; Jürgen MIETHKE, Politische Theorie in der Krise der Zeit. Aspekte der Aristotelesrezeption im frühen 14. Jahrhundert, in: Institutionen und Geschichte. Theoretische Aspekte und mittelalterliche Befunde, hg. v. Gert MELville, Köln, Weimar, Wien 1992, S. 155-186; vgl. zu den in der päpstlichen Bibliothek aufbewahrten Exemplaren von Aristoteles' Politica EHRLE, Bibliotheca, S. 328, n. 529, S. 334, n. 599. 
neten einer Herrschaft, die weder durch Gewalt und Unterdrückung, noch durch Vertreibung und Habsucht pervertiert werde. Vitia, iniuria und scandala seien hingegen Kennzeichen der Tyrannis ${ }^{758}$. Ein viertes Unterscheidungskriterium trat hinzu, durch das jedoch nicht auf den Unterschied zwischen regnum und tyrannidem, sondern auf den zwischen regnum und anderen, der Gerechtigkeit verpflichteten Herrschaftsformen verwiesen wurde: die excellentia in ambitu. Ein regnum habe immer dann eine hervorragende Stellung inne, wenn die Herrschaft als solche legitim sei (virtuose acceptatum), wenn das Regiment mit Bedacht ausgeübt werde (studiose gubernatum), die notwendigen Ressourcen (copiose dotatum et ditatum) und schließlich die territoriale Ausdehnung (spatiose dilatatum) vorhanden seien ${ }^{759}$, so der Papst.

Die Verbindung zur Person des Legaten und seinem Amt wurde an dieser Stelle hergestellt. Aus den vier vorgenannten Gründen erfolgte eine Gleichsetzung des officium legationis mit dem regnum ${ }^{760}$, das Legatenamt wurde also als bestmögliche Herrschaftsform gewertet - und der Papst lieferte dafür gute Gründe. Das Legatenamt sei ein von Heiligkeit geprägtes Amt mit herausgehobener Machtfülle, ein Amt voller Aufrichtigkeit und Wahrheit, voller Fülle und Fruchtbarkeit, voller Würde und Adel ${ }^{761}$. Was dieses Amt also letztendlich auszeichne, sei die überragende Machtstellung, die es seinem Inhaber insbesondere auf jurisdiktionellem Gebiet verleihe. Lediglich einige

758 Vgl. hierzu Aristotelis Politicorum libri octo cum veteri translatione Guillelmi de Moerbeka, hg.v. Franz SuSEMIHL, Leipzig 1872, lib. III, c. 7f.; ARISTOTELES, Werke in deutscher Übersetzung, Bd.9/2 (Politik, Buch II/III), übersetzt und erläutert von'Eckart SCHÜTRUMPF, Darmstadt 1991, S.61. Im Umgang mit oberitalienischen Tyrannen konnte Clemens VI. im Laufe seines Pontifikates einige Erfahrung und die Erkenntnis gewinnen, $\mathrm{da} ß$ es die Zwänge der Staatsraison durchaus notwendig erscheinen lassen konnten, aus Tyrannen kaiserliche oder päpstliche Vikare zu machen, vgl. Diego QUAGLIONI, Politica e diritto nel Trecento italiano. Il »De tyranno « di Bartolo da Sassoferrato (1314-1357). Con l'edizione critica dei trattati »De Guelphis et Gebellinis«, "De regimine civitatis« $\mathrm{e}$ »De tyranno«, Florenz 1983, S. 59f., 204; vgl. auch Renate PLETL, Irdisches Regnum in der mittelalterlichen Exegese. Ein Beitrag zur exegetischen Lexikographie und ihren Herrschaftsvorstellungen (7.-13. Jahrhundert), Frankfurt a. M. 2000 u.a., S. 61-108, 213-216.

759 MS 240, fol.440vb: Patet ergo, quod per primas tres condiciones regnum differt a tyrannide, sed propter quartam condicionem, scilicet quia regnum debet habere in ambitu excellentiam, differt ab aliis dominationibus etiam iustis sicut comitatu, ducatu, baronia etc., et immo quia regnum Christi nullis artatur terminis, proprie dicitur regnum [...]. Patet ergo, quod regnum proprie dicitur, quando est virtuose acceptatum, studiose gubernatum, copiose dotatum et ditatum, spaciose dilatatum.

760 Ibid.: Modo videtur michi, quod legationis officium, maxime legati a latere sicut fuit cardinalis, qui hodie reversus, recte potest dici regnum ex istis quatuor conditionibus.

${ }^{761}$ Ibid., fol.441ra: Habet enim potestatem infra terminos sue legationis in omnibus casibus, qui non sunt a iure retenti. Est secundo officium rectitudinis et inconcusse veritatis, quam debet servare legatus in vita, in iustitia et in doctrina [...]. Tertio est officium plenitudinis et magne fecunditatis, constituitur enim velut alter Jeremias [Jer 1,10] [...], ut velut alter Thimotheus [II Tim 4,5; I Tim 4,12] [...]. Quarto est officium amplitudinis et clare nobilitatis. Ipse enim maior quocumque in legatione sua existente et potestate et auctoritate, et nullus eo superior nisi solus papa. 
Reservatfälle seien der Vollmacht des Legaten entzogen, dem innerhalb seines Legationsgebietes eine unbestreitbare Präzedenz vor allen anderen Amts- und Würdenträgern - ausgenommen allein der Papst - zukomme. Der Papst stilisierte in der Folge die Legation des Kardinals von S. Cecilia, deren territoriale Ausdehnung bisher unerreicht gewesen sei, zu einer Erfolgsgeschichte um und verwies auf die enge Bindung zwischen Erfolg und ausführender Person. $\mathrm{Zu}$ einem Erfolg konnte die Legation nur deshalb werden, weil Gui de Boulogne sein Amt in Demut angenommen (humiliter acceptavit), glücklich ausgeübt (feliciter gubernavit), nützlich ausgeführt (utiliter fecundavit) und schließlich auf lobenswerte Weise beendet habe (laudabiliter consummavit $)^{762}$. Insbesondere der letzte Punkt wurde hervorgehoben. Der erfolgreiche Abschluß der Legation schien an die Fähigkeit des Legaten gekoppelt, den Fallstricken, mit denen sich jede an verantwortlicher Position tätige Persönlichkeit konfrontiert sieht, auszuweichen. Schenkt man den Aussagen Clemens' VI. Glauben, war Gui den aus blindem Ehrgeiz, Herrschsucht, tyrannischem Unrecht und Untätigkeit resultierenden Gefahren aufgrund der ihm eigenen virtus entronnen ${ }^{763}$. Nach einer ersten Zusammenfassung der bisher geäußerten Gedanken ${ }^{764}$ verharrte der Papst auf dem Aspekt der dem Legaten inhärenten Eigenschaften. Abstammung, Demut, Würde und Soziabilität zeichneten ihn vor allen anderen aus, machten ihn empfehlenswert (commendabilis). Den Geboten der dilatatio folgend, band Clemens VI. nicht nur diese vier Elemente an das in vier Bestandteile aufgefächerte Thema, sondern bemühte noch weitere vier Vierergruppen, was ihm insgesamt ausreichend Material für die Weiterentwicklung seiner Gedanken lie-

762 Ibid., fol. 441rb: Istud autem legationis officium, quod quidem fuit in ambitu amplium et latum et forte latius quam unquam legerim, quia in tota Ungaria, in parte Alammanie, videlicet in provincia Salzeburgensis et in tota Lombardia, iste humiliter acceptavit, feliciter gubernavit, utiliter fecundavit, laudabiliter consummavit.

763 Ibid., fol. 441va: Et videtur michi, quod iste sic laudabiliter consummavit, ut eius ingressus fuerit quasi pacificus et exitus illis de sua legatione molestus cum eius presentia esset illis quamplurimum grata vita, iusta memoria in benedictionibus propter quattuor, que ex se et sua mente exclusit. Exclusit enim vitium cece ambitionis, appetitum superbe dominationis, improperium tirannice exactionis, otium voluptuose pigritationis. Iste enim non fuit ambitiosus aut cupidus, non fuit iniuriosus aut tumidus, non fuit infructuosus aut aridus, non fuit otiosus aut tepidus.

764 Ibid.: Habemus ergo tria: primo quomodo regnum habet in ortu sanctimoniam, in cultu iustitiam, in fructu habundantiam, in ambitu excellentiam. Habemus secundo quomodo officium legationis a latere habet istas quattuor conditiones utpote quia est officium sanctitudinis et excelse potestatis, rectitudinis et inconcusse veritatis, plenitudinis et magne fecunditatis, amplitudinis et clare nobilitatis. Habemus tertio, quod noster cardinalis istud officium legationis in regione lata et spatiosa et humiliter acceptavit et feliciter gubernavit et utiliter fecundavit et laudabiliter consummavit. Ut merito dicam de eo verba thematis preasssumpta: Homo quidam nobilis abiit in regionem longinquam, ad litteram in Ungariam, in Alammaniam, in Lombardiam etc. accipere sibi regnum, id est legationis officium, quod regno comparatur, ut dixi, et reverti. Non enim abiit ibi perpetuo remansuro, sed ad nos hodie cum gaudio reversurus. 
ferte $^{765}$. Herausgestellt wurden die hochadlige Abkunft des Legaten, sein Gehorsam gegenüber dem Papst und sein erfolgreiches Wirken - basierend auf den Fähigkeiten im Umgang mit anderen.

Konkrete, unmittelbar auf die Legation beziehbare Elemente sind rar. Einzig der innerhalb der dritten Vierergruppe erwähnte Verweis auf die „Süße« eines geschlossenen Bündnisses (dulcedo federis copulati) könnte in Hinblick auf den am 13. April 1349 in Treviso geschlossenen Waffenstillstand zwischen einigen Signori Oberitaliens getätigt worden $\operatorname{sein}^{766}$. Ausgeschlossen werden kann wohl eine Bezugnahme auf den Waffenstillstand vom Juni 1349, dessen Bruch durch Ludwig von Ungarn der päpstlichen Diplomatie eine peinliche Niederlage bescherte. Ausführlich ging der Papst auf den ersten Gesichtspunkt ein - dico ergo primo, quod reddit eum commendabilem claritas generosa -, stützte sich zu Beginn seiner Betrachtungen jedoch auf das, was den homo nobilis von anderen beseelten Lebewesen unterscheide: die äußere Erscheinungsform (statura), die Korrektivgewalt (censura) und sein Wesen (natura $)^{767}$. Der aufrechte Gang - statura - unterscheide den Menschen nicht nur vom Tier, sondern versinnbildliche darüber hinaus auch seine Gabe, sich mittels Reflexion über überzeitliche Werte zu Höherem aufzuschwingen. Aufgrund besonderer Eigenschaften übertreffe der Mensch alle übrigen Lebewesen, so der Papst. Der Mensch gehe nicht nur aufrecht, sondern habe ein schönes Angesicht, ein langmütiges Herz, weise in seinem Herzen eine Gottesebenbildlichkeit auf, sei wachen Geistes und könne die ewige Seligkeit erhoffen. Diese für das Menschengeschlecht insgesamt gültigen Aussagen wurden unmittelbar an die Person des Legaten gekoppelt ${ }^{768}$. Gerechtigkeit, Urteils-

765 Ibid., fol.441vb-442ra: In quibus verbis quattuor tanguntur, que reddunt eum valde commendabilem: primo claritas generosa (homo quidam nobilis), secundo humilitas obsequiosa (abiit in regionem longinquam), tertio dignitas gloriosa (accipere sibi regnum), quarto societas gaudiosa (et reverti). Vel tertio [hier wohl eher: secundo] distinguamus sic: Commendant, quod reddunt eum commendabilem primo fastigium honoris accepti (homo quidam nobilis), secundo obsequium laboris suscepti (abiit in regionem longinquam), tertio exercitium vigoris immensi (accipere sibi regnum), quarto consortium amoris intensi (et reverti). Vel tertio distinguamus sic: Commendant enim eum celsitudo generis nominati (homo quidam nobilis), longitudo itineris perlustri (abiit in regionem longinquam), magnitudo numeris acceptate (accipere sibi regnum), dulcedo federis copulati (et reverti). Unde videtur michi, quod verba ista describunt eum quadrupliter: Primo quidem in ortu celebrem et preeminentem (homo quidam nobilis), secundo in motu et in iussu celerem et obedientem (abiit in regionem longinquam), tertio in fructu utilem et proficientem (accipere sibi regnum), quarto in convictu amabilem et complacentem (et reverti). Ut sic videamus eius egressum virtuosum (homo quidam nobilis), eius progressum laboriosum (abiit in regionem longinquam), eius accessum fructuosum (accipere sibi regnum), eius regressum gaudiosum (et reverti).

766 Vgl. dazu JUGIE, Légation, S. 42.

${ }^{767}$ MS 240, fol.442ra: Et videtur michi, quod hic ponuntur tres dictiones secundum tres conditiones, quas homo nobilis habet inter cetera animantia [...]. Est enim pulchrior et rectior in statura (homo), est virtuosior et moderatior in censura (quidem), est tertio clarior in natura (nobilis).

768 Ibid., fol.442rb-442va: Primo quidem est pulchrior et rectior in statura [...]. Quam autem rectus, quam pulcher, quam magnus sit noster legatus patet intuenti, ut sit quasi ille Absalon, 
kraft, Gewissen, Milde, Gottesebenbildlichkeit, Weisheit, Wissen, Klugheit, zukünftige Seligkeit zeichneten eine Persönlichkeit aus, die mit Hilfe eines Esra-Zitats näher beschrieben wurde: Gui de Boulogne durchlief so eine Entwicklung hin zum Homo homo de domo Israhel, der die Eigenschaften des äußeren und inneren Menschen in seiner Person vereinte, dessen spirituelle Ambitionen von den Zwängen des profanen Lebens nicht verdrängt, sondern im Gleichgewicht gehalten wurden ${ }^{769}$.

Der zweite Unterpunkt - dicebam secundo, quod est virtuosior et moderatior in censura - wurde mit nur zwei Zitatbelegen denkbar knapp abgehandelt und endete mit der Feststellung, der Legat habe von seinen Zensurfakultäten in Hinblick auf die Verabschiedung neuer Statuten und die Beseitigung verbreiteter Laster sinnvollen Gebrauch gemacht ${ }^{770}$. Damit wurde wohl auf seine Tätigkeit als Reformer bei der in Padua im Mai 1350 tagenden Provinzialsynode verwiesen ${ }^{771}$. Im dritten Unterpunkt - tertio dicebam, quod est clarior in natura, quia dicitur nobilis - fand die durch Autoritäten wie Boethius und Aristoteles belegte enge Verbindung zwischen Bluts- und Seelenadel Behandlung ${ }^{772}$. Zum Beweis für das fruchtbare Mit- und Nebeneinander von nobilitas corporis und nobilitas virtutis wurde aus den Briefen des Hieronymus an Demetriades und Celantia zitiert ${ }^{773}$.

Die Behandlung des zweiten Punktes - dico secundo, quod eum reddit commendabilem humilitas obsequiosa - fiel kurz aus. Analog zu dem bereits bekannten Vorgehen wurden auch hier drei Elemente bemüht (motum, termi-

de quo dicitur II Reg XIIII [2 Sam 14,25]: Porro sicut Absalon erat pulchrior in omni Israhel et decorus nimis, a planta pedis usque ad verticem non erat in eo ulla macula [...]. Idcirco noster legatus statura erectus, animo rectus, corpore procerus et mente celsus homo [...]. Considerabam enim, quod homo habet sex conditiones valde excellentes. Habet enim homo in corpore rectitudinem, in facie pulchritudinem, in corde mansuetudinem, in mente Dei ymaginem et similitudinem, in ratione limpitudinem, in fine beatitudinem. Modo noster legatus habet rectitudinem iustitie, pulchritudinem iuditie et conscientie, mansuetudinem clementie, ymaginem et similitudinem divine essentie, limpitudinem sapientie, scientie et prudentie, beatitudinem nunc in spe et tandem in re eterne glorie. Das letze Satzelement weist Anklänge an I Cor 13,12 auf.

769 Vgl. Esra 14,4; MS 240, fol.442vb: Iste ergo noster legatus dicitur homo homo, quia homo secundum exteriorem et homo secundum interiorem hominem, unde iste est homo, qui secundum Deum creatus est in iustitia et sanctitate veritatis, ad Ephe. IIII [Eph 4,24].

770 Die Zitate stammen aus Job 4,16 und einem Brief Bernhards von Clairvaux an den Erzbischof von Reims, vgl. Epistola XXV, in: San Bernardo, Opere, VI/1, Mailand 1986, S.148; MS 240, fol.442vb: Sic autem servavit iste in sua legatione tam in statutis edendis quam in vitiis corrigendis.

771 Vgl. zur Bedeutung von Legatensynoden SCHMIDT, Kirche, Staat, Nation, S. 262-265.

772 MS 240, fol.443ra: Nobilis quidem carne et generosus in mente, nobilis quidem carne, quia de genere regum, ducum et comitum [...]. Das zweite Buch der Rhetorik des Aristoteles wird zur Erläuterung des Unterschieds zwischen nobilitas und generositas herangezogen.

773 Ibid., fol. 443rb-443va; vgl. Hieronymus, Epistulae, hg.v. Isidor HilberG, Wien 1996, ep. 130, 148; vgl. auch Barbara CoNRING, Hieronymus als Briefschreiber. Ein Beitrag zur spätantiken Epistolographie, Tübingen 2001. 
num et medium) und mit dem zweiten Bestandteil des Themas - abiit in regionem longinquam - verbunden. Damit richtete sich der Blick von der Person des Legaten auf die Legation selbst ${ }^{774}$. Ziel der Legation war ein Gebiet, das der Präsenz eines tatkräftig vorgehenden und den Geboten der virtus folgenden Kardinals bedurfte. Causa brevitatis wurden die einzelnen Gesichtspunkte nicht in der gewohnt feingliedrigen Form aufgefächert, dennoch blieb ausreichend Raum, um den Charakter des Legaten zu würdigen: Er sei ohne Fehl und Tadel - sine macula - gewesen, so der Papst, und habe insbesondere einer Versuchung widerstanden: der Gier nach Geld. Bereits in der Collatio Egrediebatur et intrabat stand dieser Aspekt an zentraler Stelle und wurde anhand desselben Bernhard-Zitats verdeutlicht ${ }^{775}$.

Gui de Boulogne wurde mit dem Geliebten aus dem Hohelied verglichen, der sich in den Garten begab und dort Lilien pflückte. Das Bild der Lilie versinnbildlichte die Ergebnisse der Legation, die der Papst auf zwei Aspekte verengte. In der einen zu pflückenden Lilie erblickte er Ludwig von Duras, den Titularkaiser von Konstantinopel, und dessen Bruder, die beide durch das Wirken des Legaten aus dem Gefängnis befreit werden sollten, die andere Lilie stand für die Friedensvermittlung zwischen Ungarn und Sizilien ${ }^{776}$. Allen gemeinsam war ein Element ihres persönlichen Wappens: die Lilie. Mit dem Verweis auf Mt 6,28 ("Seht die Lilien auf dem Felde, wie sie wachsen «) blieb der Papst im Bild und nutzte die Möglichkeit zu einer Schilderung der mit der Legation verbundenen Unannehmlichkeiten und Gefahren. Die räumliche Distanz zwischen Kurie und Legationsgebiet habe nicht nur zu Sprachproblemen, sondern auch zu massiven Einschränkungen der bisher gewohnten Lebensweise geführt und den Legaten dazu gezwungen, mit Zwietracht und Widerspruch fertigzuwerden 777 .

774 MS 240, fol.443va: Dico II, quod eum reddit commendabilem humilitas obsequiosa, quia abiit in regionem longinquam, ubi possumus considerare secundum tres dictiones tria: motum scilicet, terminum et medium. Motum quidem efficacie et virtuositatis (abiit), terminum maioris indigentie et necessitatis (in regionem, que ad litteram multum indigebat praesentis legati), medium longioris distantie et anxietatis (longinquam).

775 De consideratione, in: San Bernardo, Opere, I, S. 878; vgl. auch Sir 31,8f.

776 MS 240, fol. 443vb: Dilectus meus descendit in ortum suum ad areolam aromatum, ut ibi pascatur in ortis et lilia colligat [Can 6,1]. Et dicit bene: et lilia colligat. Ad litteram enim ad hoc abiit, ad hoc declinavit, ad hoc descendit, ut colligeret lilia dupliciter. Primo quidem, ut procuraret lilia, id est carissimum filium nostrum imperatorem Constantinopolitanum et dominos L. de Amacio et Fremevis; colligeret, id est de carcere liberaret et procuraret, qui portant in armis lilia. De flore illo lilii candidissimo, pulcherrimo et odorifero domo scilicet Francie per masculinam lineam descenderunt. Secundum etiam, ut lilia colligeret, ut scilicet reginam Sicilie et eius virum una cum rege Ungarie pacificaret et ad concordiam revocaret, qui quidem similiter sunt lilia ex eodem lilio descendentes et in armis lilia deferentes. Vgl. zum Problem um Konstantinopel WooD, Clement VI, S. 186; Jules GAY, Le pape Clément VI et les affaires d'Orient (1342-1352), Paris 1904, S. 94-96; Donald M. NicOL, The last centuries of Byzantium, London 1972, S. $241 f$.

777 MS 240, fol.444ra: Considerate lilia agri quomodo crescunt [Mt 6,28]. Creverunt enim non solum obtinendo regnum Francie, sed Sicilie et Ungarie. Hic autem invenio et vocaliter 
Anhand des dritten Gesichtspunktes - tertio dicebam, quod reddit eum commendabilem dignitas gloriosa - wurde erneut auf einige Charaktereigenschaften des Legaten vewiesen, die die erzielten Ergebnisse erst ermöglichten. In dieser Auflistung sucht man allerdings vergeblich nach Spezifika, die die Person des Gui de Boulogne vor anderen Legaten auszeichnen würden ${ }^{778}$. Clemens VI. verblieb in vorgezeichneten Bahnen und wurde erst wieder bei der Behandlung des vierten und abschließenden Gesichtspunktes - dicebam ultimo, quod reddit eum commendabilem societas gaudiosa - persönlicher. Er, der Papst, habe dem Legaten die Erlaubnis zur Rückkehr mit Verweis auf Can 6,12 - revertere, revertere Sunamitis, revertere et revertere, ut intueamur te - erteilt. Die dem Namen Sunamitis innewohnende Bedeutung - misera et captiva - habe auf die Person des Legaten Anwendung finden können, der Elend und Gefahr ausgesetzt gewesen sei. Nach seiner Rückkehr an die Kurie könne er seine Gaben und Erfahrungen in vielfältiger Weise einbringen, sich dem Papst gehorsam erweisen, die Gemeinschaft mit dem Kardinalskolleg erneuern und die kuriale Politik durch beratende Tätigkeit fördern ${ }^{779}$.

Damit endete eine Collatio, deren Bezug auf reale Gegebenheiten in legatione man vergeblich sucht. Auf Kritik wurde gänzlich verzichtet, selbst ein in anderen Collationes durchaus feststellbarer Subtext, in dem kritische Einwürfe ihren Platz fanden, fehlt gänzlich. Tatsächlich war das Gewicht des Kardinals innerhalb des Kollegiums durch die ausgesprochen vorteilhafte Heiratsverbindung seiner Nichte mit dem Herzog der Normandie gewachsen - der Papst selbst spielte auf diese neue Verbindung im letzten Abschnitt an. Verwandtschaftliche Beziehungen des Kardinals zum Thronerben Frankreichs könnten den Papst in der Tat von expliziter und impliziter Kritik abgehalten haben. Mit Ludwig von Ungarn, der im rhetorischen Procedere des Papstes verdächtig nahe an die Gestalt des Tyrannen rückte, war Gui de Boulogne auf einen Gegner getroffen, dem er klar unterlegen war. Auf das Aussprechen dieser unangenehmen Wahrheit verzichtete man.

et realiter responsum; longinquam quippe propter spatii distantiam, scilicet quod abiit in regionem longinquam; propter verbi et labii differentiam; propter modi vivendi disconvenientiam; $[. .$.$] propter voti et animi discordantiam vel discrepantiam.$

778 MS 240, fol. 444ra-rb: Tertio dicebam, quod reddit eum commendabilem dignitas gloriosa, dignitas fructuosa, quia accipere sibi regnum, sicut supra declaravi legationis officium, in quo magnum fructum attulit non solum corrigendo vitia, celebrando consilia, edendo statuta salubria, sed etiam inclinando magnatum corda. Si dictis verba compensasseret ad talia et tam grandia, quod erant nobis et fratribus nostris stupenda et mirabilia et plurimum gaudiosa, accepit ergo regnum, ut puto, quia ipse est caritate fervidus, claritate lucidus, veritate et probitate inclitus, auctoritate preditus, puritate incidus. Accepit iam in spe et tandem accipiet in re regnum amoris, regnum splendoris, regnum vigoris, regnum honoris, regnum decoris. 779 MS 240, fol.444rb: Et dicit bene Sunamitis, que interpretatur misera et captiva, quia ad litteram duci Normannie, ducisse eius uxori, nepti sue, et ceteris amicis suis videbatur, quod esset in miseria et captivitate constitutus [...]. Revertere [...] ad impendendum michi obsequium filialis reverentie, ad resumendum consortium fraternalis amicitie, ad intuendum collegium virtualis excellentie, ad dandum salutaris sapientie. 
